\title{
Field Testing Unvented Roofs with Asphalt Shingles in Cold and Hot- Humid Climates
}

Kohta Ueno and Joseph W. Lstiburek Building Science Corporation

September 2015 


\section{NOTICE}

This report was prepared as an account of work sponsored by an agency of the United States government. Neither the United States government nor any agency thereof, nor any of their employees, makes any warranty, express or implied, or assumes any legal liability or responsibility for the accuracy, completeness, or usefulness of any information, apparatus, product, or process disclosed, or represents that its use would not infringe privately owned rights. Reference herein to any specific commercial product, process, or service by trade name, trademark, manufacturer, or otherwise does not necessarily constitute or imply its endorsement, recommendation, or favoring by the United States government or any agency thereof. The views and opinions of authors expressed herein do not necessarily state or reflect those of the United States government or any agency thereof.

This report is available at no cost from the National Renewable Energy Laboratory (NREL) at www.nrel.gov/publications.

Available electronically at SciTech Connect http:/www.osti.gov/scitech

Available for a processing fee to U.S. Department of Energy and its contractors, in paper, from:

U.S. Department of Energy

Office of Scientific and Technical Information

P.O. Box 62

Oak Ridge, TN 37831-0062

OSTI http://www.osti.gov

Phone: 865.576.8401

Fax: 865.576.5728

Email: reports@osti.gov

Available for sale to the public, in paper, from:

U.S. Department of Commerce

National Technical Information Service

5301 Shawnee Road

Alexandria, VA 22312

NTIS http://www.ntis.gov

Phone: 800.553 .6847 or 703.605 .6000

Fax: 703.605.6900

Email: orders@ntis.gov 


\title{
Field Testing Unvented Roofs with Asphalt Shingles in Cold and Hot-Humid Climates
}

\author{
Prepared for: \\ The National Renewable Energy Laboratory \\ On behalf of the U.S. Department of Energy's Building America Program \\ Office of Energy Efficiency and Renewable Energy \\ 15013 Denver West Parkway \\ Golden, CO 80401 \\ NREL Contract No. DE-AC36-08GO28308 \\ Prepared by: \\ Kohta Ueno and Joseph W. Lstiburek \\ Building Science Corporation \\ 3 Lan Drive, Suite 102 \\ Westford, MA 01886 \\ NREL Technical Monitor: Stacey Rothgeb \\ Prepared under Subcontract No. KNDJ-0-40337-05
}

September 2015 
The work presented in this report does not represent performance of any product relative to regulated minimum efficiency requirements.

The laboratory and/or field sites used for this work are not certified rating test facilities. The conditions and methods under which products were characterized for this work differ from standard rating conditions, as described.

Because the methods and conditions differ, the reported results are not comparable to rated product performance and should only be used to estimate performance under the measured conditions. 


\section{Contents}

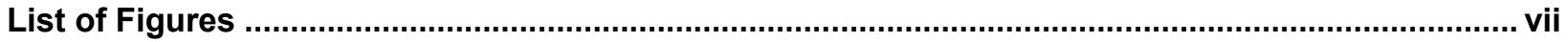

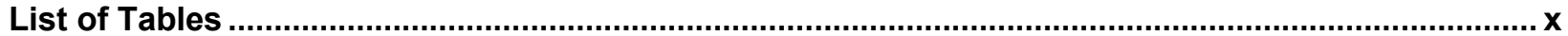

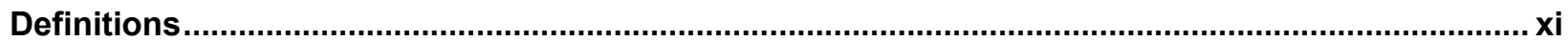

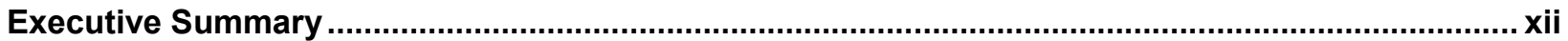

1 Introduction

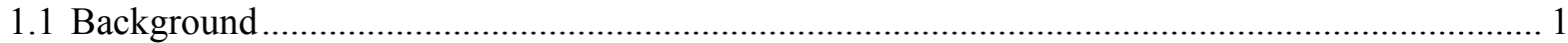

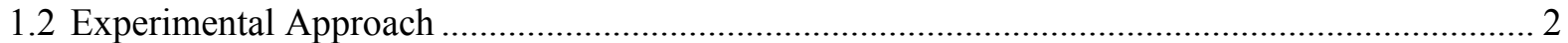

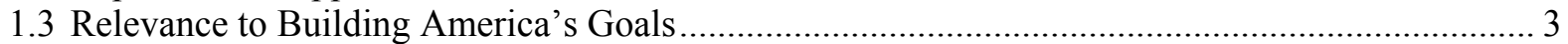

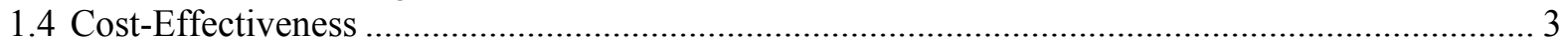

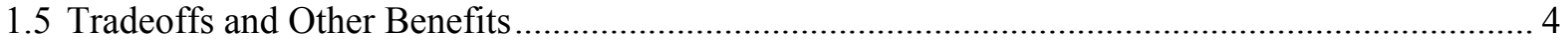

2 Background Literature and Field Experience

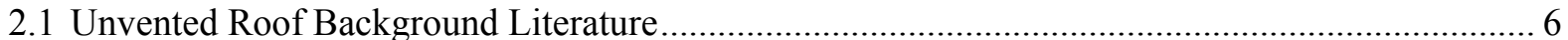

2.2 Field Experience in Houston, Texas, and Jacksonville, Florida (Climate Zone 2A) .................... 8

2.3 Field Experience in Northern California (Climate Zone 3C)................................................... 9

2.4 Salonvaara et al. (2013): Modeling Unvented Roofs in Climate Zones 1-4 ............................. 10

2.5 Boudreaux et al. (2013): Sealed Attic Monitored Performance (Climate Zones 3A and 4A) ....... 12

2.6 Lstiburek (2014): Humidity Behavior of Unvented/Sealed Attics ............................................ 12

2.7 Smegal and Straube (2014): Monitoring and Simulation of Spray-Polyurethane-Foam-Insulated Roofs

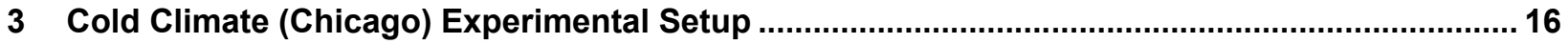

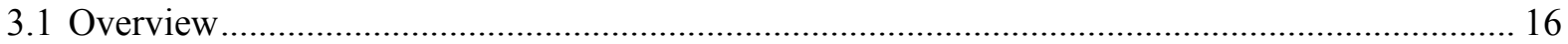

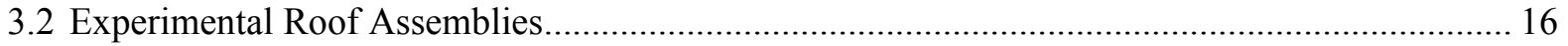

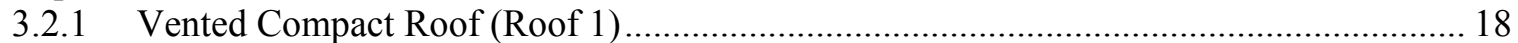

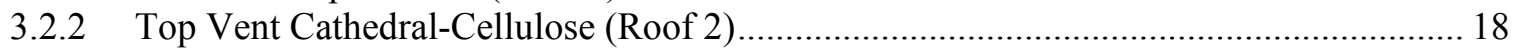

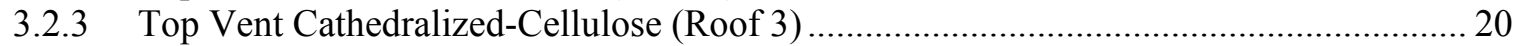

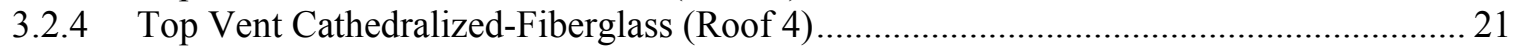

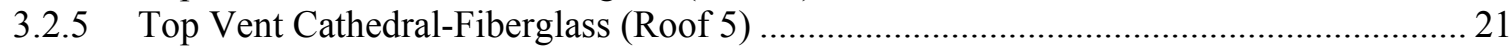

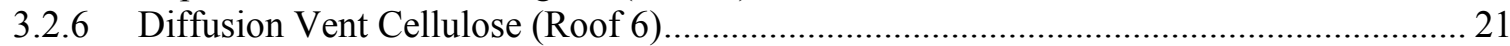

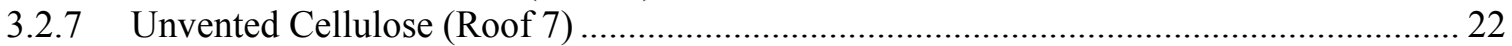

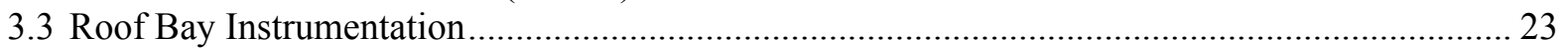

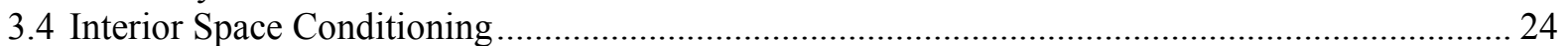

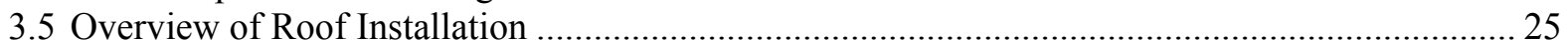

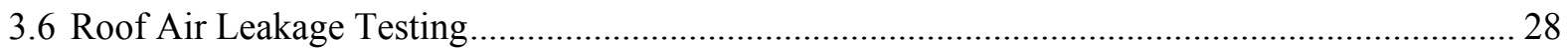

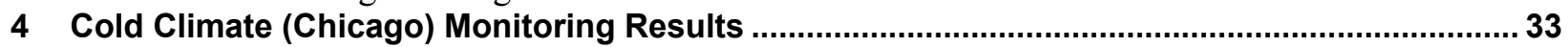

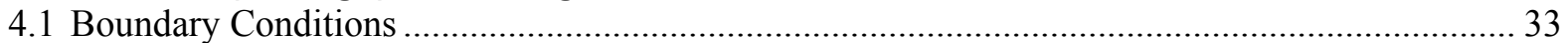

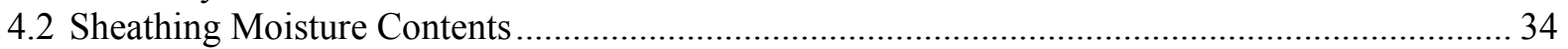

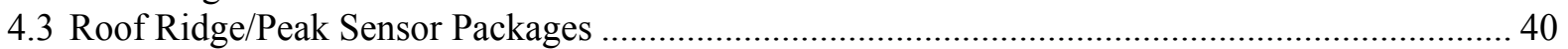

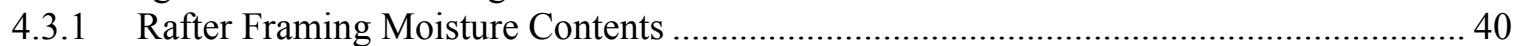

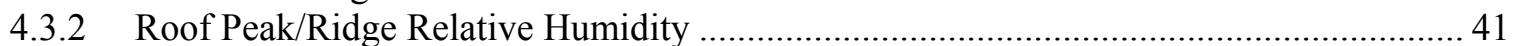

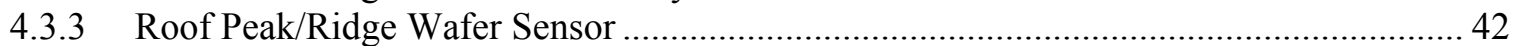

4.3.4 Roof Doghouse Sheathing Moisture Content .................................................................... 44

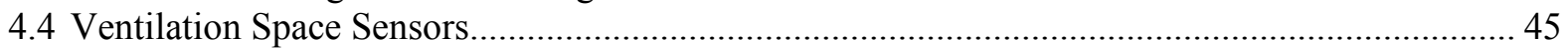

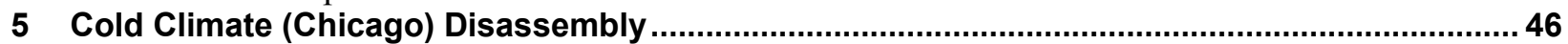

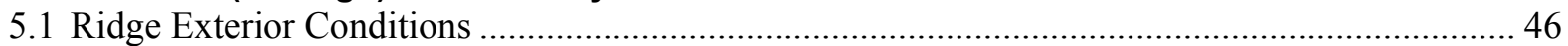

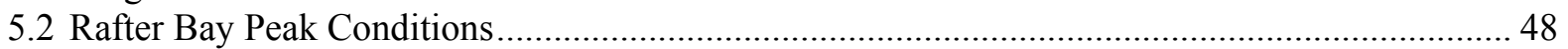

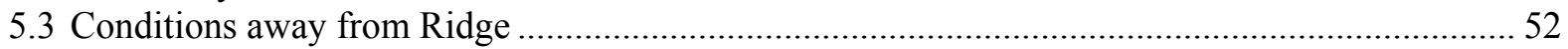

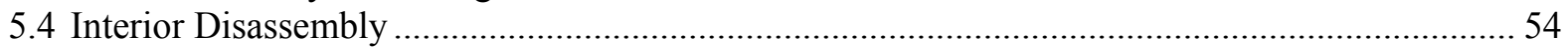

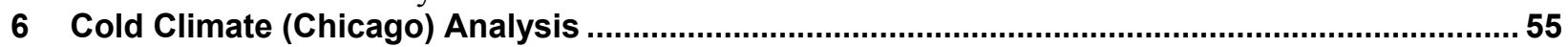

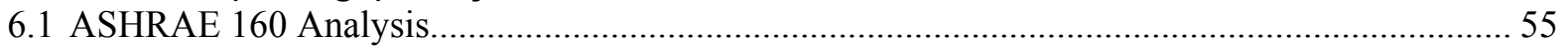


6.2 Ridge Average Temperature

6.3 Sheathing Temperatures and Ventilation Space Behavior......................................................5

6.4 Conclusions for Cold Climate (Chicago) Test Roof..................................................................... 57

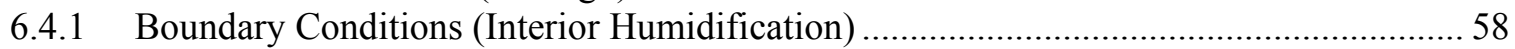

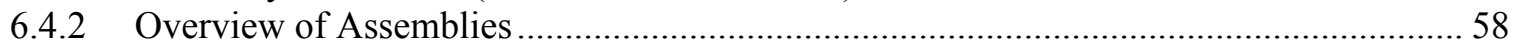

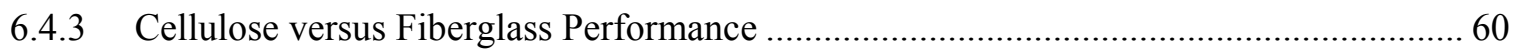

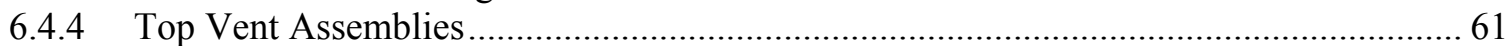

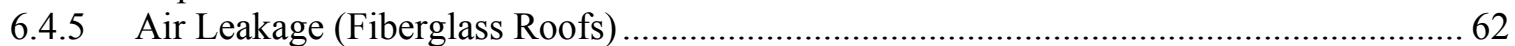

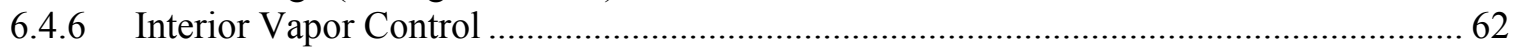

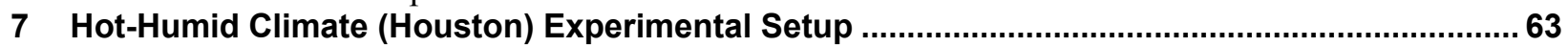

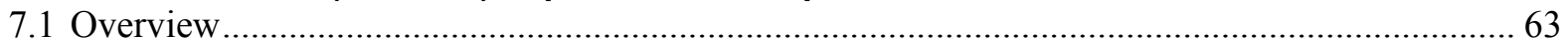

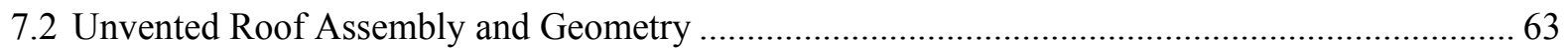

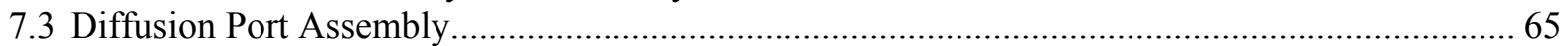

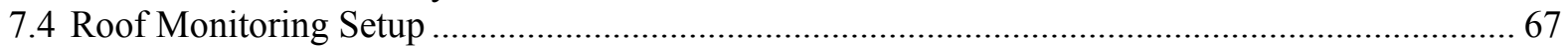

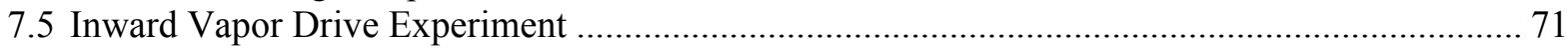

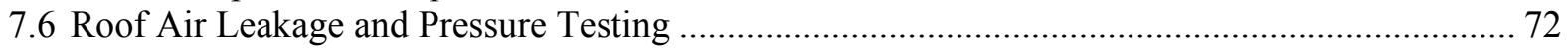

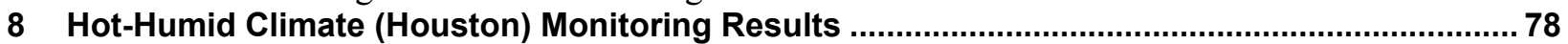

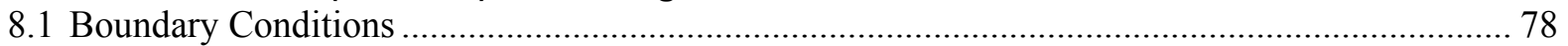

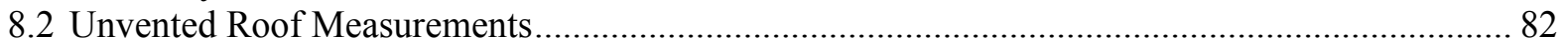

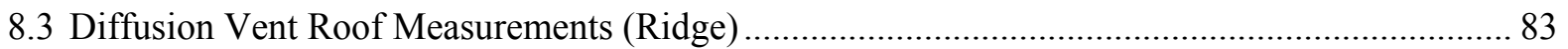

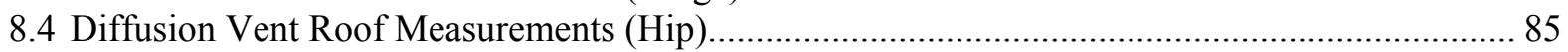

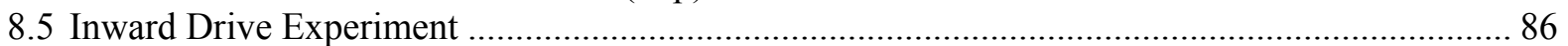

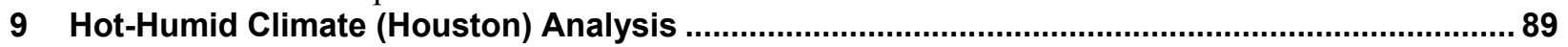

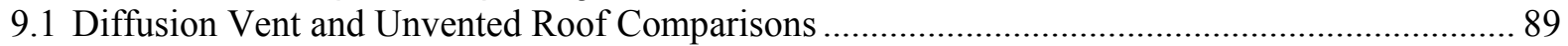

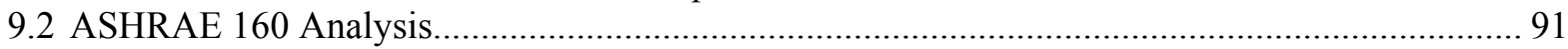

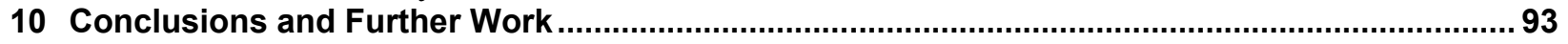

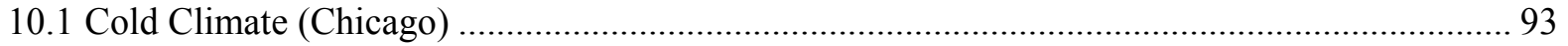

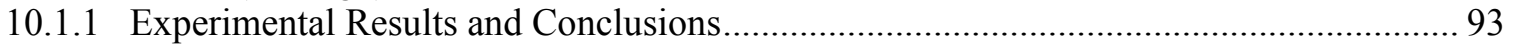

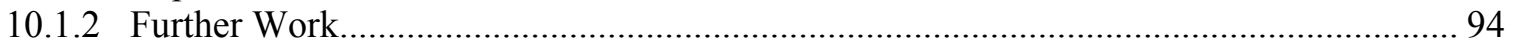

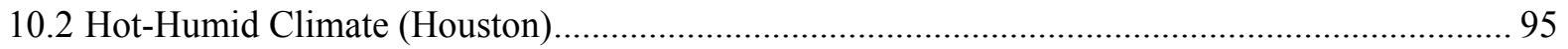

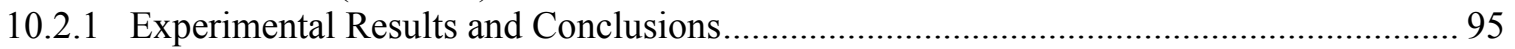

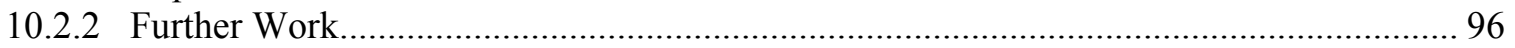

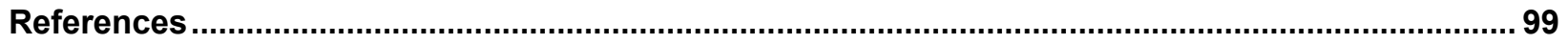

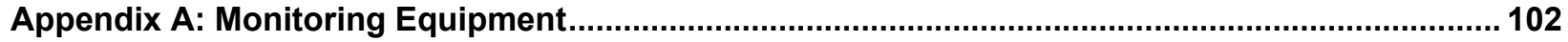

Appendix B: Chicago Attic Roof Ventilation Dew Points ....................................................... 103

Appendix C: Chicago Sheathing Temperature and Ventilation Space....................................... 108 


\section{List of Figures}

Figure 1. Dense-pack insulation of roof (left); resulting moisture issues (right) .............................. 1

Figure 2. Insulation material costs (no installation), in $\$ / \mathrm{ft}^{2} \cdot \mathrm{R}$-value ............................................. 4

Figure 3. Condensation on HVAC equipment located in vented attic (CZ 2A) ................................ 5

Figure 4. Unvented roof hybrid insulation options: rigid foam overclad (left); SPF (right) ............... 6

Figure 5. Bottom ventilated roof deck ........................................................................................ 7

Figure 6. Top ventilated dense-packed roof assembly ................................................................ 7

Figure 7. Netted and blown cellulose roof insulation in Houston (left); MC at the roof ridge (right). 8

Figure 8. Netted and blown cellulose roof insulation in Jacksonville (left); corrosion of ridge truss

plate (right)

Figure 9. Ridge sheathing degradation with dense-pack cellulose in northern California............... 10

Figure 10. Dry sheathing lower at roof (left); interior ridge conditions (right) ................................. 10

Figure 11. Air leakage communication from unvented attic to main space (left); Houston-area roof

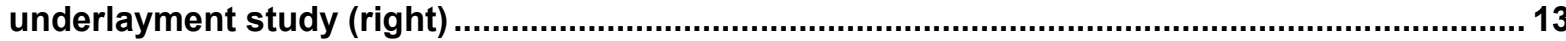

Figure 12. Test home with attached garage used for the experimental roofs .................................. 16

Figure 13. Chicago experimental roof test bays showing materials .............................................. 17

Figure 14. Ridge condition at Roof 1 -vented compact roof ........................................................ 18

Figure 15. Roof 1-vented compact roof insulation (left); airspace/ventilation detail (right) ............ 18

Figure 16. Ridge condition at Roof 2-top vent cathedral-cellulose $(3,4$, and 5 similar) ................ 19

Figure 17. Soffit condition at roofs $2,3,4$, and 5 -top vent cathedral/cathedralized....................... 19

Figure 18. Dropped sheathing and breather mesh at roof deck of top vent roofs $(2,3,4$, and 5$)$.... 19

Figure 19. Top vent roof $(2,3,4$, and 5$)$ ridge house wrap covering (left); cut openings (right) ...... 20

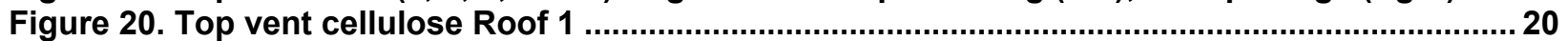

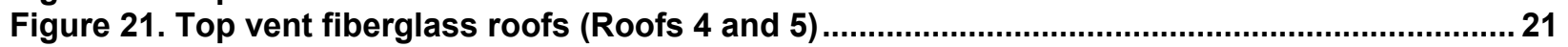

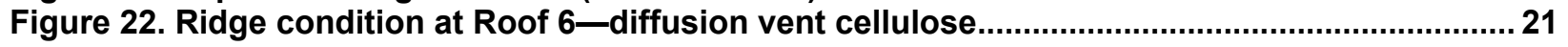

Figure 23. Ridge condition at Roof 6 -diffusion vent cellulose ........................................................22

Figure 24. Diffusion vent (6) (left); unvented (7) ridge conditions (right) ..................................... 22

Figure 25. Instrumentation setup for Roof 2-top vent cathedral-cellulose $(3,4$, and 5 similar) ..... 23

Figure 26. Instrumentation setup for Roof 7-unvented cellulose ................................................ 24

Figure 27. Experimental attic space heating (left); garage heating and relay box (right) ................. 25

Figure 28. Schematic and photos of humidification setup (left); heated bucket and reservoir

(right)

Figure 29. Completed test attic over garage (left); disassembled doghouse detail (right) ............. 26

Figure 30. Interior of experimental roof bays, showing air sealing, gaskets, and instrumentation. 26

Figure 31. West (front) face of experimental roof bays interior ....................................................... 27

Figure 32. East (rear) face of experimental roof bays interior........................................................... 27

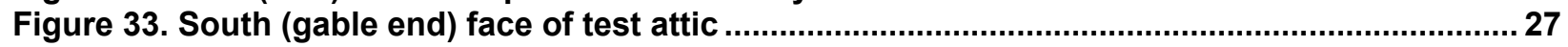

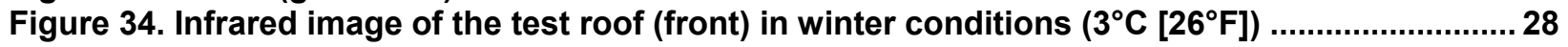

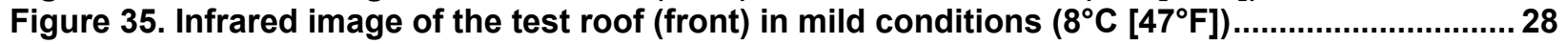

Figure 36. Air leakage at roof connection to main house (XPS sheathed wall) ................................29

Figure 37. Air leakage at ridge and instrumentation wire penetrations .......................................... 29

Figure 38. Air leakage at gable end rake wall (connects to unvented cellulose Roof 7) ...................30

Figure 39. Air leakage testing of attic space (left); multipoint test results (right)................................ 30

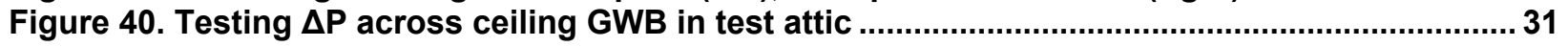

Figure 41. Test attic interior, garage, and exterior temperatures, winter 2013-2014....................... 33

Figure 42. Test attic interior RH, winter 2013-2014 ................................................................ 34

Figure 43. Test attic interior and exterior dew point temperature, winter 2013-2014...................... 34

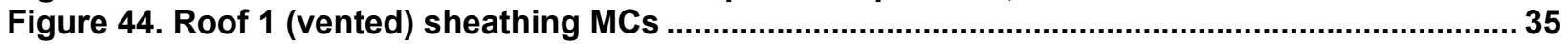

Figure 45. Roof 7 (unvented cellulose) sheathing MCs (unfiltered data)......................................... 35

Figure 46. Roof 6 (diffusion vent cellulose) sheathing MCs (unfiltered data) ................................... 36

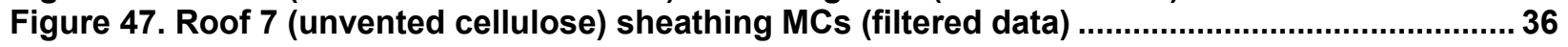

Figure 48. Roof 6 (diffusion vent cellulose) sheathing MCs (filtered data)...................................... 37

Figure 49. Roof 2 (top vent cellulose with GWB) sheathing MCs ....................................................... 37

Figure 50. Roof 3 (top vent cellulose, no GWB) sheathing MCs ................................................... 38 
Figure 51. Roof 5 (top vent fiberglass with GWB) sheathing MCs................................................... 38

Figure 52. Roof 4 (top vent fiberglass, no GWB) sheathing MCs .................................................... 39

Figure 53. Top vent fiberglass, no GWB (4) water leak (left); wet fiberglass batt (right).................. 39

Figure 54. Top vent fiberglass, no GWB (4) wet sheathing (left); wet batt (right) ............................. 40

Figure 55. Rafter framing MC, vented (1), diffusion vent (6), and unvented (7)................................ 41

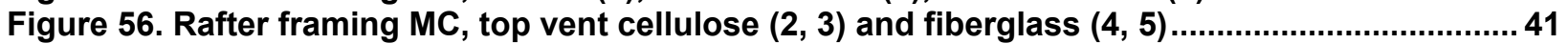

Figure 57. Roof ridge peak RH, diffusion vent (6) and unvented (7) ................................................42

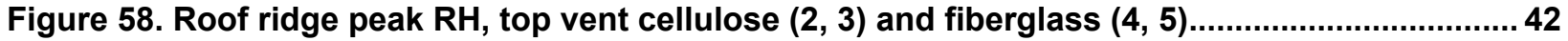

Figure 59. Roof ridge wafer sensor example next to RH sensor .................................................43

Figure 60. Roof ridge wafer sensor, vented (1), diffusion vent (6), and unvented (7).......................43

Figure 61. Roof ridge wafer sensor, top vent cellulose (2 and 3 ) and fiberglass (4 and 5)...............44

Figure 62. Roof doghouse sheathing MC sensor ......................................................................... 44

Figure 63. Roof doghouse sheathing MC measurements ................................................................ 45

Figure 64. Roof doghouse sheathing MC measurements with precipitation ...................................45

Figure 65. Ridge conditions before the breather mesh was removed ..........................................46

Figure 66. Ridge conditions after the breather mesh was removed...................................................46

Figure 67. Ridge conditions after the breather mesh was removed............................................4 47

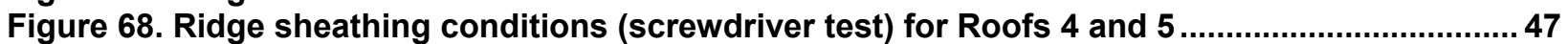

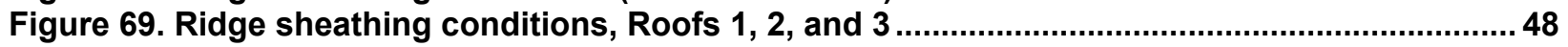

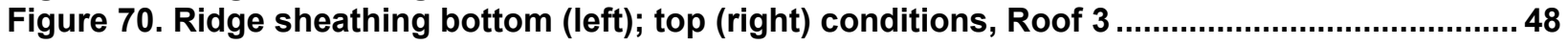

Figure 71. Ridge sheathing top conditions, Roof 2 (left); cellulose conditions (right)...................... 49

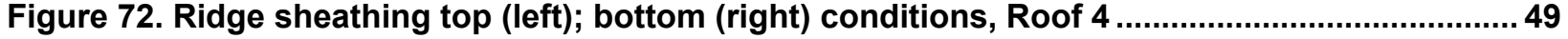

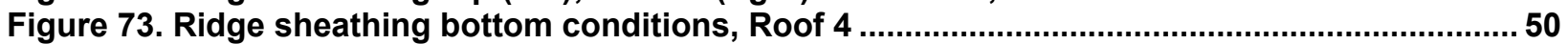

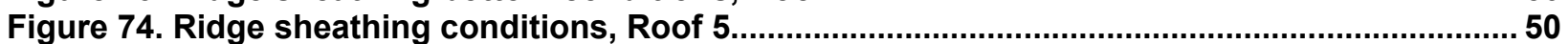

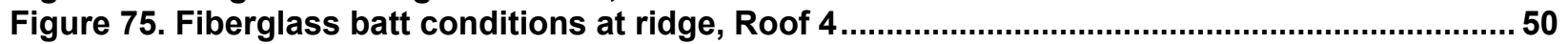

Figure 76. Fiberglass batt and framing conditions at ridge, Roof 4 (left); Roof 5 (right) ................51

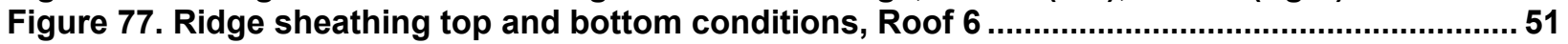

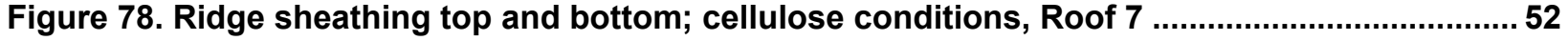

Figure 79. Sheathing away from ridge, west (front) face of roof.......................................................5 52

Figure 80. Sheathing away from ridge, east (rear) face of the roof ............................................... 53

Figure 81. Sheathing away from ridge, Roofs 4 and 5 (left); Roofs 6 and 7 (right) .........................53

Figure 82. Sheathing away from ridge, Roof 4 (left); Roof 5 (right) ..................................................5 54

Figure 83. Staining of the ceiling GWB (left); mold on the framing (right), Roof $5 \ldots \ldots \ldots \ldots \ldots \ldots \ldots \ldots . . . . .54$

Figure 84. ASHRAE 160 failures, vented (Roof 1), diffusion vent (Roof 6), and unvented (Roof 7). 55

Figure 85. ASHRAE 160 failures: top vent cellulose (Roofs 2 and 3 ) and fiberglass

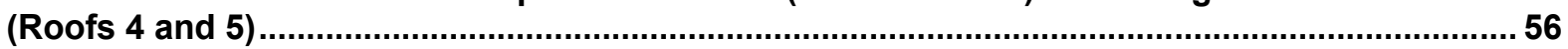

Figure 86. 30-day running average temperatures at the ridge (T/RH sensors) for all roofs ............. 57

Figure 87. Top vent roofs, no interior GWB, east/front face; cellulose (left); fiberglass (right) ....... 60

Figure 88. Vapor permeance of plywood and OSB sheathing as a function of $\mathrm{RH}$.........................61

Figure 89. Ridge condensation issues; CZ 3A pool with interior polyethylene vapor barrier...........62

Figure 90. Front and side views of the Houston-area test house ...................................................63

Figure 91. Rear quarter and overhead views of the Houston-area test house ..................................63

Figure 92. Interior of spray-applied fiberglass insulation in a conditioned attic ..............................64

Figure 93. ccSPF used for the roof-wall air barrier connection .................................................... 64

Figure 94. Air barrier and conditioned space line for an unvented attic, front (left); side (right)..... 65

Figure 95. Diffusion vent design at the roof ridge and hip ............................................................65 65

Figure 96. Open ridge (diffusion port) detail (left); permeable membrane applied over the ridge

(right)

Figure 97. Hip diffusion port drilled hole detail (left); permeable membrane applied at the hips (right)

Figure 98. Venting detail at the ridge (left) and hip (right) showing the vent profile .......................67 67

Figure 99. Ridge monitoring package (sensors at the ridge and hip peaks) ...................................68

Figure 100. Houston roof plan showing ridges, hips, valleys, and measurement locations ............69

Figure 101. Typical ridge monitoring package with sensors highlighted.......................................... 70

Figure 102. Ridge sheathing $M C / T$ sensor and T/RH (left); ridge $M C / T$ and wafer sensor (right) ....70 
Figure 103. Interior attic T/RH sensor (left); exterior T/RH sensor under north soffit (right)........... 71

Figure 104. Inward drive box before insulation (left); after insulation and clear plastic cover

(right)

Figure 105. Inward drive sensor package.

72

Figure 106. Air leakage (blower door) testing (left); multipoint hatch open/closed results (right) .. 73

Figure 107. Unsealed gas appliance exhaust and intake with evidence of air leakage.....................74

Figure 108. Air leakage at roof-to-wall details at dormer/intersecting roofs (location A) .................75

Figure 109. Air leakage at front attic gable end (location B) ........................................................ 75

Figure 110. Front and rear elevations, showing air barrier failure locations................................... 75

Figure 111. Air leakage at roof-to-wall details at roof-wall intersection (location C)......................... 76

Figure 112. Air leakage at the rear attic over the master bedroom (location $\mathrm{D}$ )................................. 76

Figure 113. Air leakage at roof-wall connections from the interior space (first floor)......................77

Figure 114. Air leakage at roof-wall connections from the interior space (second floor) ................. 77

Figure 115. Houston exterior, attic, and main conditioned space temperatures ............................78

Figure 116. Heating degree days (left) and cooling degree days (right) for Houston (IAH airport) . 78

Figure 117. Houston temperatures in the summertime (July 2014) detail ........................................ 79

Figure 118. Attic T/RH sensor locations highlighted in plan (left) and front/rear elevations (right) 79

Figure 119. Houston temperatures in the wintertime (January 2015) detail ...................................... 80

Figure 120. Houston exterior, attic, and main conditioned space dew point temperatures ............. 80

Figure 121. Houston dew point temperatures in the summertime (July 2014) detail ....................... 81

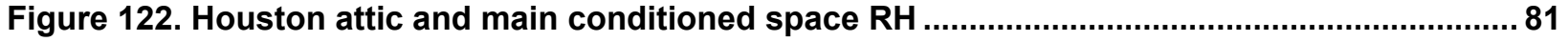

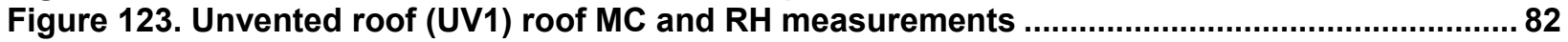

Figure 124. Unvented roof (UV2) roof MC and RH measurements .............................................. 82

Figure 125. Diffusion vent (DV1) roof MC and RH measurements ............................................... 83

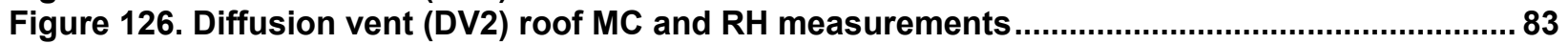

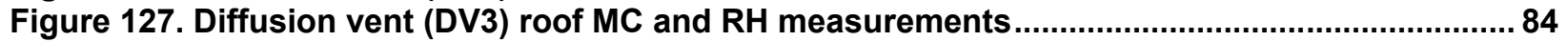

Figure 128. Diffusion vent (DV6) roof MC and RH measurements ................................................... 84

Figure 129. Diffusion vent (DV1) roof MC and RH measurements, summer (July 2014) detail ........ 85

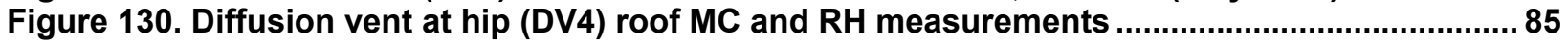

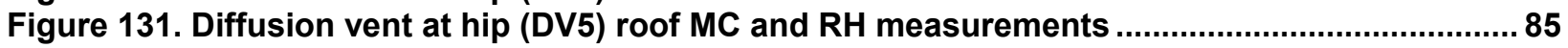

Figure 132. Inward drive interior-side RH and wafer sensor with outdoor temperature ...................86 86

Figure 133. Inward drive wafer sensor MC and sheathing MCs with outdoor temperature............... 87

Figure 134. Inward drive wafer sensor MC and precipitation with outdoor temperature.................. 87

Figure 135. Inward drive interior-side RH, wafer MC, and sheathing temperature 24-hour average 88

Figure 136. Inward drive interior-side RH, wafer MC, and sheathing temperature 24-hour average

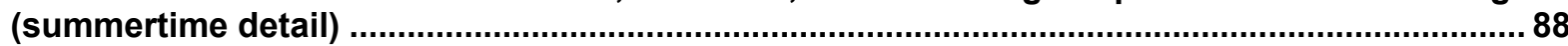

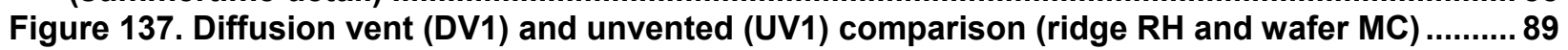

Figure 138. DV1 and UV1 comparison (ridge RH and wafer), summertime detail.............................90

Figure 139. DV1 and UV1 comparison (ridge RH and wafer), summertime detail..........................90

Figure 140. Summertime dew point comparison: interior, attic, exterior, and UV1/DV1 .................. 91

Figure 141. Story-and-a-half compact roof example (with insulation and ventilation chute) ........... 95

Figure 142. Interior temperature data and Houston unvented data.................................................. 97

Figure 143. Interior RH data and Houston unvented data ........................................................... 97

Figure 144. Interior dew point data and Houston unvented data.................................................. 98

Figure 145. Intake and exhaust dew points, interior and exterior (Roof $1-$ vented).......................103

Figure 146. Intake and exhaust dew points, interior and exterior (Roof 1-vented) detail ............. 103

Figure 147. Intake (left) and exhaust (right) T/RH sensors for top vent roofs .............................. 104

Figure 148. Intake and exhaust dew points, interior and exterior (Roof 2-top vent cellulose with GWB)

Figure 149. Intake and exhaust dew points, interior and exterior (Roof 2-top vent cellulose with

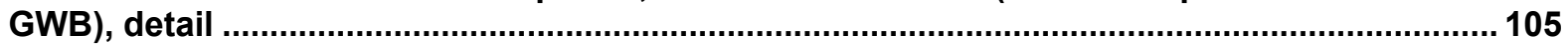

Figure 150. Intake and exhaust dew points, interior and exterior (Roof 3-top vent cellulose) ....... 105

Figure 151. Intake and exhaust dew points, interior and exterior (Roof 3-top vent cellulose), detail 
Figure 152. Intake and exhaust dew points, interior and exterior (Roof 5-top vent fiberglass with GWB)

Figure 153. Intake and exhaust dew points, interior and exterior (Roof 4-top vent fiberglass) ... 107

Figure 154. Wintertime sheathing temperatures for Roof 2 (top vent cellulose with GWB) ............ 108

Figure 155. Wintertime sheathing temperatures for Roof 7 (unvented cellulose) ........................... 108

Figure 156. Snow deposits and melting at front (west) orientation of test roof.............................109

Figure 157. Summertime sheathing temperatures for Roof 2 (top vent cellulose with GWB) ........ 109

Figure 158. Summertime sheathing temperatures for Roof 7 (unvented cellulose) ........................ 109

Figure 159. Ridge and doghouse monitoring detail, unvented cellulose roof .............................. 110

Figure 160. Summertime sheathing temperatures for Roof 1 (vented fiberglass) .......................... 110

Unless otherwise noted, all figures were created by Building Science Corporation.

\section{List of Tables}

Table 1. Summary of Simulation Results (roof sheathing MCs) ..................................................11

Table 2. Test Roof Assemblies Monitored in Smegal and Straube (2014) ........................................ 14

Table 3. Description of Chicago Experimental Roof Test Bays ......................................................... 17

Table 4. Results of Test Attic Air Leakage Testing ...........................................................................30

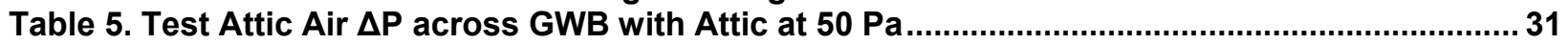

Table 6. Color Code Labels Used for Cold-Climate (Chicago) Roof Assemblies ............................. 40

Table 7. Number of Hours Roof Ridge T/RH Failing ASHRAE 160 Criteria ......................................56

Table 8. Third-Party Air Leakage and Duct Leakage Test Results .................................................. 73

Table 9. Houston Test House Hatch Open and Closed Air Leakage Measurements ......................... 73

Table 10. Houston Test House Hatch Open and Closed Air Leakage Measurements ...................... 74

Table 11. Houston Test House Zone Pressure Diagnostic (ZPD) Calculation Results......................74

Table 12. Hours and Percent of Monitored Period Failing ASHRAE 160 Criteria ...............................92

Table 13. Testing and Monitoring Equipment Specifications........................................................ 102

Unless otherwise noted, all tables were created by Building Science Corporation. 


\section{Definitions}

ACH50 Air Changes per Hour at $50 \mathrm{~Pa}$

ASHRAE American Society of Heating, Refrigerating and Air-Conditioning Engineers, Inc.

ASTM American Society for Testing and Materials

ccSPF Closed-Cell Spray Polyurethane Foam

CFM50 Cubic Feet per Minute at $50 \mathrm{~Pa}$

CZ Climate Zone

$\Delta \mathrm{P} \quad$ Pressure Difference

EqLA Equivalent Leakage Area

GWB Gypsum Wallboard

HVAC Heating, Ventilating, and Air Conditioning

MC Moisture Content

$\mathrm{MC} / \mathrm{T} \quad$ Moisture Content and Temperature

ocSPF Open-Cell Spray Polyurethane Foam

OSB Oriented Strand Board

$\mathrm{Pa} \quad$ Pascal

RH Relative Humidity

SPF Spray Polyurethane Foam

T Temperature

W Watt

WRB Water-Resistive Barrier

XPS Extruded Polystyrene 


\section{Executive Summary}

In cold climates, a common practice of the weatherization industry is to retrofit compact roof/ceiling assemblies with blown-in dense-pack cellulose. However, this assembly has high moisture and durability risks due to wintertime interior-sourced condensation and violates building code. Developing methods to retrofit dense-pack insulation into compact roof assemblies while controlling moisture risks would allow for widespread application of this lowcost technique without potentially compromising building durability.

In hot-humid climates, heating, ventilating, and air-conditioning equipment is typically located in vented, unconditioned attics, a situation that results in energy penalties. One method of moving the ductwork inside the conditioned space is to insulate at the roof deck; however, market penetration of this method has been slow because of the cost. Insulating at the roof line, which typically uses polyurethane spray foam, is expensive. If roof assemblies with fibrous insulation could be developed that control moisture risks, this would likely reduce the first cost of unvented roofs and may increase their adoption.

To understand the long-term moisture performance of unvented roof assemblies with fibrous insulation, the U.S. Department of Energy's Building America team Building Science Corporation built and monitored test roofs in two climates: a cold-climate test house in Bolingbrook, Illinois (Chicago area; zone 5A), and a hot-humid test house in Friendswood, Texas (Houston area, zone 2A). The Chicago-area test bed had seven parallel experimental rafter bays. The assemblies included a control vented compact (cathedral) roof, a dense-pack cellulose unvented roof, and an unvented roof with a "diffusion vent" (a strip of vapor-permeable gypsum sheathing at the ridge to allow drying). The interior finish was gypsum wallboard (GWB) with latex paint. The other four bays were top vent roof assemblies, which have a polypropylene breather mesh between the roof sheathing and the asphalt shingles to allow ventilation drying of the assembly from underneath the vapor-impermeable shingles. Two of the four "top vent" roofs were fiberglass batt and two were dense-pack cellulose roofs with either interior GWB or open to the interior. Wintertime moisture-related failure was accelerated by providing interior humidification $\left(22.2^{\circ} \mathrm{C}\left[72^{\circ} \mathrm{F}\right] / 50 \%\right.$ relative humidity $\left.[\mathrm{RH}]\right)$, which is known to be an extreme interior loading). Data were captured over 8 months, including a winter and the following spring and early summer.

Under these conditions, all roofs except the vented cathedral assembly experienced wood moisture contents (MCs) and RH levels high enough to constitute failure. The unvented densepack cellulose roof experienced sheathing MCs well in excess of $40 \%$ at the ridge (i.e., risk of mold, rot, and decay). MCs lower in the roof were less severe (higher than $30 \%$ ) but still in the dangerous range. In all assemblies, sheathing MCs were corroborated by rafter MC and roof peak RH. Other sensors indicated that liquid water was condensing at the peaks of all the unvented test roofs. The diffusion vent roof exhibited similar behavior to the unvented cellulose roof, but in the spring, ridge conditions dried much more rapidly in the diffusion vent roof. The top vent assemblies showed similar behavior to the unvented assemblies (high MCs). The roof assemblies with GWB had drier moisture levels than the assembly without GWB, which indicates that the painted GWB provided some level of air leakage and vapor flow control. When the results were analyzed using ASHRAE Standard 160, all the unvented roof assemblies were 
shown to have failed for significant parts of the spring. This analysis indicated that moisture levels remained high into the warmer weather, which would have allowed mold growth.

The roof was disassembled at the end of the experiment to correlate measurements with actual assembly conditions. The unvented fiberglass batt roofs had wet sheathing and mold growth but no structural failure. The cellulose roofs had only slight issues, such as rusted fasteners, staining, and sheathing grain raise, despite the measured extreme moisture conditions. This difference was ascribed to cellulose's borate preservatives, its airflow-retarding properties (especially compared to batts), and its ability to safely store moisture. The comparison of batt (installed with gaps) versus loose-fill insulation puts the fiberglass roof at a disadvantage.

The Houston-area roof is in a model house that was unoccupied during the testing period. The test house was configured with an unvented/sealed attic and insulated at the roofline. Unlike the cold-climate roof, the entire roof was insulated with a single material (spray-applied/adhered fiberglass left exposed). No intentional humidification or conditioning was provided in the unvented attic space; the space floats at conditions between interior set point and exterior conditions. Most of the roof ridges and hips were built with a diffusion vent detail and capped with a strip of a highly vapor-permeable (550 perms) roof membrane. Some ridge sections were built as a conventional unvented roof to provide a control comparison. Data have been collected from February 2014 through June 2015 (16 months); data collection is ongoing.

In the control unvented roofs, roof peak RHs reached high levels $(90 \%+)$ in the first winter. As exterior conditions warmed, RHs quickly fell to $40 \%-50 \%$ because solar heating drove moisture out of the roof sheathing (inward). MC measurements were consistent with RH measurements; initial winter conditions were higher than recommended but fell to safe levels in the summer. During the second winter (2014-2015), peak RHs rose again (60\%-80\% typical) but not to the same levels as the first winter. This difference was due to lower interior RH levels in the second winter.

In contrast, the diffusion vent roofs had drier conditions at the roof peak in wintertime. During the summer, however, RHs and MCs were higher than the unvented roof. Even so, these moisture levels were well within the safe range. The diffusion vent roof also showed strong diurnal variations of RH levels. Both these behaviors are consistent with the roof rafter bay having a hygric/moisture connection to outside air due to the vapor-open diffusion vent. The hip roofs treated with a diffusion vent showed behavior halfway between the unvented and diffusion vent roofs. This was attributed to the limited diffusion vent area (2-in.-diameter drilled holes rather than a 3 -in. strip) that is available in the hip geometry.

Overall, these results indicate that the diffusion vent roof had more drying and less wintertime moisture accumulation than the unvented roof. However, the unvented roof did not have high enough MCs to truly constitute failure. 


\section{Introduction}

\subsection{Background}

In cold climates, a common practice of the weatherization industry is to retrofit compact roof/ceiling assemblies (e.g., cathedral ceilings) with blown-in dense-pack cellulose. Coldclimate house plans often have conditioned space with compact sloped roof/ceiling assemblies above. This dense-pack retrofit minimizes the interior and exterior demolition required for retrofitting insulation compared to (for example) spray foam retrofits.

However, a dense-packed compact roof assembly has high moisture and durability risks due to wintertime interior-sourced condensation (Lstiburek 2010b); Schumacher and LePage 2012) (Figure 1).
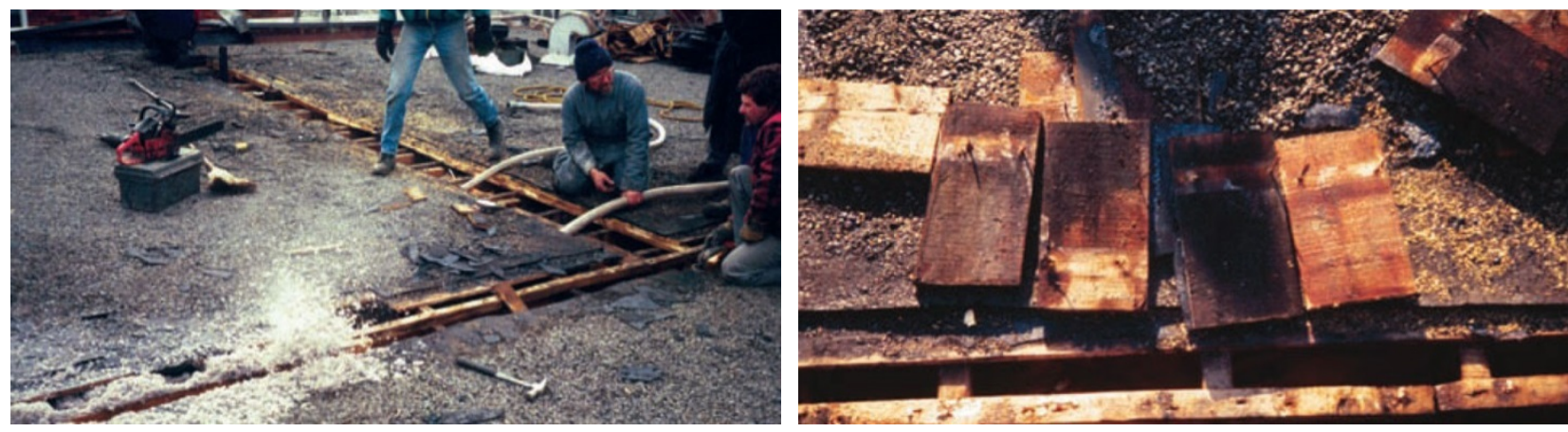

Figure 1. Dense-pack insulation of roof (left); resulting moisture issues (right)

Source: Lstiburek (2010b)

Furthermore, this assembly does not meet the International Residential Code $§ R 806.4$ "Unvented attic assemblies" (ICC 2009), which has requirements for minimum quantities of airimpermeable insulation on the exterior side of the assembly to control condensing surface temperatures in the winter.

Developing methods to retrofit dense-pack insulation into compact roof assemblies and control moisture risks would allow for widespread application of this lower cost technique without potentially compromising building durability.

In hot-humid climates, heating, ventilating, and air-conditioning (HVAC) equipment (ductwork and air handlers) are typically located in vented, unconditioned attics and have associated energy penalties due to duct leakage and conductive losses. One method of moving the ductwork inside the conditioned space (air barrier and thermal barrier) is to insulate at the roof deck to create a cathedralized attic space (Rudd et al. 1997; Rudd and Lstiburek 1998; Lstiburek 2006). Despite its performance benefits however, market penetration of this method has been slow because of the cost. Insulating at the roof line is expensive because it typically uses polyurethane spray foam-a more costly material than typical fibrous insulation materials. Previous experience creating cathedralized attics in a hot-humid climate (U.S. Department of Energy climate zone [CZ] 2A) with asphalt roof shingles showed that moisture-related failures (condensation at the ridge) can occur. (See §"Field Experience in Houston, TX and Jacksonville, FL.” This knowledge led to the requirements provided in $\S R 806.4$ of the International Residential Code 
(ICC 2009). If roof assemblies could be developed that control moisture risks, this would likely reduce the first cost of unvented roofs and could increase their adoption.

At their core, both issues are studies of the moisture-safe performance of unvented roof assemblies with vapor-impermeable roofing materials (i.e., layers of asphalt shingles and underlayment) on the exterior. This research involved building and instrumenting a variety of unvented roof assemblies that were insulated with air-permeable insulation (such as dense-pack cellulose) in cold and hot-humid climates and analyzing the assemblies' moisture performance over time. The goals were reasonable cost, low moisture risk, and buildable assemblies that could be promoted in the new-construction and retrofit markets.

\subsection{Experimental Approach}

The U.S. Department of Energy's Building America research team Building Science Corporation built unvented roof test assemblies in houses and installed instrumentation to measure their longterm moisture performance (i.e., performed long-term monitoring). The cold-climate test house was in Bolingbrook, Illinois (Chicago area, CZ 5A), and was provided by K. Hovnanian Homes. The hot-humid test house was in Friendswood, Texas (Houston area, CZ 2A), and was provided by David Weekley Homes. One test house was monitored at each site.

The Chicago-area test bed for the experimental roofs was the attic of an attached garage. Seven parallel rafter bays were used as experimental test bays; the assemblies included unvented densepack cellulose and fiberglass batt roofs; and one vented fiberglass roof was used as a control comparison. The attic space was heated and humidified for the experiment. Data were collected from October 2013 through June 2014 to capture a winter and the following spring and early summer. At the conclusion of the experiment, the assemblies were disassembled to find any evidence of condensation, moisture accumulation, or moisture-related damage. The roof was then rebuilt and returned to its original nonexperimental condition.

The Houston-area roof is in a model house that was unoccupied during the testing period. The test house was configured with an unvented/sealed attic that was insulated at the roofline. Unlike the cold-climate roof, the entire Houston roof was insulated with spray-applied/adhered fiberglass that was left exposed. It had no interior finish. No intentional humidification or conditioning was provided in the unvented attic space; the space floats at conditions between the interior set point and exterior conditions. Most of the roof ridges and hips were built with a diffusion vent detail and capped with a strip of a highly vapor-permeable roof membrane. Some ridge sections were built as a conventional unvented roof for a control comparison. Data were collected from February 2014 through June 2015 (16 months); data collection is ongoing.

Instrumentation was installed per Straube et al. (2002) using a central data acquisition system for each house. The roof assemblies were measured for temperatures (Ts), wood moisture contents (MCs) (both sheathing and framing), and relative humidity (RH). Interior and exterior T/RH conditions were measured onsite; exterior data were supplemented with airport weather data (e.g., precipitation and wind). Appendix A includes an instrumentation listing and specifications. 


\subsection{Relevance to Building America's Goals}

Given the Building America goals of reducing home energy use by 30\%-50\% (compared to 2009 energy codes for new homes and preretrofit energy use for existing homes), the two cases described in the introduction will help the program achieve those goals more cost-effectively:

- In cold climates, retrofit insulation of roofs with dense-pack cellulose is a lower cost and less intrusive technique than demolition and the use of spray foam insulation. However, this method may cause moisture and durability problems. Removing this risk will allow adoption of the cellulose technique in cases where it would have been avoided in the past.

- In hot-humid climates, unvented roof assemblies can be used to bring ductwork and air handling units into the conditioned space and improve airtightness. Doing so with materials that are lower cost than spray foam (the current solution) may increase adoption of this approach.

The National Renewable Energy Laboratory and the Standing Technical Committee on Enclosures (NREL 2013b) presented top priorities for research. In the Enclosures section, Item E4 specifically addressed the issue of unvented dense-pack roof assemblies in cold climates:

By end of 2015, address common practices that use methods in violation existing codes, including those routinely performed by the weatherization industry such as dense packing unvented cathedral ceilings and low slope roofs.

Significance: Promoting methods that violate existing codes raise legal, moral and ethical issues.

Interim Steps: Change existing codes to allow alternative methods that currently do meet existing codes

Challenges: Field testing of alternative methods in various climate zones is necessary. Often failures and lessons learned are not disclosed due to litigation.

This work also falls under the category of " 2.0 Risk Reduction and Minimization" from NREL 2013a.

\subsection{Cost-Effectiveness}

One goal of this research was to find moisture-safe methods to replace higher cost spray polyurethane foam (SPF) or rigid board foam with lower cost fibrous fill insulation. The retrofit of an empty cavity (per the cold-climate example of retrofit insulation of a cathedral ceiling) will clearly be a cost-effective measure; this cost-effectiveness is compounded by the moderate air sealing effects of dense-pack insulation (Schumacher 2011).

The installed cost of closed-cell spray polyurethane foam (ccSPF) varies widely based on contractor availability, the size of the installation, regional pricing, feedstock (crude oil) prices, and access (e.g., requirement for lifts or scaffolding; confined space installation). However, a typical installed price used for estimation purposes is about $\$ 1$ /board foot $(1 \mathrm{in} . \times 12 \mathrm{in} . \times 12$ in.), although pricing may vary in practice from $\$ 0.45$ to $\$ 1.40 /$ board foot. 
Figure 2 shows a comparison of insulation material costs based on big box home center pricing gathered from 2007 through 2011 . The comparison shows the normalization metric of $\$ / \mathrm{ft}^{2} \cdot \mathrm{R}$ value, which normalizes the area costs based on the R-values.

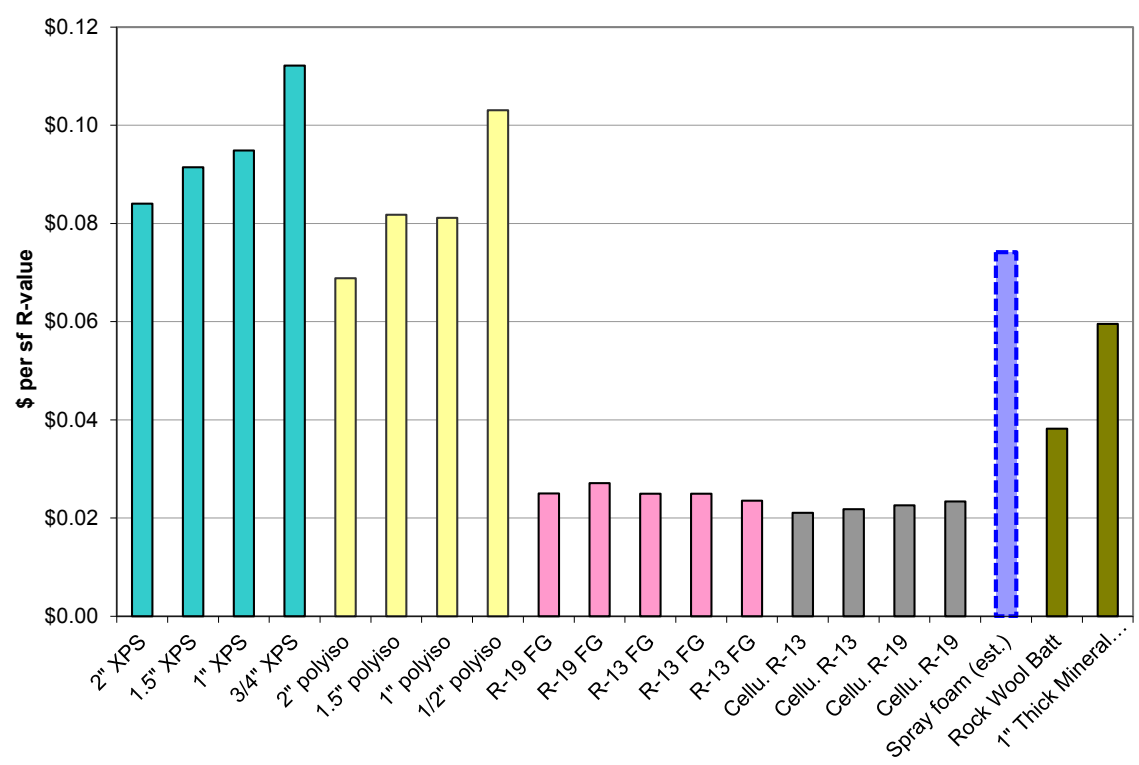

Figure 2. Insulation material costs (no installation), in $\$ / \mathrm{ft}^{2} \cdot \mathrm{R}$-value

The figure shows values for extruded polystyrene (XPS), polyisocyanurate, fiberglass, cellulose, $\mathrm{SPF}$, and mineral fiber. The ccSPF is included in the graph with a caveat: no isolated material cost for ccSPF is shown, because it is effectively manufactured and installed as a single step. An estimate was made using the $\$ 1 /$ board foot price and dividing by 2 (50\% materials and $50 \%$ labor).

The graph shows that ccSPF is priced comparably to the rigid board foam plastic products (XPS and polyisocyanurate), which are both substantially more expensive than cavity fill fibrous insulation such as fiberglass or cellulose.

Closed-cell SPF, XPS, and polyisocyanurate are all premium products - with an associated cost penalty - because they are air-impermeable insulation materials that are intrinsically moisture tolerant. When enclosures are being designed, these premium materials should be used to take advantage of their properties. Assembly R-value can be augmented (if desired) with lower cost fibrous insulation products, assuming that durability is not compromised by adding it to the design.

\subsection{Tradeoffs and Other Benefits}

The basic benefits of retrofit insulation of compact roof assemblies (including cathedral ceilings) include energy savings from reduced heat flow and reduced airflow and thermal comfort improvements for occupants from radiant surface temperature effects.

The benefits of unvented roof assemblies in hot-humid climates include energy savings from eliminating duct conductive and air leakage losses; shifting the enclosure geometry to the roof line commonly improves building airtightness. Bringing the ductwork and HVAC equipment 
within the conditioned space can reduce the risks of surface condensation on cold equipment surfaces compared with high-dew-point attic air (essentially exterior air).
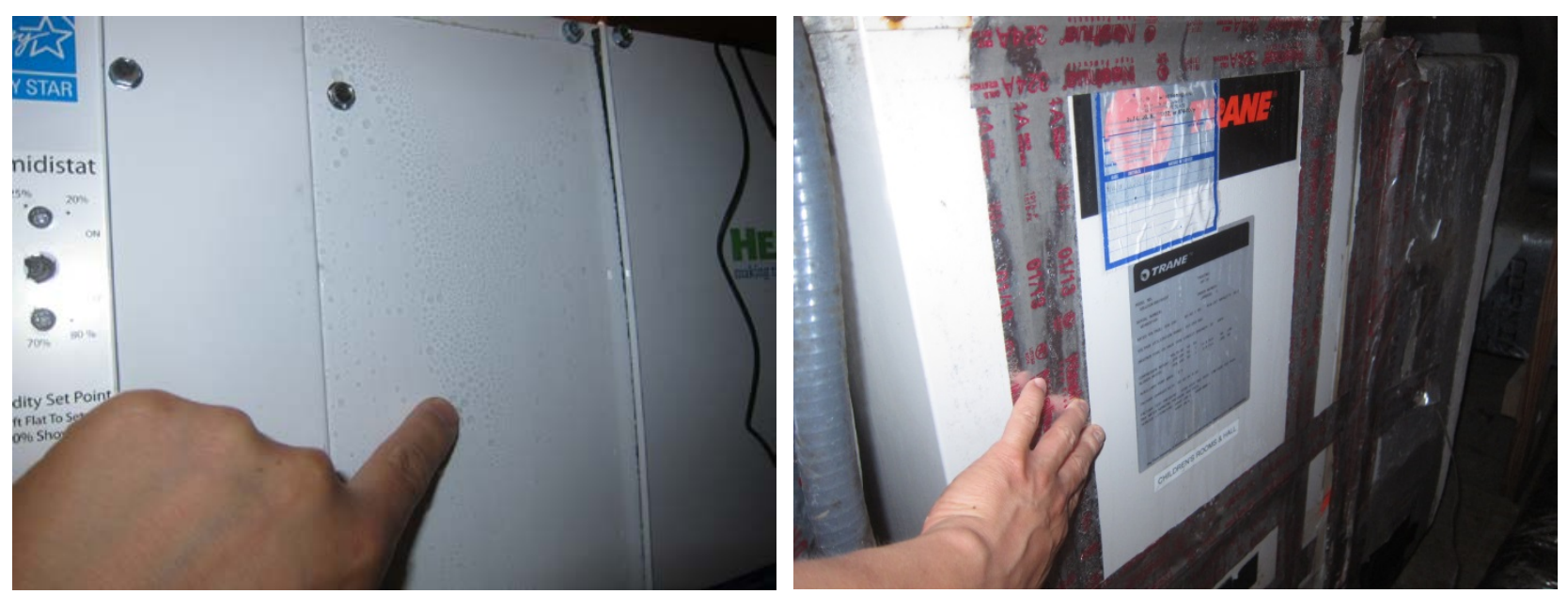

Figure 3. Condensation on HVAC equipment located in vented attic (CZ 2A) 


\section{Background Literature and Field Experience}

\subsection{Unvented Roof Background Literature}

Lstiburek (2010b) provides an overview of the use of dense-pack cellulose insulation and shows examples of the problems that can occur in compact roof assembly applications. Schumacher and LePage (2012) provide a comprehensive analysis of the use of dense-pack insulation in compact roof assemblies. They provide an overview of the problem and cite previous literature:

Many contractors and cellulose sales people falsely believe that dense-pack assemblies are "airtight". This has been shown not to be the case (Derome 2005, Schumacher 2011) - with disastrous consequences in cold and mixed climates where roof rafters have been "dense packed" with no provision for rafter ventilation (to remove moisture) or for control of condensing surface temperatures (to minimize moisture accumulation) (Lstiburek 2010b). Approximately two assemblies in ten fail - typically within 10 years (Fitzgerald 2010).

Schumacher and LePage also provide hygrothermal analysis of a variety of assemblies to show the moisture risks associated with unvented dense-pack roofs. They suggest that failures are not endemic, because postretrofit houses achieve only moderate airtightness. Thus, interior moisture generation is sufficiently diluted by wintertime air leakage to result in low wintertime interior RH levels. They provide several options for moisture-safe roof assemblies that use dense-pack cellulose:

- Exterior insulation: roof deck overclad, (Figure 4, left)

- Hybrid insulation: spray foam at roof deck with fibrous insulation, (Figure 4, right)

- Bottom-vented decks: air space or rafter ventilation chutes underneath the roof deck, outboard of insulation (Figure 5)

- Top vented decks: airspace underneath the asphalt shingles and roof cladding. This creates a drained and ventilated cavity (Figure 6) (Lstiburek 2010a; Straube and Burnett 2005). This is not a common assembly with asphalt shingles and was considered somewhat experimental or conceptual.
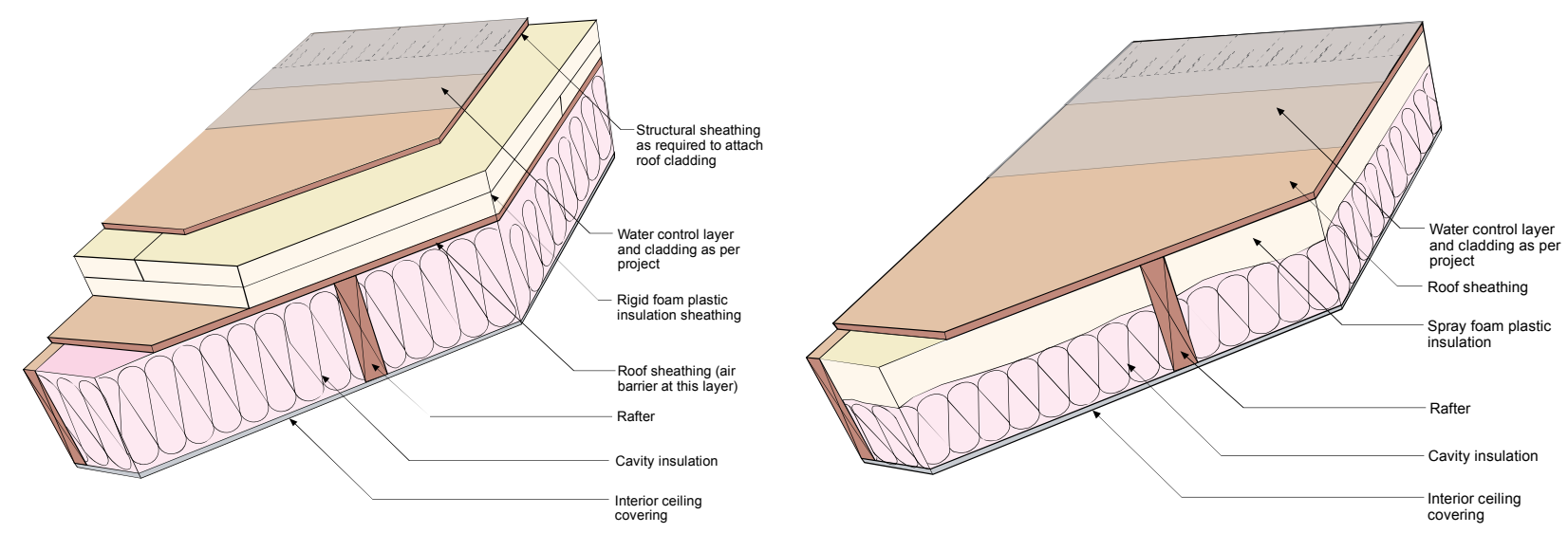

Figure 4. Unvented roof hybrid insulation options: rigid foam overclad (left); SPF (right) 

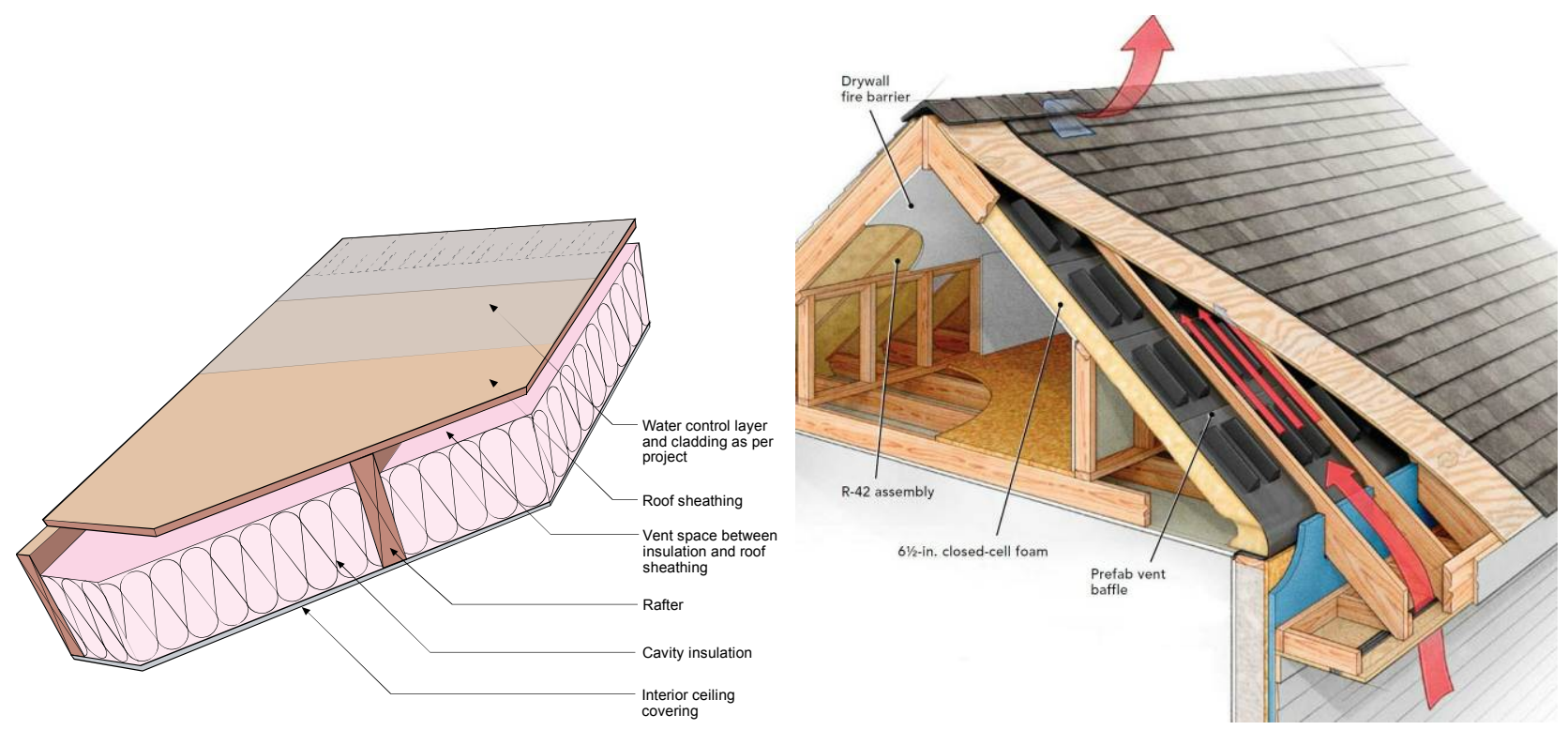

Figure 5. Bottom ventilated roof deck

Source of right figure: Lstiburek (2011)

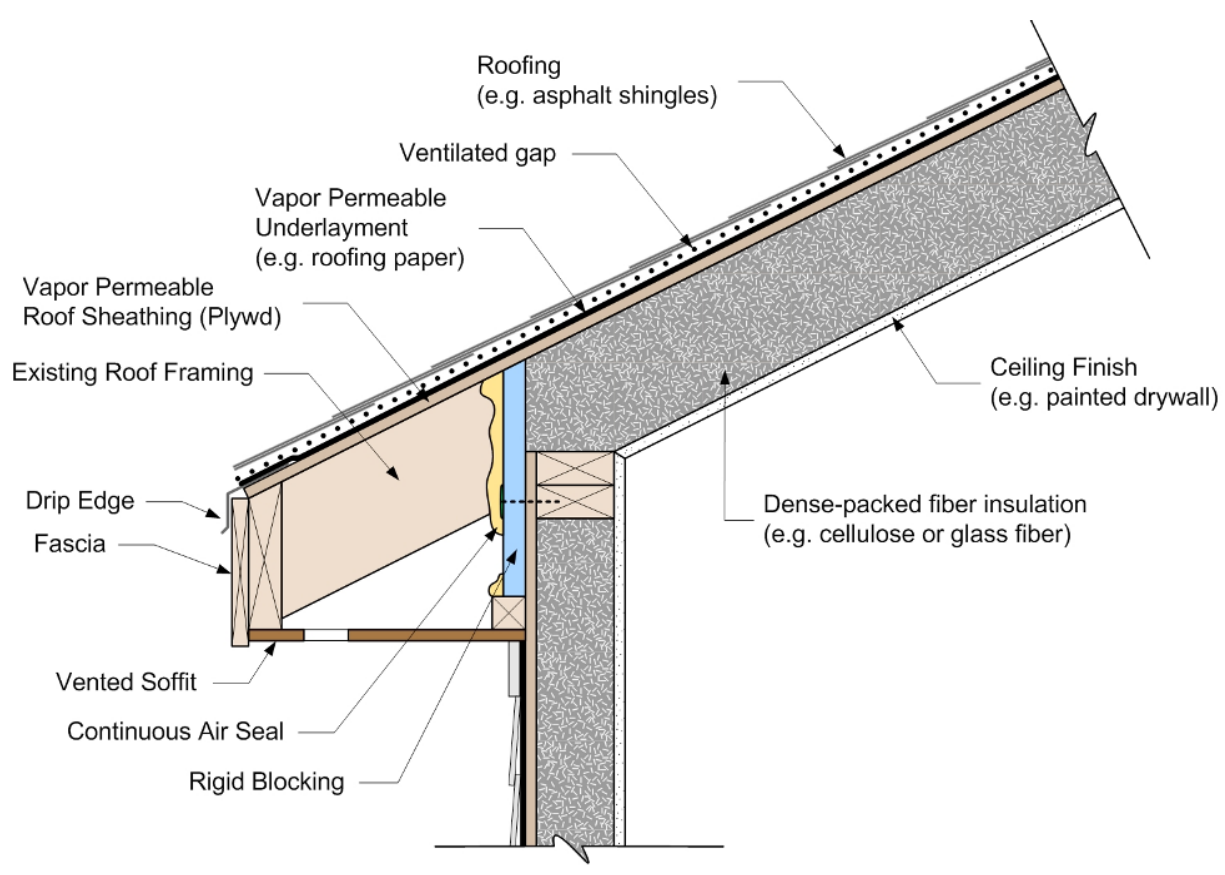

Figure 6. Top ventilated dense-packed roof assembly

Source: Schumacher and LePage (2012)

The top ventilated deck warrants further explanation; Schumacher and LePage (2012) describe the design and provide recommendations for implementation.

A number of low-rise residential roofing systems incorporate ventilated gaps between the roofing and the roof deck (e.g. clay roof tiles, concrete roof tiles \& 
slate tiles installed on strapping; cedar shakes installed over drainage/ventilation mat). The top-ventilated deck strategy might be considered for dense-pack insulation retrofits where the existing ceiling must be kept but exterior insulation cannot be added (e.g. due to historical preservation considerations, spatial limitations or cost constraints).

When a ventilation gap is incorporated above the roof deck, the roofing can dry to the underside. If a vapor permeable underlayment is used, the roof sheathing can also dry to this ventilated gap; however, the rate of drying through the sheathing is limited by the vapor permeance of the sheathing and the drainage plane installed on top of the sheathing.

Top-ventilated retrofit roofs may provide better moisture performance than common retrofit roofs; however, further research is needed to better understand and establish the sensitivity to sheathing and underlay vapor permeance. At this point in time the likely moisture performance of top-ventilated retrofit roofs is not expected to be as good as the other three retrofit strategies: exterior insulated, hybrid-insulated and bottom-ventilated retrofits. Builders are encouraged to employ one of the first three strategies. If a top-ventilated retrofit must be implemented, it should be completed using plywood sheathing and high vapor permeance underlayment.

\subsection{Field Experience in Houston, Texas, and Jacksonville, Florida (Climate Zone 2A)}

Building Science Corporation made discoveries about unvented roof behavior in hot-humid climates during field implementation; several of these roofs were built in the Houston, Texas, area circa 2001 (CZ 2A). The typical roof assembly was asphalt shingles, roofing felt, oriented strand board (OSB) sheathing, and netted and blown cellulose insulation (Figure 7, left). Netting was attached to the underside of the dimension lumber $(2 \times 8$ to $2 \times 12)$ rafters.

During the first fall of operation, the homeowner reported seeing reflections of moisture condensation and dripping from the ridge of the unvented attic from the interior. Site investigations (Figure 7, right) revealed elevated wood MCs at the ridge and evidence of previous condensation (such as rusted staples).
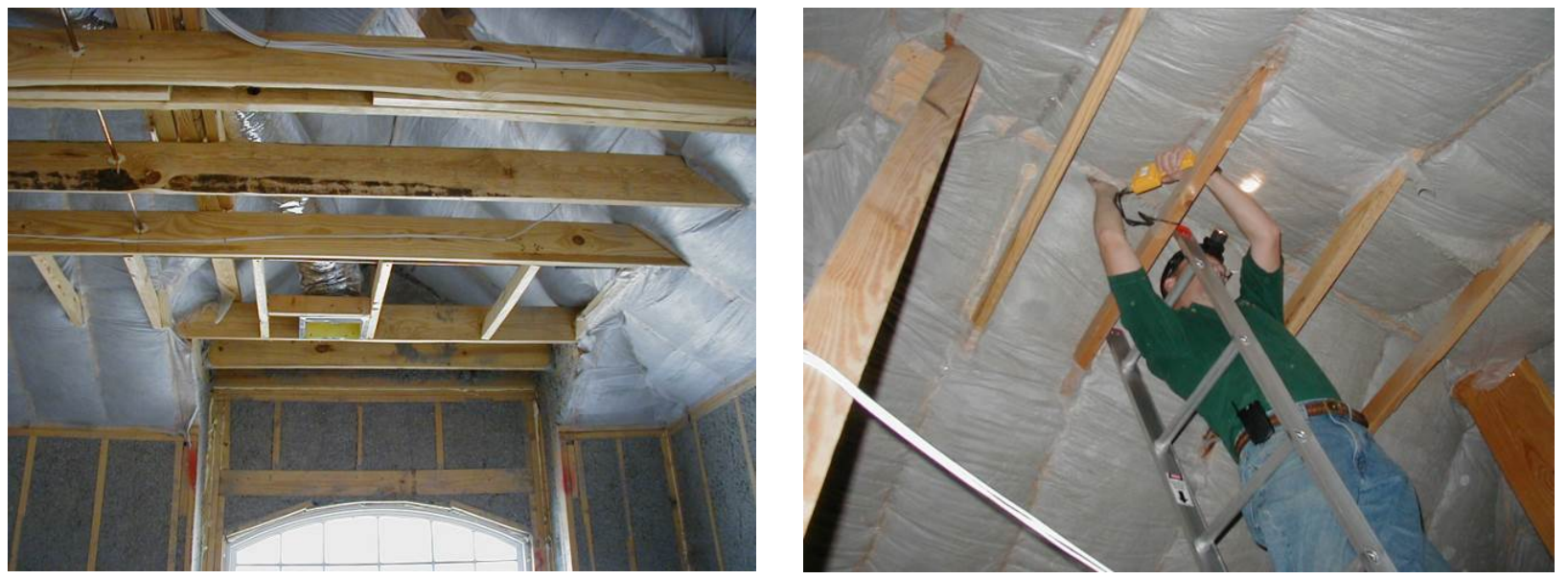

Figure 7. Netted and blown cellulose roof insulation in Houston (left); MC at the roof ridge (right) 
The cellulose insulation at the peak had a noticeably "packy" or compactable texture as opposed to the "fluffy" texture of dry cellulose. This failure was localized at the peak of the roof. These moisture issues were remediated by removing the insulation at the roof ridge; of course, a thermal penalty was caused by this modification.

A similar type of issue arose in two production homes in Jacksonville, Florida (CZ 2A) circa 2000. Again, the roof assembly was asphalt shingles, roofing felt, OSB sheathing, and netted and blown cellulose insulation (Figure 8 , left). The house was relatively airtight for the climate $(2.5$ $\mathrm{ACH} 50)$.

During a site visit, the cellulose and roof sheathing above were wet to the touch, and the steel truss plate was corroded; however, the wood had not decayed. In response, the insulation was removed near the ridge (roughly 2 feet; Figure 8, right) to increase surface temperatures at the condensing roof sheathing surface. This roof has been rechecked over time (circa 2003 and as recently as March 2014); roof sheathing conditions remained dry with this assembly.
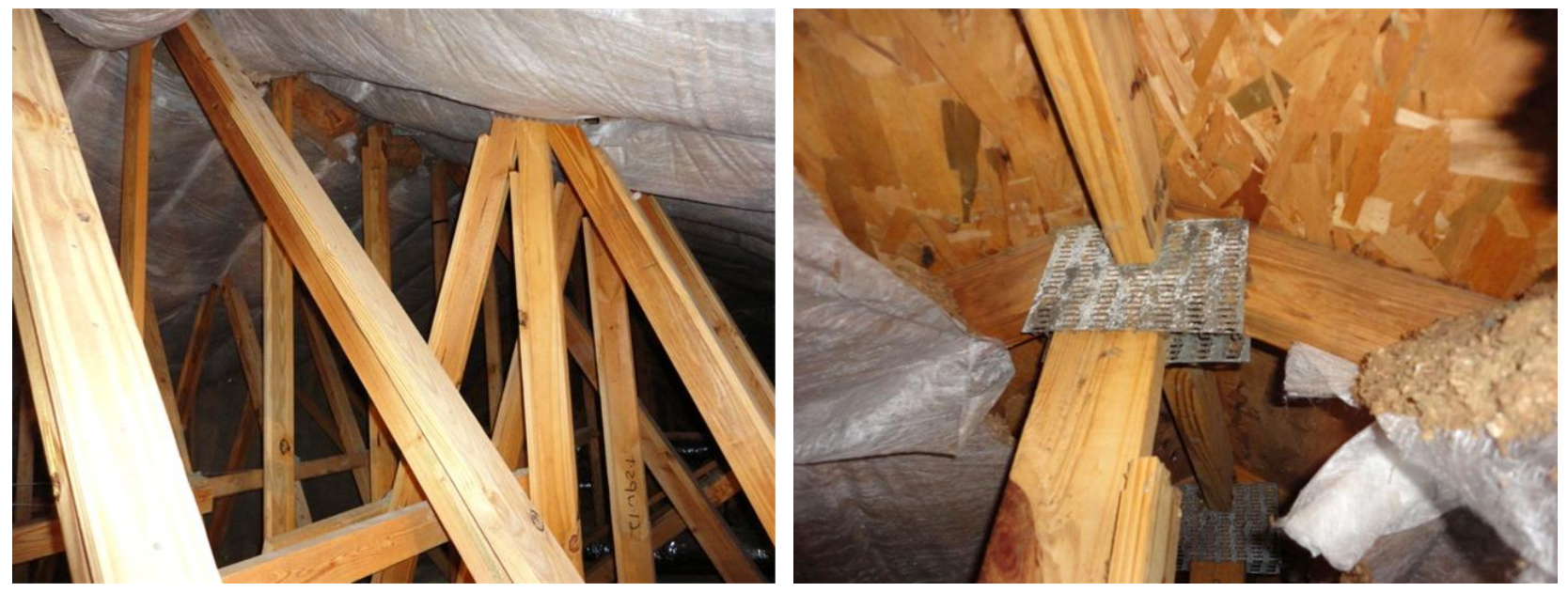

Figure 8. Netted and blown cellulose roof insulation in Jacksonville (left); corrosion of ridge truss plate (right)

\subsection{Field Experience in Northern California (Climate Zone 3C)}

Moisture issues in unvented roof assemblies often manifest in the form of damage to the sheathing at the ridge of a sloped roof, colloquially known as ridge rot. An example is shown in Figure 9, which was a dense-pack cellulose roof in a northern California location (CZ 3C).

These issues arose soon after construction (during the first winter); the problems were manifested as paint blistering at the interior gypsum wallboard (GWB) near the roof (Figure 10, right), due to dripping of accumulated condensation. The issue was definitely localized at the ridge of the roof; disassembly at a lower section of the roof showed dry sheathing conditions (Figure 10, left). Air barrier imperfections at the interior GWB (especially at the ridge board interruption) were contributing factors.

The pattern of moisture accumulation seen here and in $\mathrm{CZ} 2 \mathrm{~A}$ influenced the experimental design: sensors were concentrated near the roof ridge, where problems appeared to be prevalent. 

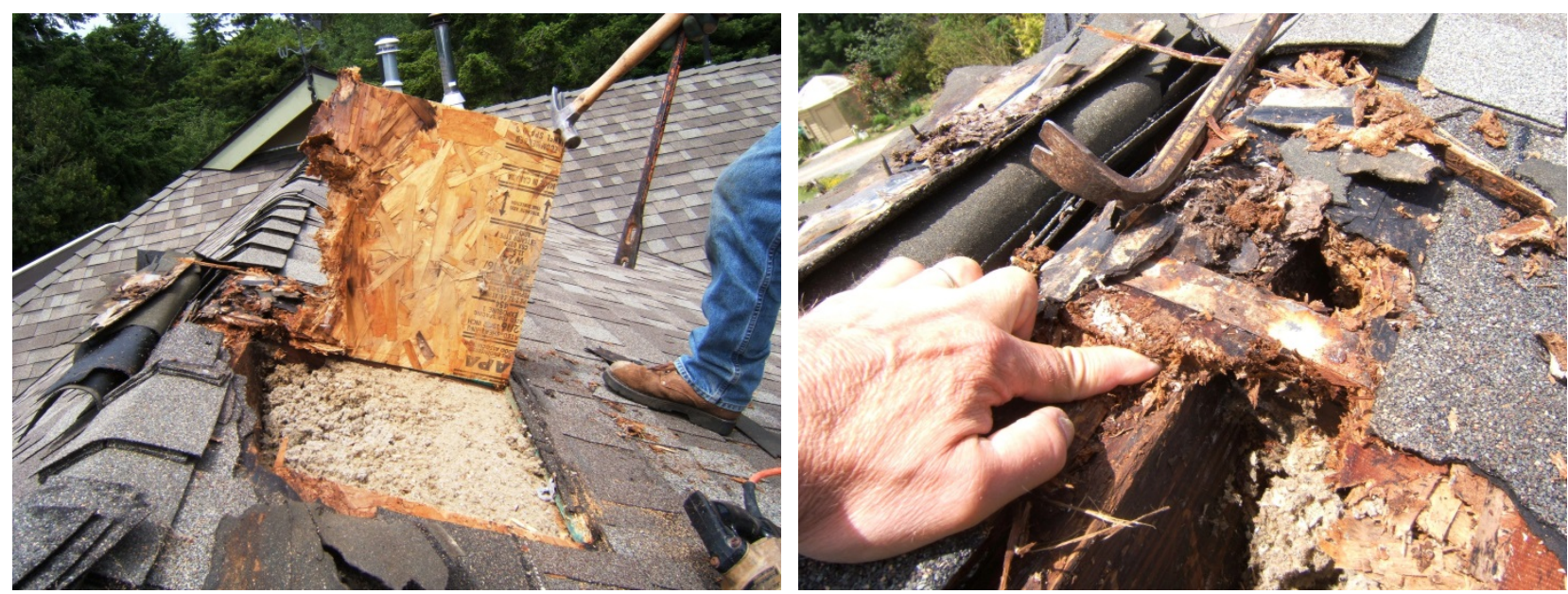

Figure 9. Ridge sheathing degradation with dense-pack cellulose in northern California
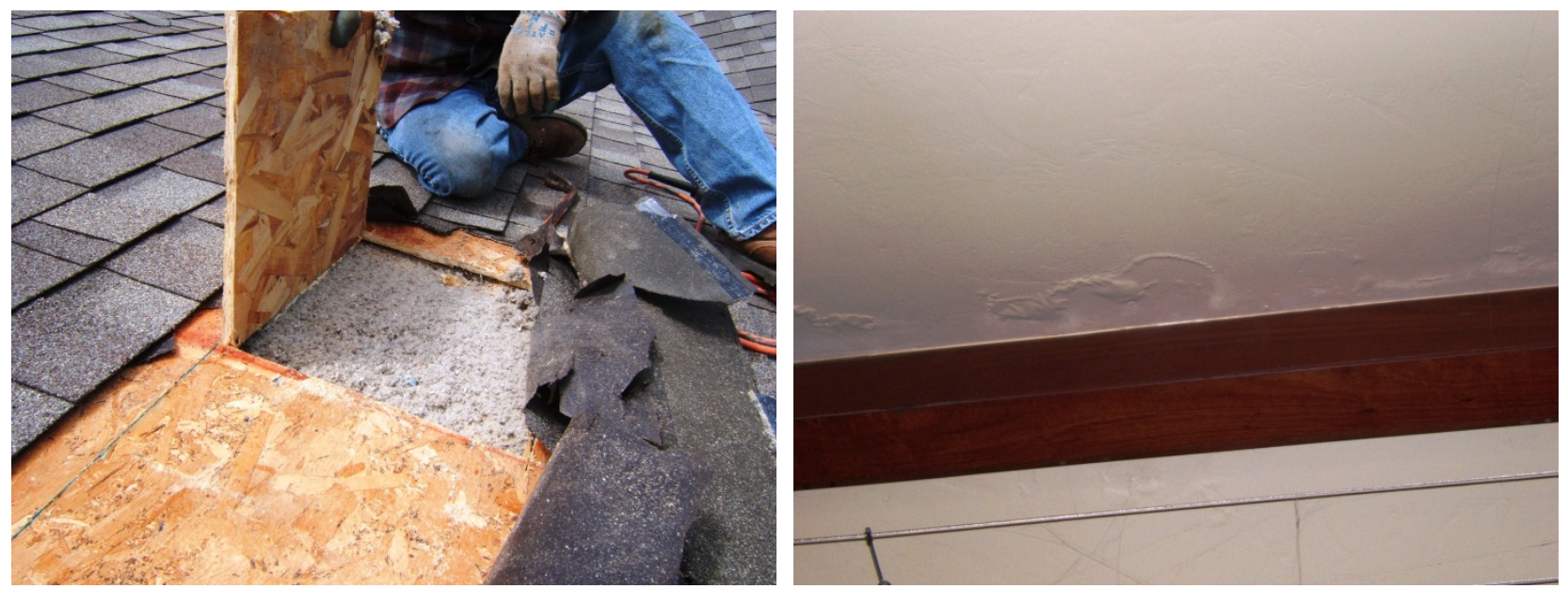

Figure 10. Dry sheathing lower at roof (left); interior ridge conditions (right)

\subsection{Salonvaara et al. (2013): Modeling Unvented Roofs in Climate Zones 1-4}

Salonvaara et al. (2013) studied unvented attics with simulations in CZs 1-4. They first presented an overview of unvented (or sealed) attics with the positives and negatives of this design compared to conventional vented attics.

The authors calibrated their models against field monitoring results from Boudreaux et al. (2013). One factor noted when comparing modeled and monitored results was the difference between the high-temperature $\left(60^{\circ} \mathrm{C}\left[140^{\circ} \mathrm{F}\right]\right)$ sorption isotherm (relationship between $\mathrm{RH}$ and $\mathrm{MC)}$ compared with the room-temperature isotherm. Slightly better correlation was achieved by using a temperature-dependent sorption response.

The authors then ran hygrothermal simulations (WUFI Pro) models of vented and unvented roof assemblies in various configurations in CZs 1-4. Interior RH levels were set at design conditions (higher than average or typical conditions); this exacerbates wintertime interstitial condensation risks. The roof assemblies consisted of asphalt shingles, felt paper, OSB sheathing, and insulation (open-cell spray polyurethane foam [ocSPF] or fiberglass). Cases were run for no water intrusion and for a rainwater leak ( $1 \%$ of incident rain hitting the surface bypasses the 
water-resistive barrier [WRB]) to the roof sheathing. The results are summarized in the form of peak roof sheathing MCs for the various cases in Table 1; peak MCs higher than 20\% are highlighted in red. CZs 1, 3, and 4 results are shown to provide a range.

Table 1. Summary of Simulation Results (roof sheathing MCs)

Source: Salonvaara et al. (2013)

\begin{tabular}{c|c|c|c|c|c|c}
\hline \multirow{2}{*}{ Case } & \multicolumn{3}{|c|}{$\begin{array}{c}\text { No Rain Leak } \\
\text { (Peak MCs) }\end{array}$} & \multicolumn{3}{c}{$\begin{array}{c}1 \% \text { Rain Leak } \\
\text { (Peak MCs) }\end{array}$} \\
\cline { 2 - 7 } Vented Attic & CZ 1 & $\mathbf{C Z 3}$ & $\mathbf{C Z 4}$ & $\mathbf{C Z 1}$ & $\mathbf{C Z 3}$ & $\mathbf{C Z 4}$ \\
\hline Unvented, ocSPF (23 perm-in.) & $8 \%$ & $7 \%$ & $7 \%$ & $12 \%$ & $12 \%$ & $12 \%$ \\
\hline Unvented, ocSPF (54 perm-in.) & $8 \%$ & $16 \%$ & $\mathbf{2 2} \%$ & $14 \%$ & $\mathbf{2 7 \%}$ & $\mathbf{3 5 \%}$ \\
\hline $\begin{array}{c}\text { Unvented, ocSPF (23 perm-in.) + 1 Perm } \\
\text { Coating }\end{array}$ & $6 \%$ & $8 \%$ & $9 \%$ & $\mathbf{2 5 \%}$ & $\mathbf{4 9 \%}$ & $\mathbf{3 7 \%}$ \\
$\begin{array}{c}\text { Blown Fiberglass, No Interior Vapor Retarder } \\
\text { Blown Fiberglass, 10 Perm Interior Vapor } \\
\text { Retarder }\end{array}$ & $8 \%$ & $19 \%$ & $\mathbf{3 0 \%}$ & $13 \%$ & $\mathbf{3 0 \%}$ & - \\
\hline
\end{tabular}

The authors concluded from these simulations that a vented attic assembly has better drying ability than unvented assemblies in all climates. Most unvented ocSPF assemblies had safe MCs without rain leakage, but in colder climates (CZ 4) with very vapor-open ocSPF (54 perm-in.), peak MCs reached risky levels. With the addition of rain leakage, MCs were substantially higher; these likely constitute failure in most CZs. The addition of a 1-perm coating (intumescent paint with 1-perm dry cup and 3-perm wet cup) on the interior side of the ocSPF resulted in lower MCs without rain leakage (the interior-sourced vapor flow was reduced) but higher MCs with rain leakage (reduced ability to dry inward).

The two final cases use blown fiberglass insulation (100 perm-in.) instead of ocSPF; only CZs 13 were plotted. These results show that when vapor-open interior netting is used for installation, acceptable MCs were found in CZs 1 and 2, but riskier conditions were seen in CZs 3 and 4. Adding netting with a vapor permeance of 10 perms reduces risks to reasonable levels in CZs 13. The authors recommended that the current code requirement (International Residential Code $\S 806.4)$ for R-5 air-impermeable insulation in CZs 1 and 2 be dropped based on these results.

The authors then used whole-house energy simulations (WUFI-Plus) to study airflow issues between the interior conditioned zone, unvented attic, and exterior. They noted that a house can have overall low enclosure air leakage; however, stack effect will act downward during the summer, and exterior air will be drawn predominantly into the attic if there is leakage to the outdoors. Thus, infiltration of hot-humid air can have a disproportionate effect on attic humidity conditions. In the simulations, air leakage resulted in high enough attic humidity to cause concerns about mold growth. Although the common solution is to add some space conditioning (summertime cooling and dehumidification) to the attic, the authors are wary of this solution for indoor air quality reasons (connecting uncleaned attic space with interior air). The authors conclude that air sealing the attic to the exterior is critical. 


\subsection{Boudreaux et al. (2013): Sealed Attic Monitored Performance (Climate Zones 3A and 4A)}

Boudreaux et al. (2013) presented data collected at eight houses in CZs 3A and 4A-four with vented attics and four with sealed attics - to understand their moisture performance. The authors noted that multiple practitioners and online sources have reported high humidity problems in unvented attics.

Their data showed that attic absolute MCs (vapor pressures) were consistently higher in the sealed attics than the vented attics. Similarly, the vapor pressures in the main spaces were higher in the sealed attic houses. When the individual house data were plotted, the two groups overlapped. The worst-performing unvented attic had the highest air leakage (10 ACH 50) of the sample; the authors described other factors that influenced interior moisture levels, including occupant density and set point.

Plots of vapor pressure at various sections of the roof assembly indicated that the sealed attic roof typically had patterns of daytime drying (desorption into the attic) and nighttime wetting (adsorption from the attic air). Similar cycling was seen in the vented attic houses, but with a much smaller vapor gradient given roof sheathing temperatures. The authors noted that the spikes in vapor pressure were associated with high solar gain days or roof sheathing temperature, or both.

Vapor pressure measurements were combined with differential pressure and air leakage measurements to estimate moisture flow to and from the attic. Their calculations showed the strongest vapor drives (from attic to interior) during the afternoons and early evenings and airflow downward (attic to interior) during the day and upward at night.

The authors theorized that seasonally, moisture accumulates in the roof sheathing from summer to fall and is then desorbed in the winter and spring.

Several sources of moisture for the sealed attic were discussed, including roof sheathing storage, solar-driven moisture from moisture stored in asphalt shingles (judged unlikely by the authors), exterior air leakage (likely, especially given the downward stack effect during the summer).

The authors used collected HVAC data to estimate the penalty associated with directly conditioning the sealed attic to control humidity. They noted a 7\% increase in energy use, which cuts into the performance improvement associated with bringing the ductwork within the conditioned space. The authors recommended that alternatives other than sealed attics be used to bring ductwork within the conditioned space.

\subsection{Lstiburek (2014): Humidity Behavior of Unvented/Sealed Attics}

Lstiburek (2014) clarified some background and terminology for unvented attics. He proposed the alternative, more descriptive term of conditioned attic. In earlier construction, attic ductwork was typically leaky, and supply leakage would slightly pressurize the attic. This would cause air leakage from the attic to the main space (communication, see Figure 11, left). This air communication would dehumidify the attic space; the moisture load in the attic was driven primarily by interior sources. Moisture would concentrate in the attic (top of the building) due to the buoyancy of moisture-laden air (which has a lower density than dry air). 
The author cites Houston-area field research about the effect of vapor-permeable and vaporimpermeable shingle underlayments on inward vapor drives (Figure 11, right); the study found no measurable differences between these roof test bays. Therefore, he notes that shingle inward drive issues are not a significant moisture source.
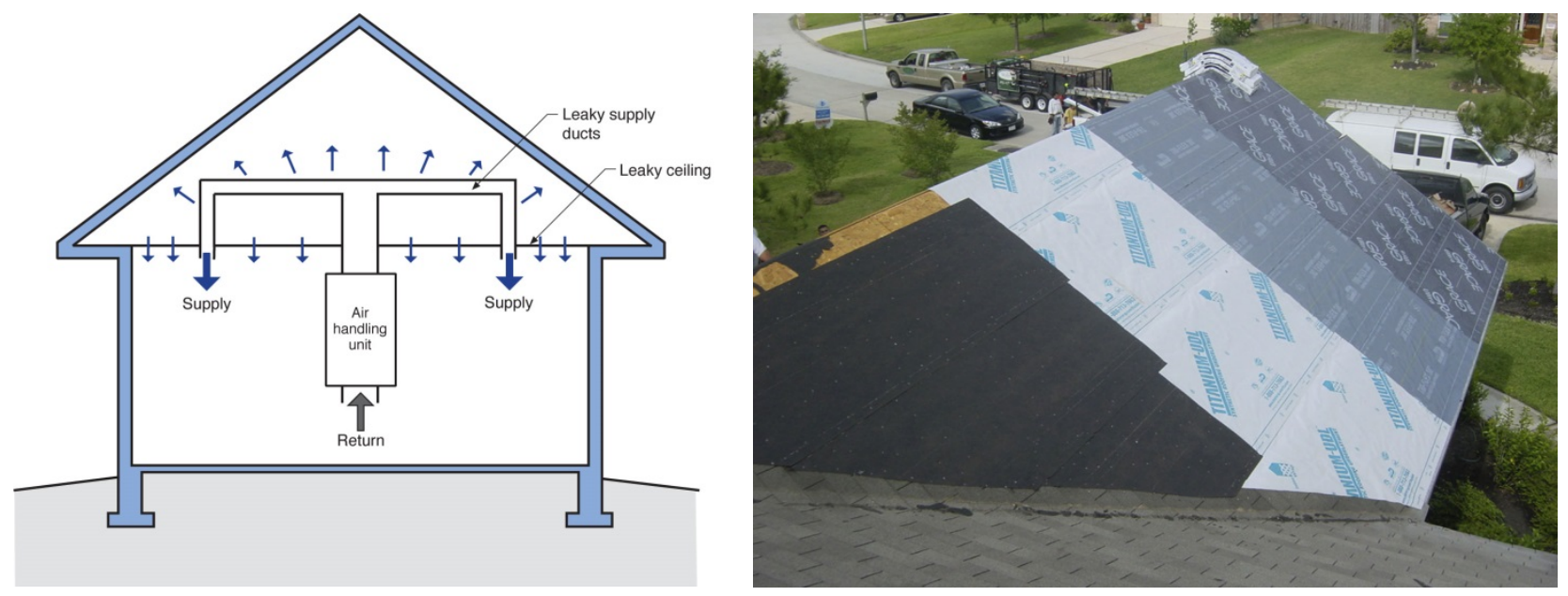

Figure 11. Air leakage communication from unvented attic to main space (left); Houston-area roof underlayment study (right)

Source: Lstiburek (2014)

As airtight HVAC ductwork became more common, incidental space conditioning provided to unvented attics and communication between the attic and the main space was reduced. The resulting problem has been higher humidity levels in unvented/sealed attics, especially with vapor-open insulation materials such as ocSPF. Interior moisture is adsorbed and desorbed from the roof sheathing with daily warm/cold cycles; without communication to remove the moisture, it accumulates due to moisture buoyancy.

The proposed resolution to this issue is to add supply and return space conditioning to the attic space at $50 \mathrm{CFM}(24 \mathrm{~L} / \mathrm{s})$ per $93 \mathrm{~m}^{2}\left(1,000 \mathrm{ft}^{2}\right)$ of ceiling area. However, this may conflict with code fire separation requirements. One option is to add a return duct smoke detector that shuts down the attic air handler when smoke is detected.

\subsection{Smegal and Straube (2014): Monitoring and Simulation of Spray- Polyurethane-Foam-Insulated Roofs}

Smegal and Straube (2014) covered more than 2 years of monitoring data (2010-2012) for seven vented and unvented roof assemblies installed in a test hut in Waterloo, Ontario (CZ 6). Interior conditions were set at $20^{\circ} \mathrm{C}\left(68^{\circ} \mathrm{F}\right)$ and $50 \% \mathrm{RH}$, which is a high moisture level that stresses assemblies because of wintertime condensation.

All assemblies were cathedral (compact) roofs with roughly R-30 insulation, OSB roof sheathing, black asphalt shingles, and latex paint on GWB as an interior finish. The roof assemblies are described in detail in Table 2. All roofs face east. 
Table 2. Test Roof Assemblies Monitored in Smegal and Straube (2014)

\begin{tabular}{c|c|c|c}
\hline Assembly & $\begin{array}{c}\text { Short } \\
\text { Name }\end{array}$ & $\begin{array}{c}\text { Vented/ } \\
\text { Unvented }\end{array}$ & $\begin{array}{c}\text { Vapor Control } \\
\text { (lowest perm interior layer) }\end{array}$ \\
\hline Unvented Closed Cell & NCC & Unvented & ccSPF \\
Vented Closed Cell & VCC & Vented & ccSPF \\
Vented Fiberglass & VFG & Vented & Latex paint and GWB \\
Unvented Painted Open Cell & NOCP & Unvented & Paint on ocSPF, latex paint, and GWB \\
Vented Open Cell & VOC & Vented & Latex paint and GWB \\
\hline Unvented Open Cell & NOC & Unvented & Latex paint and GWB \\
\hline
\end{tabular}

The vented roof assemblies were ventilated with a polystyrene foam baffle installed under the roof sheathing, which connected to soffit and roof vents low and high. Sensors were installed to measure assembly temperatures, $\mathrm{RH}, \mathrm{MC}$, and boundary conditions (interior and exterior). Wetting systems were installed between the roof sheathing and shingle underlayment to determine the drying ability of the assemblies after a wetting event.

Sheathing MCs were plotted: most roofs had a seasonal swing with drier $(5 \%-10 \%)$ MCs in summer, and wetter $(8 \%-13 \%)$ in winter; all these levels are well within the safe range for durability. However, the MCs for unvented ocSPF (NOC) and painted unvented ocSPF (NOCP) exceeded $20 \%$ each winter. In the first winter, the interior was at $40 \% \mathrm{RH}$, and $20 \%-28 \% \mathrm{MC}$ peaks were seen. The second winter had 50\% RH conditions and higher $(20 \%-34 \%)$ MCs were seen. However, in each following summer, sheathing MCs in these ocSPF roofs fell to safe levels. This indicates that ocSPF roof assemblies in CZ 6A face some durability risks, even with the addition of a painted vapor control layer on the ocSPF.

RH levels within the roof assemblies were examined:

- In the ccSPF roofs (NCC/VCC), RHs within the foam were in the safe range. In the vented ccSPF roof (VCC), the ventilation chute RH levels were similar to outdoor conditions.

- In the fiberglass roof (VFG), ventilation chute RH levels were similar to outdoors. Cavity RHs fluctuated daily and showed moisture movement through the assembly (convective looping, diurnal heating/moisture drive, or air leakage).

- In the unvented ocSPF roofs (NOCP, NOC), RHs on the exterior side of the cavity rose and fell seasonally, similar to sheathing MCs. The latex painted foam had a slightly drier exterior-side RH (by 5\%), which might be insignificant; however, it might reflect the slight increase in vapor resistance in the unvented painted assembly NOCP.

- In the vented ocSPF roof (VOC, the RH on the exterior side of the cavity was very high (peaks at $95 \%$ and $100 \%$ during the two winters) with possible condensation risks. The low vapor permeance of the polystyrene foam chute and the lack of moisture storage (compared to OSB sheathing) may contribute to these high RHs. 
The wetting system was used in the summer and fall of 2010; the applied wettings (multiple 30to 60 -mL wettings; $240 \mathrm{~mL}$ total) caused only small increases in sheathing MCs and remained well within the safe range.

The monitoring work was followed by hygrothermal simulations (WUFI 5.1 Pro) of the assemblies; the modeled and measured data correlated reasonably well. The roof assemblies were simulated in other Canadian CZs and various interior RH levels (low/medium/high), using worst-case (north/12:12 roof pitch) orientation.

The ccSPF roof assemblies worked well under most conditions; the cases that were at risk of failure were high interior $\mathrm{RH}(50 \%)$ in colder climates. These risks are seen for worst-case orientation; at a south orientation, these assemblies have no risk.

The vented ocSPF roofs worked well under all conditions; however, this assumed no vapor resistance for the baffle/chute, which seemed to affect conditions in the monitored data.

The unvented ocSPF roofs showed risks in many CZs with latex paint (Class III) as interior vapor control. Polyethylene (Class I) reduced risks substantially, but at the cost of eliminating inward drying. An ocSPF roof with a Class II (1 perm) vapor retarder worked in conditions as cold as Ottawa with medium RH levels.

The vented fiberglass roof showed excellent performance in the simulation; however, this simulation did not include the effect of air bypass leakage from the interior, which is likely in practice and will add significant moisture load to the roof assembly.

The authors provided overall recommendations for construction and for further research on the permeance effects of ventilation baffles/chutes. 


\section{Cold Climate (Chicago) Experimental Setup}

\subsection{Overview}

The cold-climate test house was located in Bolingbrook, Illinois, roughly 35 miles southwest of Chicago (CZ 5A). This model house was provided by K. Hovnanian Homes. The house was unoccupied during the testing period; it also served as a demonstration/test house for meeting Challenge Home requirements in a production builder setting.

The test bed for the experimental roofs was the attic of the attached garage (third garage bay; Figure 12, in red). The gable end wall of the garage faces south; the two test roof orientations are east and west. Seven rafter bays were used as experimental test bays.
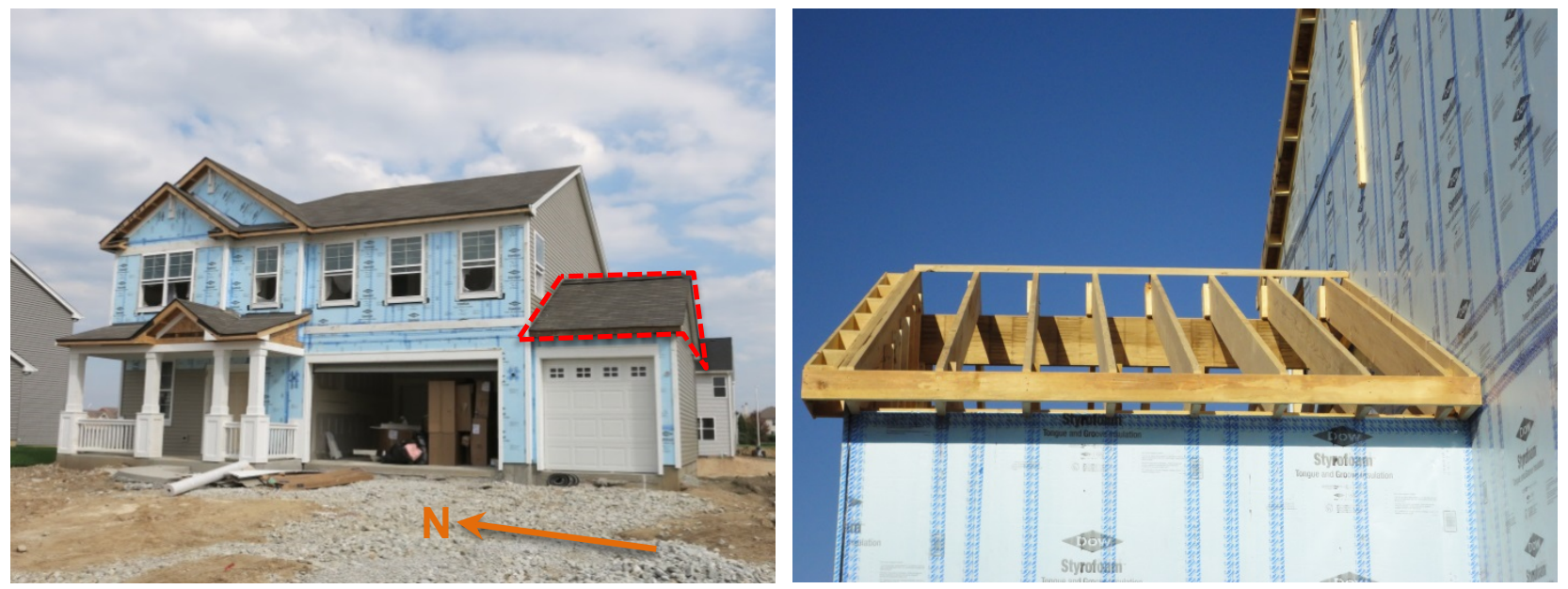

Figure 12. Test home with attached garage used for the experimental roofs

The roof assemblies were measured for temperatures, wood MCs (both sheathing and framing), and $\mathrm{RH}$ at various locations. Interior and exterior $\mathrm{T} / \mathrm{RH}$ conditions were measured onsite; exterior data were supplemented with airport weather data (e.g., precipitation and wind). Measurements were collected in a central data acquisition system (connected to the wired sensors); measurements were taken at 5-minute intervals and hourly averages recorded.

Appendix A includes an instrumentation listing and specifications.

Data were collected via cellular modem; one advantage of this communication connection was that interior T/RH set points could be adjusted remotely.

\subsection{Experimental Roof Assemblies}

A cross section of the experimental roof design is shown in Figure 13; the assemblies are described in Table 3 (with color codes used later as identifiers). The roofs were set up with one experimental assembly per rafter bay; each bay extended east-west so that each experimental rafter bay pair was a complete cross section of a roof, including eaves and ridge. 


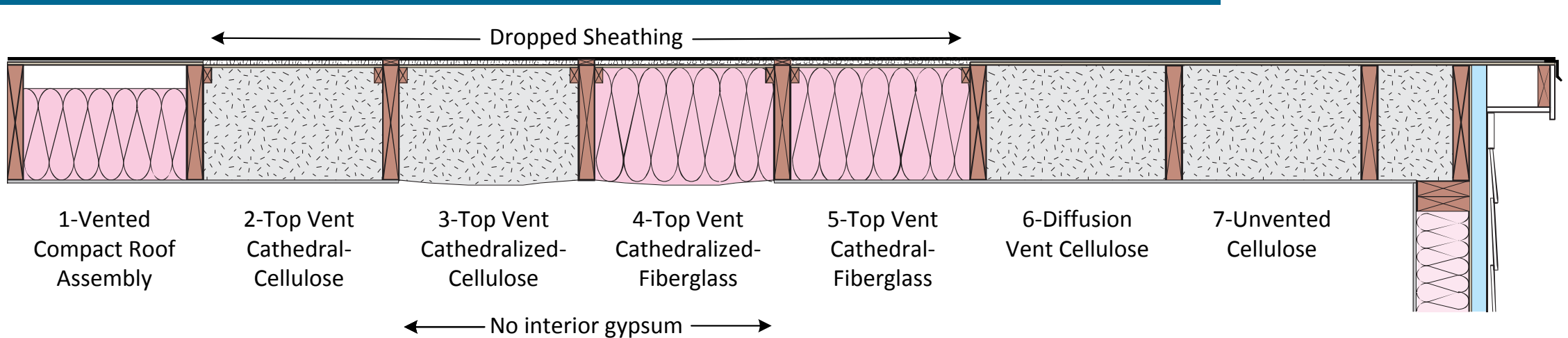

$\longleftarrow$ No interior gypsum

Figure 13. Chicago experimental roof test bays showing materials

Table 3. Description of Chicago Experimental Roof Test Bays

\begin{tabular}{|c|c|c|c|c|c|}
\hline$\#$ & Description & Interior & Rafter Bay & Exterior & Roof Ventilation \\
\hline 1 & Vented compact roof & $\begin{array}{l}\text { 1/2-in. GWB, latex } \\
\text { paint }\end{array}$ & $\begin{array}{l}\text { R-30 fiberglass batt, } \\
\text { 4-in. airspace }\end{array}$ & $\begin{array}{l}\text { 7/16-in. OSB, \#30 } \\
\text { felt, asphalt shingle }\end{array}$ & $\begin{array}{l}\text { 4-in. air space ventilated at } \\
\text { eave and ridge }\end{array}$ \\
\hline 2 & $\begin{array}{l}\text { Top vent cathedral- } \\
\text { cellulose }\end{array}$ & $\begin{array}{l}\text { 1/2-in. GWB, latex } \\
\text { paint }\end{array}$ & $\begin{array}{l}\text { R-38 cellulose, } \\
\text { dense packed }\end{array}$ & $\begin{array}{l}\text { 7/16-in. OSB, mesh, } \\
\text { asphalt shingle }\end{array}$ & $\begin{array}{l}\text { Breather mesh ventilation from } \\
\text { eave to ridge under shingles }\end{array}$ \\
\hline 3 & $\begin{array}{l}\text { Top vent cathedralized- } \\
\text { cellulose }\end{array}$ & None (open) & $\begin{array}{l}\mathrm{R}-38 \text { cellulose, } \\
\text { dense packed }\end{array}$ & $\begin{array}{l}\text { 7/16-in. OSB, mesh, } \\
\text { asphalt shingle }\end{array}$ & $\begin{array}{l}\text { Breather mesh ventilation from } \\
\text { eave to ridge under shingles }\end{array}$ \\
\hline 4 & $\begin{array}{c}\text { Top vent cathediralized- } \\
\text { fiberglass }\end{array}$ & None (open) & R-38 fiberglass batt & $\begin{array}{l}\text { 7/16-in. OSB, mesh, } \\
\text { asphalt shingle }\end{array}$ & $\begin{array}{l}\text { Breather mesh ventilation from } \\
\text { eave to ridge under shingles }\end{array}$ \\
\hline 5 & $\begin{array}{l}\text { Top vent cathedral- } \\
\text { fiberglass }\end{array}$ & $\begin{array}{l}\text { 1/2-in. GWB, latex } \\
\text { paint }\end{array}$ & R-38 fiberglass batt & $\begin{array}{l}\text { 7/16-in. OSB, mesh, } \\
\text { asphalt shingle }\end{array}$ & $\begin{array}{c}\text { Breather mesh ventilation from } \\
\text { eave to ridge under shingles }\end{array}$ \\
\hline 6 & Diffusion vent cellulose & $\begin{array}{l}1 / 2 \text {-in. GWB, latex } \\
\text { paint }\end{array}$ & $\begin{array}{l}\text { R-38 cellulose, } \\
\text { dense packed }\end{array}$ & $\begin{array}{l}\text { 7/16-in. OSB, \#30 } \\
\text { felt, asphalt shingle }\end{array}$ & $\begin{array}{l}\text { Ridge diffusion vent (glass } \\
\text { fiber-faced GWB) }\end{array}$ \\
\hline 7 & Unvented cellulose & $\begin{array}{l}\text { 1/2-in. GWB, latex } \\
\text { paint }\end{array}$ & $\begin{array}{l}\mathrm{R}-38 \text { cellulose, } \\
\text { dense packed }\end{array}$ & $\begin{array}{l}\text { 7/16-in. OSB, \#30 } \\
\text { felt, asphalt shingle }\end{array}$ & $\begin{array}{l}\text { Ridge sealed with self-adhered } \\
\text { membrane; unvented }\end{array}$ \\
\hline
\end{tabular}


Further explanation of the assemblies described in Table 3 is provided in Section 3.2.1 through Section 3.2.3.

\subsubsection{Vented Compact Roof (Roof 1)}

This is a typical code-compliant cathedral roof ( $(\mathrm{R} 806.1$ through $\mathrm{R} 806.3)$ with a ventilated air space above the fiberglass insulation. An R-30 batt was chosen for installation in the $2 \times 12$ (11$1 / 4$-in.) rafter bay, leaving roughly a 4 -in. airspace (Figure 15 ). The ridge ventilation detail was somewhat unconventional. A "doghouse" assembly was built of $2 x$ framing and OSB sheathing; however, this detail was necessary for a similar appearance between experimental roof assemblies.

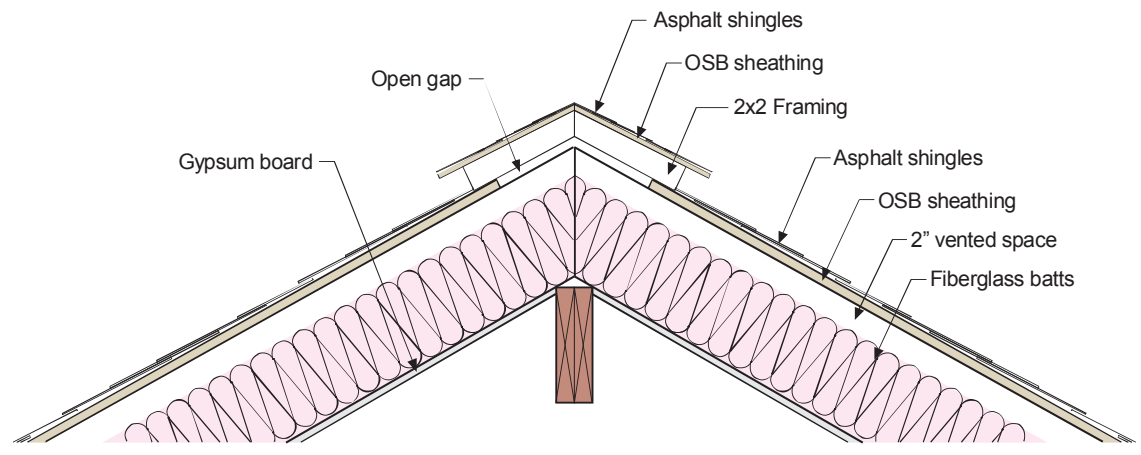

Figure 14. Ridge condition at Roof 1-vented compact roof
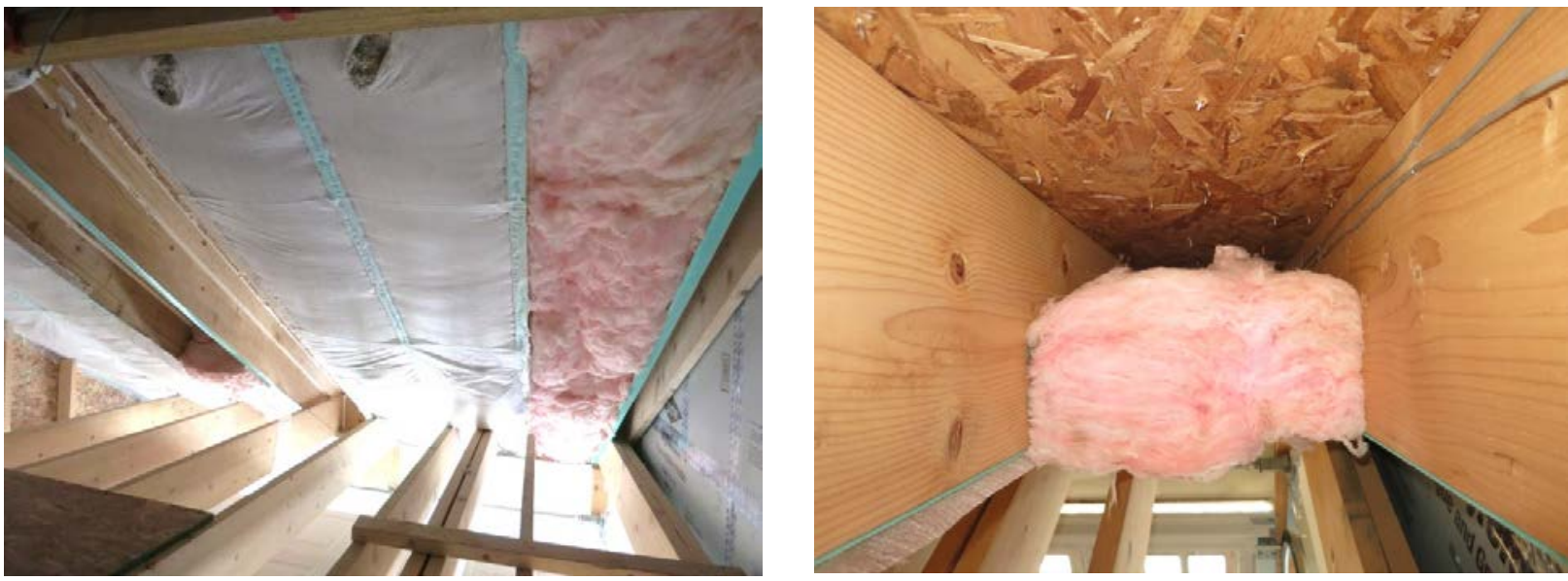

Figure 15. Roof 1-vented compact roof insulation (left); airspace/ventilation detail (right)

\subsubsection{Top Vent Cathedral-Cellulose (Roof 2)}

This is one of four roof assemblies that use a top vent strategy (Schumacher and LePage 2012). In this type of assembly, if a vapor-permeable WRB is used (or if the WRB is omitted), the sheathing can dry upward to the air space, and moisture is removed from the assembly by ventilation. The ventilation space under the shingles was created using a polypropylene breather mesh or spacer mesh that is commonly used for drainage and ventilation under cedar shingles. This mesh was sufficiently strong to support shingles without damage and created a reliable airspace. However, the completed roof showed some degree of waviness of the shingles at joints between roof bays (Figure 29), which might not be acceptable in practice. 
This assembly also allows drying of the shingles to the underside (into the airspace) (Figure 16).

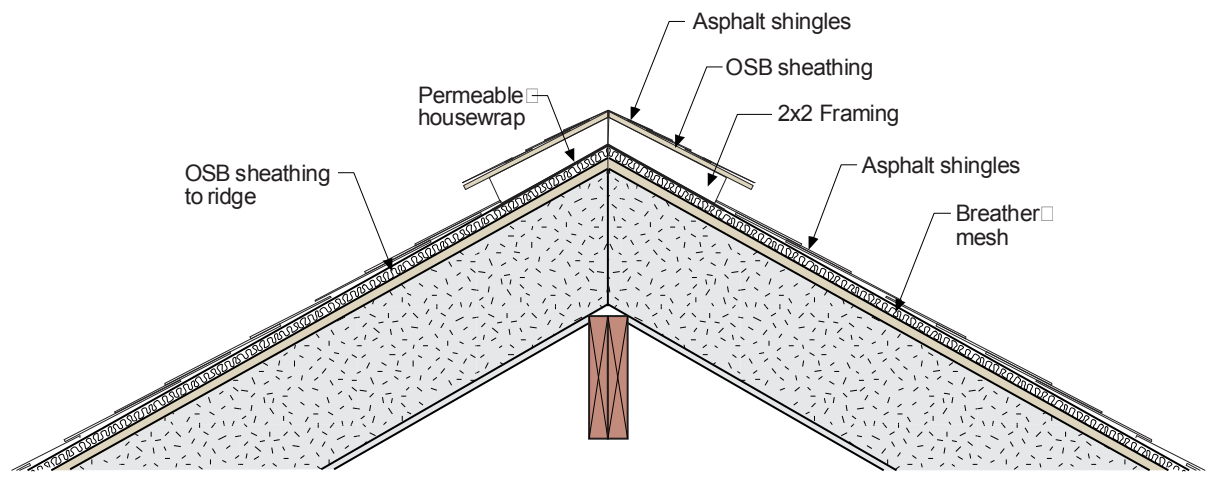

Figure 16. Ridge condition at Roof 2 -top vent cathedral-cellulose $(3,4$, and 5 similar)

At the soffit, air enters the ventilation space at a gap between the fascia and the subfascia created by the breather mesh (Figure 17 and Figure 18).

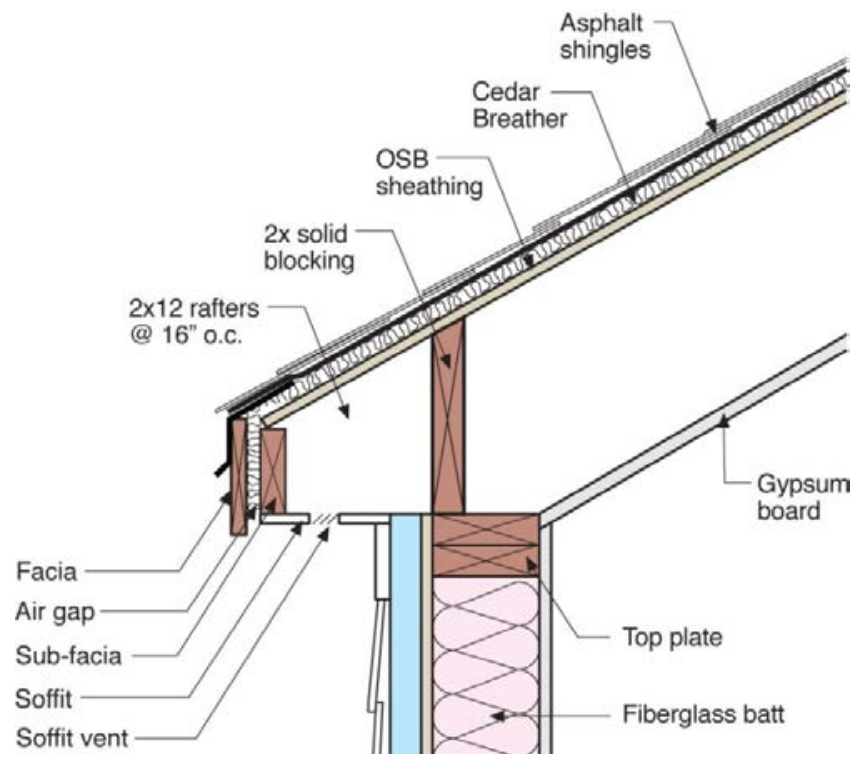

Figure 17. Soffit condition at roofs 2, 3, 4, and 5-top vent cathedral/cathedralized
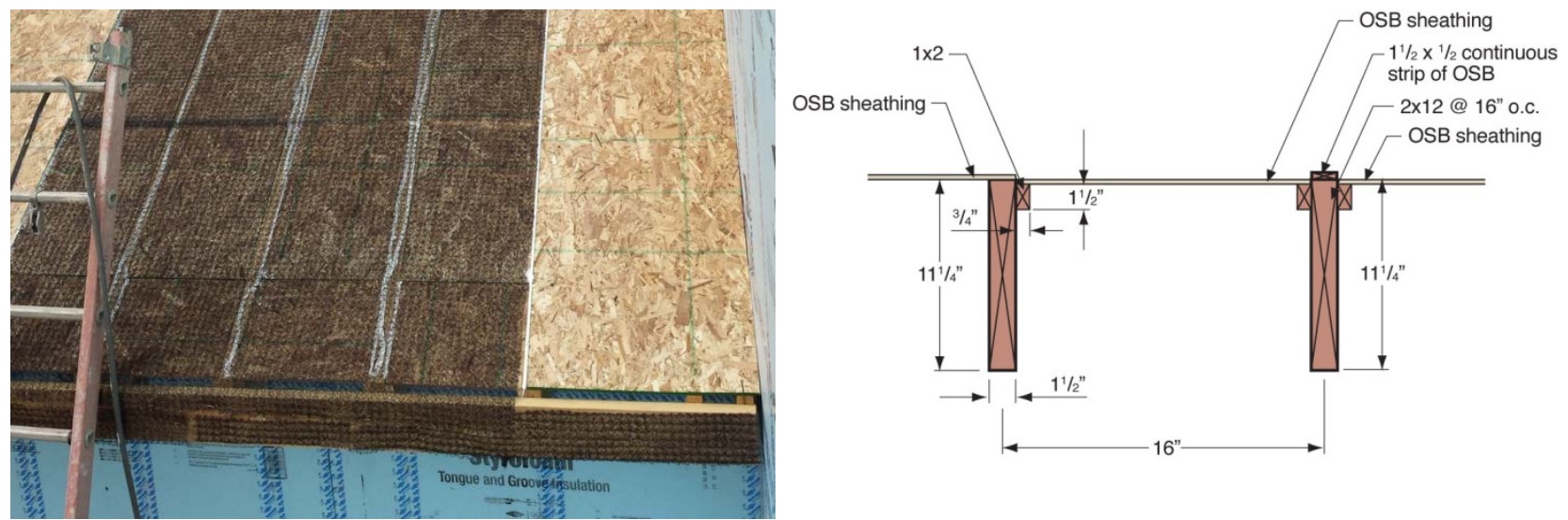

Figure 18. Dropped sheathing and breather mesh at roof deck of top vent roofs $(2,3,4$, and 5$)$ 
At the ridge, the breather mesh was covered with a vapor-permeable house wrap that sheds water blown into the doghouse ridge (Figure 16). However, to allow escaping air to flow from the breather mesh, holes were cut into the house wrap (roughly 3 in. $\times 3$ in.). See Figure 19.
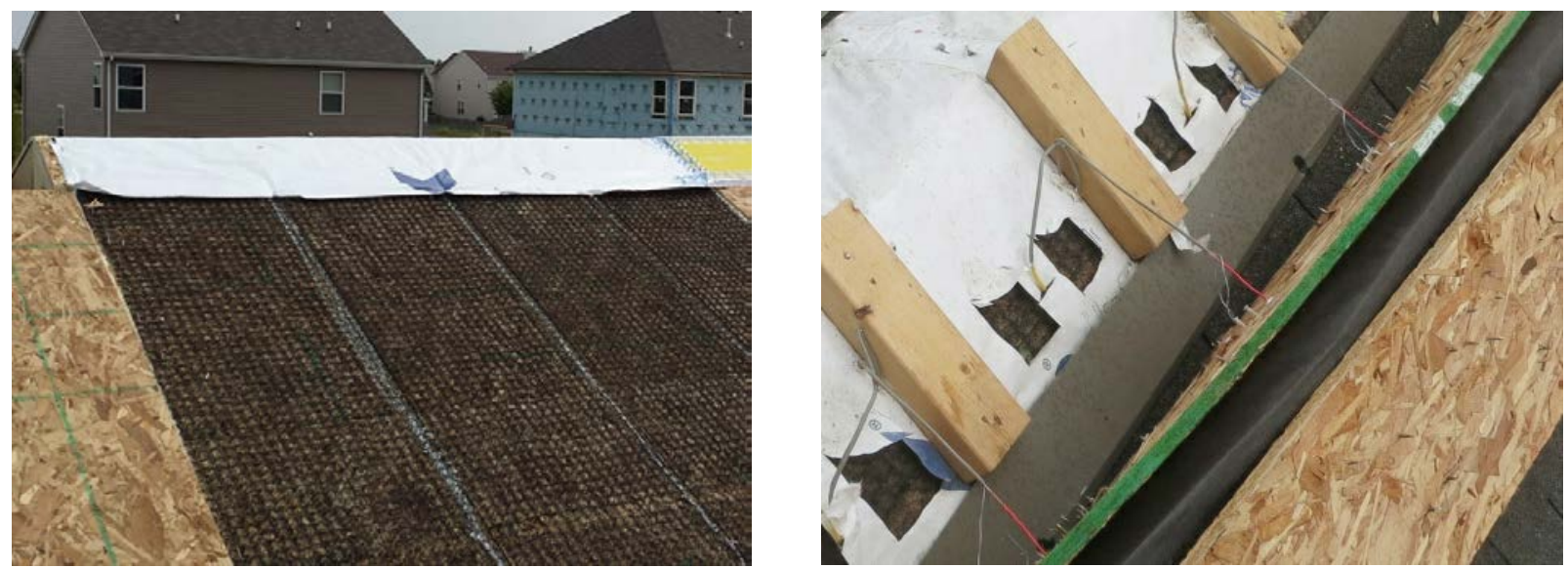

Figure 19. Top vent roof $(2,3,4$, and 5$)$ ridge house wrap covering (left); cut openings (right)

The roof sheathing was dropped flush with the top of the rafters at the top vent assemblies (Figure 18, right), to create a flat plane/substrate for asphalt shingles across all test bays. Additional nailers $(1 \times 2 s)$ were required to support the sheathing between rafters at these bays.

This system was implemented with no underlayment or WRB below the asphalt shingles. This was done to provide a best-case scenario that provided the maximum drying of the OSB sheathing without the reduction in permeance due to the vapor resistance of a WRB.

\subsubsection{Top Vent Cathedralized-Cellulose (Roof 3)}

This assembly is identical to Roof 2 (top vent cathedral-cellulose), except that the interior GWB was omitted to create a cathedralized (versus cathedral) roof/ceiling assembly.

This roof shows the effect of omitting the interior air barrier in the assembly; the cellulose netting was left exposed at the interior. Images of the cellulose installation and the finished assembly are shown in Figure 20.
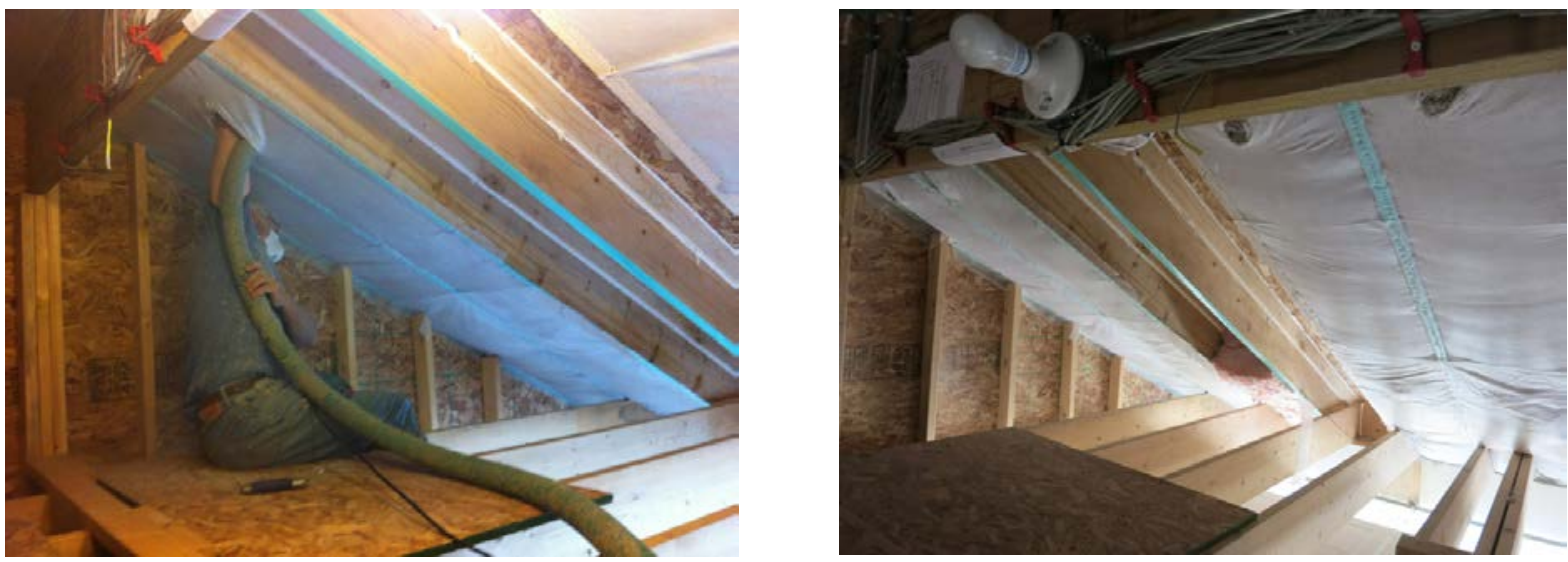

Figure 20. Top vent cellulose Roof 1 


\subsubsection{Top Vent Cathedralized-Fiberglass (Roof 4)}

This assembly is identical to Roof 3 (top vent cathedralized-cellulose/no GWB); fiberglass batt replaces the dense-pack cellulose.

\subsubsection{Top Vent Cathedral-Fiberglass (Roof 5)}

This assembly is identical to Roof 2 (top vent cathedral-cellulose/GWB), but fiberglass batt replaces the dense-pack cellulose. Installation of the R-38 batt in these roofs is shown in Figure 21; even with careful installation the batts buckle away from the roof sheathing (not Grade I installation).
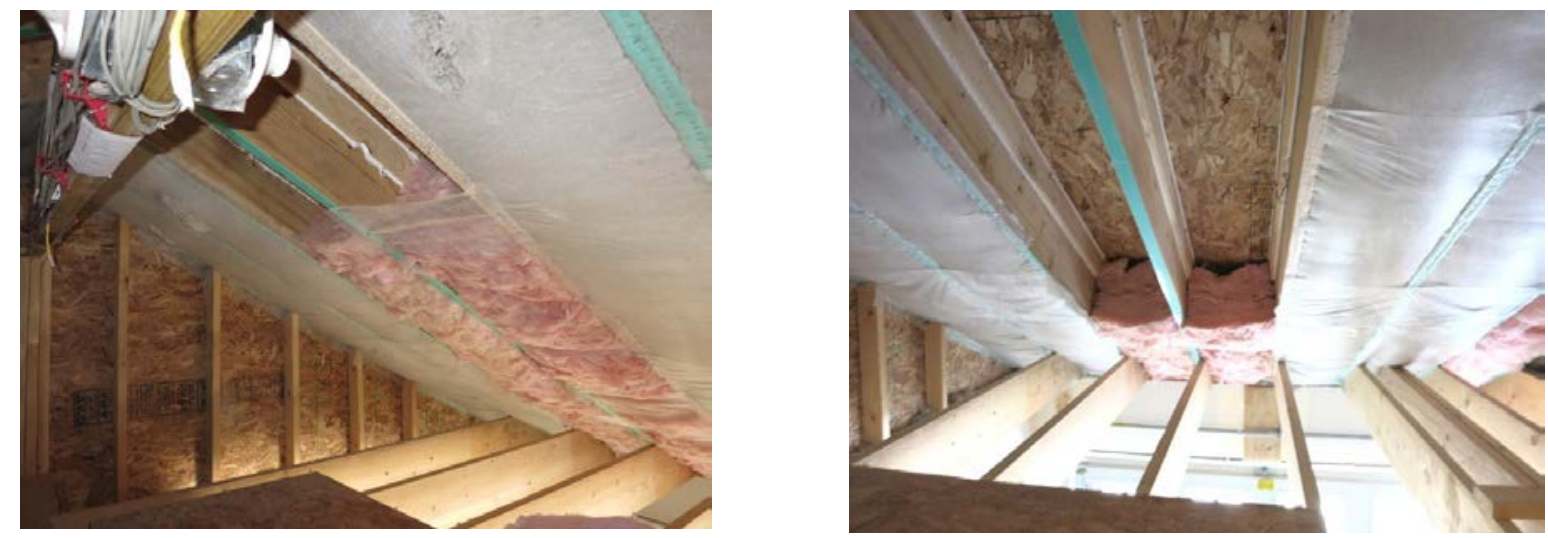

Figure 21. Top vent fiberglass roofs (Roofs 4 and 5)

\subsubsection{Diffusion Vent Cellulose (Roof 6)}

This assembly has rafter bays with dense-pack cellulose insulation (similar to the unvented roof/Roof 7), except that at the ridge, an 8-in.-wide strip of OSB sheathing was replaced with vapor-permeable glass fiber-faced exterior GWB (Figure 22 and Figure 24). This GWB section is intended to function as a diffusion vent as described below.

In previous field experience, sloped compact roof assemblies had moisture problems predominantly at the ridge, where moisture accumulates due to thermal/moisture buoyancy and convective looping. The purpose of the diffusion vent was to dry this accumulated moisture via vapor diffusion, while still acting as an effective air barrier. Installing a diffusion vent over a small portion of the roof would likely be a simpler and lower cost retrofit than a full topventilated deck. Air barrier connections are made with tape that was adhered at the joints.

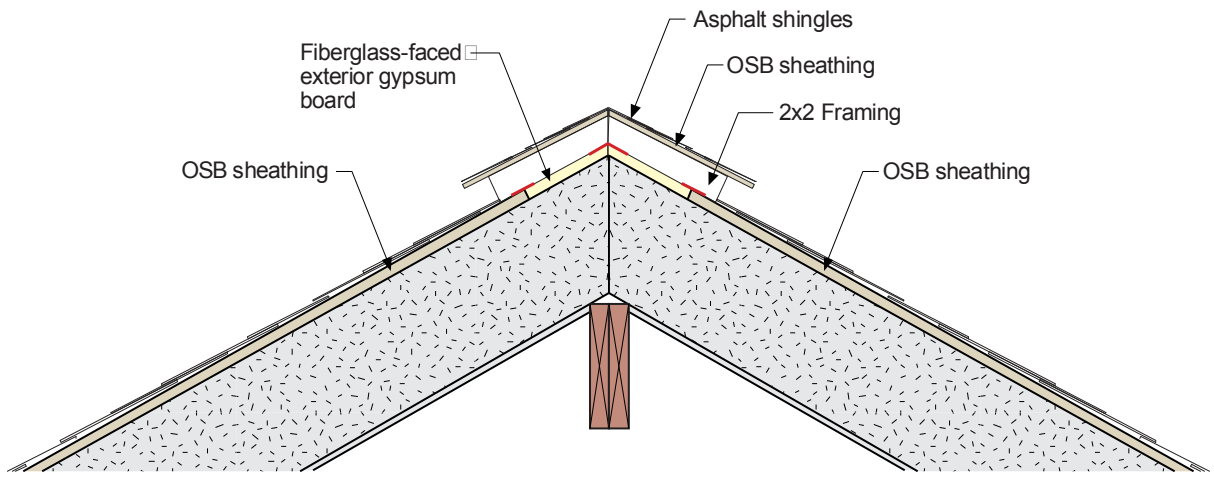

Figure 22. Ridge condition at Roof 6-diffusion vent cellulose 
The vapor permeance (in perms) of the exterior GWB sheathing is stated in the manufacturer's literature as 23 perms (dry cup/ASTM E96 Procedure A). However, further permeance testing data over a range of humidities were obtained from Oak Ridge National Laboratory and are plotted in Figure 23. The manufacturer's permeance is plotted for reference ("spec value") with values for other structural sheathings (OSB and plywood) and $1 / 2$-in. unpainted GWB from ASHRAE (2009a) data. This demonstrates that the exterior GWB sheathing would allow significantly more drying than plywood or OSB.

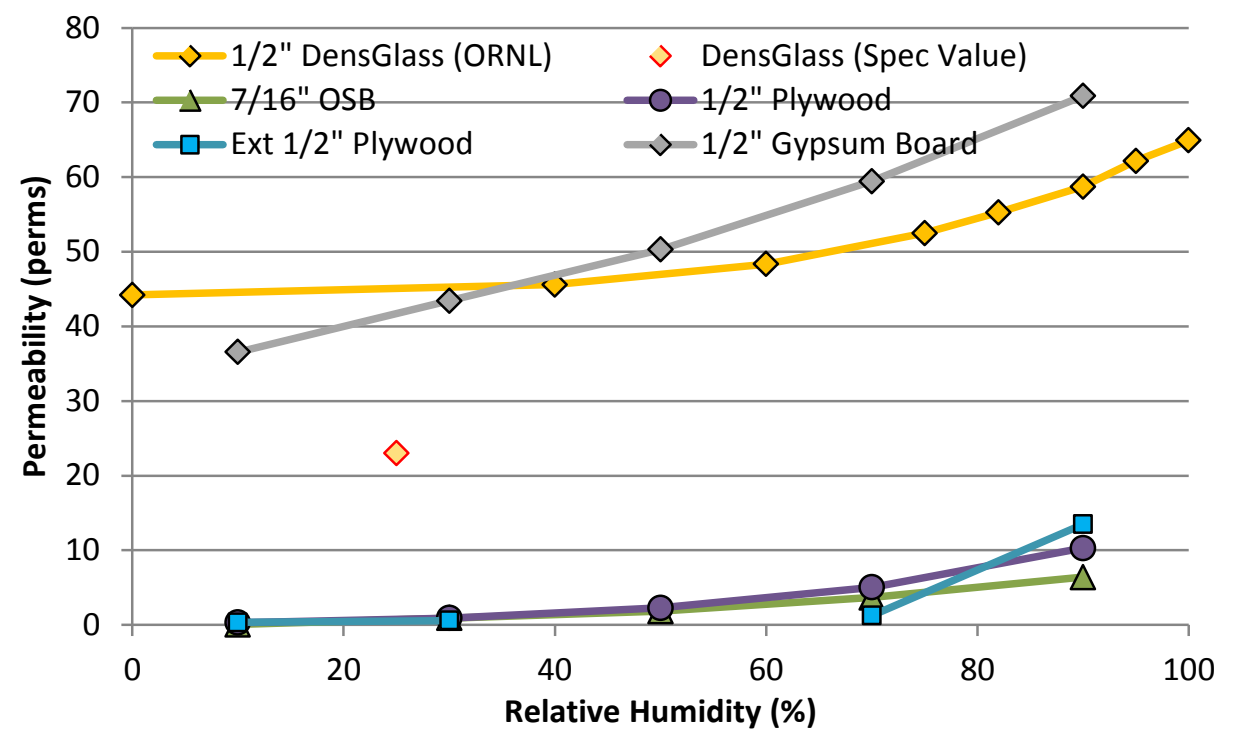

Figure 23. Ridge condition at Roof 6-diffusion vent cellulose

\subsubsection{Unvented Cellulose (Roof 7)}

This assembly is the unvented dense-pack cellulose roof that failed in previous work. This bay was intended as a control and to provide a comparison between previous known failures and the experimental assemblies.
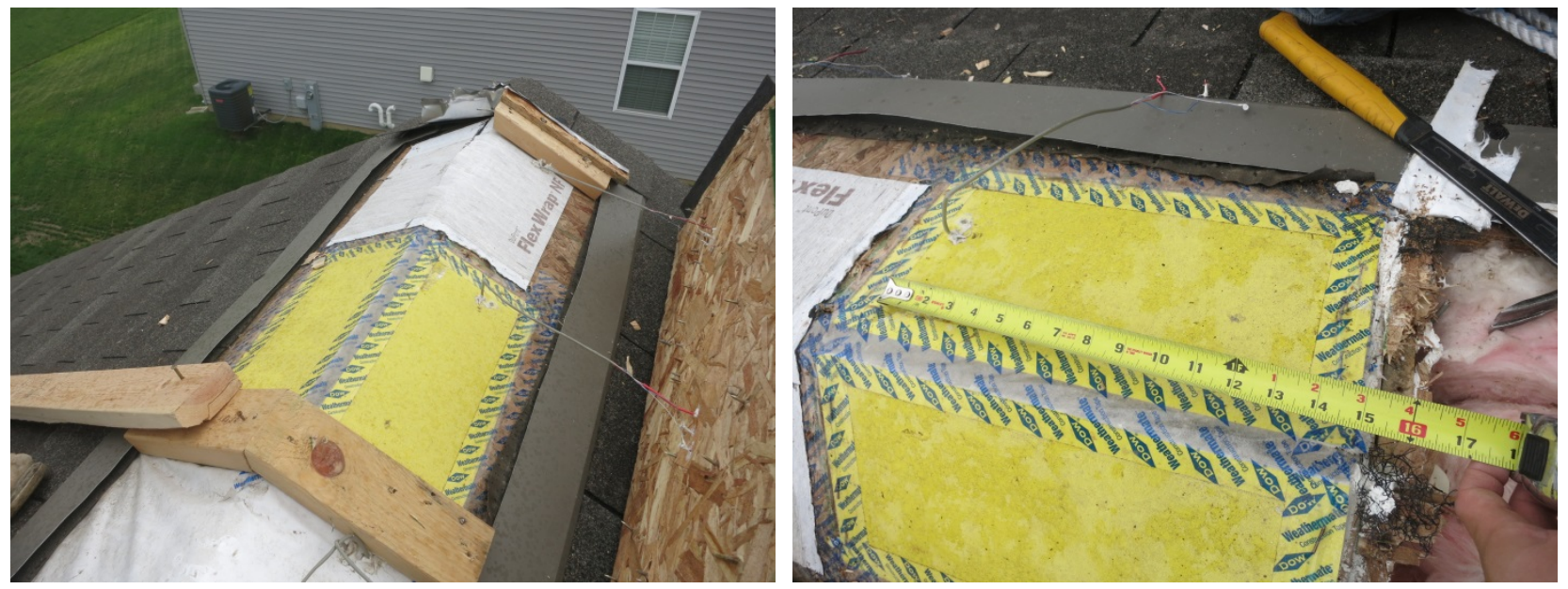

Figure 24. Diffusion vent (6) (left); unvented (7) ridge conditions (right) 


\subsection{Roof Bay Instrumentation}

The roofs were instrumented with temperature, wood MC, and RH sensors per Straube et al. (2002). A typical instrumentation package for a top vent roof is shown in Figure 25.

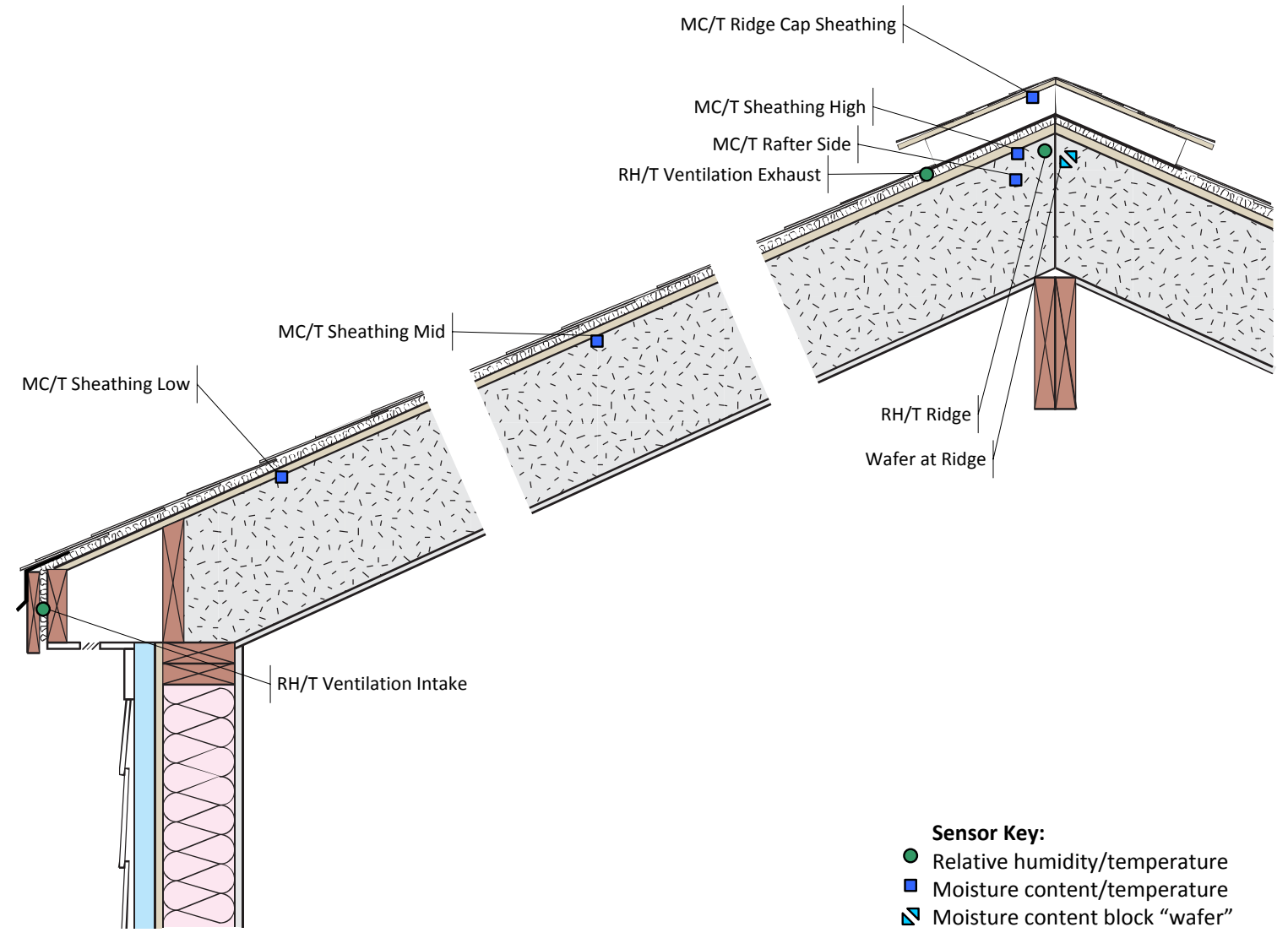

Figure 25. Instrumentation setup for Roof 2 -top vent cathedral-cellulose $(3,4$, and 5 similar $)$

The sensors are described in the following groups:

- Sheathing sensors: Rotting or damage of sheathing is the most common type of moisture-related failure seen in building assemblies. Given the ridge rot issues (moisture accumulation at the peak) described earlier, measuring $\mathrm{MC}$ and temperature $(\mathrm{MC} / \mathrm{T})$ at the sheathing at multiple locations is useful to understand the spatial variations.

Therefore, $\mathrm{MC} / \mathrm{T}$ sensors were installed at low, middle, and high points in the sheathing on the east and west orientations.

- Ridge sensors: Ridge moisture accumulation issues were also studied with sensors installed near the peak. The sensors included a T/RH sensor, $\mathrm{MC}$ at the ridge framing, and a "wafer" sensor, which is a small wood sample measured for MC. The wafer sensor uses the relationship between $\mathrm{RH}$ and $\mathrm{MC}$ (the sorption isotherm) to act as a surrogate humidity sensor that tracks long-term patterns; see Ueno and Straube (2008).

- Ventilation cavity T/RH: To examine the effect of heat and moisture removal from the ventilation cavity, T/RH sensors were installed at the eave intakes and the ridge exhaust. 
- Doghouse sensors: To determine whether there is any risk of moisture release from the roof accumulating at the sheathing of the doghouse detail, the $\mathrm{MC} / \mathrm{T}$ of the sheathing were measured at the underside of the doghouse.

The instrumentation at the vented compact assembly (Roof 1) was similar to the top vent package, except that the ventilation cavity T/RH sensors measure conditions at the 4-in.-deep ventilated space, not the mesh air space of the top vent roofs.

The instrumentation package for the diffusion vent (Roof 6) and unvented cellulose (Roof 7) assemblies was reduced from the top vent package (Figure 26), which had no ventilation cavity. The remaining sensors were parallel to those found in the top vent assemblies.

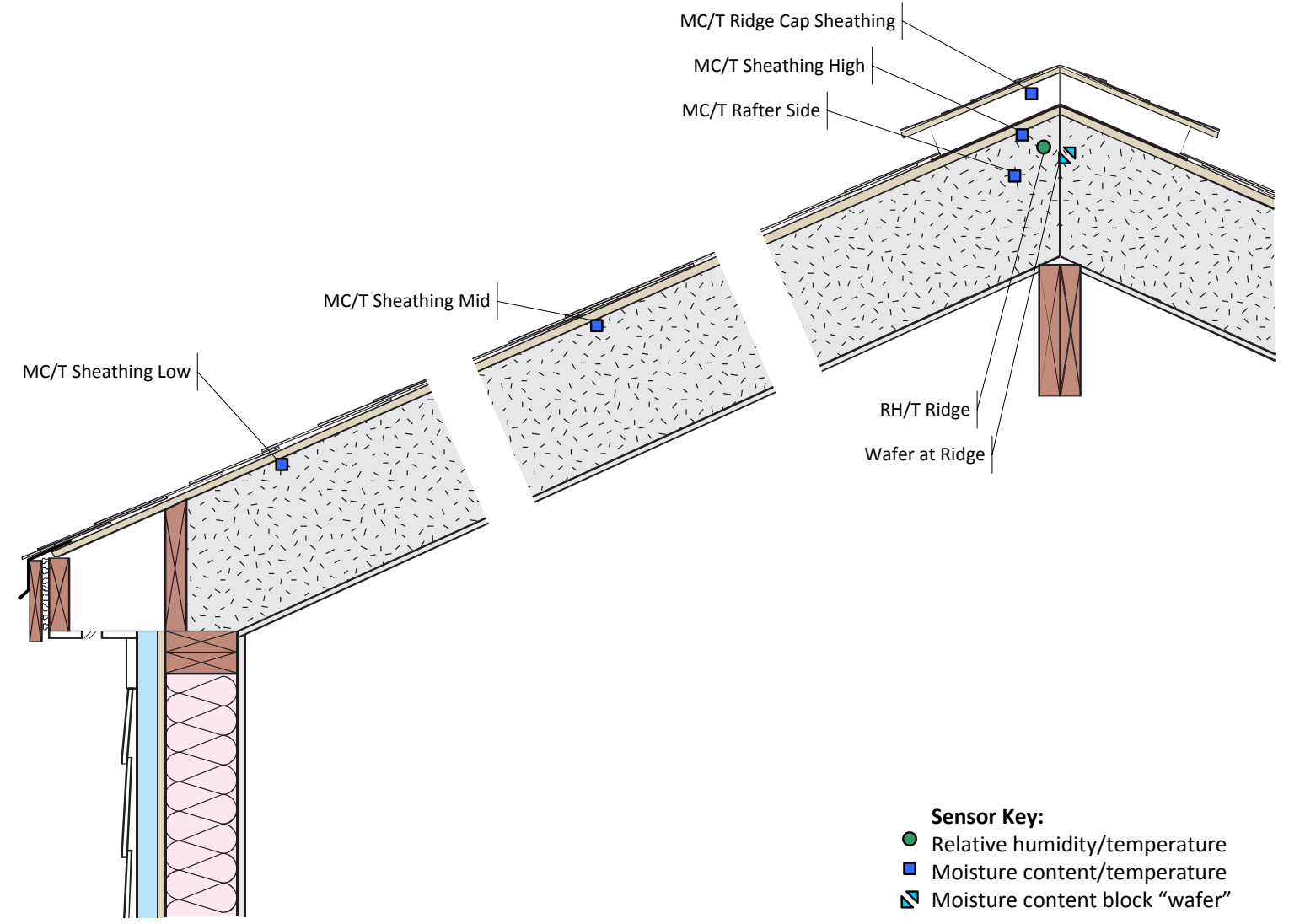

Figure 26. Instrumentation setup for Roof 7-unvented cellulose

\subsection{Interior Space Conditioning}

The experimental attic was set up to run at constant temperature and humidity conditions through the winter. Electric resistance space heating was installed in the attic space (Figure 27, left) and controlled by the data acquisition system. A constant $22^{\circ} \mathrm{C}\left(72^{\circ} \mathrm{F}\right)$ set point was used; no cooling was provided. To reduce the heating load on the attic unit, additional space heating (also controlled by the data logger) was installed in the garage space (Figure 27, right). 

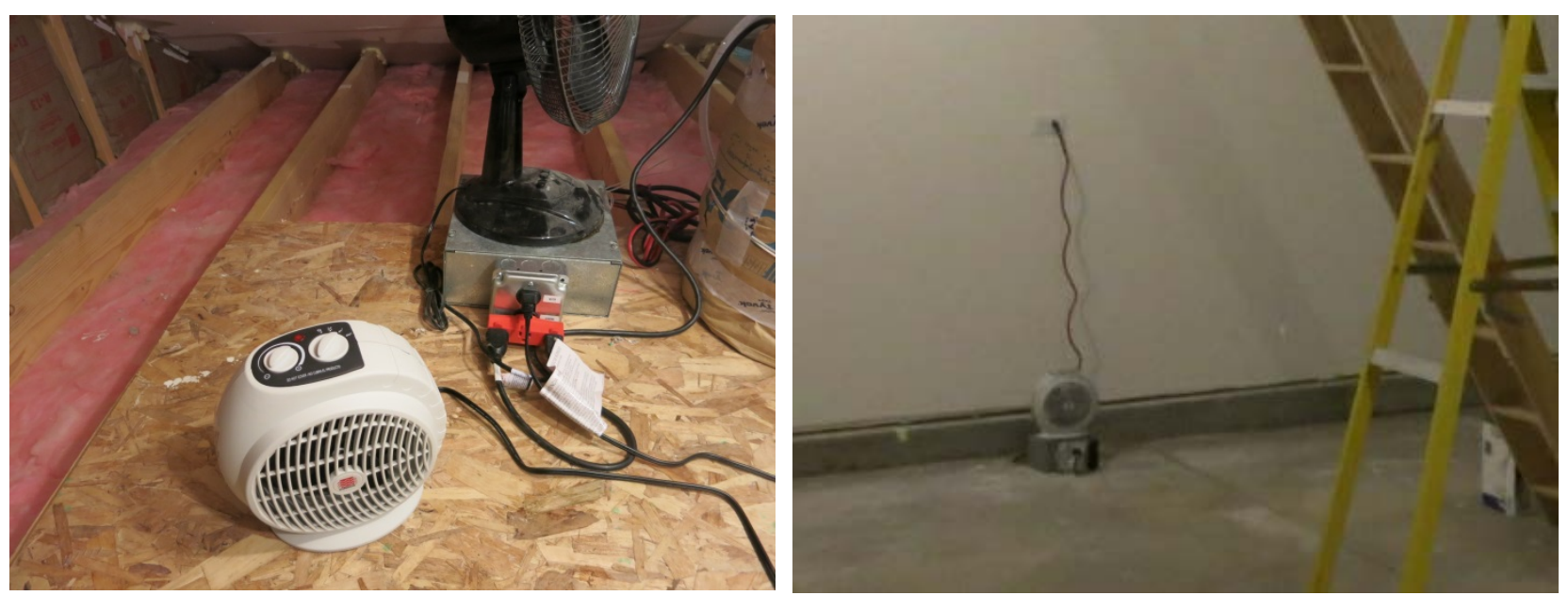

Figure 27. Experimental attic space heating (left); garage heating and relay box (right)

To stress the assemblies through the winter, the attic interior space was run at a high RH; the target was $50 \%$. Humidity conditions were maintained by a heated water reservoir-type humidifier (Figure 28) that was controlled by the data acquisition system.
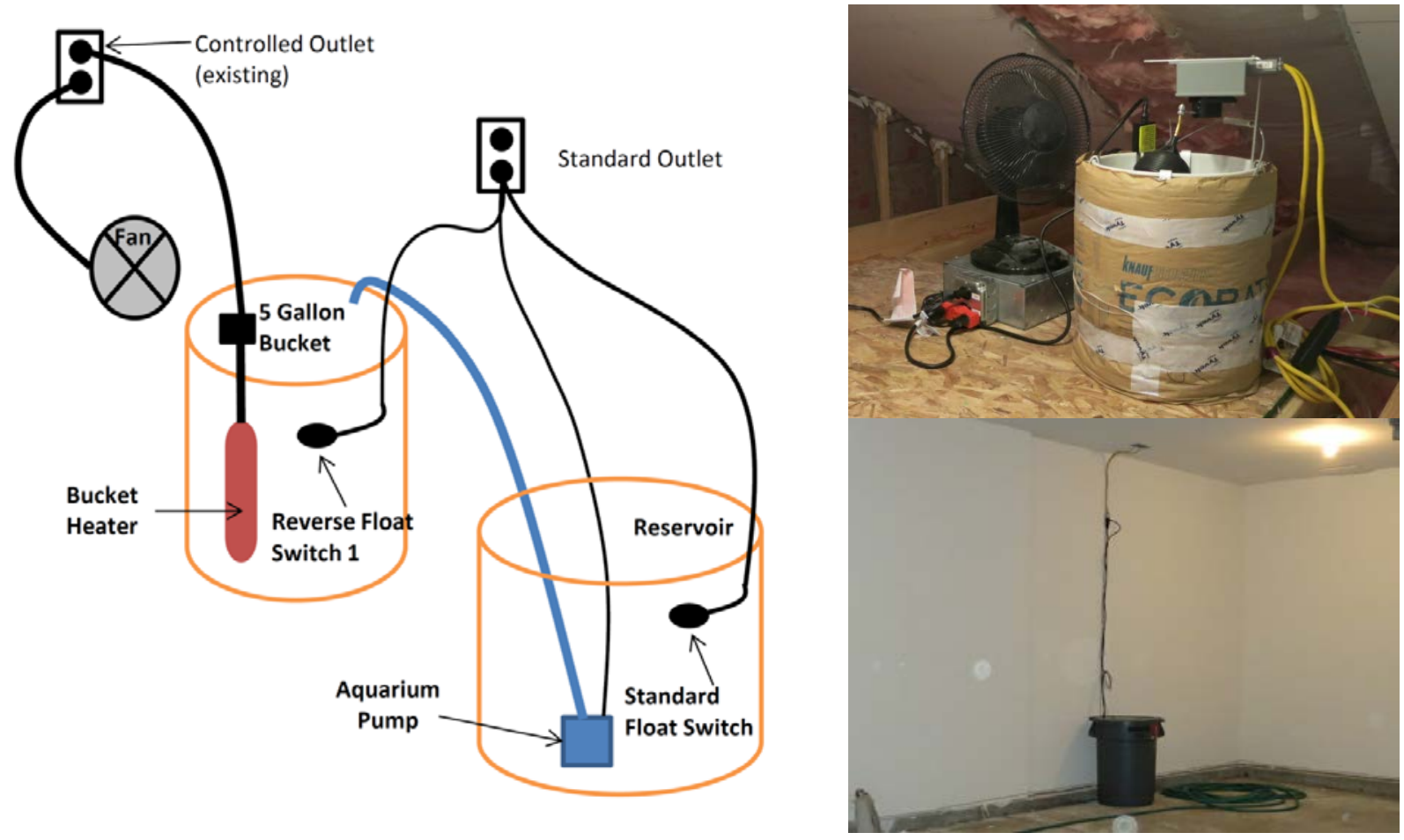

Figure 28. Schematic and photos of humidification setup (left); heated bucket and reservoir (right)

\subsection{Overview of Roof Installation}

The completed roof assembly is shown in Figure 29 (left); the doghouse ventilation detail was partially disassembled to install instrumentation (Figure 29, right) and then reassembled. 

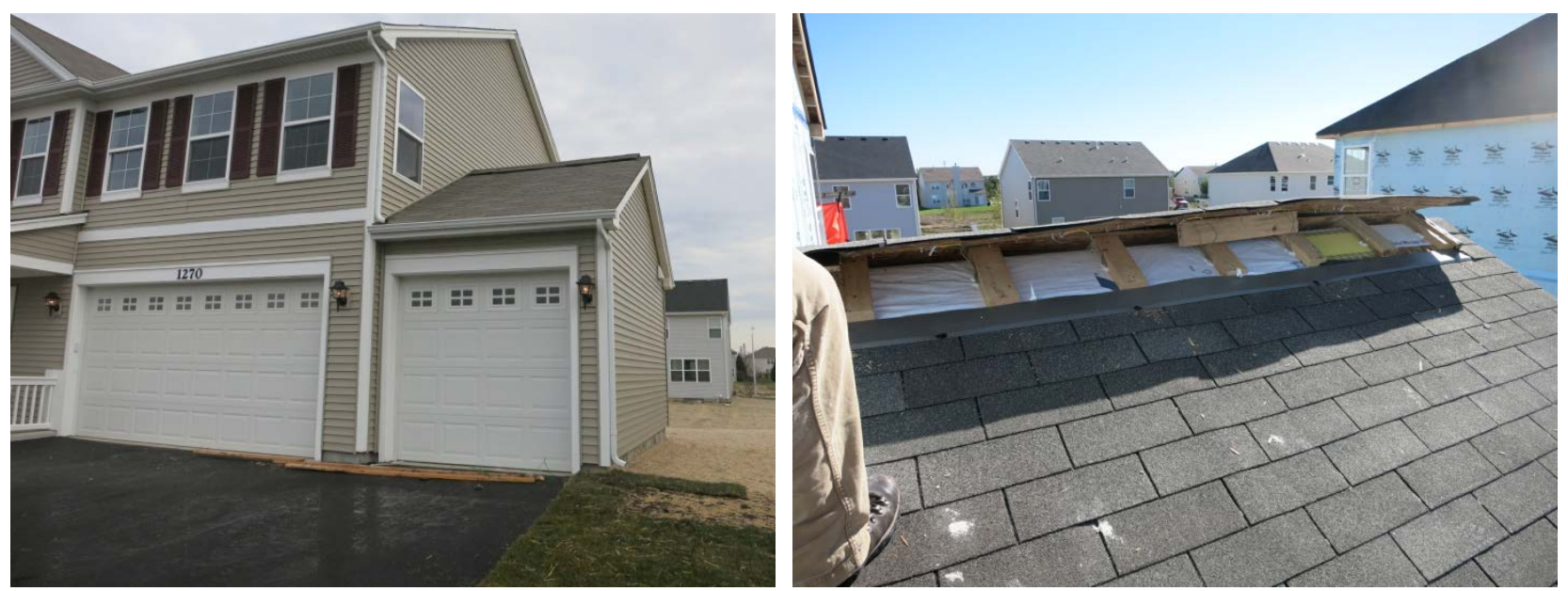

Figure 29. Completed test attic over garage (left); disassembled doghouse detail (right)

The experimental roof bays were sealed against lateral air movement and communication with air barrier detailing that included caulk or expanding foam at the sheathing-to-framing joints, framing connections, and compressible gaskets at the interior faces of the rafters (Figure 30, left). Rafter bay leakage to exterior was controlled with similar foam and caulk details (Figure 30, right).

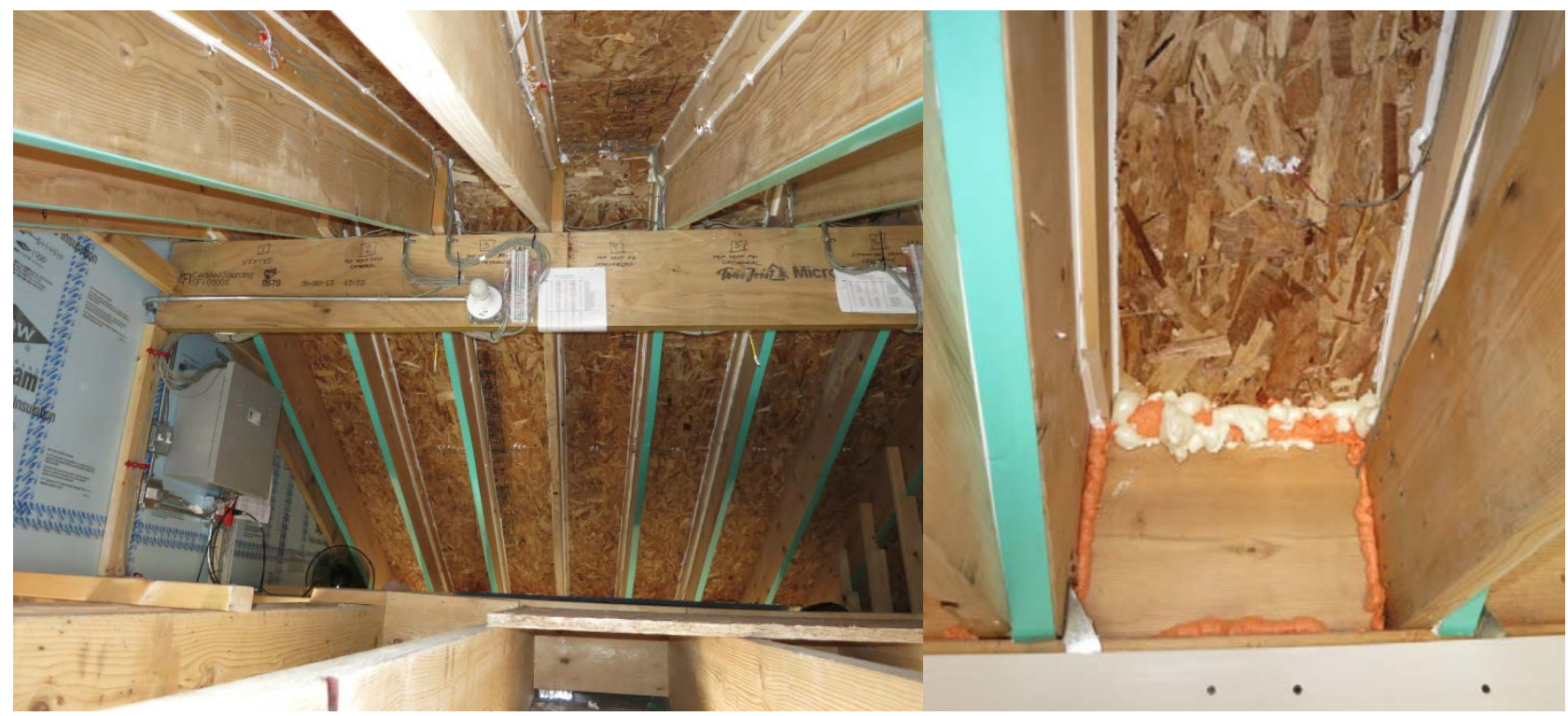

Figure 30. Interior of experimental roof bays, showing air sealing, gaskets, and instrumentation

The interior of all roof bays except 3 and 4 (top vent cathedralized-cellulose and fiberglass) were finished with $1 / 2$-in. GWB that was finished with a single coat of latex paint. This was not tested, but it may be more permeable than a Class III vapor retarder (Figure 31 and Figure 32). 


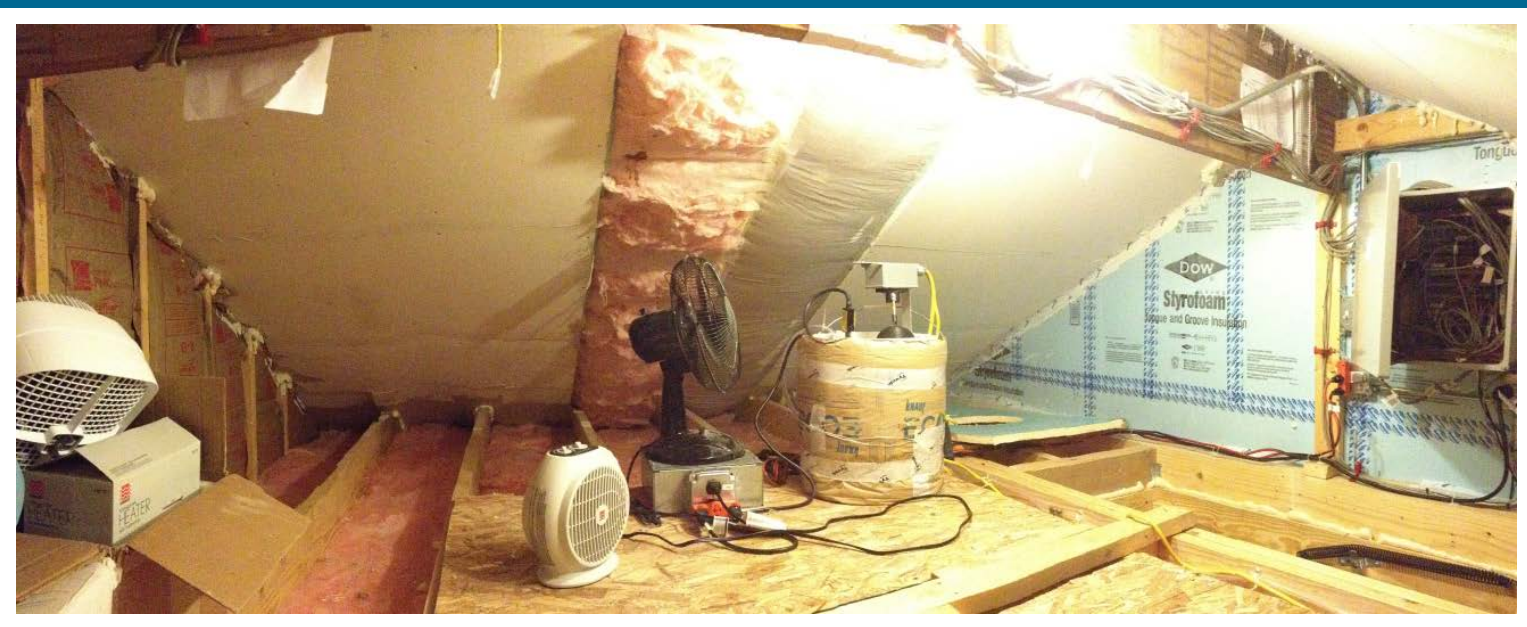

Figure 31. West (front) face of experimental roof bays interior

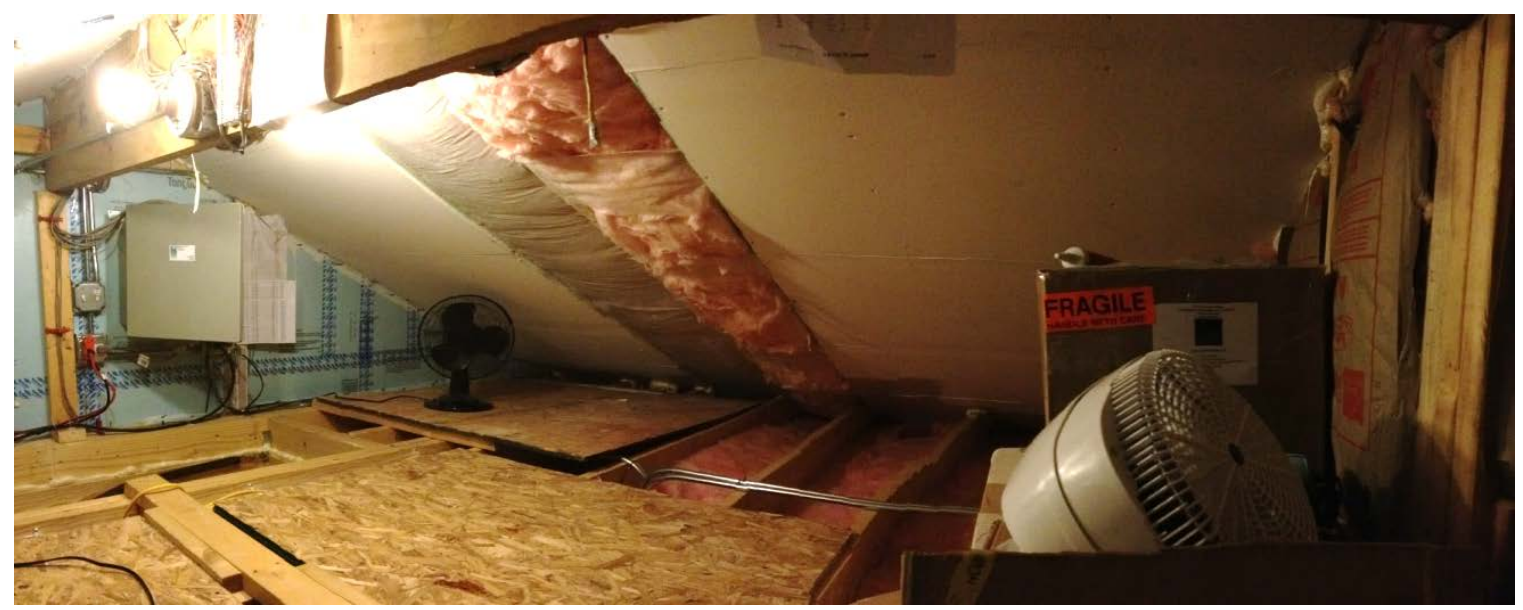

Figure 32. East (rear) face of experimental roof bays interior

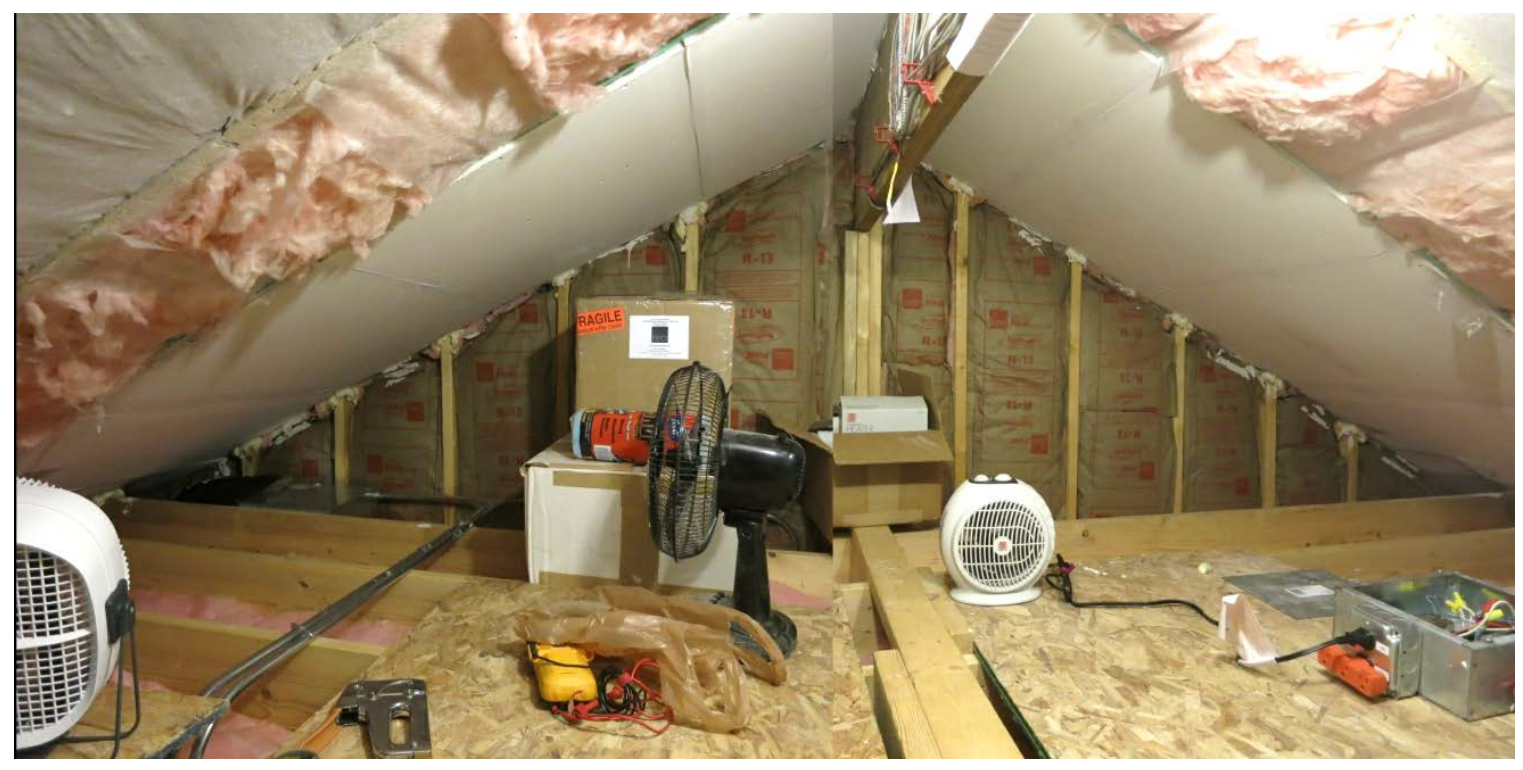

Figure 33. South (gable end) face of test attic 
The gable end wall and floor of the test attic were insulated with R-13 fiberglass batt.

The exterior of the roof was examined with infrared thermography to determine if greater heat loss occurred from any of the experimental assemblies. No discernable difference was seen between the roof bays in cold conditions $\left(3^{\circ} \mathrm{C}\left[26^{\circ} \mathrm{F}\right]\right.$, although the roof deck had (Figure 34$)$ or in milder conditions of $8^{\circ} \mathrm{C}\left(47^{\circ} \mathrm{F}\right)$ (Figure 35).
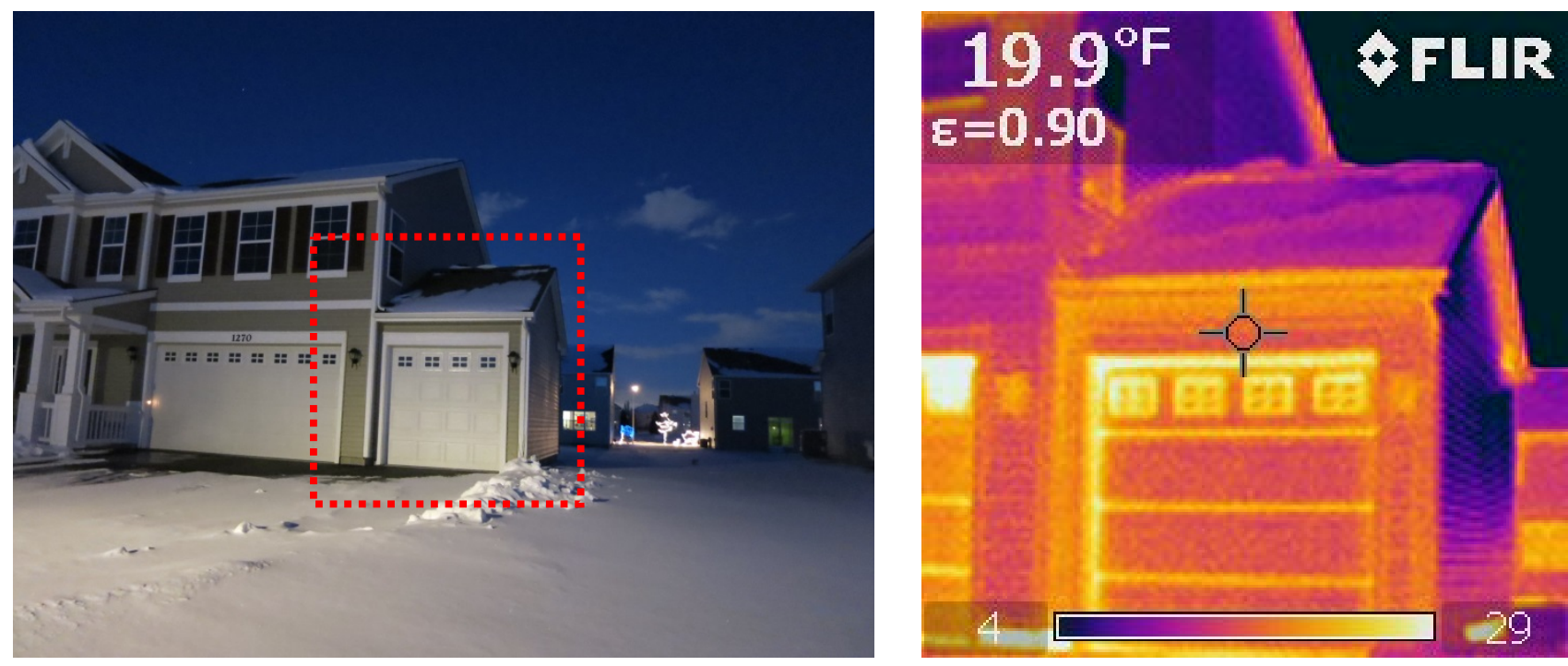

Figure 34. Infrared image of the test roof (front) in winter conditions $\left(3^{\circ} \mathrm{C}\left[26^{\circ} \mathrm{F}\right]\right)$
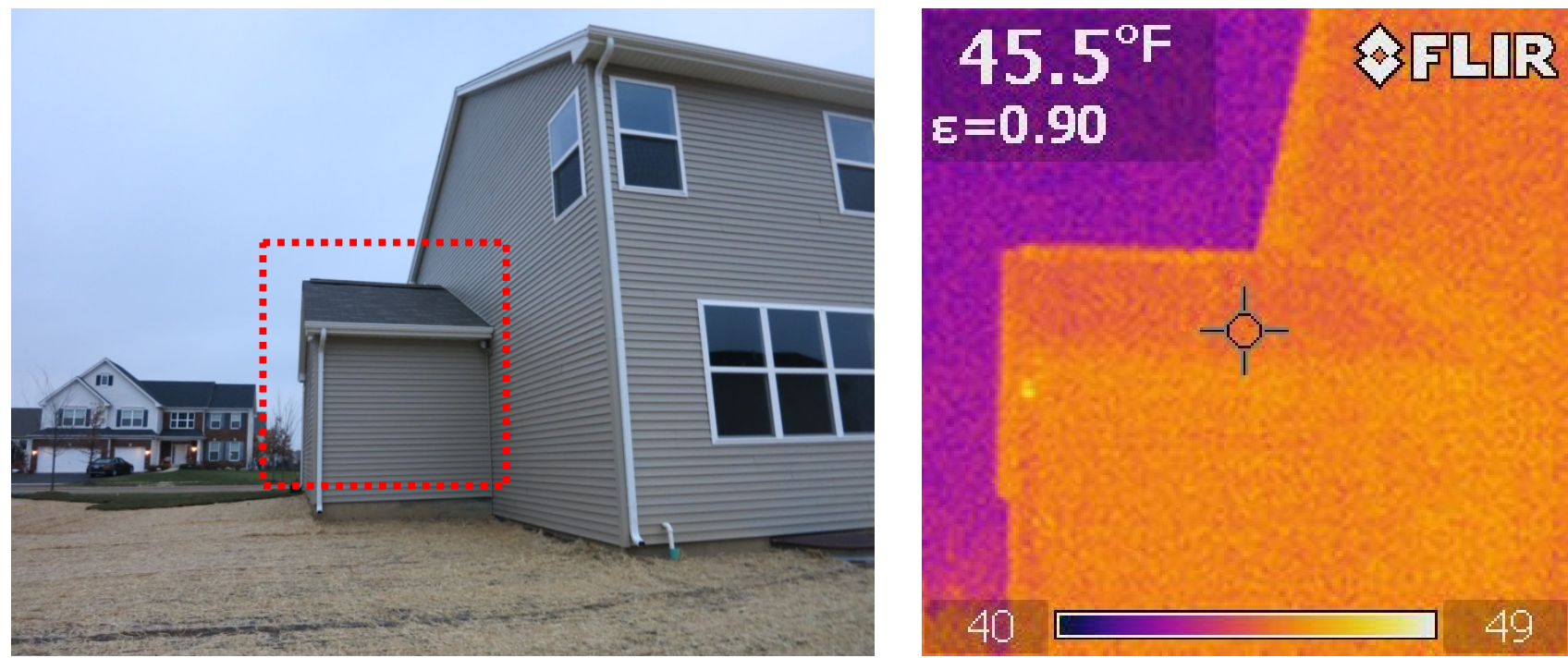

Figure 35. Infrared image of the test roof (front) in mild conditions $\left(8^{\circ} \mathrm{C}\left[47^{\circ} \mathrm{F}\right]\right)$

\subsection{Roof Air Leakage Testing}

The air leakage of the test attic was measured for two reasons:

- To ensure that air leakage of the space was low enough that the electric resistance space heater $(1,000 \mathrm{~W}$ or 3,400 British thermal units/hour) could maintain interior temperatures. 
- Excessive air leakage in one experimental roof assembly (compared to others) would result in anomalies that create unwanted variations between assemblies.

The air leakage of the attic was tested with an Energy Conservatory Minneapolis Duct Blaster Series B Fan placed in a rigid foam filler panel in the attic hatch (Figure 39, left). The rollup garage door was opened during the testing to relieve pressure. The initial tests, when combined with infrared thermography, revealed substantial air leakage at several sections of the roof (Figure 36 through Figure 38). These leaks were rectified as much as possible with available materials and tools.
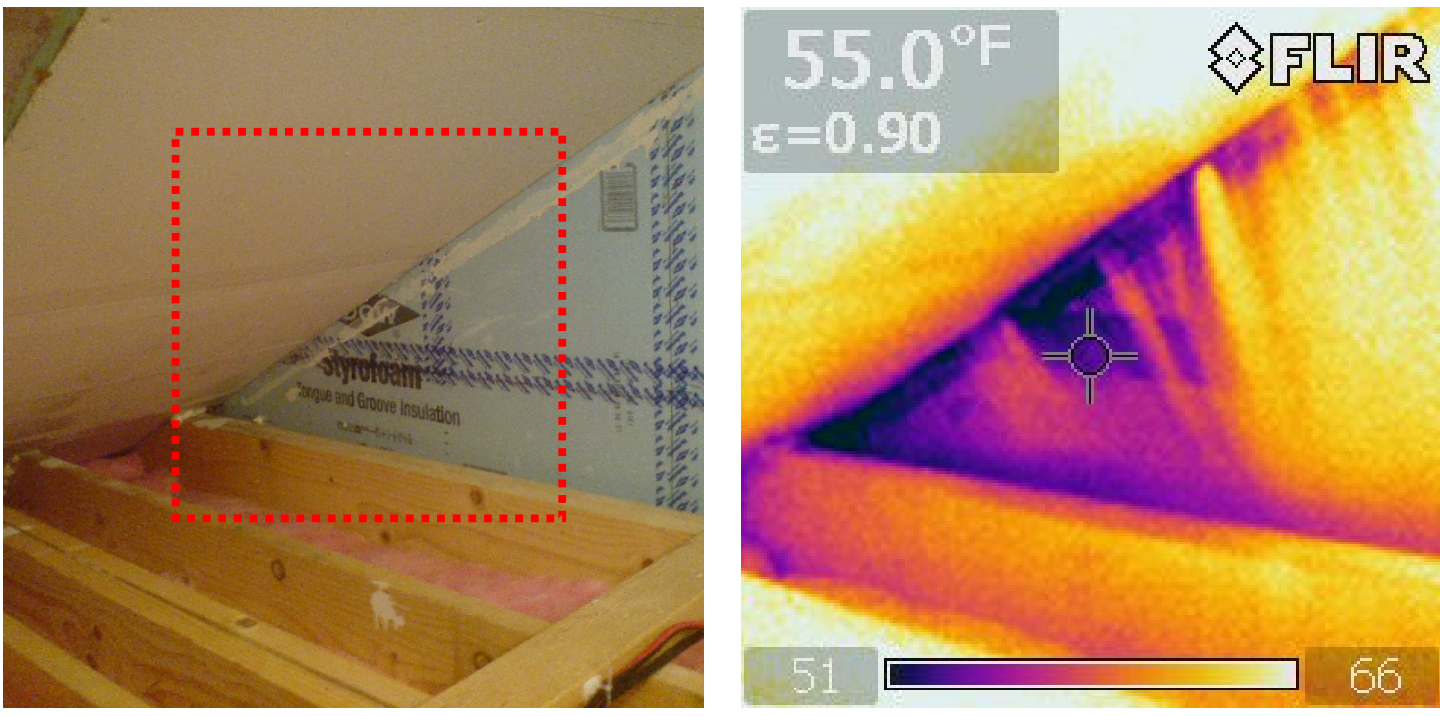

Figure 36. Air leakage at roof connection to main house (XPS sheathed wall)
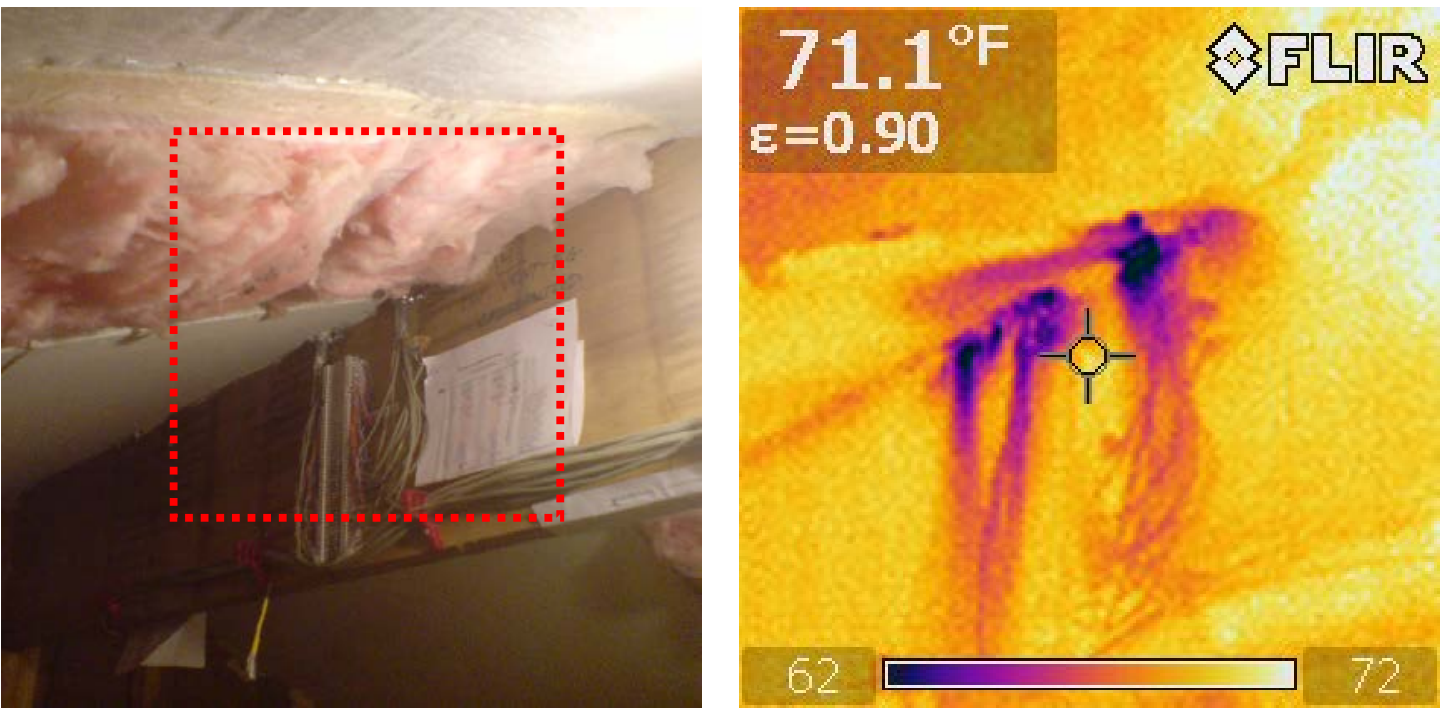

Figure 37. Air leakage at ridge and instrumentation wire penetrations 

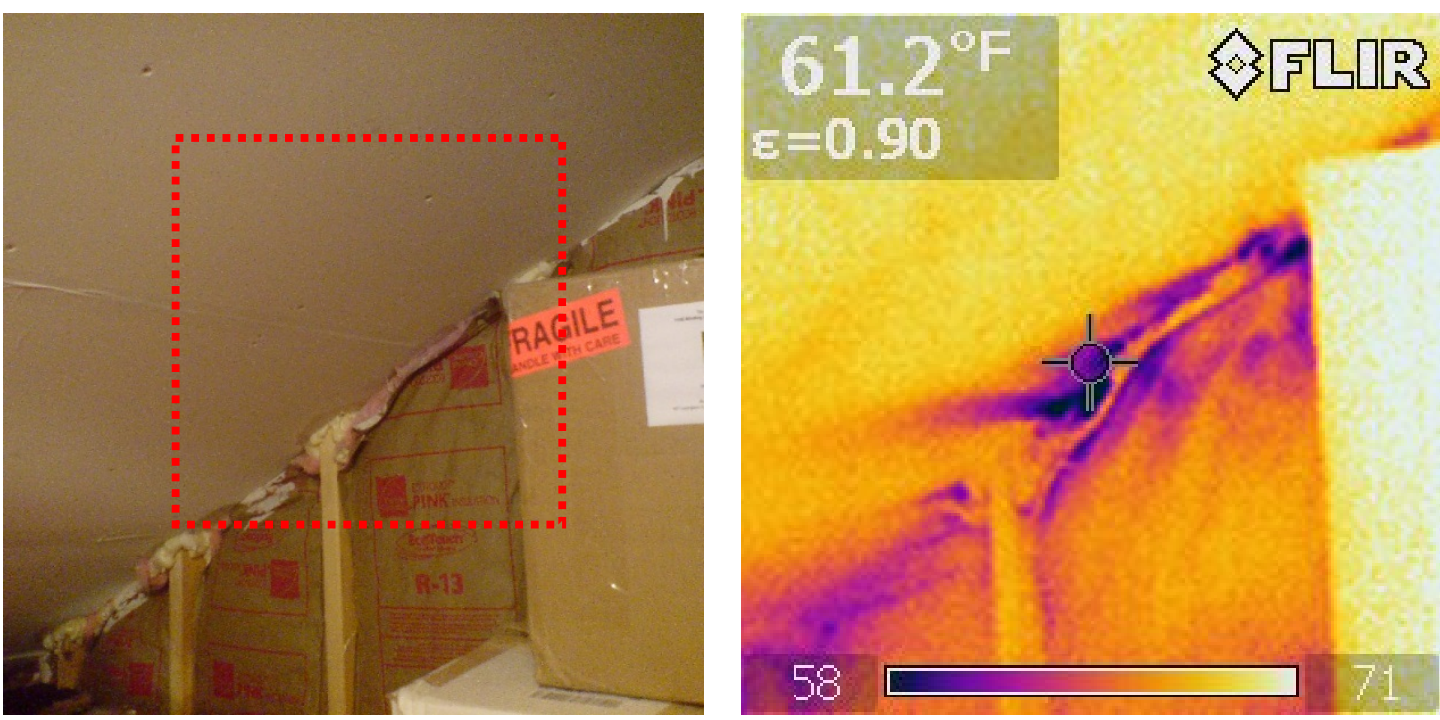

Figure 38. Air leakage at gable end rake wall (connects to unvented cellulose Roof 7)

After retrofit air sealing, a multipoint air leakage test was completed (results in Figure 39, right). The overall air leakage measurements are shown in Table 4 in terms of raw measurement (cubic feet per minute at $50 \mathrm{~Pa} / \mathrm{CFM} 50$ ), volume-normalized metric (air changes per hour at 50 $\mathrm{Pa} / \mathrm{ACH} 50$ ), and surface-area normalized metric (CFM 50/ $\mathrm{ft}^{2}$ enclosure). The surface-areanormalized results are the most useful and reflect higher air leakage than recommended for energy-efficient construction, but not so high as to indicate a problem reaching the interior set point. The ACH 50 figure is strongly distorted by the small volume of the attic space.
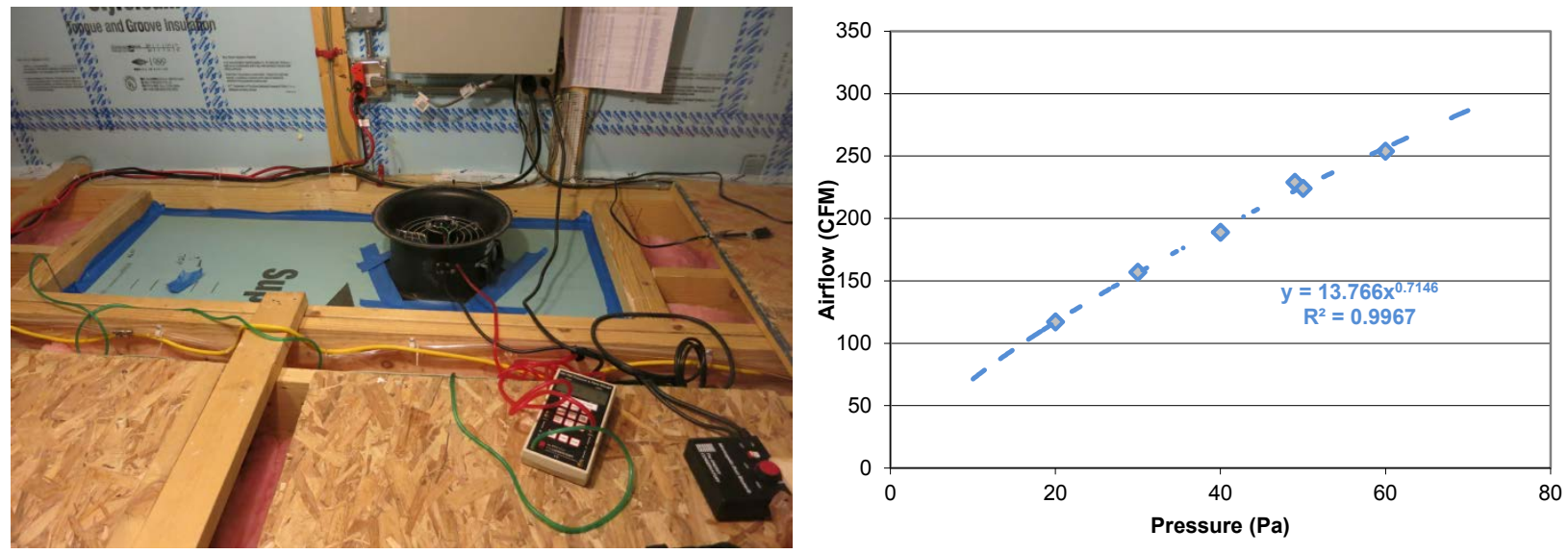

Figure 39. Air leakage testing of attic space (left); multipoint test results (right)

Table 4. Results of Test Attic Air Leakage Testing

\begin{tabular}{c|c|c}
\hline Measurement & Metric & Normalizing Metric \\
\hline $\mathbf{2 2 5}$ & Cubic feet per minute at 50 Pa (CFM 50) & \\
$\mathbf{3 2 . 9}$ & Air changes at 50 Pa (ACH 50) & $\left(411 \mathrm{ft}^{3}\right)$ \\
$\mathbf{0 . 4 5}$ & CFM 50/ $\mathrm{ft}^{2}$ enclosure & $\left(503 \mathrm{ft}^{2}\right.$ surface area) \\
$\mathbf{2 3 . 2}$ & Square inches equivalent leakage area (EqLA) & \\
\hline
\end{tabular}


Following the air leakage test, the attic was depressurized to $-50 \mathrm{~Pa}$, and the pressure difference $(\triangle \mathrm{P})$ across the ceiling GWB was measured for the various roof assemblies. Measurements were taken low and high in the rafter bays on both orientations (Figure 40). Roofs 3 and 4 (cathedralized) were not tested in this manner, because these assemblies have no interior GWB/air barrier.
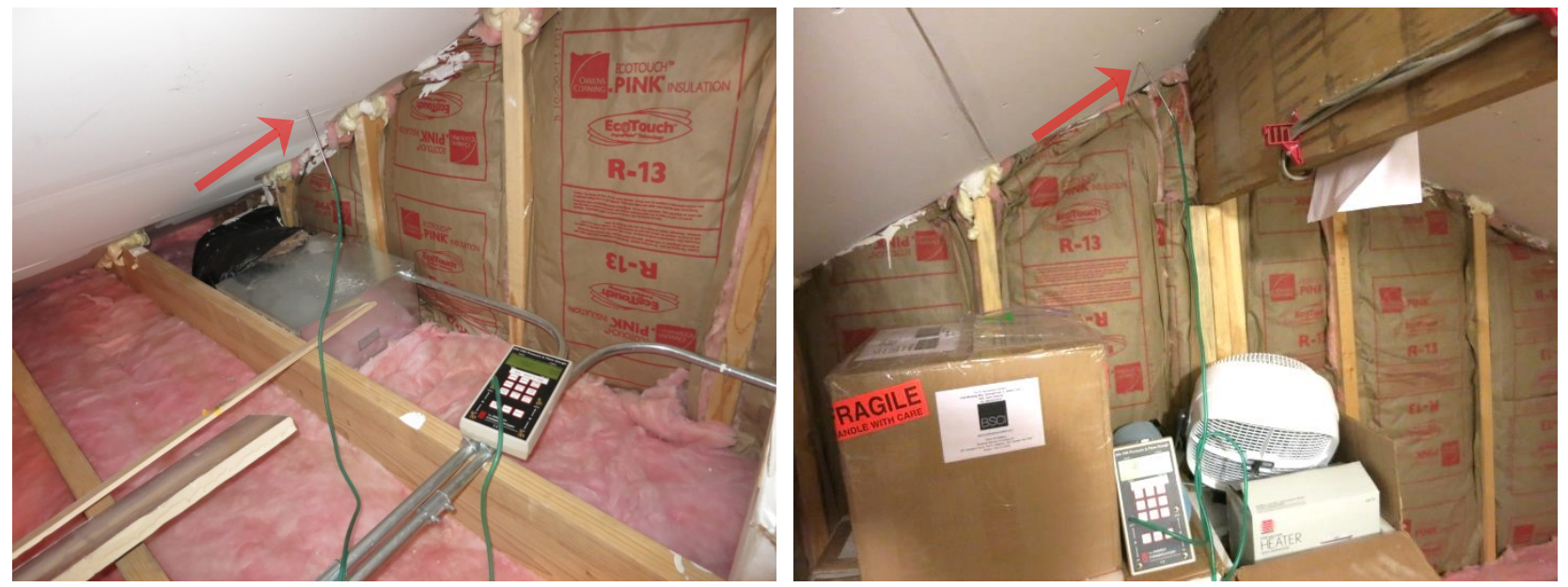

Figure 40. Testing $\Delta P$ across ceiling GWB in test attic

The measurements are shown in Table 5 with the average of the measurements and the percentage of the interior-exterior $\Delta \mathrm{P}$ due to the interior GWB.

Table 5. Test Attic Air $\Delta \mathrm{P}$ across GWB with Attic at $50 \mathrm{~Pa}$

\begin{tabular}{c|c|c|c|c|c}
\hline & $\begin{array}{c}\text { 1- Vented } \\
\text { Compact } \\
\text { Roof }\end{array}$ & $\begin{array}{c}\text { 2-Top Vent } \\
\text { Cathedral } \\
\text { Cellullose }\end{array}$ & $\begin{array}{c}\text { 5-Top Vent } \\
\text { Cathedral } \\
\text { Fiberglass }\end{array}$ & $\begin{array}{c}\text { 6-Diffusion } \\
\text { Vent } \\
\text { Cellullose }\end{array}$ & $\begin{array}{c}\text { 7-Unvented } \\
\text { Cellulose }\end{array}$ \\
\hline East Upper & $47 \mathrm{~Pa}$ & $30 \mathrm{~Pa}$ & $20 \mathrm{~Pa}$ & $19 \mathrm{~Pa}$ & $18 \mathrm{~Pa}$ \\
East Lower & $46 \mathrm{~Pa}$ & $28 \mathrm{~Pa}$ & $21 \mathrm{~Pa}$ & $17 \mathrm{~Pa}$ & $10 \mathrm{~Pa}$ \\
West Upper & $45 \mathrm{~Pa}$ & $23 \mathrm{~Pa}$ & $24 \mathrm{~Pa}$ & $21 \mathrm{~Pa}$ & $19 \mathrm{~Pa}$ \\
West Lower & $47 \mathrm{~Pa}$ & $13 \mathrm{~Pa}$ & $25 \mathrm{~Pa}$ & $19 \mathrm{~Pa}$ & $19 \mathrm{~Pa}$ \\
Average & $\mathbf{4 6} \mathbf{P a}$ & $\mathbf{2 4} \mathbf{P a}$ & $\mathbf{2 3} \mathbf{P a}$ & $\mathbf{1 9} \mathbf{P a}$ & $\mathbf{1 7} \mathbf{P a}$ \\
Average \% $\mathbf{\Delta P}$ & $93 \%$ & $\mathbf{4 7 \%}$ & $45 \%$ & $38 \%$ & $33 \%$ \\
\hline
\end{tabular}

One conclusions of the $\Delta \mathrm{P}$ testing was that in the vented compact roof (Roof 1 ), the interior GWB comprises more than $90 \%$ of the air barrier, as would be expected with a rafter bay ventilated to the exterior. The measurements do not seem to indicate gross differences in air leakage in the remaining bays that would make them noncomparable (17-24 Pa range). The top vent assemblies ( 2 and 5 ) had greater pressure differences across the drywall than the diffusion vent and unvented roofs (6 and 7). Based on later disassembly, this indicates that the "dropped sheathing" detail (at the top vent roofs) had more air leakage than the conventionally sheathed roofs.

Two of the roof bays ( 2 and 7 ) had a single measurement that was an outlier relative to the other measurements; both were lower air leaks in cellulose bays. A plausible explanation is that the 
airflow-retarding properties of cellulose can result in a $\Delta \mathrm{P}$ across a nominally open rafter bay cavity.

An ideal measurement would have been a zone pressure diagnostic (ZPD, per Bohac 2002), which involves cutting a known-size hole through the interior GWB and repeating the pressure testing (measuring the difference). It would have provided estimates of (1) leakage area from the rafter bay to interior and (2) leakage area from the rafter bay to exterior. However, this was not done due to time constraints and the need to repair the GWB after the work was completed. 


\section{Cold Climate (Chicago) Monitoring Results}

\subsection{Boundary Conditions}

Interior (test attic space), exterior, and garage temperatures are shown in Figure 41 for the test period. Attic space heating was added in mid-November 2013; garage space heating was added in mid-December. Weather data for Lewis University Airport/KLOT (Romeoville, Illinois, roughly 5 miles from the site) is also graphed as a comparison point.

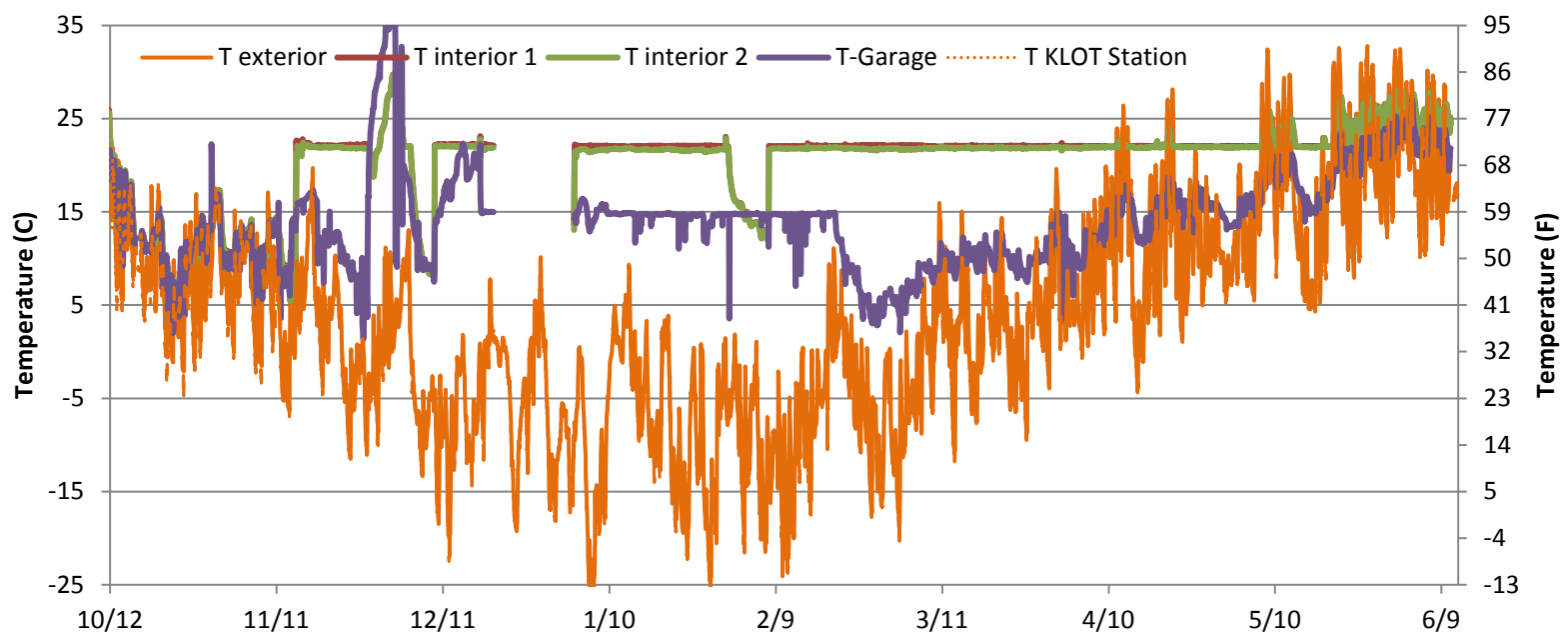

Figure 41. Test attic interior, garage, and exterior temperatures, winter 2013-2014

Several control issues arose over the course of the experiment, including temperature overshoot (due to equipment failures, site issues, and power failures). However, the test attic ran at a constant $22^{\circ} \mathrm{C}\left[72^{\circ} \mathrm{F}\right]$ set point for most of the winter. Garage heating was run from December through February.

Winter 2013-2014 was exceptionally cold $\left(7,110\right.$ heating degree days $65^{\circ} \mathrm{F}$ versus 6,460 heating degree days normal), which provide ideal conditions for condensation-related failure. The lowest temperature measured onsite was $-25.2^{\circ} \mathrm{C}\left(-13.4^{\circ} \mathrm{F}\right)$ in early January 2014 . This was comparable to the Aurora, Illinois, $99.6 \%$ temperature of $\left.-17^{\circ} \mathrm{C}\left[-2^{\circ} \mathrm{F}\right]\right)$.

The test attic RH is shown in Figure 42; although humidification was started in mid-November again, control and site issues resulted in periodic failures and loss of control. However, conditions were maintained at $50 \% \mathrm{RH}$ for most of the winter. As outdoor temperatures rose in the spring, the inward temperature gradient caused moisture desorption from the sheathing; thus, RH levels exceeded the set point.

RH data alone do not reflect the critical moisture condition of absolute air moisture content. This is indicated by dew point, which is graphed in Figure 43 for test attic and exterior conditions. It shows the net effect of the loss of T/RH control; for instance, during some periods humidity control was maintained but heating failed. The periods showing constant dew point $\left(11^{\circ} \mathrm{C}\right.$ $\left.\left[51^{\circ} \mathrm{F}\right]\right)$ are highlighted with the gray and green bar graphic. This graphic is used in later plots to indicate periods at or away from constant interior moisture conditions. 


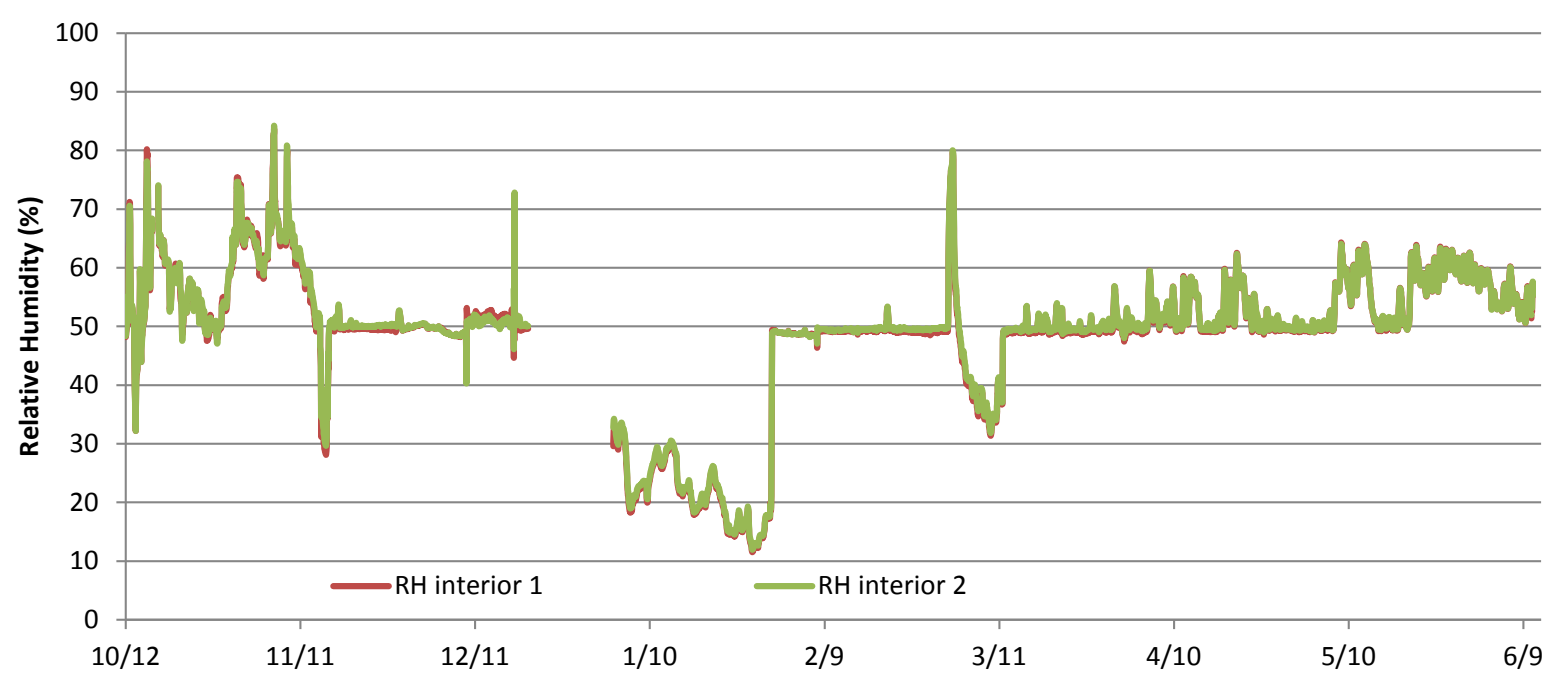

Figure 42. Test attic interior RH, winter 2013-2014

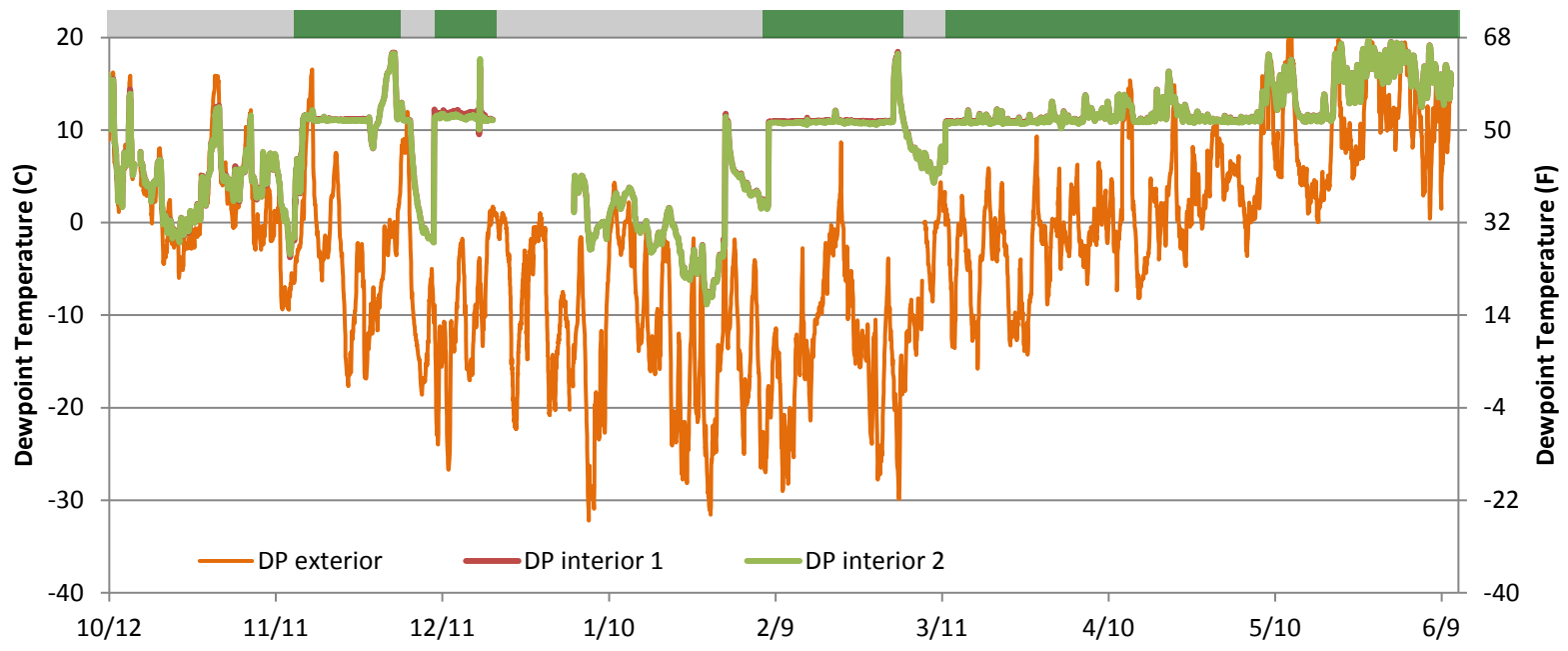

Figure 43. Test attic interior and exterior dew point temperature, winter 2013-2014

\subsection{Sheathing Moisture Contents}

OSB roof sheathing MCs are shown in the following graphs. Three measurements (upper, middle, and lower) were taken on each orientation (east and west). The results are shown in the graph using blue shades for the east-facing roof and reds for the west-facing roof. Height is indicated by color intensity: low sensors are lighter shades, and high sensors are darker shades. Exterior temperature is also graphed for reference.

Sheathing MCs often exceeded the fiber saturation point (wood cell walls are saturated). The fiber saturation point is typically $30 \% \mathrm{MC}$ in solid wood (FPL 2010) but only $25 \%-26 \%$ in adhered wood products such as OSB (Glass 2013). From the fiber saturation point up to capillary saturation, the relationship between MC and electrical resistance is not well defined (James rev. 1988), so the plotted values should not be taken as absolute measurements. However, the high values are useful to show higher wetness levels rather than lower values. 
The results for Roof 1 (compact vented) assembly are shown in Figure 44. For most of the winter, MCs are well below 20\%, which is safe for discouraging mold growth. The occasional spikes to higher than $20 \%$ appear to be associated with precipitation events; the spikes seen at the upper sheathing sensors may be associated with wind-driven rain that blew into the ridge vent. However, these wetting events quickly dried. The safe behavior of this roof is consistent with Smegal and Straube's (2014) monitoring results.

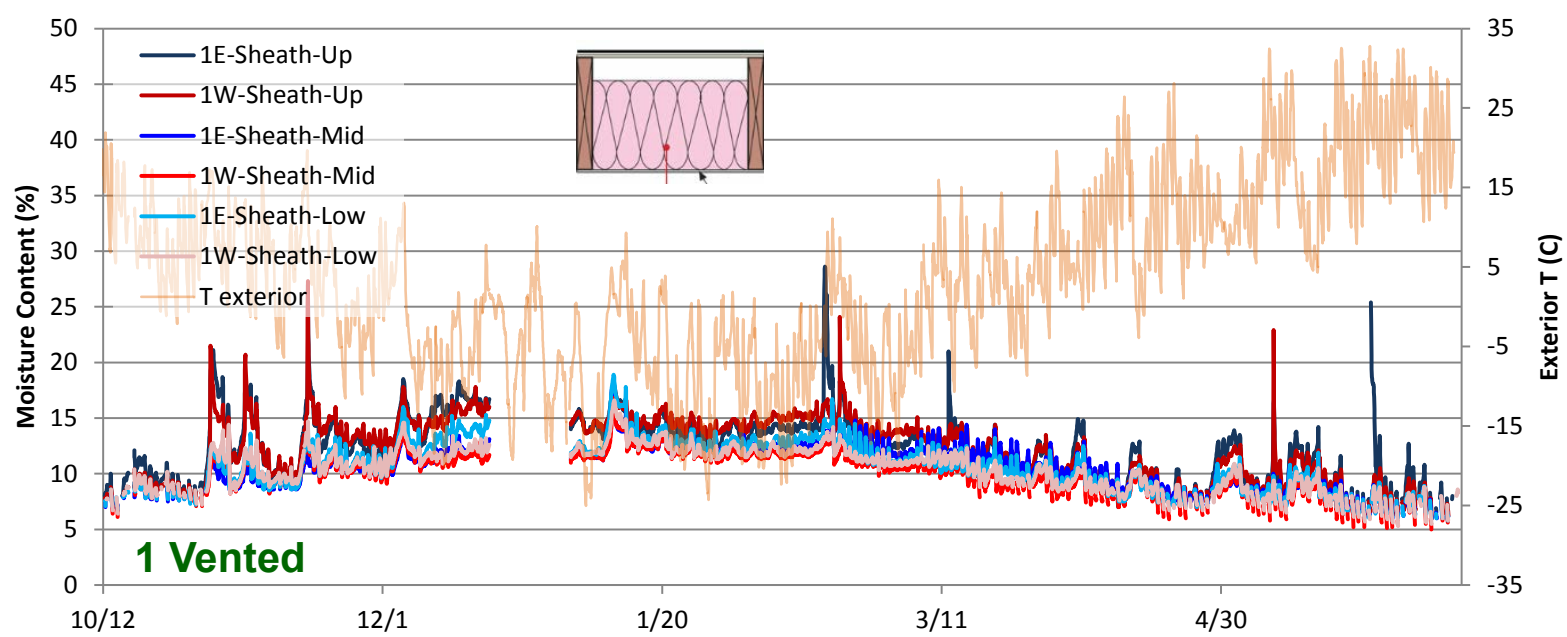

Figure 44. Roof 1 (vented) sheathing MCs

The results for unvented cellulose (Roof 7) and diffusion vent cellulose (Roof 6) are shown in Figure 45 and Figure 46, respectively. MCs were much higher; during much of the winter they exceeded $20 \%$. Both roofs also showed the expected spatial pattern: moisture levels were higher at the higher section of the roof; roof ridge MCs exceeded $40 \%$, which has risks rot and decay.

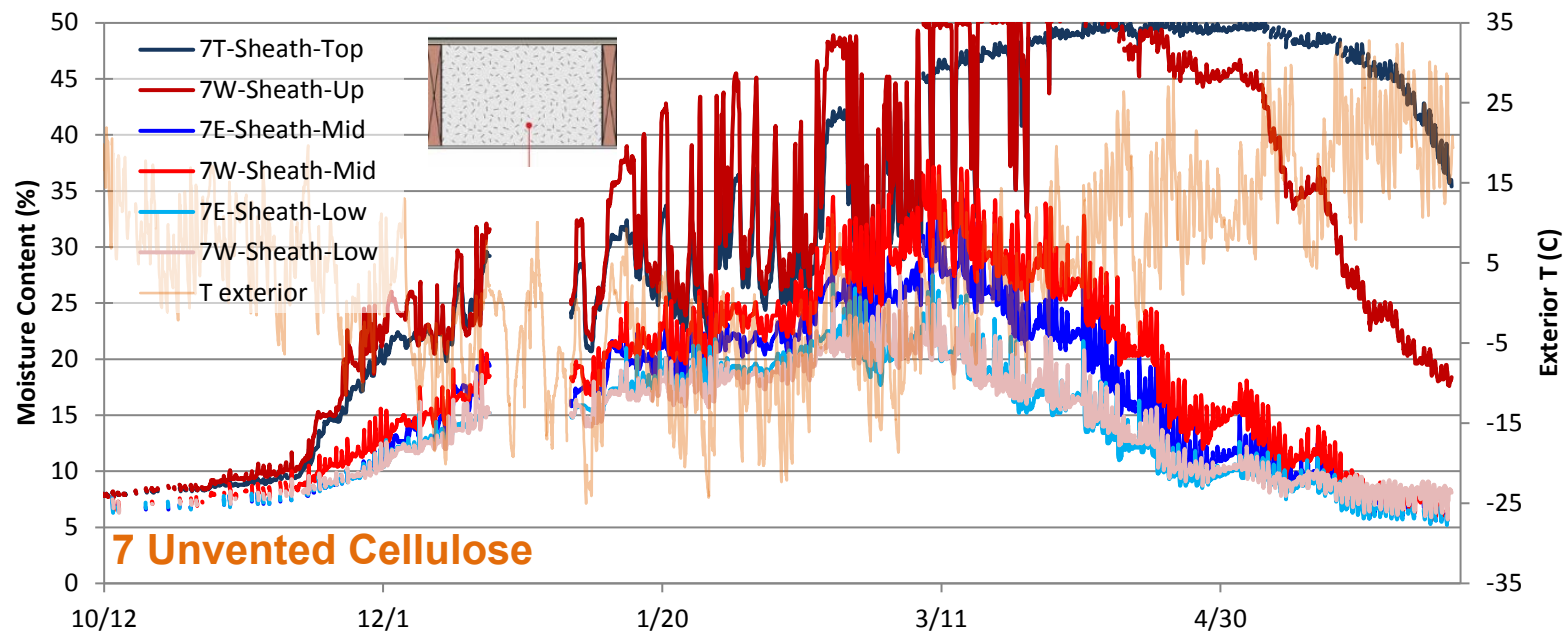

Figure 45. Roof 7 (unvented cellulose) sheathing MCs (unfiltered data) 


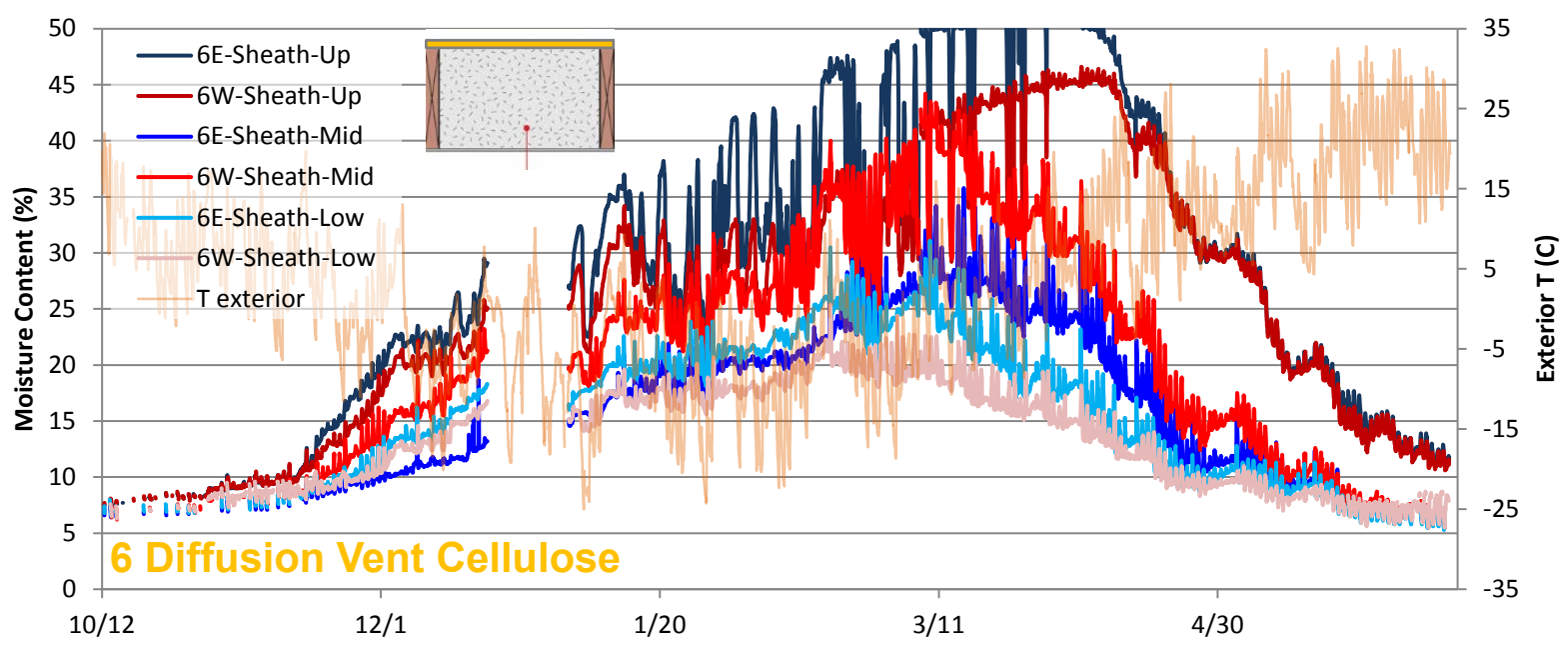

Figure 46. Roof 6 (diffusion vent cellulose) sheathing MCs (unfiltered data)

The upper MC measurements are difficult to read because they shifted suddenly high levels. These MC anomalies coincided with freezing temperatures; freezing of water in the sheathing likely resulted in inconsistent electrical resistance and thus measured MC. The MC trends during nonfreezing temperatures are more representative of actual conditions. Therefore, the previous data were filtered (only $\mathrm{MC}$ measurements higher than $0^{\circ} \mathrm{C}\left[32^{\circ} \mathrm{F}\right]$ are plotted) to make the graphs more readable; all remaining graphs are shown with filtered data. The filtered data for unvented cellulose (Roof 7) and diffusion vent cellulose (Roof 6) are shown in Figure 47 and Figure 48.

One marked difference between these two roofs is their dry-down period in the spring, highlighted in dashed gray rectangles. The MC in the diffusion vent (Roof 6) roof falls much faster, and to a lower level (12\% MC) than the unvented roof (Roof 7) (17\% and 35\% MC). This probably indicates the greater drying available by diffusion in Roof 6.

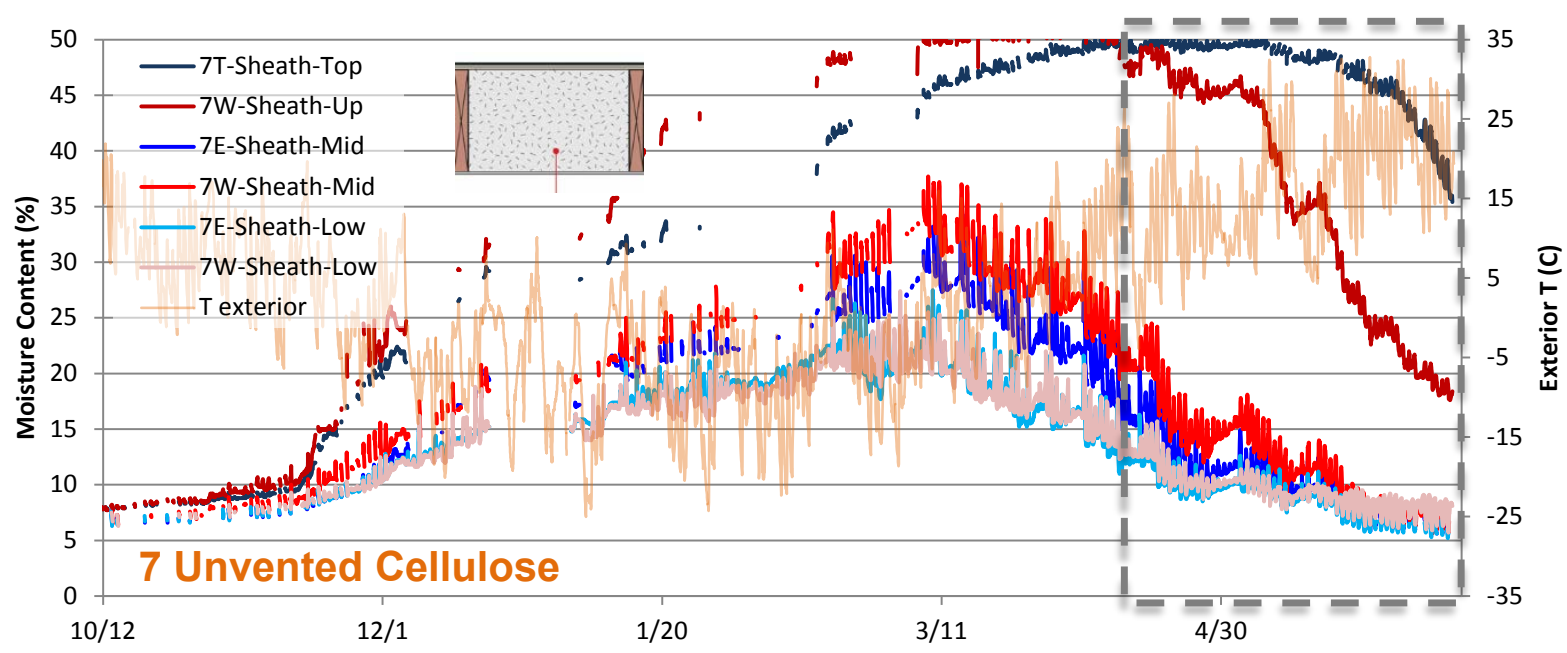

Figure 47. Roof 7 (unvented cellulose) sheathing MCs (filtered data) 


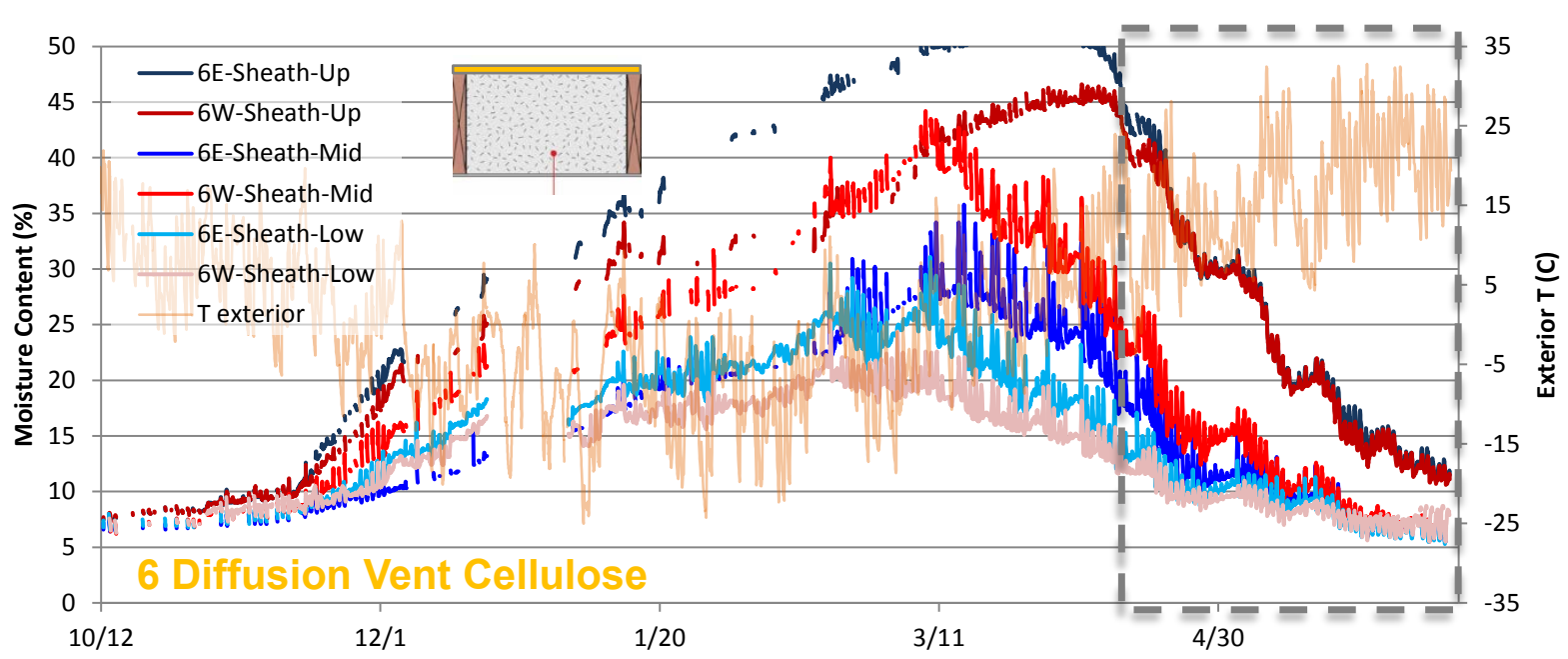

Figure 48. Roof 6 (diffusion vent cellulose) sheathing MCs (filtered data)

The results for the cellulose top vent (breather mesh netting under shingles) roofs are shown in Figure 49 (top vent cellulose with GWB) and Figure 50 (top vent cellulose, no GWB). The same high MCs and spatial patterns were seen (the greatest moisture was at roof peak). The GWB assembly (Roof 2) had drier moisture levels at the lower sections of the roof than the assembly without GWB (Roof 3). This is reasonable given that the painted GWB provides some level of air leakage and vapor flow control. These roofs had springtime drying rates that were similar to the diffusion vent roof, possibly due to upward drying into the mesh air space.

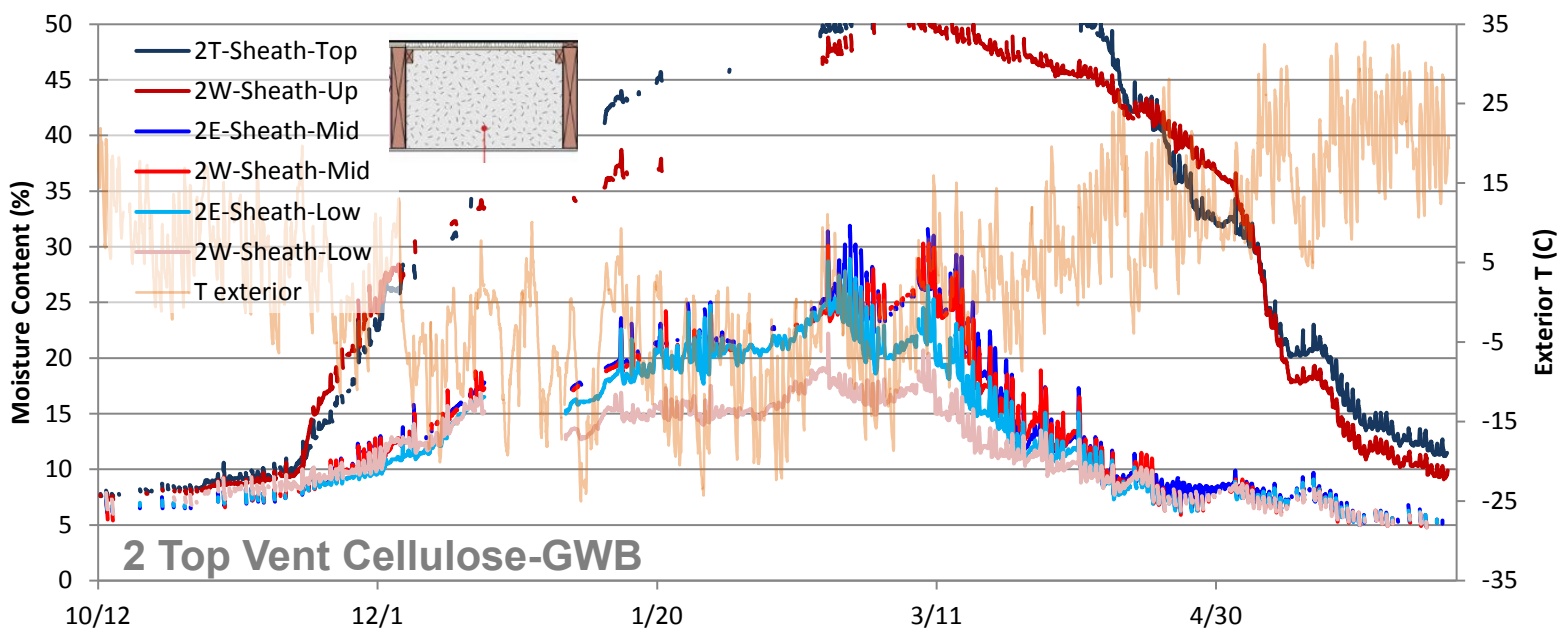

Figure 49. Roof 2 (top vent cellulose with GWB) sheathing MCs 


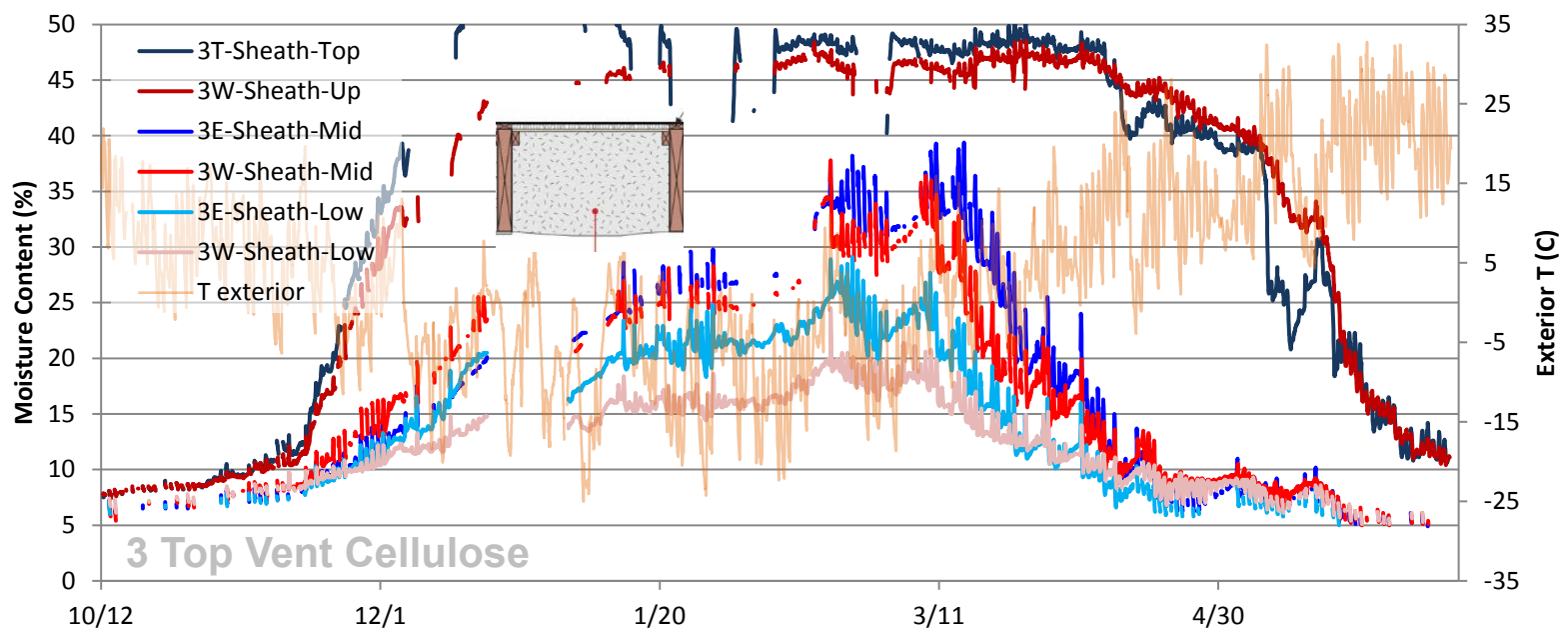

Figure 50. Roof 3 (top vent cellulose, no GWB) sheathing MCs

The results for the fiberglass top vent roofs (breather mesh netting under shingles) are shown in Figure 51 (top vent fiberglass with GWB) and Figure 52 (top vent fiberglass, no GWB). These measurements showed much greater variation in moisture levels during the winter; MC showed sudden drops. Therefore, these graphs were plotted with the constant dew point graphic; periods of sudden drying and periods when humidification was not running show some correlation.

The two assemblies show different responses: the GWB assembly (Roof 5) has some degree of stratification (higher MCs at the upper parts of the roof); the no GWB assembly (Roof 4) showed high MCs at almost all locations.

The difference in behavior between the fiberglass and cellulose top vent roofs $(2,3,4$, and 5) may be a function of the hygric storage/moisture buffering effect of the cellulose insulation; fiberglass insulation has minimal moisture storage.

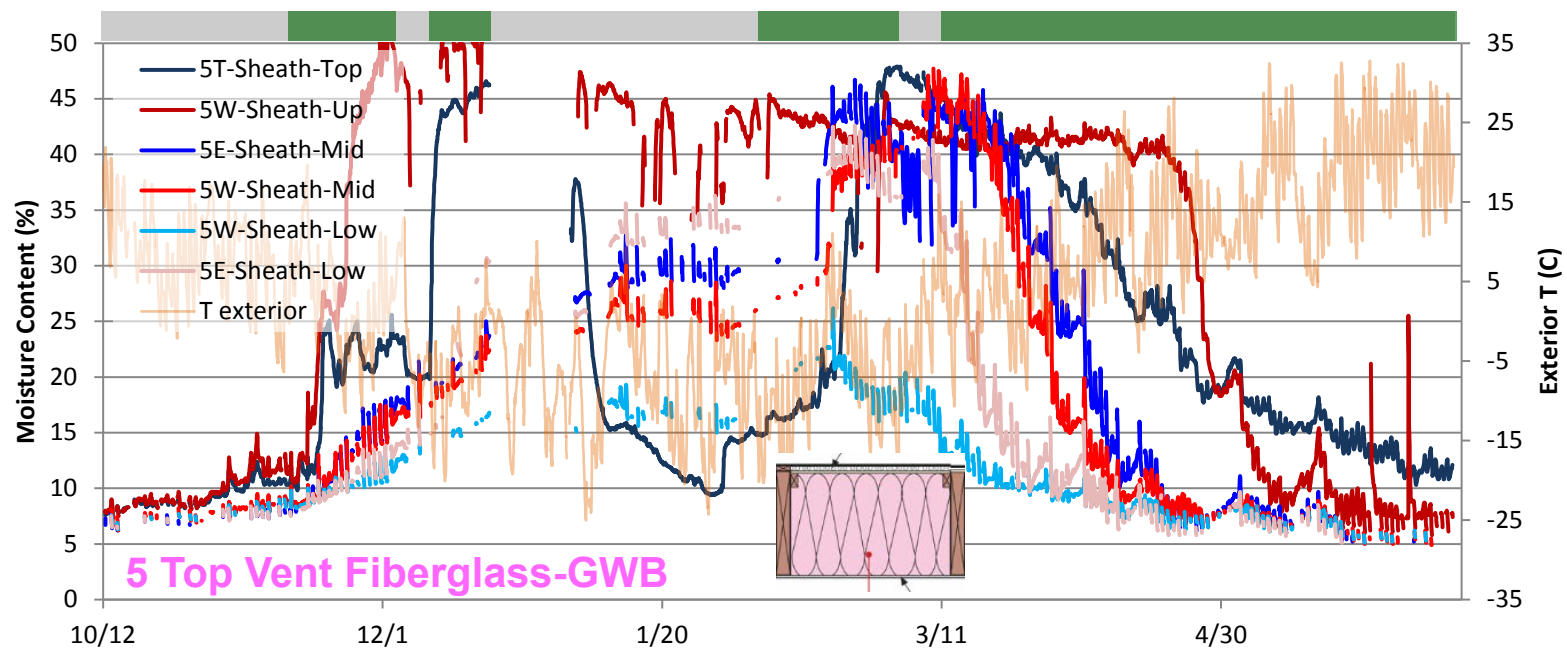

Figure 51. Roof 5 (top vent fiberglass with GWB) sheathing MCs 


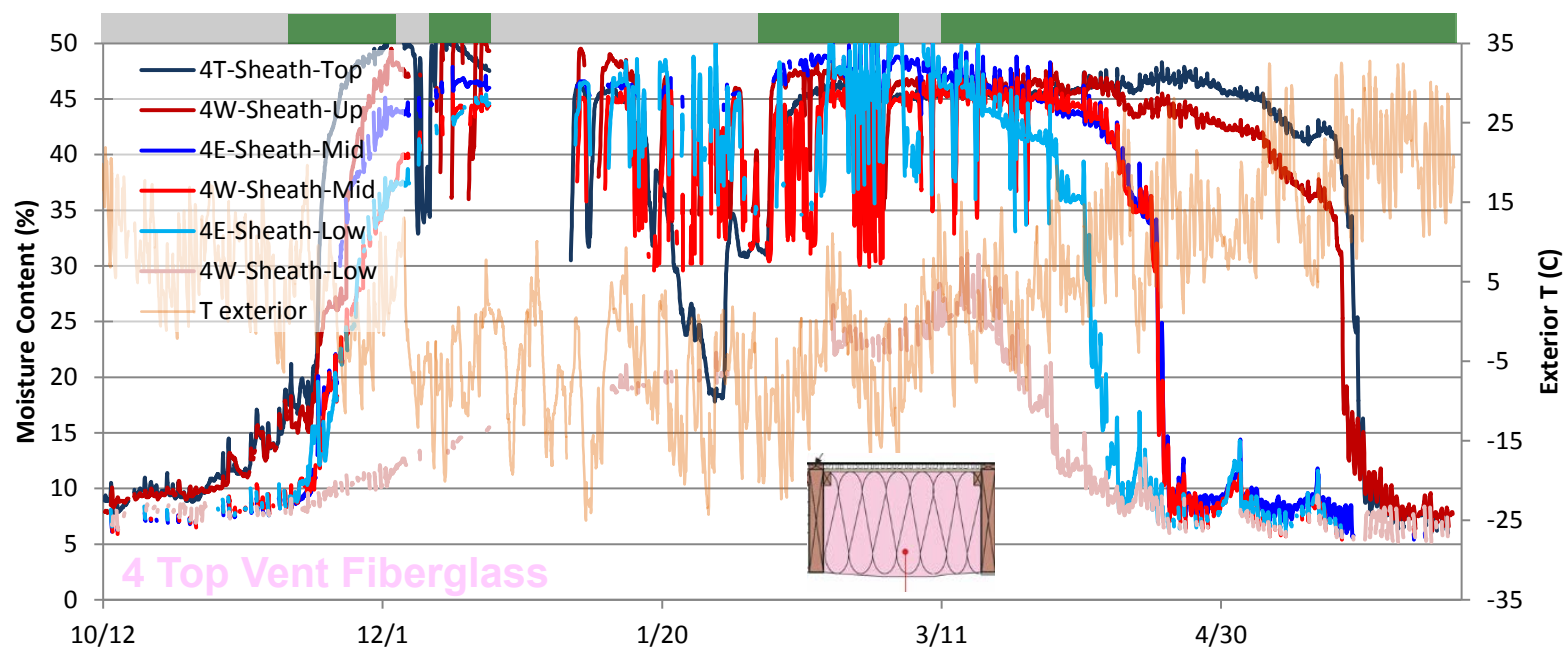

Figure 52. Roof 4 (top vent fiberglass, no GWB) sheathing MCs

When the roof assemblies dry in the spring, the uppermost parts of the roof stay wet the longest, and the lowermost parts of the roof dry first.

A mid-December site visit enabled researchers to verify that the monitored data reasonably reflected reality. The top vent fiberglass assembly without GWB (Roof 4) was examined from the interior. A brown stain that indicated water leakage was found (Figure 53, left); when the batt was removed, very wet and saturated roof sheathing and fiberglass were observed (Figure 53, right).
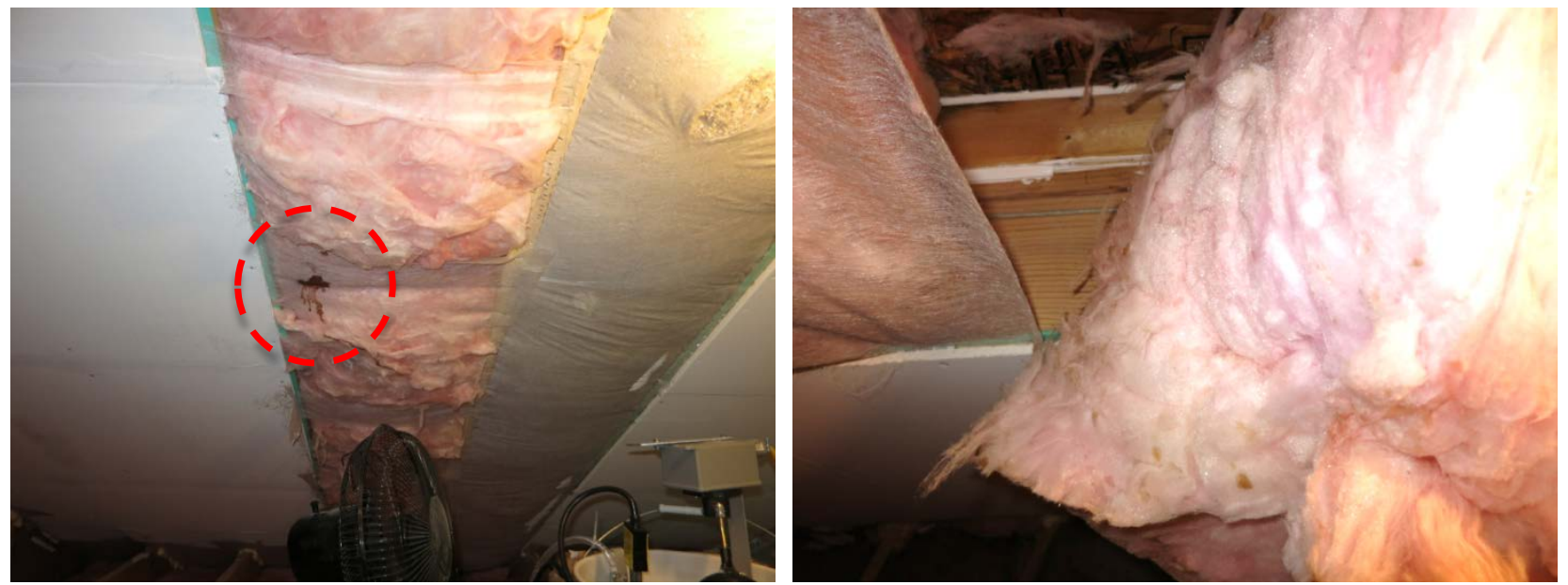

Figure 53. Top vent fiberglass, no GWB (4) water leak (left); wet fiberglass batt (right)

The sheathing was saturated with liquid water/condensation (Figure 54, left); the fiberglass was also saturated with condensation at the exterior surface (Figure 54, right). 

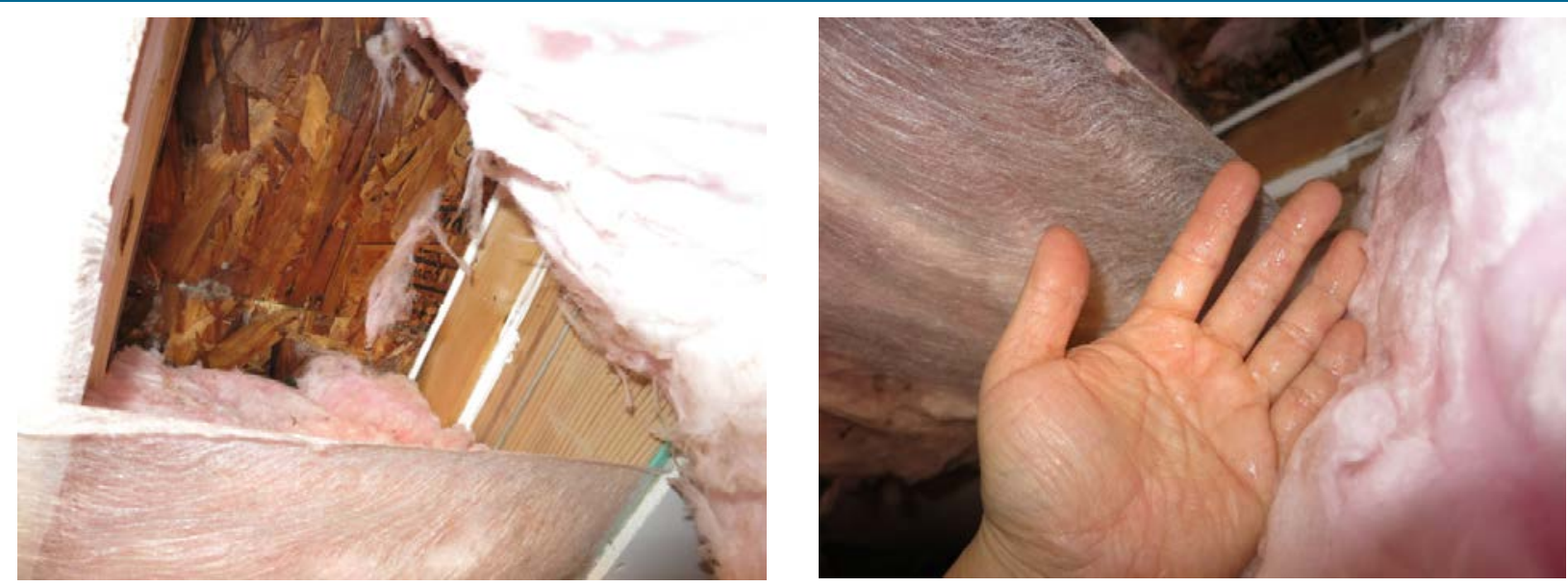

Figure 54. Top vent fiberglass, no GWB (4) wet sheathing (left); wet batt (right)

\subsection{Roof Ridge/Peak Sensor Packages}

Multiple sensor packages were installed at the roof ridge/peak, because the damage there was localized in previous observations. The data are plotted in parallel for multiple roofs; the color coding used for these graphs is shown in Table 6.

Table 6. Color Code Labels Used for Cold-Climate (Chicago) Roof Assemblies

\begin{tabular}{|r|l|}
\hline \# & Name \\
\hline $\mathbf{1}$ & Vented \\
\hline $\mathbf{2}$ & Top Vent Cellulose-GWB \\
\hline 3 & Top Vent Cellulose \\
\hline 4 & Top Vent FG \\
\hline $\mathbf{5}$ & Top Vent FG-GWB \\
\hline 6 & Diffusion Vent Cellulose \\
\hline $\mathbf{7}$ & Unvented Cellulose \\
\hline
\end{tabular}

Both top vent cellulose roofs ( 2 and 3 ) are shown in gray (of different shading), and both fiberglass roofs (4 and 5) are shown in pink. The diffusion vent (6) and unvented cellulose roofs (7) are shown in gold and orange, respectively. Typically, the top vent roofs are plotted together; the rest (Roofs 1, 6, and 7) are in another grouping.

\subsubsection{Rafter Framing Moisture Contents}

Rafter framing MCs reflect patterns similar to the previous roof sheathing MC measurements. Results for the vented (1), unvented (7), and diffusion vent (6) roofs are shown in Figure 55; the top vent roofs (2, 3, 4, and 5) are shown in Figure 56.

The vented roof (1) shows consistently dry performance (all MCs are lower than 15\%); roofs 6 and $7 \mathrm{MCs}$ rise in winter to peaks of $40 \%-45 \%$. However, the diffusion vent (6) roof dries more rapidly than the unvented (7) roof and to a lower ending MC ( $8 \%$ versus $15 \%$ ). 


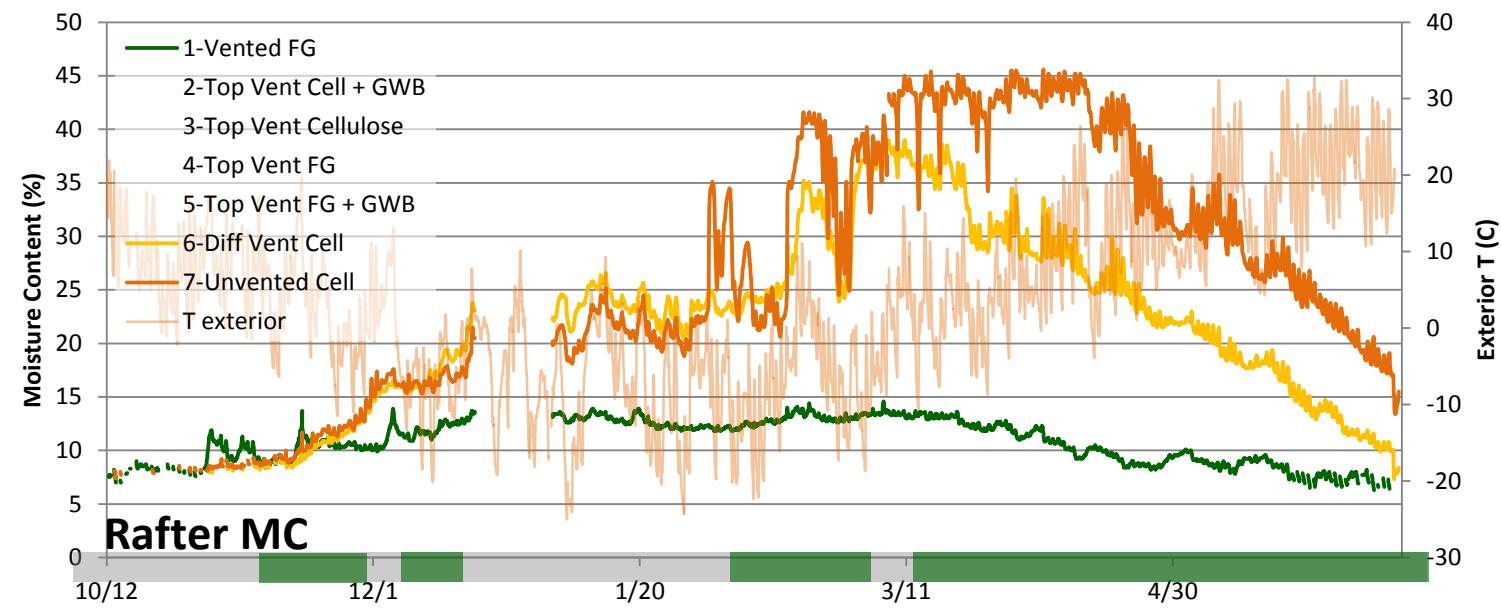

Figure 55. Rafter framing MC, vented (1), diffusion vent (6), and unvented (7)

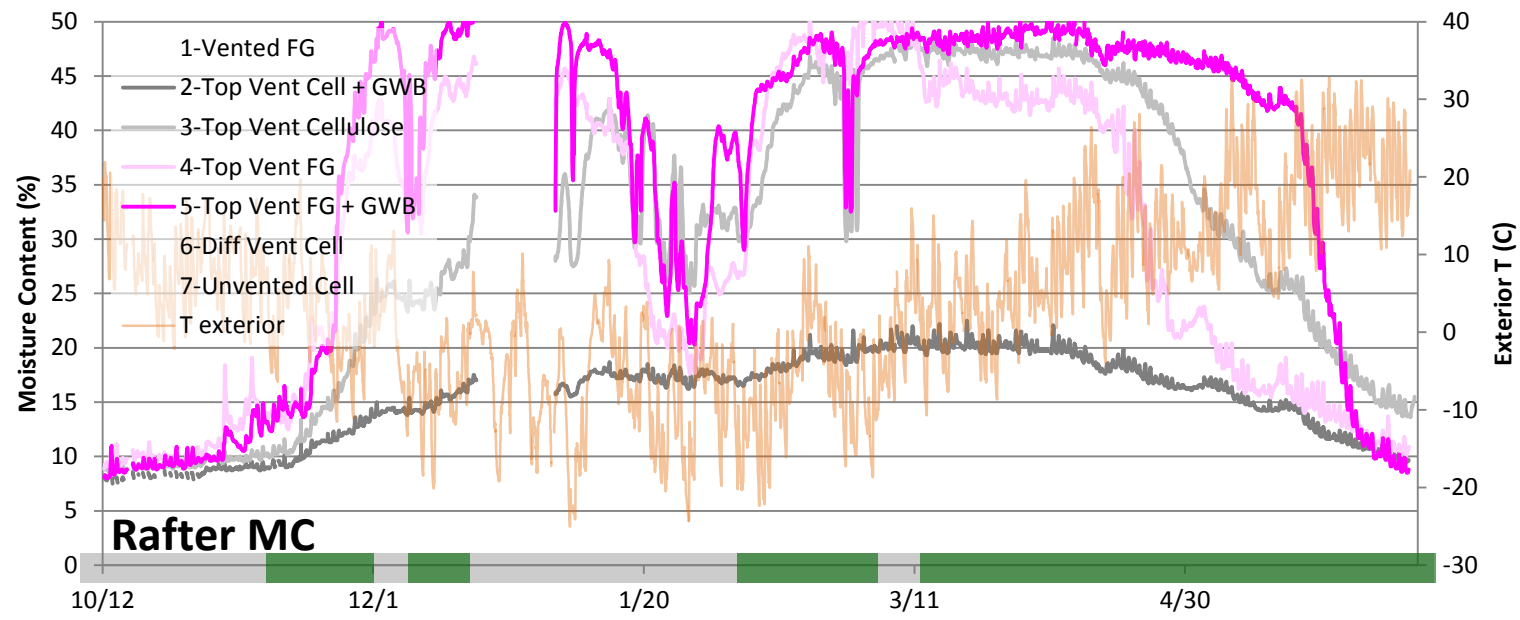

Figure 56. Rafter framing MC, top vent cellulose $(2,3)$ and fiberglass $(4,5)$

The top vent roofs (Figure 56) show greater MC variations over the course of the winter, but three of the four roofs move roughly in parallel. The top vent cellulose with GWB (2) assembly stays much drier (peak $21 \% \mathrm{MC}$ ) than the remaining roofs $(45 \%-50 \% \mathrm{MC})$. The $\mathrm{MC}$ rise and fall patterns can be roughly correlated with humidification system operation (green/gray bar). All top vent roofs dry in the spring to the $10 \%-15 \% \mathrm{MC}$ range. The top vent fiberglass with $\mathrm{GWB}$ (5) roof shows the slowest drying, but no clear reason is seen for this behavior.

\subsubsection{Roof Peak/Ridge Relative Humidity}

The RH at the rafter bay peak is plotted for the unvented (7) and diffusion vent (6) roof in Figure 57 and the top vent roofs $(2,3,4$, and 5) in Figure 58. The vented roof is not plotted, because it largely reflects outdoor conditions.

The unvented and diffusion vent roofs both spike in RH after the installation of humidification, and remain at high $\mathrm{RH}(90 \%-100 \%)$ through most of the winter. In the spring, the diffusion vent roof dries to safer levels; the unvented assembly remains at high RH levels. 


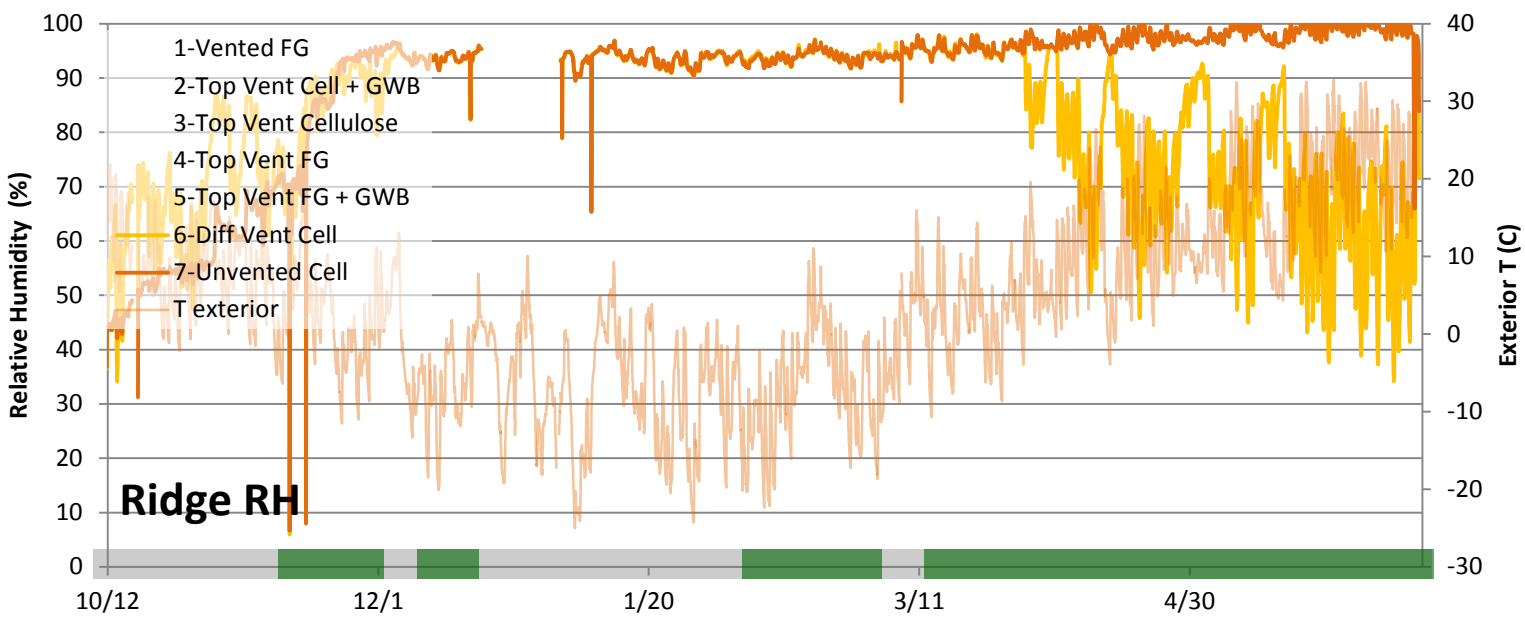

Figure 57. Roof ridge peak $\mathrm{RH}$, diffusion vent (6) and unvented (7)

The top vent cellulose roofs ( 2 and 3 ) showed similar behavior; the RH remained at $90 \%-100 \%$ through most of the winter and dried in the spring. The top vent fiberglass roofs (4 and 5) showed more variations, and Roof 4 (no WGB) showed extreme variations in $\mathrm{RH}$ (from $15 \%$ to $95 \%$ ). These extreme variations were first interpreted as sensor failure: polymer capacitancebased RH sensors are known to have issues with high RHs and condensing conditions that were consistent with the measurements taken at the roof ridge.

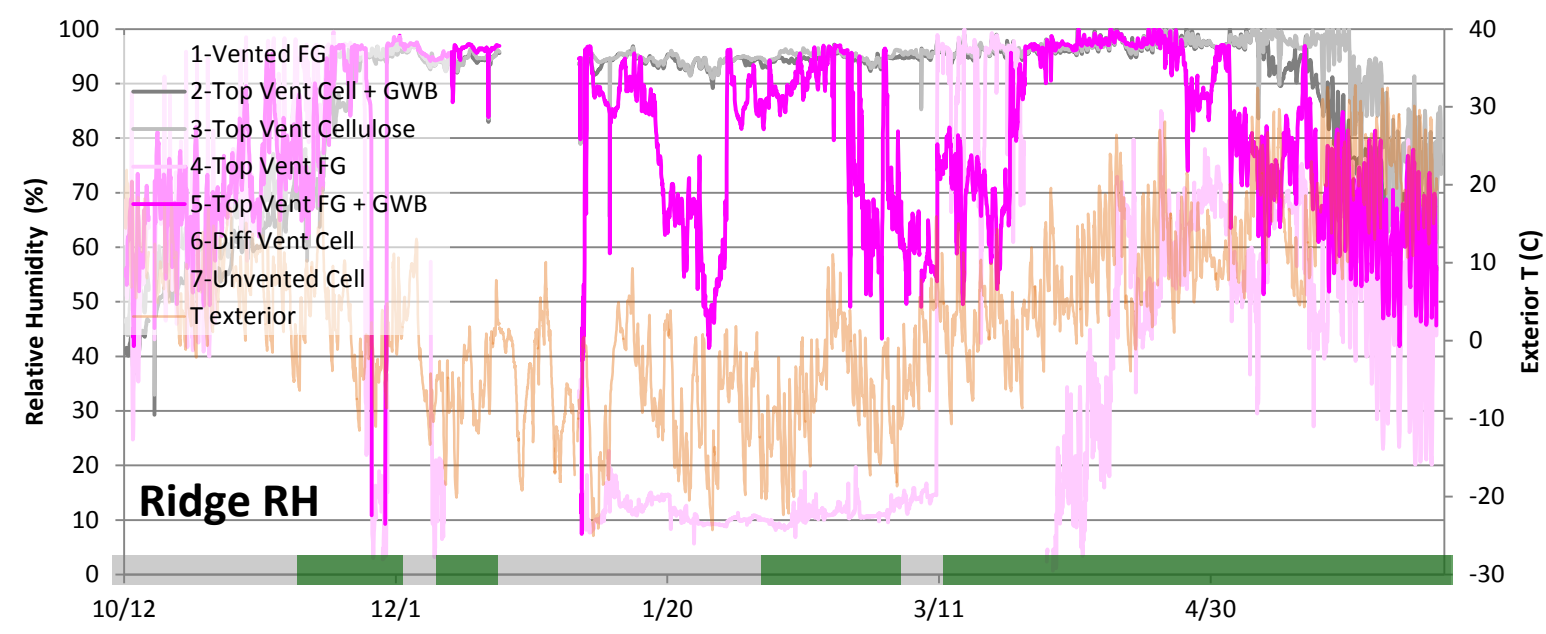

Figure 58. Roof ridge peak $\mathrm{RH}$, top vent cellulose $(2,3)$ and fiberglass $(4,5)$

\subsubsection{Roof Peak/Ridge Wafer Sensor}

Given the variations seen in the RH sensors, the wood wafer sensors were also checked as surrogates for RH (Figure 59).

Wafer sensors have greater durability than RH sensors; although they are slow to respond, they can be useful for understanding seasonal moisture accumulation and release patterns. The response of these wood-based sensors should be understood when interpreting these results. In previous calibration (Ueno and Straube 2008), the wafer sensors come to equilibrium with 100\% $\mathrm{RH}$ conditions (air in closed container over water) at 28\%-30\% MC. However, immersing the 
sensors in liquid water increases their MC to $40 \%-45 \%$. Therefore, measurements above the $100 \% \mathrm{RH}$-equivalent range indicate liquid water condensation.

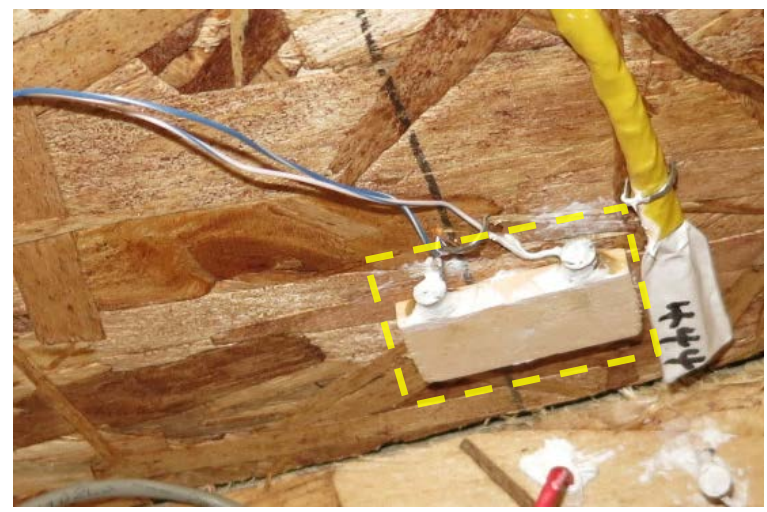

Figure 59. Roof ridge wafer sensor example next to $\mathrm{RH}$ sensor

Roof peak/ridge wafer MCs are plotted for the vented (1), unvented (7), and diffusion vent (6) roofs in Figure 60 and the top vent roofs $(2,3,4$, and 5) in Figure 61.

The vented roof (1) showed RHs that peaked at roughly 100\% RH-equivalent; conditions were drier for much of the winter. The unvented (7) and diffusion vent (6) roofs both showed MCs well into the liquid water/condensation range; similar to previous results, the diffusion vent roof (6) dried much faster than the unvented (7) roof.

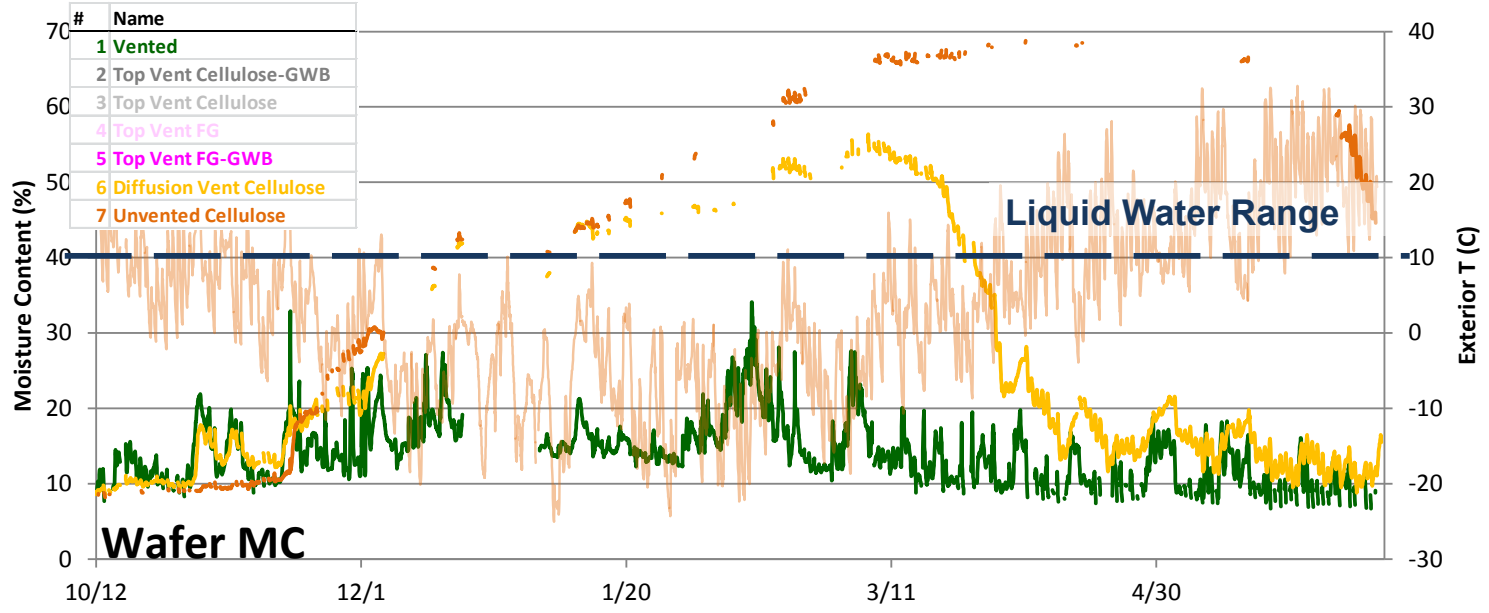

Figure 60. Roof ridge wafer sensor, vented (1), diffusion vent (6), and unvented (7)

The top vent cellulose roofs (2 and 3 ) both showed quick rises into the liquid water/condensation range and drying in the spring. The top vent fiberglass roof with GWB (5) had similar behavior but with some variations that were apparently linked with humidification operation. The top vent fiberglass roof without GWB, however, showed similar puzzling behavior as the RH sensor in the same assembly (dropping to very low RH in the winter). Both fiberglass roofs showed periods when the RH exceeded the liquid water/condensation range. 


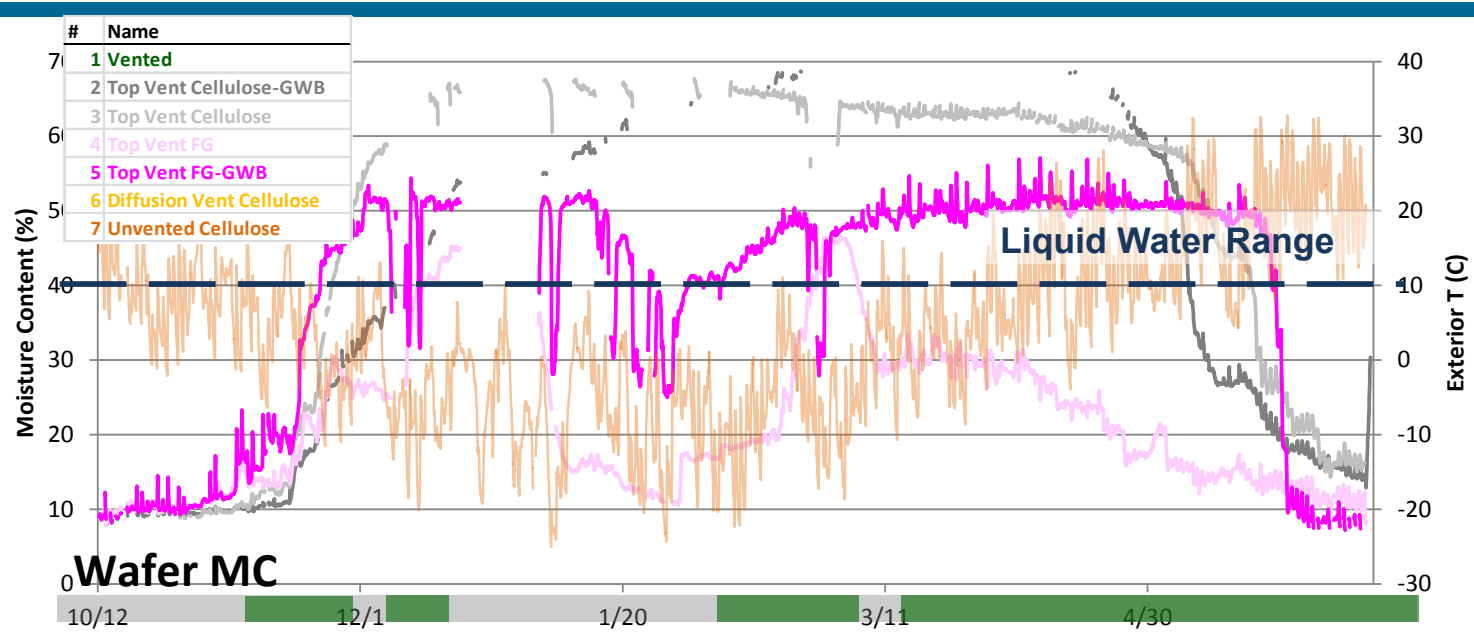

Figure 61. Roof ridge wafer sensor, top vent cellulose (2 and 3 ) and fiberglass (4 and 5)

\subsubsection{Roof Doghouse Sheathing Moisture Content}

Sheathing MC at the doghouse detail was measured (Figure 62). The principle of many of these roofs is that they release moisture at the peak: the risk is that this moisture might condense on the underside of the doghouse detail and cause damage.

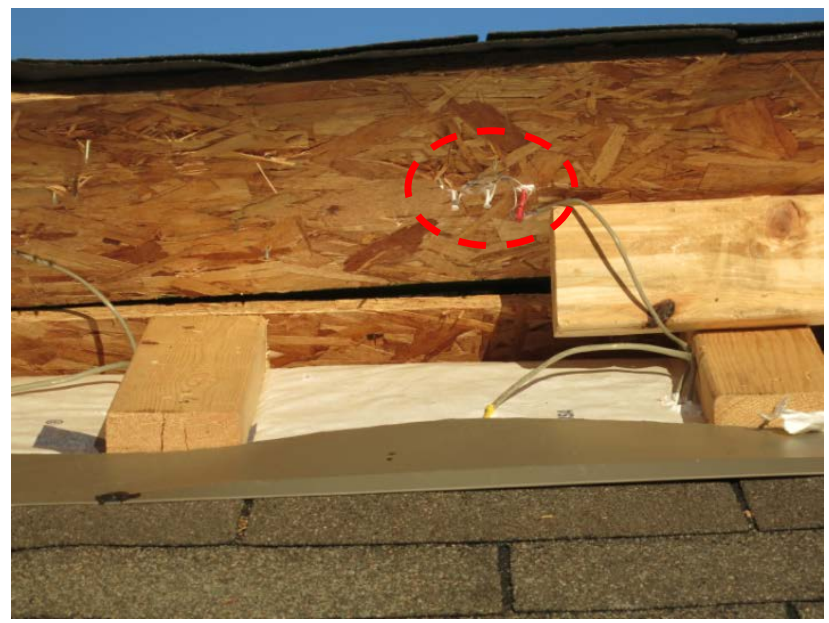

Figure 62. Roof doghouse sheathing MC sensor

The measured doghouse MCs are shown in Figure 63 with outdoor temperature for reference. MCs remained mostly lower than $20 \%$ with some brief higher excursions that dried quickly. However, the top vent fiberglass roof without GWB (Roof 4) showed much higher MCs with peaks of about $40 \%$. Combined with the anomalies seen in rafter bay peak RH (and matching wafer sensor), they suggest air may have leaked at this test bay. Leakage of high humidity indoor air could result in the doghouse sheathing wetting seen here.

The doghouse MCs spiked multiple times; the spikes are plotted with precipitation data taken from airport data in Figure 64. The data seem to indicate some correlation between moisture spikes and precipitation events. Correlation might be improved by calculating driving rain from precipitation and wind data that would push rain through the doghouse detail (predominantly east-west). 


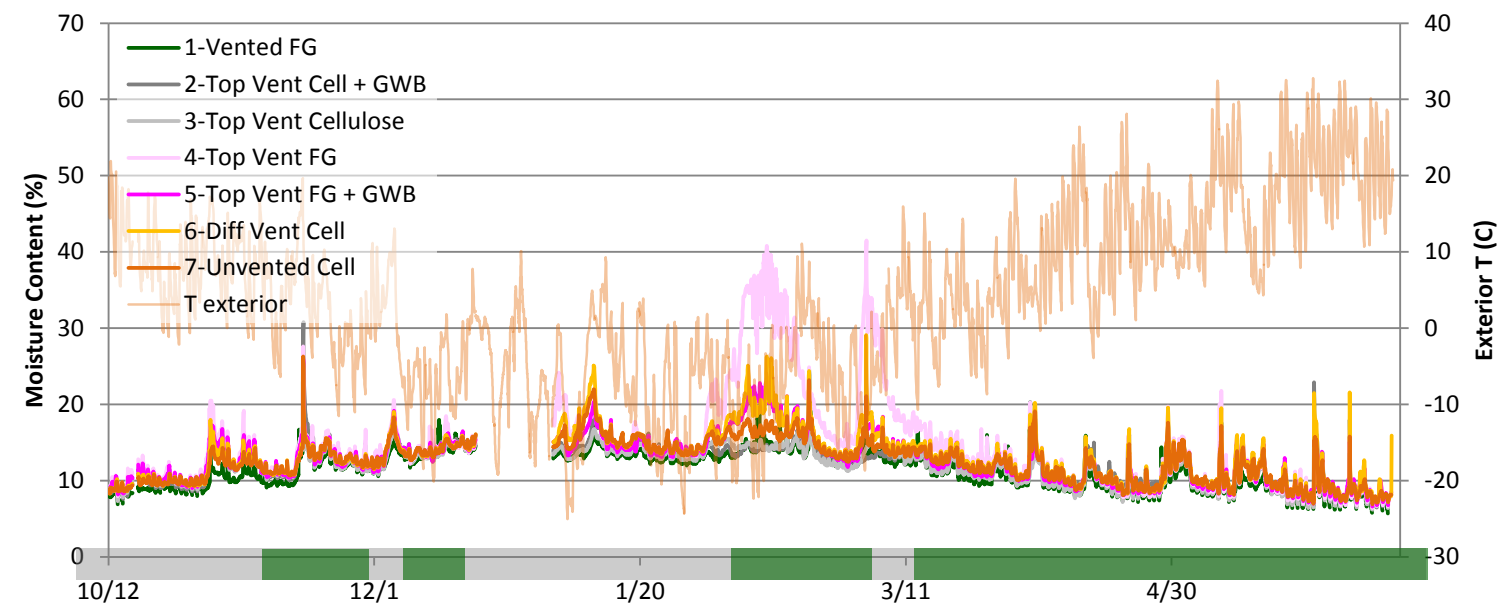

Figure 63. Roof doghouse sheathing MC measurements

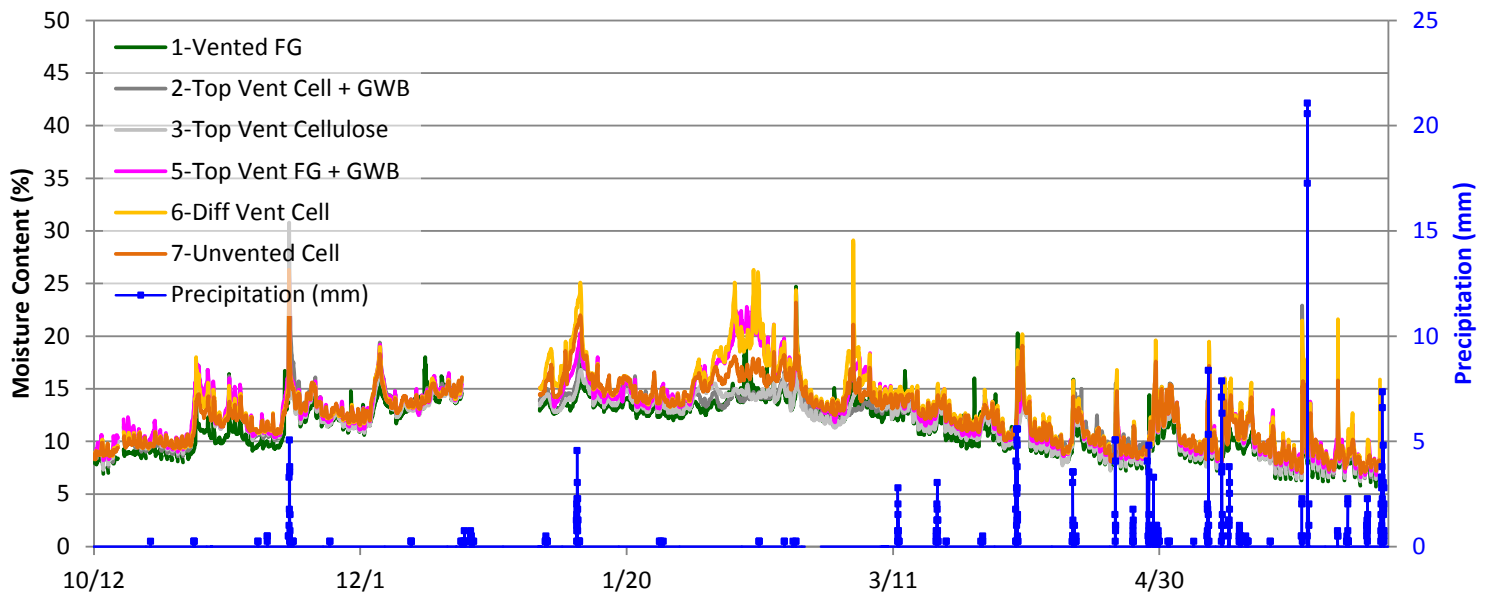

Figure 64. Roof doghouse sheathing MC measurements with precipitation

\subsection{Ventilation Space Sensors}

$\mathrm{T} / \mathrm{RH}$ sensors were installed in the airstream of the ventilated roof assemblies (1-5) to provide some indication of whether moisture was being removed. Dew points were calculated and plotted, which generally seemed to indicate higher dew points at the exhaust points of the roofs. These plots are shown in Appendix B.

Unfortunately, few conclusions can be drawn from the ventilation space measurements. Although higher dew points at the exhaust may indicate moisture removal, they might also simply indicate static moisture accumulation and stratification if there is minimal airflow. To truly measure moisture removal, both intake/exhaust air MC and airflow need to be measured. Given the limited ( $\sim 1 / 2$-in.) mesh airspace under the shingles, the airflow might be relatively low. The low-velocity airflows that occur in ventilation cavities is difficult to measure and monitor insitu (Van Straaten 2003). 


\section{Cold Climate (Chicago) Disassembly}

At the conclusion of any enclosure monitoring experiment, a useful step is to open the test assemblies and examine the conditions. It is instructive to understand how the monitored data relate to actual damage or material durability. Therefore, the test roofs were disassembled at the end of the experiment (June 2014); the builder converted the garage attic back into a conventional vented geometry.

\subsection{Ridge Exterior Conditions}

Given the concentration of moisture at the roof ridge, the exterior disassembly proceeded from the ridge downward. Figure 65 shows the conditions before the doghouse sheathing, $2 \times 4$ standoffs, and house wrap ridge wrap were removed.

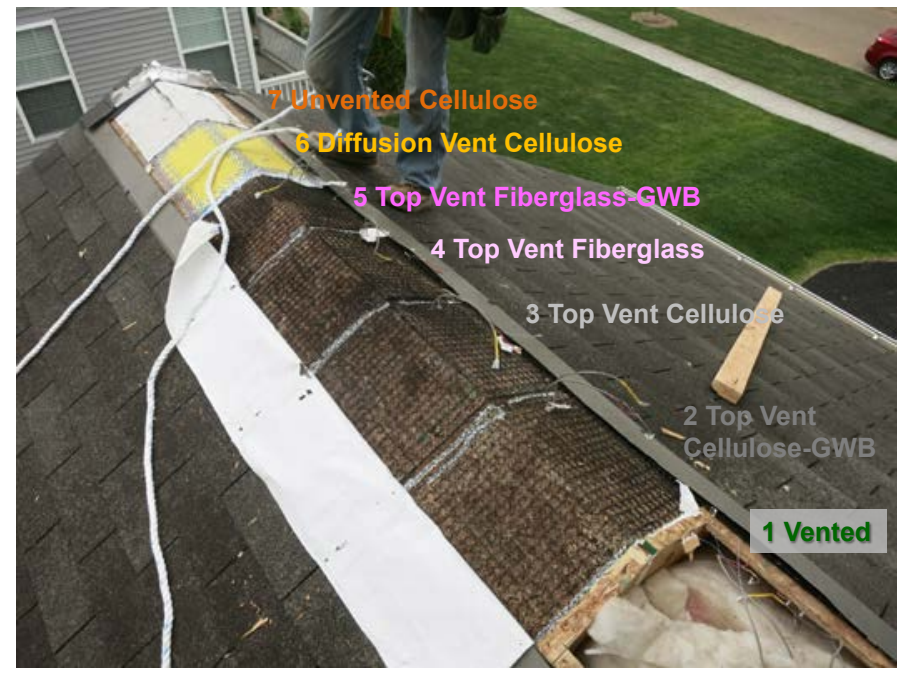

Figure 65. Ridge conditions before the breather mesh was removed

Figure 66 and Figure 67 show the conditions after the breather mesh was removed. The breather mesh was run continuously across all four top vent assemblies, so unintentional cross flow could occur here. The roof sheathing is not continuous across the four bays due to the dropped sheathing detail.

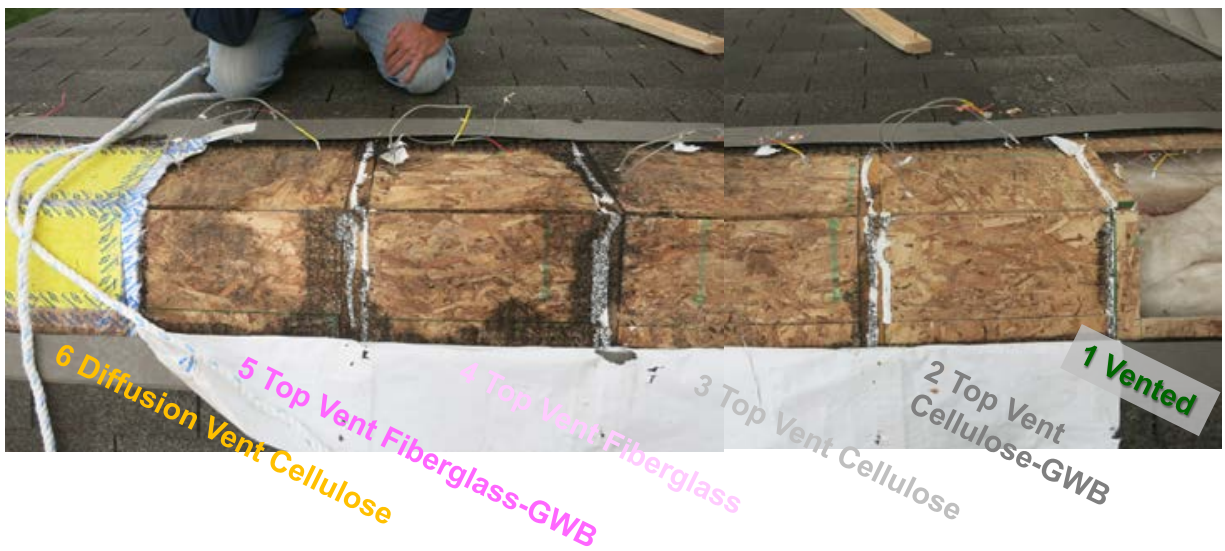

Figure 66. Ridge conditions after the breather mesh was removed 


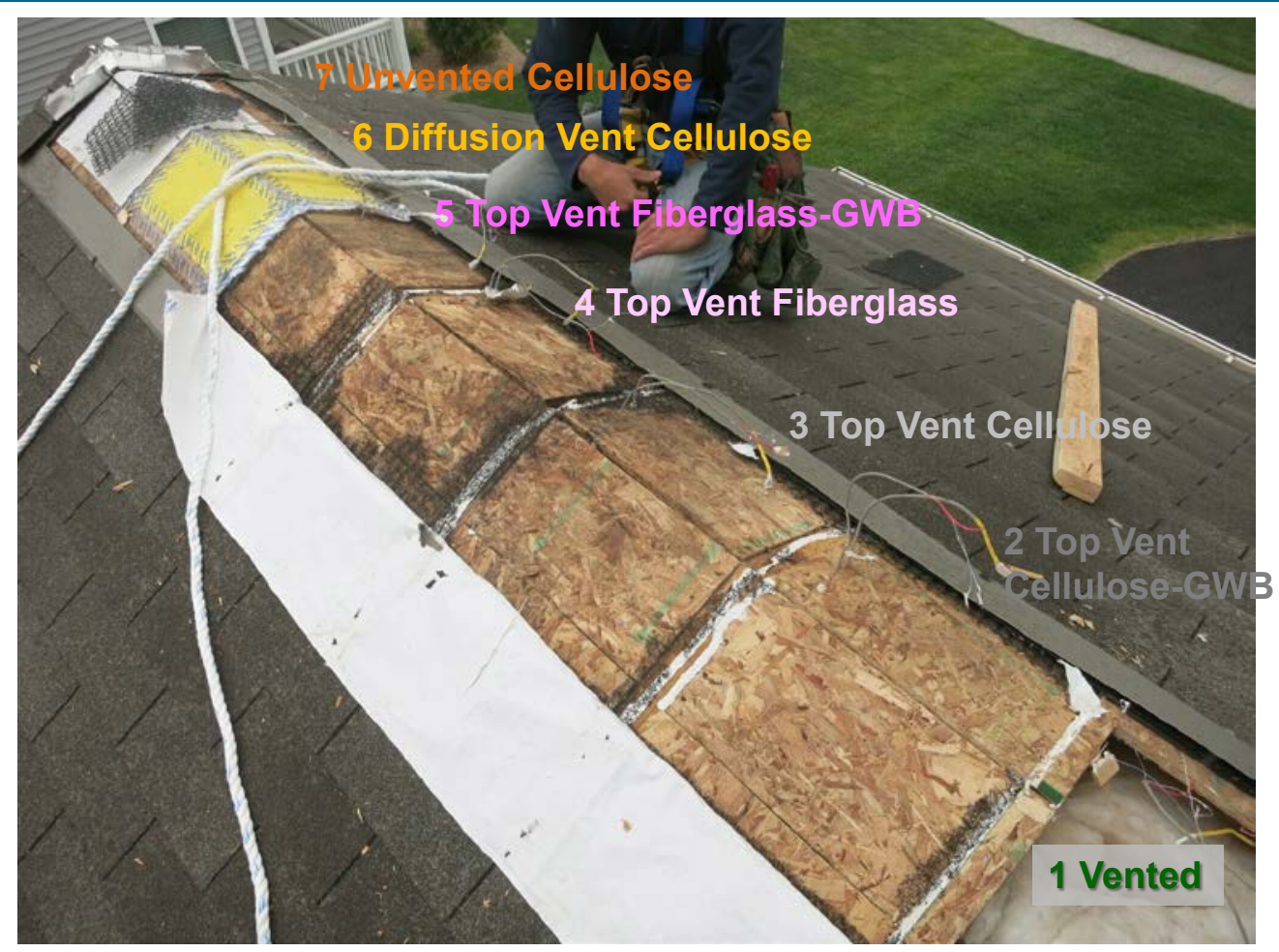

Figure 67. Ridge conditions after the breather mesh was removed

The exterior sheathing was apparently moisture damaged (stained, likely mold growth); the greatest damage was concentrated at the fiberglass bays.

The damage at the fiberglass bays was examined by probing the sheathing with a screwdriver (Figure 68). Although these stained areas appear heavily damaged, they are structurally intact.
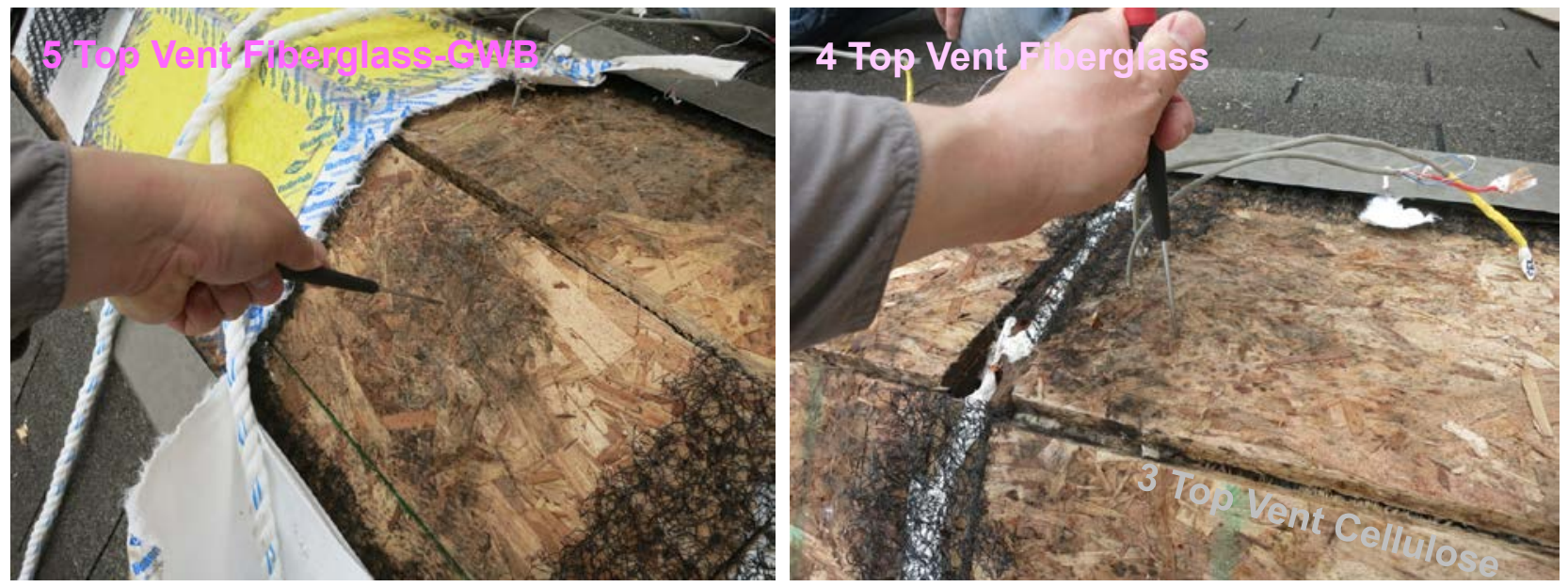

Figure 68. Ridge sheathing conditions (screwdriver test) for Roofs 4 and 5

The sheathing at the top vent cellulose roof (3) is damaged (see Figure 68). However, based on the damage pattern (adjacent to bay 4, top vent fiberglass) and the complete lack of top surface damage in the adjacent cellulose bay (top vent cellulose with GWB; Figure 69), the staining on Roof 3 is likely due to cross-airflow leakage coming from the adjacent fiberglass assembly. 


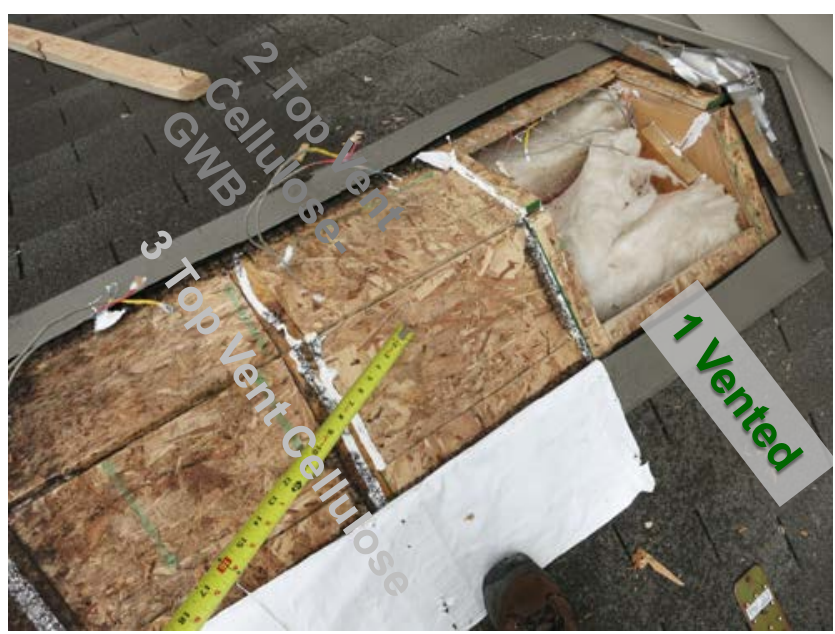

Figure 69. Ridge sheathing conditions, Roofs 1, 2, and 3

\subsection{Rafter Bay Peak Conditions}

A strip of roof sheathing was removed at the peak, and conditions were examined on the top and bottom surfaces of the sheathing and in the rafter bay.

The top and bottom of the sheathing in Roof 3 (top vent cellulose with GWB) is shown in Figure 70. The interior surface showed rusted fasteners, some discoloration, and grain raise/thickness swelling of the OSB, but no visual indication of mold growth. The top side, in contrast, showed the mold growth that is suspected to have originated from an air leak in the adjacent fiberglass bay.
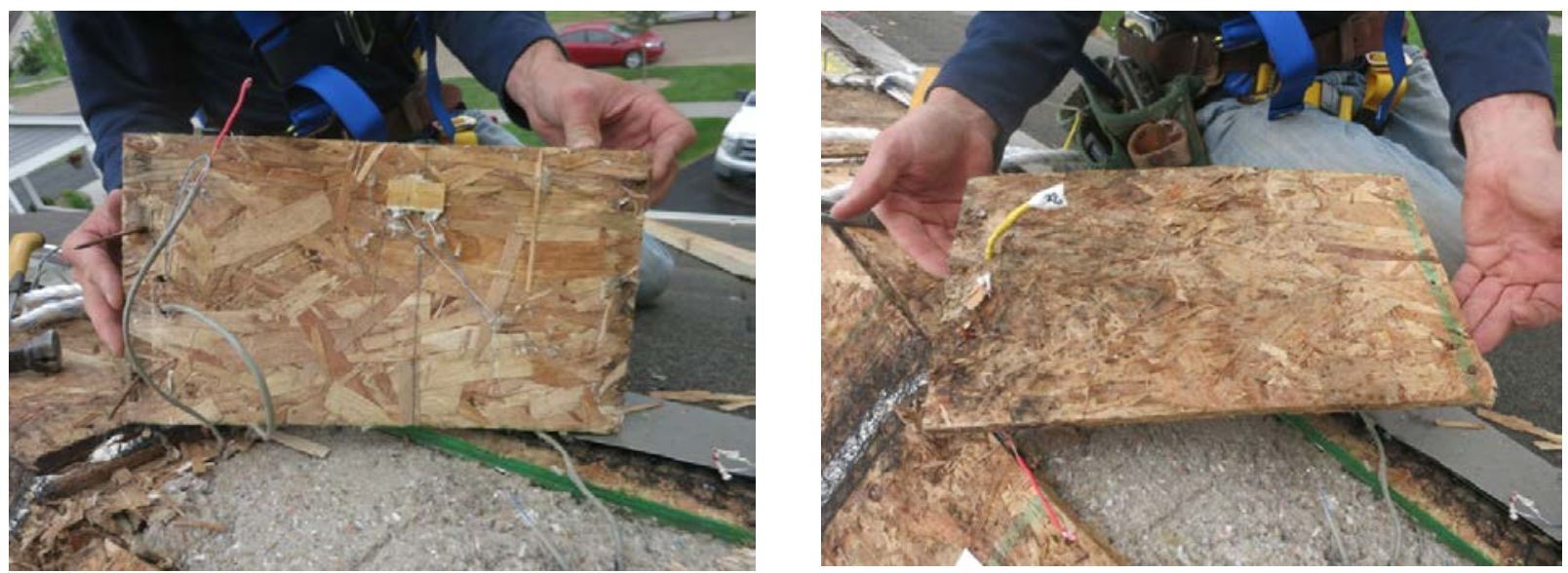

Figure 70. Ridge sheathing bottom (left); top (right) conditions, Roof 3

Conditions at Roof 2 (top vent cellulose, no GWB) are shown in Figure 71; interior sheathing had similar conditions to Roof 3 (no visible mold growth, rusted fasteners, grain raise of OSB).

The cellulose insulation had not settled over the course of a winter and was not visibly damaged. There was some caking of the cellulose (adhesions to the roof sheathing), which is regarded as an indication of dried moisture accumulation (Rose and McCaa 1998; Derome 2005). 

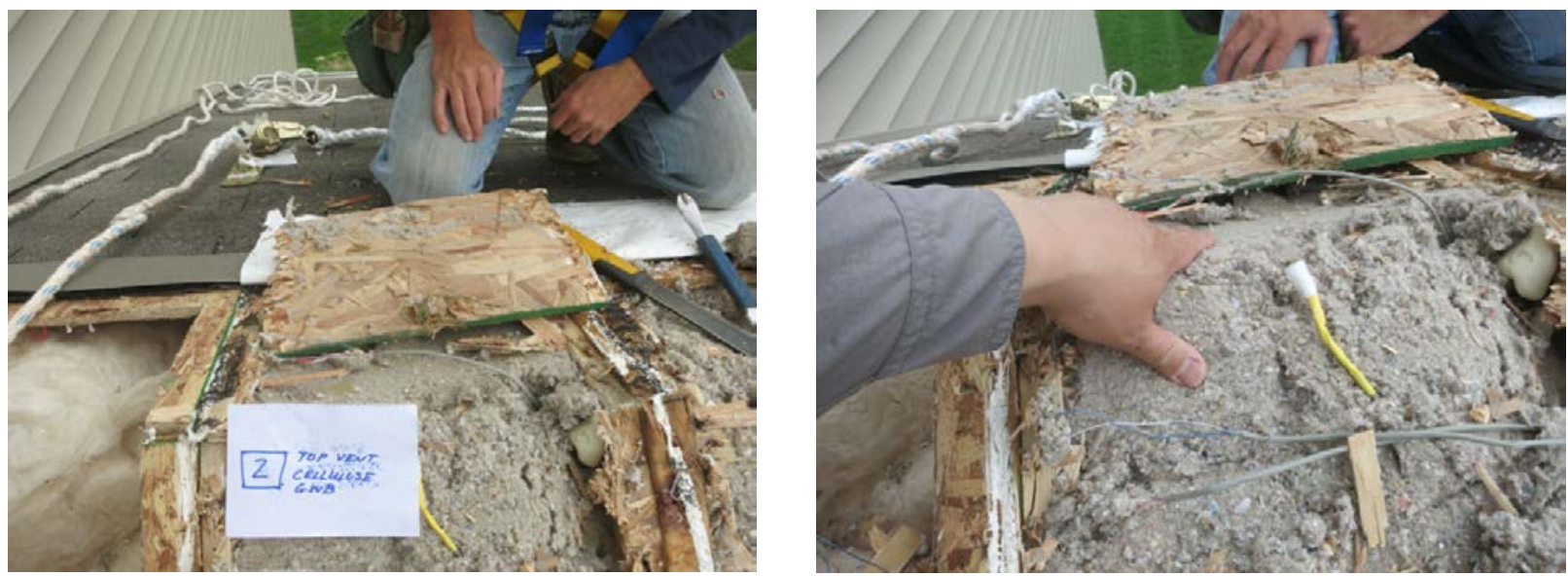

Figure 71. Ridge sheathing top conditions, Roof 2 (left); cellulose conditions (right)

In contrast, the top vent fiberglass roofs showed extensive damage. Sheathing conditions at Roof 4 (top vent fiberglass, no GWB) are shown in Figure 72; the exterior side is stained with suspected mold (near the assumed air leak), and the interior side has extensive staining and growth; insulation has adhered to the sheathing (Figure 72, left). Figure 72 (left) shows the east (rear) facing roof sheathing.
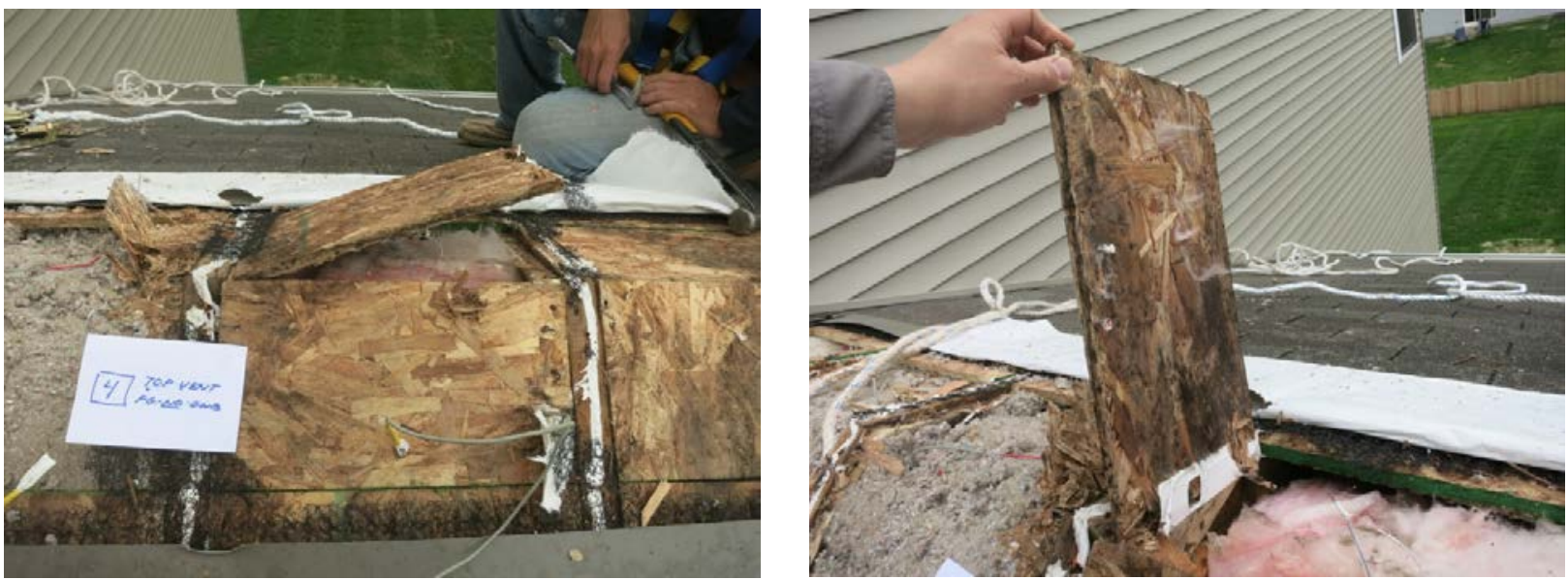

Figure 72. Ridge sheathing top (left); bottom (right) conditions, Roof 4

Another image of the interior side of the east-facing roof sheathing is shown in Figure 73 (left); the west (front) face is shown in Figure 73 (right).

Similar images are shown for Roof 5 in Figure 74 (top vent fiberglass with GWB); both exterior and interior sides showed extensive damage and staining (wetter on the inside).

The rafter bays apparently had mold growth on the framing that was concentrated at the exterior (colder in winter) side (Figure 75 and Figure 76). Although the fiberglass batts were installed meticulously from the underside, gaps between the batts and framing were evident from the top side, which would have left possible openings for airflow bypass. 


\section{U.S. DEPARTMENT OF Energy Efficiency \& \\ Renewable Energy}
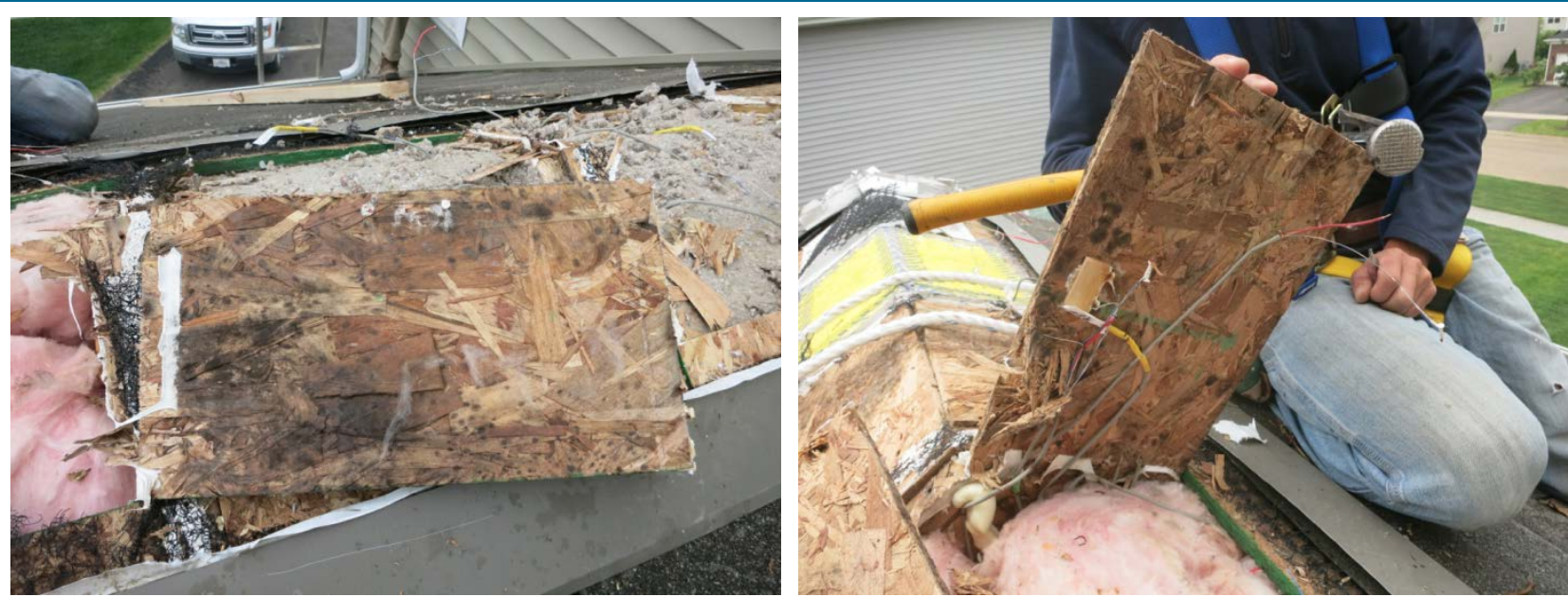

Figure 73. Ridge sheathing bottom conditions, Roof 4
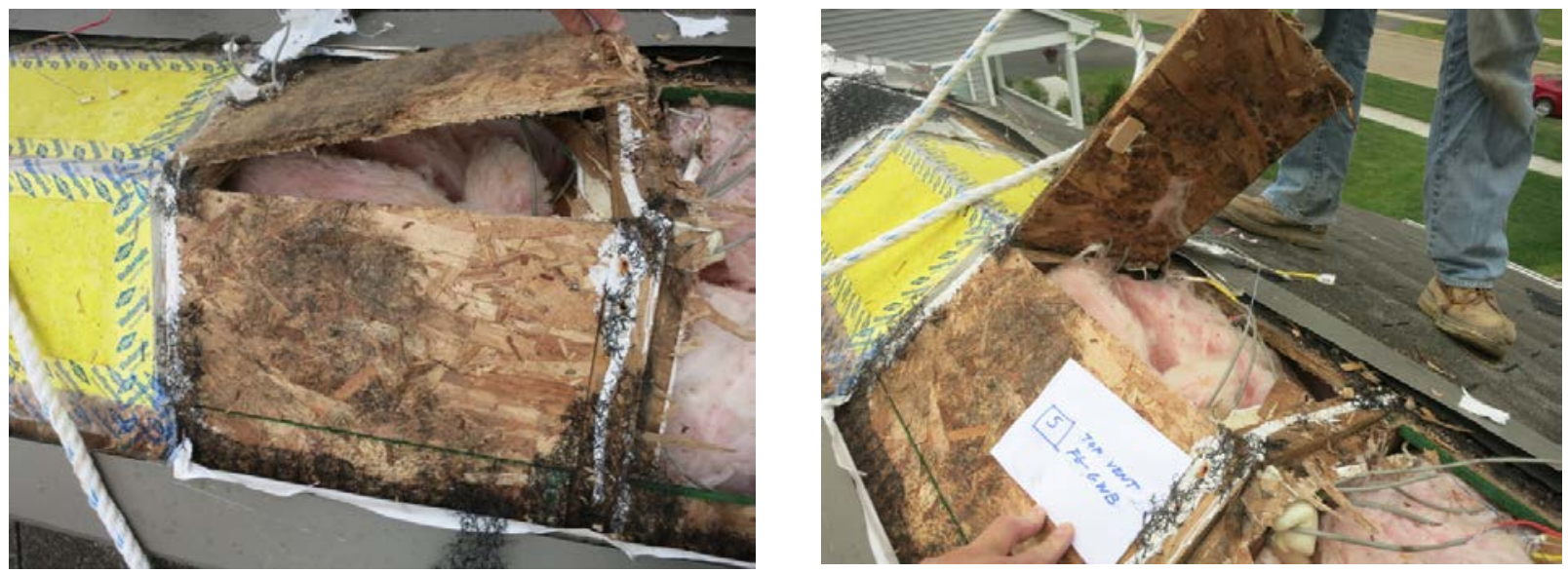

Figure 74. Ridge sheathing conditions, Roof 5
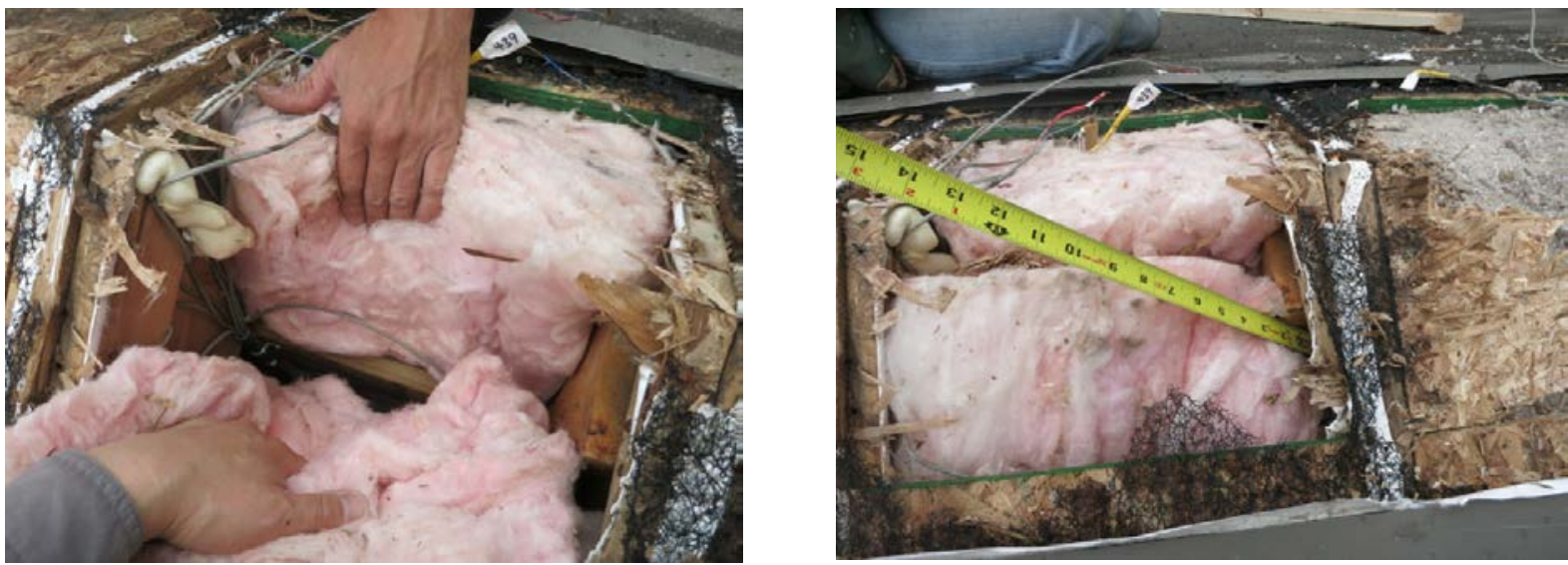

Figure 75. Fiberglass batt conditions at ridge, Roof 4 

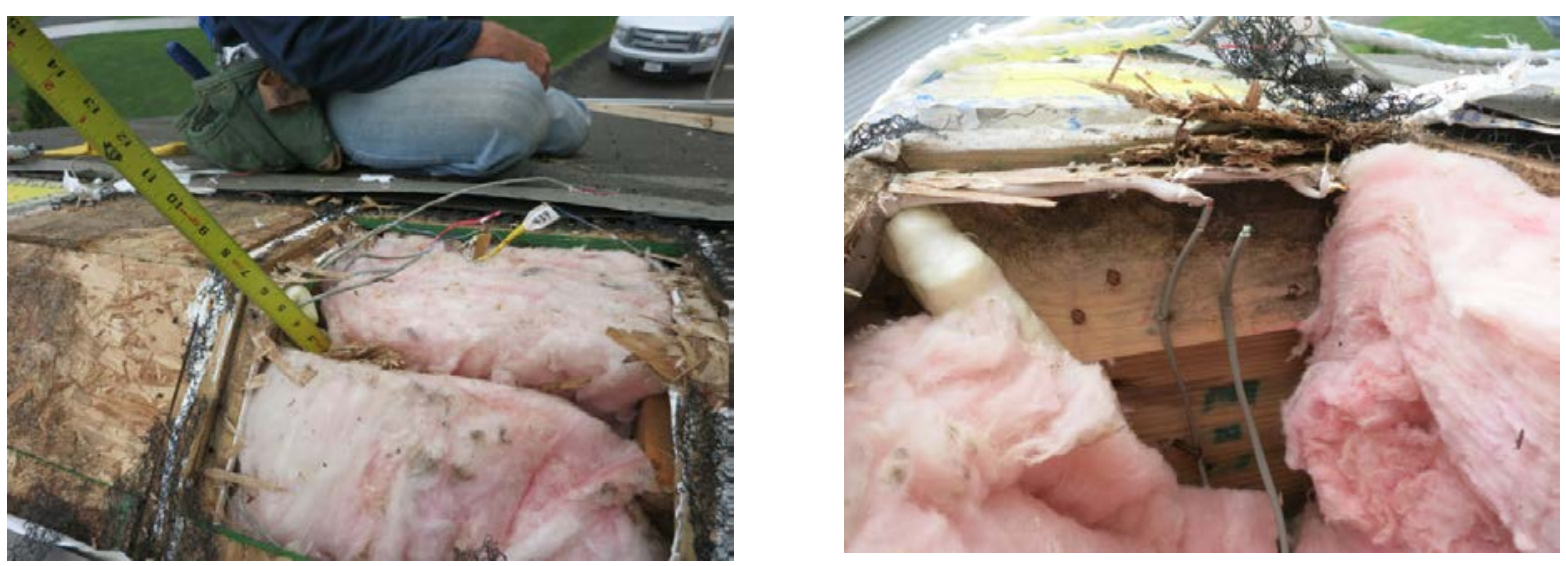

Figure 76. Fiberglass batt and framing conditions at ridge, Roof 4 (left); Roof 5 (right)

The GWB sheathing at the diffusion vent roof (6) had no evidence of damage from the exterior. When disassembled, the GWB sheathing appeared to be basically intact and showed no evidence of staining or mold growth (Figure 77).
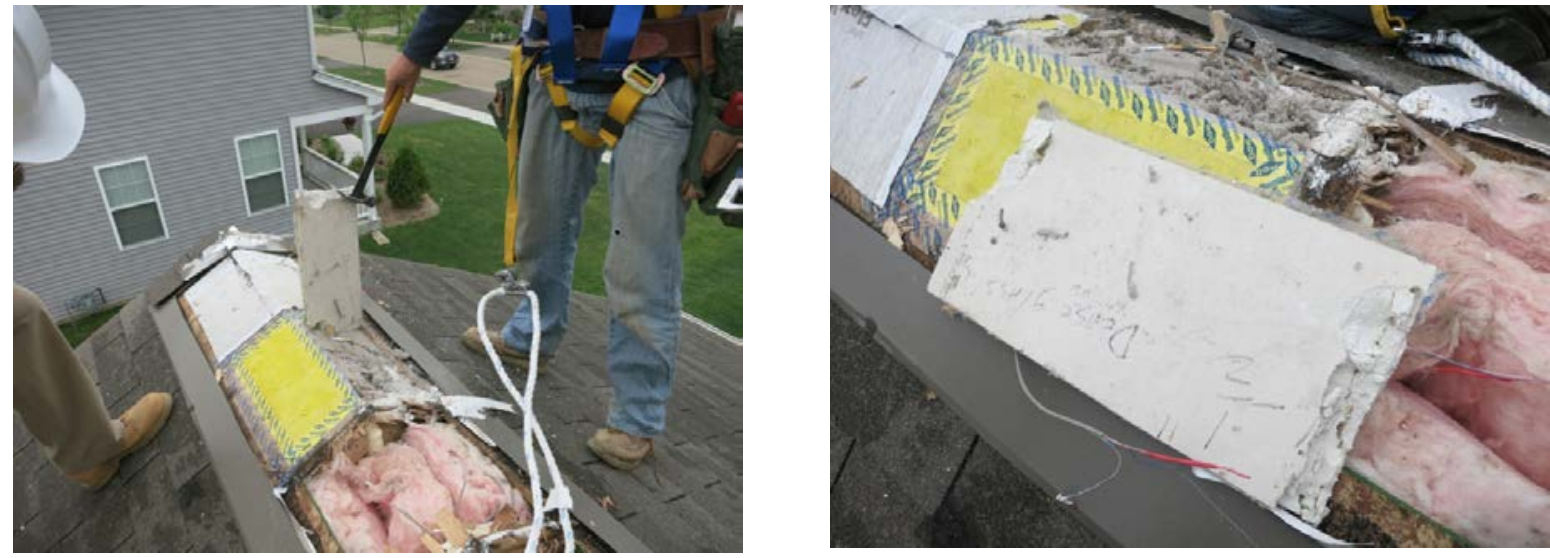

Figure 77. Ridge sheathing top and bottom conditions, Roof 6

The unvented cellulose assembly (7) showed no damage from the exterior after the self-adhered membrane was removed (remnants are visible in Figure 78, left). When the sheathing was removed, only minor evidence of moisture issues (OSB grain raise, rusted staples, and cellulose caking) were seen; no mold growth was visible. The cellulose insulation did not settle during the winter; it still filled the cavity to the ridge. 

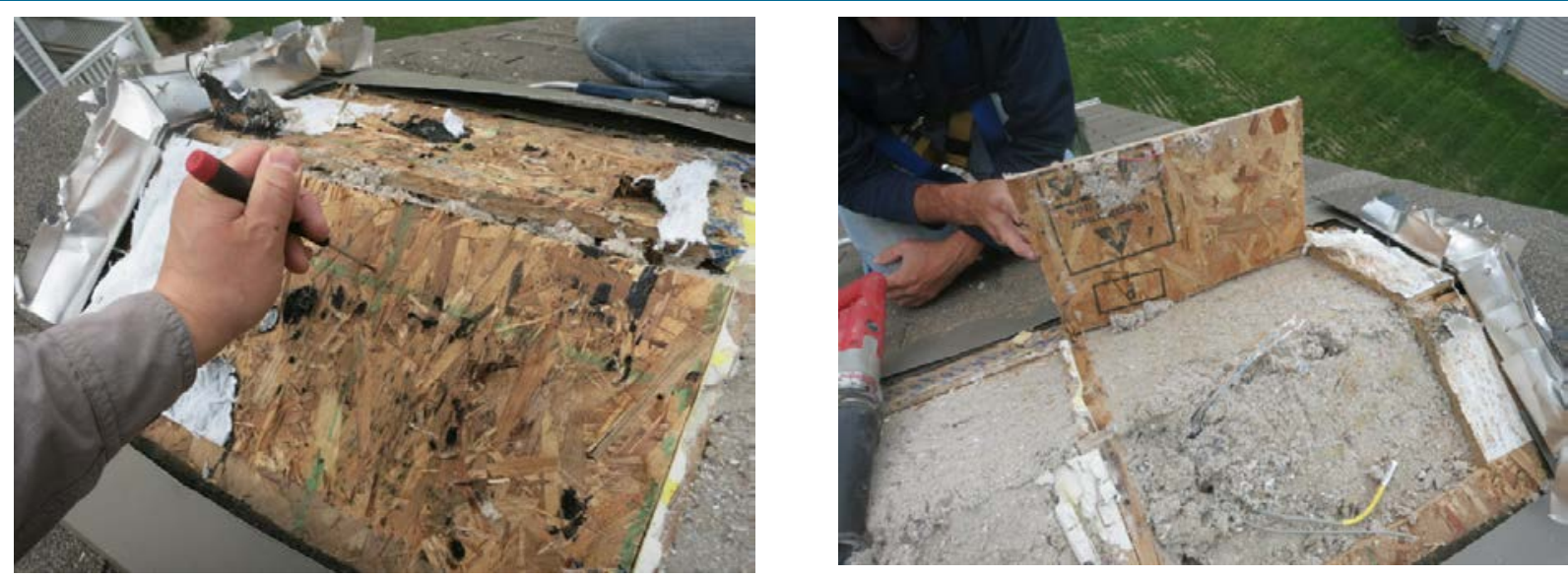

Figure 78. Ridge sheathing top and bottom; cellulose conditions, Roof 7

\subsection{Conditions away from Ridge}

After the ridge was disassembled, the roof cladding materials were stripped near the ridge; the front (west) face is shown in Figure 79. All the top vent roofs show some exterior staining, but it is more severe at the fiberglass batt roofs.

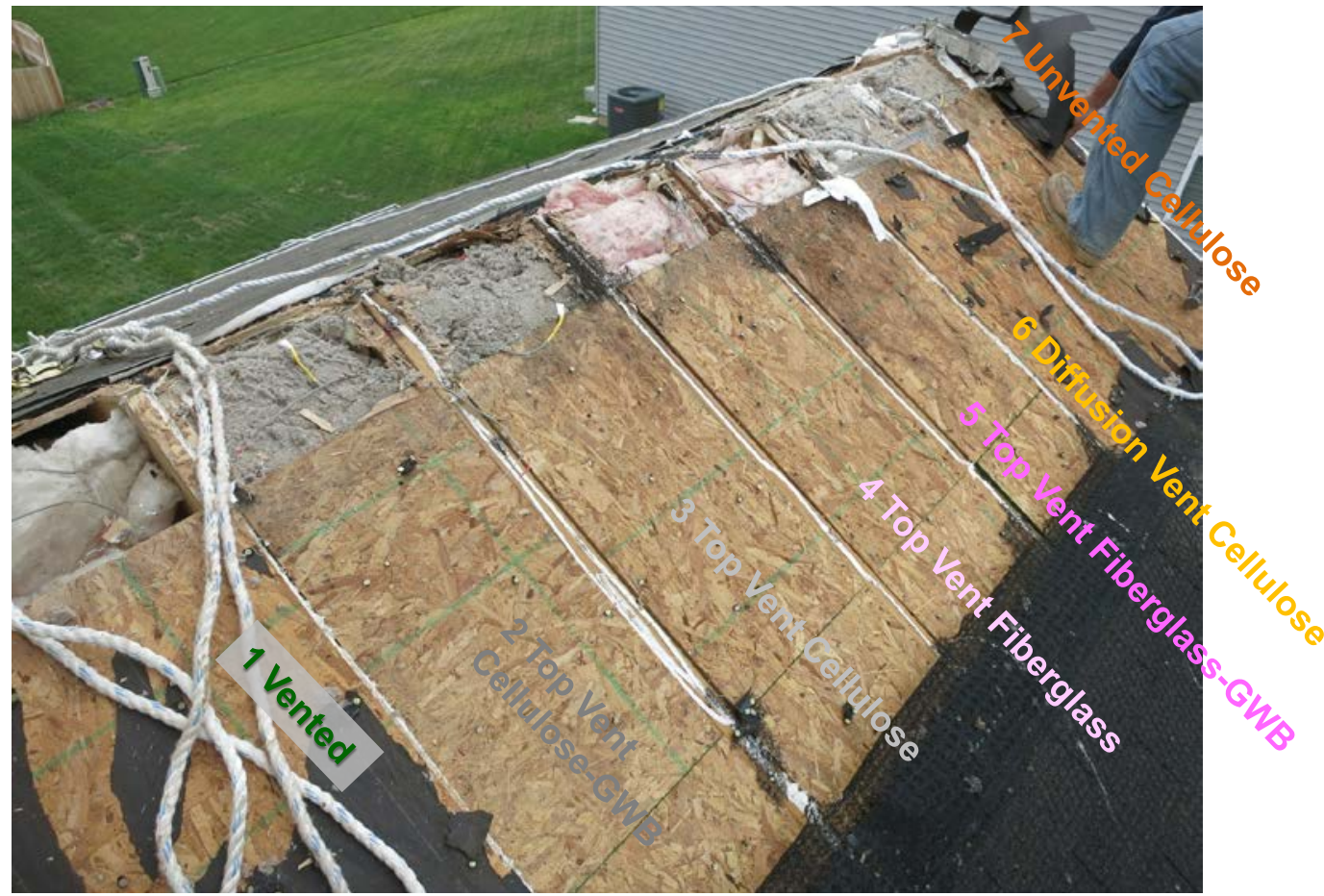

Figure 79. Sheathing away from ridge, west (front) face of roof

The same condition on the east (rear)-facing roof is shown in Figure 80, which showed similar patterns (worse conditions at fiberglass batt roofs). 


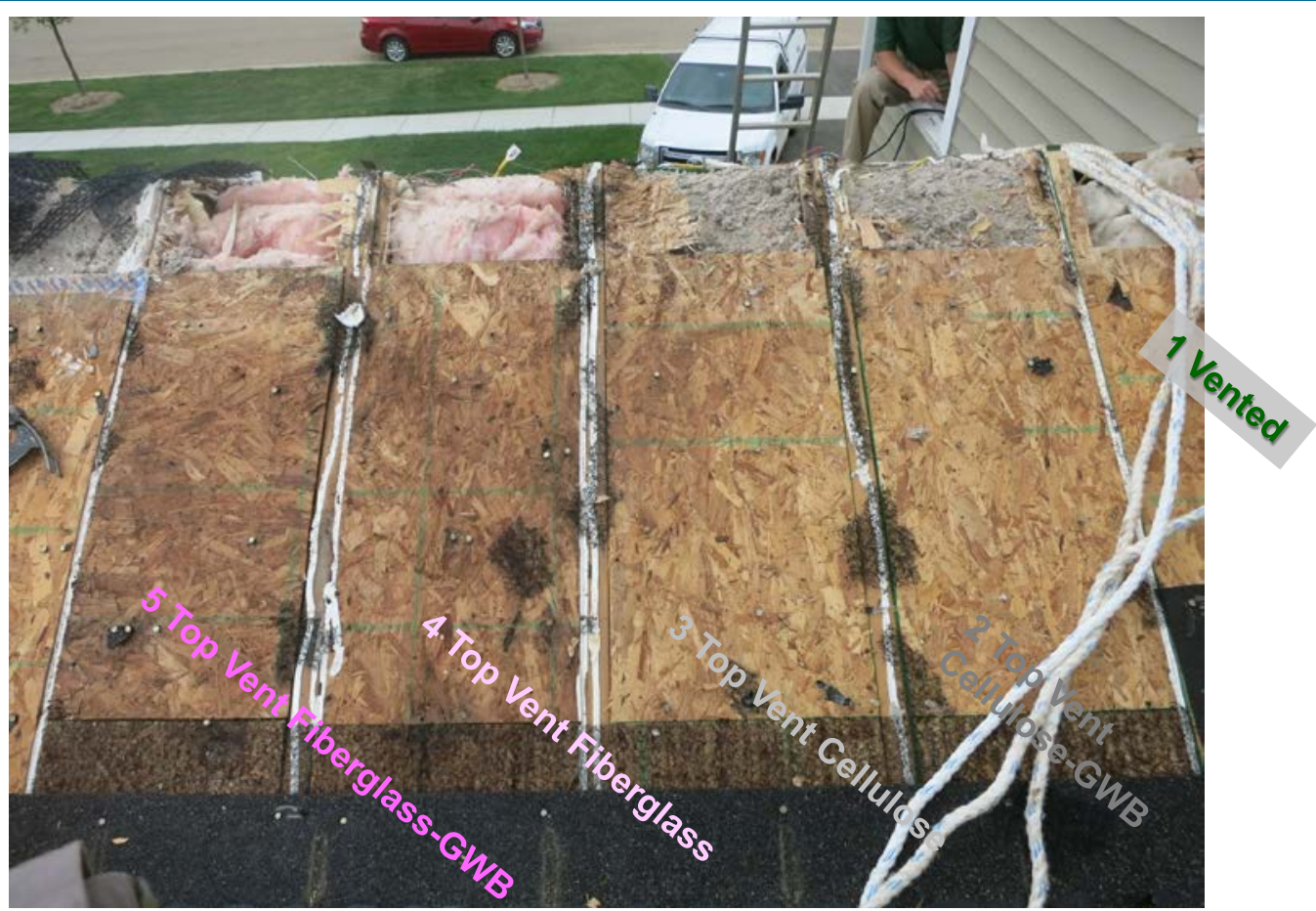

Figure 80. Sheathing away from ridge, east (rear) face of the roof

At the top vent cellulose roofs (4 and 5) and dense-pack cellulose roofs (6 and 7), the sheathing was largely intact. Minor damage was seen of grain raise, caking, and fastener corrosion (Figure 81).
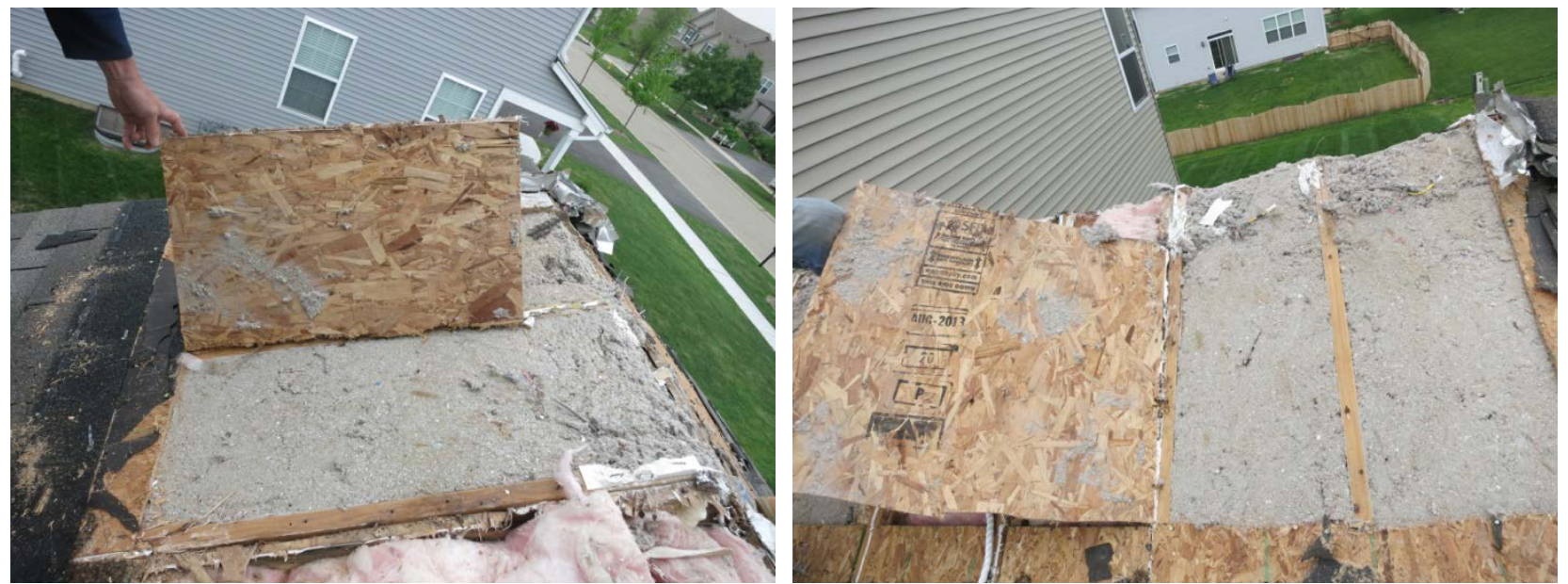

Figure 81. Sheathing away from ridge, Roofs 4 and 5 (left); Roofs 6 and 7 (right)

Similar to the ridge, the fiberglass batt roofs showed worse conditions than the cellulose bays away from the ridge (Figure 82). The sheathing condition at Roof 4 (top vent fiberglass, no GWB) was worse than Roof 5 (top vent fiberglass with GWB). 

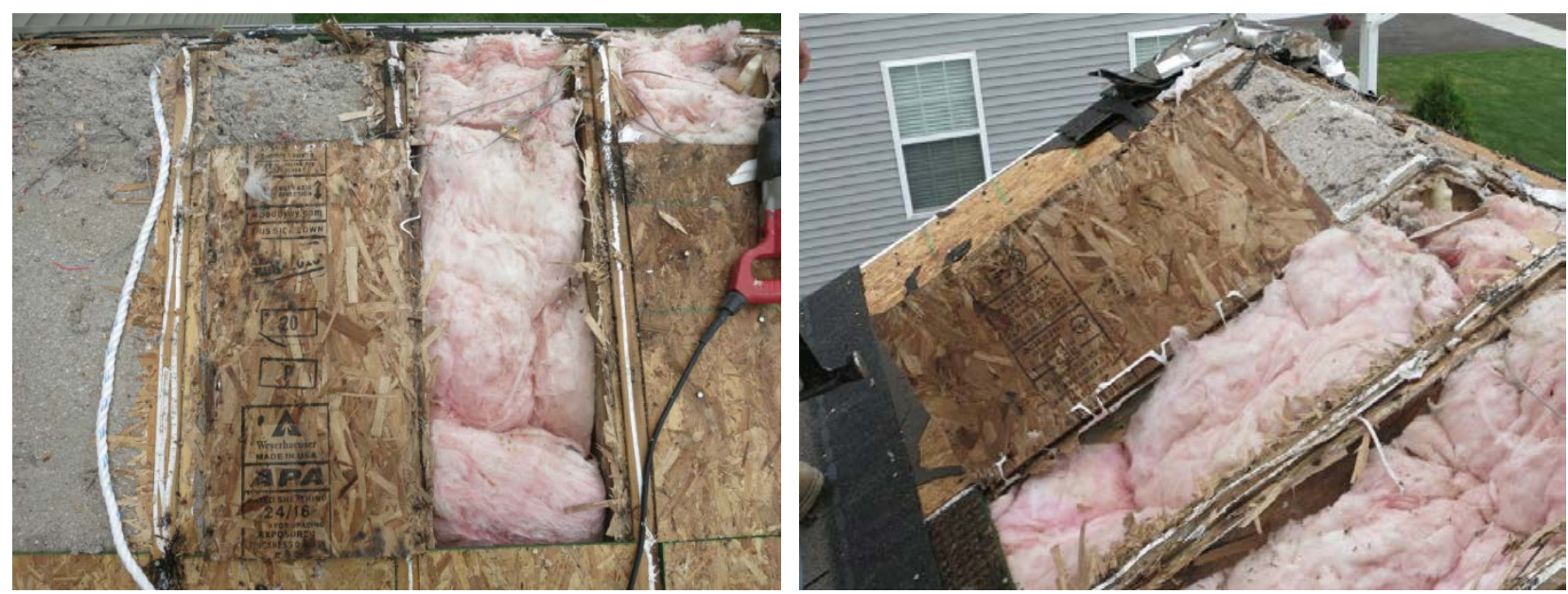

Figure 82. Sheathing away from ridge, Roof 4 (left); Roof 5 (right)

\subsection{Interior Disassembly}

The interior GWB was removed to reveal drip patterns in the fiberglass batt bays (condensation rundown) and further signs of mold on the roof framing (Figure 83).
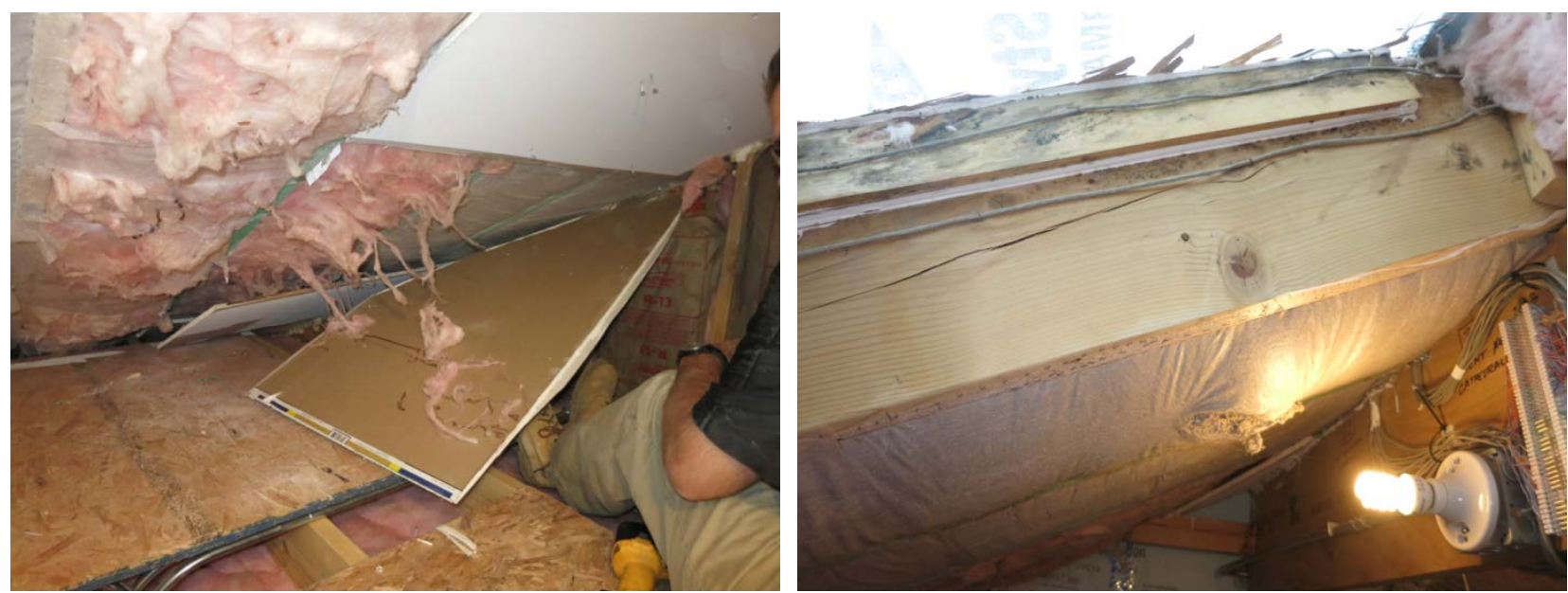

Figure 83. Staining of the ceiling GWB (left); mold on the framing (right), Roof 5 


\section{Cold Climate (Chicago) Analysis}

\subsection{ASHRAE 160 Analysis}

ASHRAE Standard 160 (ASHRAE 2009b) provides guidance on moisture analysis for building envelope design, including the moisture performance evaluation criteria in terms of mold growth risk. The failure criteria were refined in addendum (a) (ASHRAE 2011), giving the requirement of a "30-day running average surface $\mathrm{RH}$ over $80 \%$ when the 30-day running average surface temperature is between $5^{\circ} \mathrm{C}\left(41^{\circ} \mathrm{F}\right)$ and $40^{\circ} \mathrm{C}\left(104^{\circ} \mathrm{F}\right)$." Other practitioners (Arena et al. 2013; Arena 2014) have found ASHRAE 160 criteria to be excessively stringent and conservative.

The measured T/RH conditions at the roof ridge were analyzed using ASHRAE 160 criteria. Thirty-day running averages were calculated for each hour and the resulting pass/fail results tabulated. In a strict interpretation of Standard 160, a single failing hour would constitute an assembly failure.

ASHRAE 160 is not being used as a design tool (per its intent) in this exercise; instead, the monitored data can be compared with the conditions of the roof assembly after one winter based on the disassembly.

The graphs below show hours when the test assemblies failed ASHRAE 160 criteria (using point markers); exterior temperature and the 30-day average temperature at the roof ridge cavity are added for reference. The vented (1), unvented (7), and diffusion vent (6) roofs are shown in Figure 84 and the top vent roofs $(2,3,4$, and 5$)$ in Figure 85.

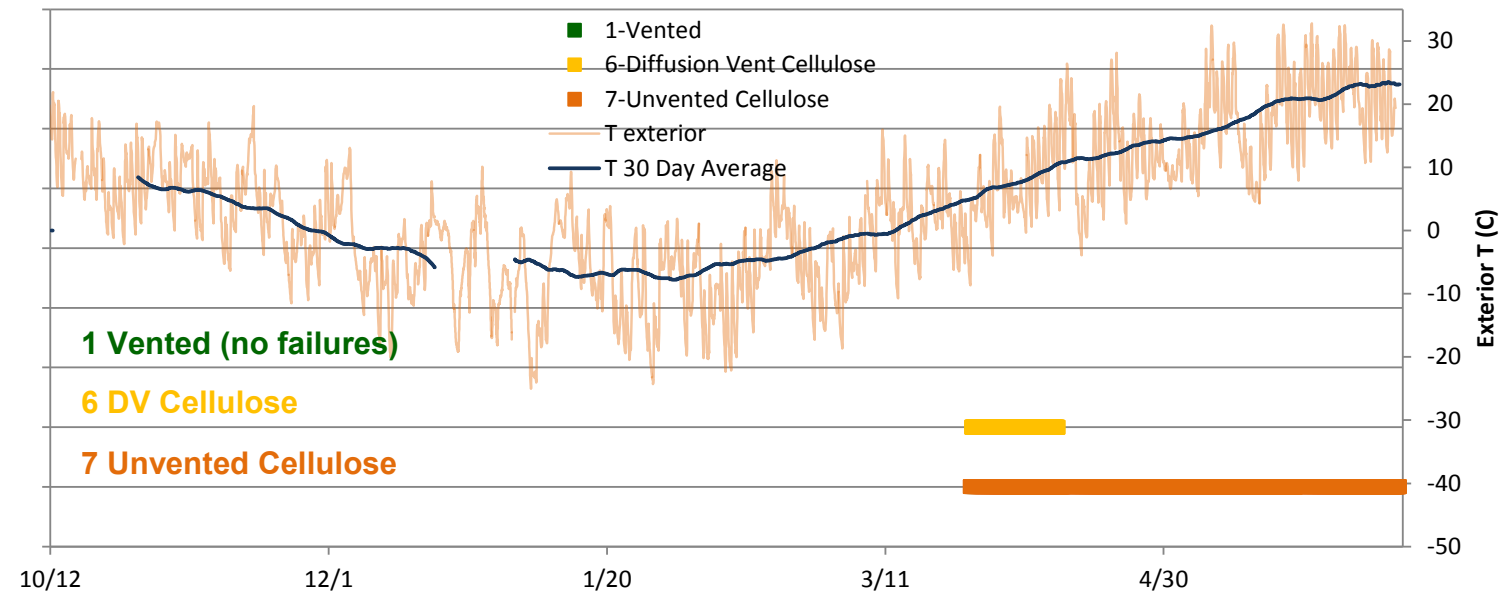

Figure 84. ASHRAE 160 failures, vented (Roof 1), diffusion vent (Roof 6), and unvented (Roof 7) 


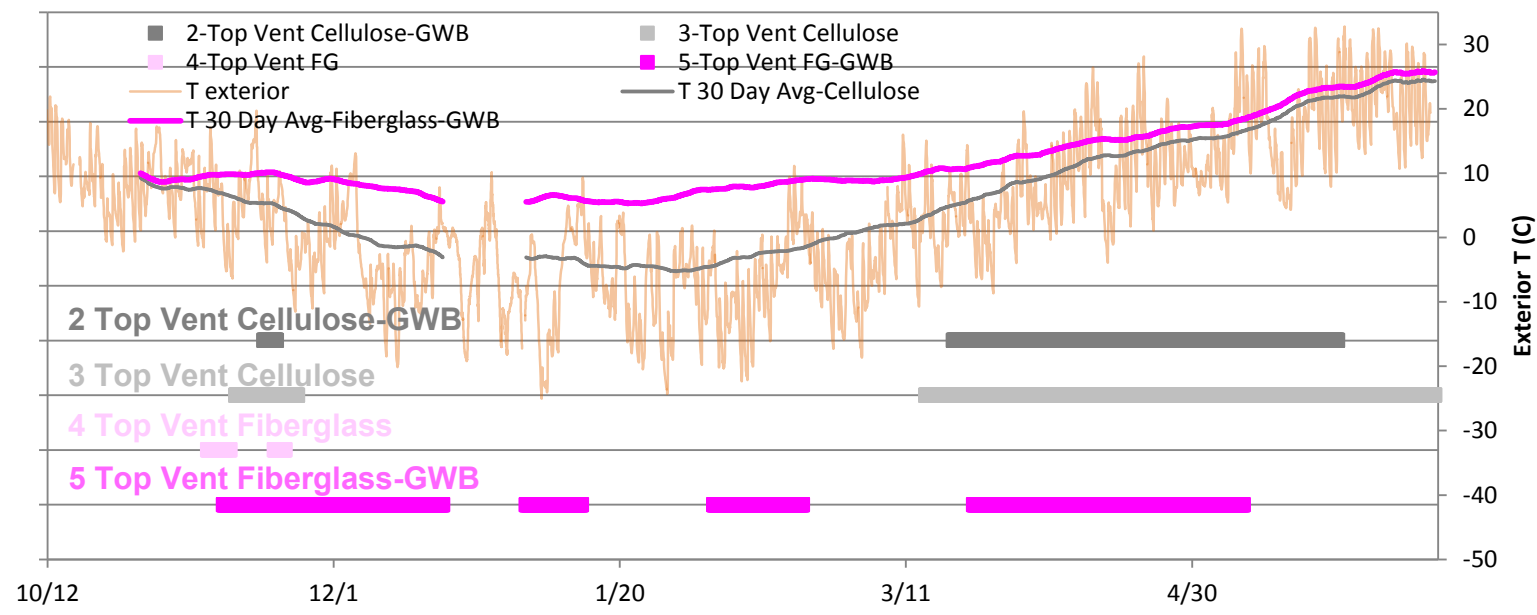

Figure 85. ASHRAE 160 failures: top vent cellulose (Roofs 2 and 3) and fiberglass (Roofs 4 and 5)

The vented (1) roof had no hours failing ASHRAE 160 during the test winter. The unvented (7) and diffusion vent (6) roofs had RH levels that exceeded $80 \%$ in the fall and early winter, but by that time temperatures had fallen below the risk range $\left(5^{\circ} \mathrm{C}\left[41^{\circ} \mathrm{F}\right]\right)$. But in the spring, as the assemblies warmed, Roofs 6 and 7 had many failing hours. The diffusion vent roof (6) dried rapidly and reached safe conditions (lower than $80 \% \mathrm{RH}$ ) by mid-April. However, the unvented assembly (7) remained wet and stayed higher than $80 \% \mathrm{RH}$ through the end of the monitoring period.

The top vent roofs $(2,3,4$, and 5) all showed periods failing ASHRAE 160 criteria in the fall, before temperatures fell below the risk range. Again, as temperatures warmed, the assemblies returned to ASHRAE 160 failure conditions. However, the top vent fiberglass roof without GWB (4) remained below $80 \%$ RH. This assembly had RHs and MCs with wide swings and dry conditions, apparently reflecting air leakage through the assembly.

The 30-day running average temperature at the ridge was calculated for the assemblies; the various assemblies differed substantially (top vent cellulose with GWB/Roof 2 and top vent fiberglass with GWB/Roof 5 plotted above). This is covered in more detail in the Section 6.2.

A tabulation of the hours failing ASHRAE 160 criteria is provided in Table 7.

Table 7. Number of Hours Roof Ridge T/RH Failing ASHRAE 160 Criteria

\begin{tabular}{c|c|c|c}
\hline $\mathbf{\#}$ & Assembly & $\begin{array}{c}\text { \# Hours Failing } \\
\text { ASHRAE 160 }\end{array}$ & $\begin{array}{c}\text { \% of Hours Failing } \\
\text { ASHRAE 160 }\end{array}$ \\
\hline $\mathbf{1}$ & Vented & 0 & $0 \%$ \\
\hline $\mathbf{2}$ & Top vent cellulose-GWB & 1,667 & $29 \%$ \\
\hline $\mathbf{3}$ & Top vent cellulose & 2,396 & $41 \%$ \\
\hline $\mathbf{4}$ & Top vent fiberglass & 129 & $2 \%$ \\
\hline $\mathbf{5}$ & Top vent fiberglass-GWB & 2,659 & $46 \%$ \\
\hline $\mathbf{6}$ & Diffusion vent cellulose & 374 & $6 \%$ \\
\hline $\mathbf{7}$ & Unvented cellulose & 1,852 & $32 \%$ \\
\hline
\end{tabular}




\subsection{Ridge Average Temperature}

Section 6.1 discussed that when the 30-day running averages temperatures at the roof ridge were calculated, noticeable differences were seen between assemblies, even though they had similar nominal R-values (all were R-38 except the R-30 vented roof/Roof 1 ). The 30 -day averages are plotted with outdoor temperatures in Figure 86.

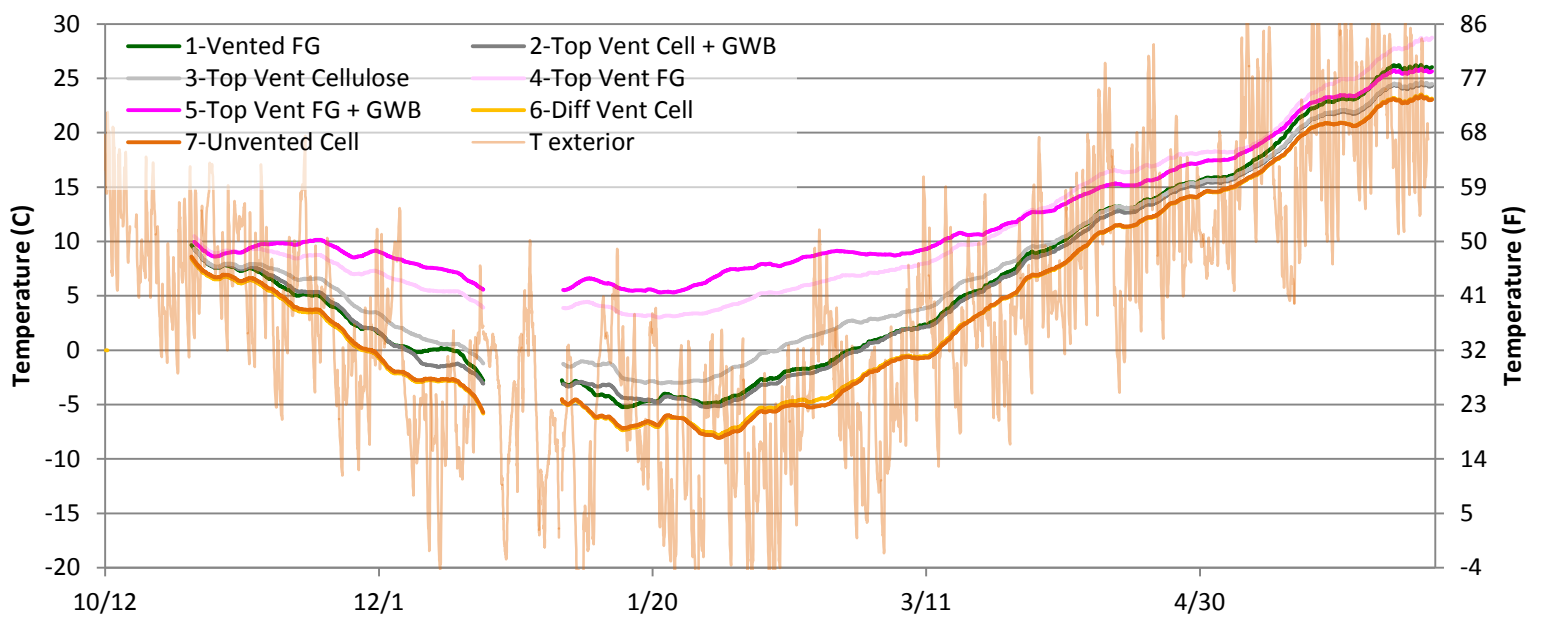

Figure 86. 30-day running average temperatures at the ridge (T/RH sensors) for all roofs

Temperatures were close during milder weather and separated as the winter grew colder. The unvented (7) and diffusion vent (6) assemblies had essentially identical behavior; the top vent cellulose (2 and 3) and vented (1) assemblies had slightly warmer but also similar temperatures. The two top vent fiberglass roofs (4 and 5) had much warmer temperatures at the roof ridge.

These differences may be due to airflow (interior-to-exterior air leakage transporting interior heat to the ridge), which is consistent with other measurements and site observations (moisture damage on the top sides of the fiberglass roofs and $\Delta \mathrm{P}$ measurements).

\subsection{Sheathing Temperatures and Ventilation Space Behavior}

Examination of dew point temperatures in the ventilation spaces (in the top vent roofs) gave inconclusive results (see Section 4.4). The difference in dew point might reflect moisture removal or simply moisture accumulation. Another way of gauging whether ventilation is effective through the top vent mesh is to examine the sheathing temperatures. Ventilation air movement up the roof might carry some heat with it, which might cool the lower roof surfaces or the entire roof surface relative to the analogous unvented roof.

Detailed graphs are provided in Appendix C; however, the temperature measurements show little indication that the top vent detail had an effect on sheathing temperatures. The fully ventilated cathedral roof had cooler summer sheathing temperatures, consistent with airflow.

\subsection{Conclusions for Cold Climate (Chicago) Test Roof}

The conclusions that can be drawn from this work by combining the monitored data, the disassembly of the assemblies, and further analysis are discussed in Section 6.4.1 and Section 6.4.2. 


\subsubsection{Boundary Conditions (Interior Humidification)}

One potential criticism of this work is that $50 \%$ interior RH in a CZ 5A climate is a severe loading. It definitely exceeds commonly observed interior RH levels; for instance, Arena et al. (2010) measured winter monthly average RHs of 36\%-38\% in a survey of CZ 5A (Massachusetts and Connecticut) newly constructed houses.

However, greater airtightness in energy-efficient housing increases the risk of high interior RHs, especially when controlled mechanical ventilation is not installed or operated. For instance, Ueno and Lstiburek (2015) measured RHs at 40\%-50\% for much of the winter in a house with low air leakage (less than $1 \mathrm{ACH} 50$ ) and an inoperable ventilation system in CZ 5A.

More importantly, the 50\% RH loading was used to accelerate moisture-related failures of the assemblies; this is a commonly used technique (Rose and McCaa 1998; Wilkinson et al. 2007; Straube et al. 2009; Smegal and Straube 2014). An ideal experiment would have first run these roof assemblies under typical interior $\mathrm{RH}$ conditions (e.g., $30 \% \mathrm{RH})$ for one winter, then during a second winter at the extreme loading $(50 \% \mathrm{RH})$. However, the roof was available for only one winter of monitoring, which eliminated that option.

\subsubsection{Overview of Assemblies}

The test roof assemblies are discussed below in an order that provides some logical flow between their relative performances.

Some patterns were seen consistently across the assemblies. When moisture accumulation and/or damage occurred, it was concentrated and most intense at the roof ridge, consistent with previous field observations. Moisture accumulation within the assembly was essentially driven by interior $\mathrm{RH}$ and exterior temperature; periods when the humidification system failed had less accumulation or even moisture removal.

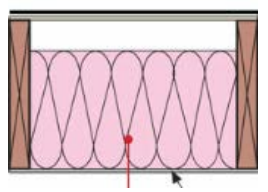

1 Vented

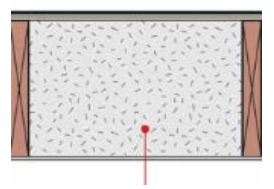

7 Unvented Cellulose
The control roof, or compact vented roof assembly (Roof 1) showed excellent performance, with low wood MCs, RHs well within the safe range, and no sign of damage during disassembly. This is especially impressive given the high interior $\mathrm{RH}$ conditions $\left(50 \% \mathrm{RH}\right.$ at $\left.22^{\circ} \mathrm{C}\left[71^{\circ} \mathrm{F}\right]\right)$. That said, the roof ventilation in this assembly was likely better than achieved in the field. The airspace cavity above the insulation was a full 4 in. (substantially larger than the code-mandated $1 \mathrm{in}$.), and the ridge ventilation opening had very low restriction, a large opening (see Figure 69), and no restriction from ridge mesh or netting.

The unvented cellulose roof (Roof 7), dense-pack cellulose roof, showed long-term accumulation of moisture, especially at the ridge, as indicated by high sheathing MCs, high RH, and wafer sensor measurements that indicated condensation or liquid water. The assembly also showed a long-term failure of ASHRAE 160 criteria (from mid-April through the end of monitoring in June). But although definite signs of moisture accumulation were visible when the roof was disassembled, the damage was by no means severe. No visible mold growth was found on the underside (interior) of the roof sheathing; damage was restricted to grain raise/thickness, swelling of OSB 


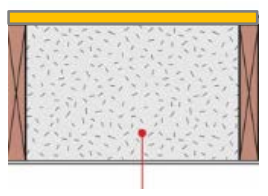

6| Diffusion Vent Cellulose
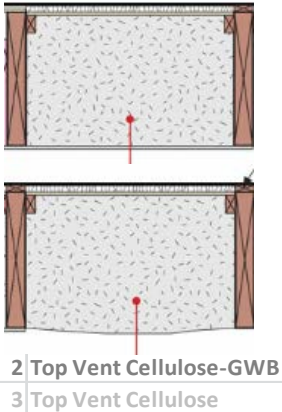

3 Top Vent Cellulose
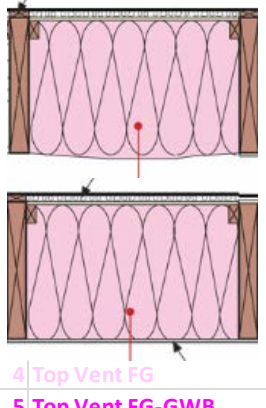

5 Top Vent FG-GWB flakes, corrosion of fasteners (structural nails and wiring staples), and caking of the cellulose insulation. No settling was seen in the cellulose insulation. However, this disassembly was conducted after only a single winter; annual cycles of wetting to this level are likely to have worse effects on durability.

The diffusion vent roof (Roof 6) had similar performance to Roof 7 with high moisture conditions during the winter (including liquid water condensation), especially at the ridge. However, all measurements (sheathing $\mathrm{MC}$, ridge $\mathrm{RH}$, wafer sensor) showed that this assembly dried much more rapidly during warmer spring weather than Roof 7 due to the outward drying available through the fiberglass-faced GWB at the ridge. Therefore, this assembly had a considerably shorter period that failed ASHRAE 160 criteria. Disassembly showed no evidence of mold growth on the GWB at the ridge or on the OSB further from the ridge. Similar to Roof 1, this roof did not show massive material failures, but it had moisture levels much higher than recommended for durability.

The top vent roofs insulated with cellulose (roofs 2 and 3 ) behaved similarly to roofs 6 and 7, but with some small differences. Overall, similar high MCs were seen. The sheathing MC measurements gave no consistent indication of greater drying due to ventilation through the breather mesh/airspace. Roof 2 and 3 MCs largely overlapped Roof 6 and 7 results. These two roofs also had hours failing ASHRAE 160 in the early winter, late winter, and spring. The extent of failures into the spring was closer to the unvented (Roof 7) assembly than the diffusion vent (Roof 6) assembly.

The underside of the ridge roof sheathing showed similar conditions to roofs 6 and 7. Suspected mold damage was seen on the top surface of the ridge sheathing at Roof 3. However, it was ascribed to cross-contamination air leakage from the adjacent fiberglass batt roof (Roof 4). This was based on the facts that (1) no other cellulose roofs showed this type of damage, and (2) the pattern was seen only on the side of the rafter bay adjacent to the fiberglass rafter bay.

The top vent roofs insulated with fiberglass batt (roofs 4 and 5) had similar moisture levels to roofs 2 and 3, with some exceptions. Roof 4 (fiberglass, no GWB) had roof sheathing MCs that remained very high for much of the winter (liquid water/condensing conditions), at lower, middle, and upper locations. Roof 5, on the other hand, showed more stratification.

Some measurements (roof peak RH and wafer sensor) of Roof 4 showed anomalies (rapid variations between low and high RH or much lower RH than expected), which were ascribed to air leakage issues. Air leakage from Roof 4 is consistent with the doghouse sheathing MC data.

During disassembly, the sheathing conditions were much worse than the cellulose roofs, even though measured moisture levels were often comparable. 
The interior side of the sheathing showed extensive wetting, staining, and mold growth. However, although extensive damage had occurred, the OSB sheathing was still structurally sound. Sufficient water accumulated at the sheathing to wet the fiberglass batt and drain or run down to the WGB.

\subsubsection{Cellulose versus Fiberglass Performance}

The top vent roofs gave a comparison of cavity insulations: dense-pack cellulose versus fiberglass batt. An ideal comparison would have compared dense-pack cellulose with blown-in fiberglass to eliminate the installation variable. The batt installation was imperfect; air leakage paths and voids allowed air to bypass the insulation and cause more serious damage.

In general, the moisture measurements were comparable, or in some cases the instrumentation in the fiberglass bays showed lower moisture levels. However, disassembly revealed that the roof sheathing and framing in the fiberglass batt roofs suffered much more moisture-related damage, including staining, mold, and mold growth, relative to the cellulose roofs (Figure 87).
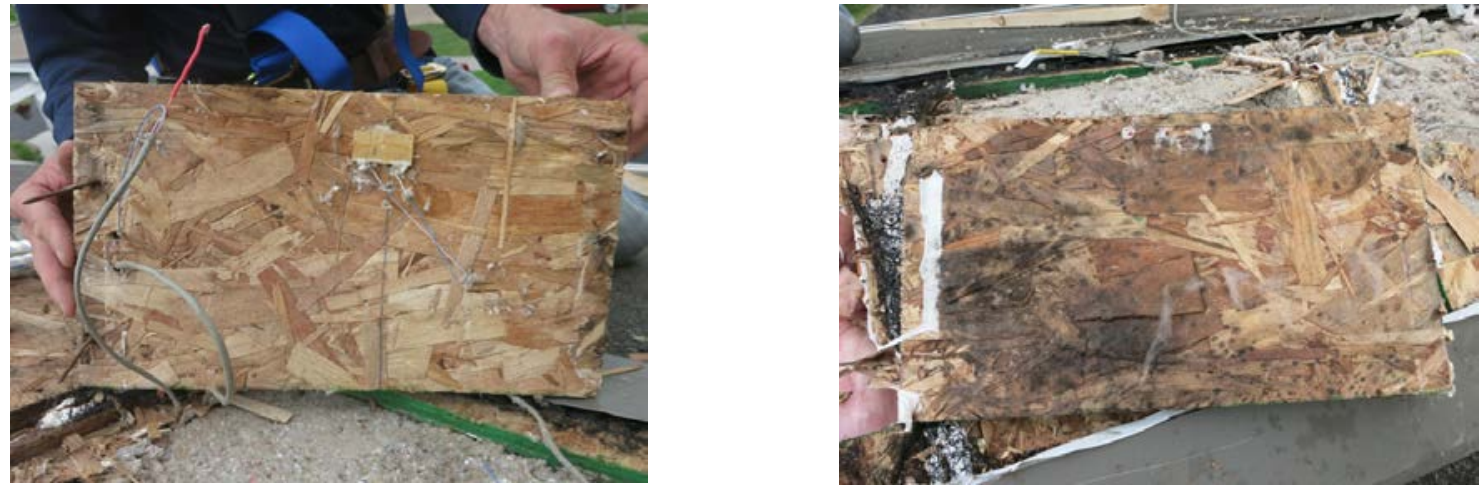

Figure 87. Top vent roofs, no interior GWB, east/front face; cellulose (left); fiberglass (right)

ASHRAE 160 analysis indicates that both the cellulose and fiberglass top vent roofs have many hours that exceed failure conditions, but the resulting sheathing and framing conditions show a stark difference.

The dense-pack cellulose insulation protects the adjacent materials in the assembly; the mechanisms likely include the following:

- Dense-packed cellulose, if properly installed, has sufficient resistance that it significantly reduces airflow through assemblies (Lstiburek 2010b; Schumacher 2011). This is particularly noticeable if other parts of the assembly have air barrier failures. Reducing airflow decreases wintertime wetting by interior-sourced humidity.

- Cellulose fiber insulation contains borates, which act both as a fire retardant and preservative/antifungal agent. Previous field observations have provided evidence that these preservatives can migrate into adjacent materials (e.g., sheathing or GWB), which provides some protection.

- Cellulose insulation can absorb and adsorb moisture safely; this has a moisture storage/buffering effect in an assembly. 
Rose and McCaa (1998) observed this type of protective effect in a 3-year in-situ monitoring study of 14 wood-frame walls in CZ 5A (Champaign, Illinois). Three walls were configured with only Class III vapor control (latex paint on GBW); cavity fill insulation materials were fiberglass batt, blown-in fiberglass, and cellulose (which was dry-blown behind netting). Interior RH was run at either $50 \%-55 \% \mathrm{RH}$ or $40 \% \mathrm{RH}$ (over multiple winters). When these three walls were disassembled, the fiberglass batt had severe mold growth; blown-in fiberglass had medium mold growth, and cellulose had mild mold growth. However, the metal fasteners were corroded because of reactions with the ammonium sulfate cellulose preservative.

\subsubsection{Top Vent Assemblies}

Schumacher and LePage (2012) discussed the concept behind top ventilated insulated roof deck assemblies; the design intent is that interior-sourced moisture will diffuse through the roof sheathing into the ventilated airspace that is provided by the spacer/breather mesh and be removed from the assembly.

The results indicated no significant drying or durability benefit for the top vent cellulose roofs ( 2 and 3) compared with the unvented roof (7). One reason these roofs had disappointing performance was the permeance of the sheathing. The moisture vapor permeance of OSB and plywood sheathing as a function of RH is shown in Figure 88. At higher moisture levels, such as the wet wintertime conditions seen in the test assemblies, plywood is much more vapor permeable (20-35 perms) than OSB (5-8 perms).

OSB sheathing was chosen for the experiment because it is the commodity material used by production builders. Keeping the sheathing material constant across all roof bays eliminated an experimental variable, simplifying analysis. If this experiment had demonstrated adequate performance with OSB, plywood would clearly also perform well. If additional research work is conducted on top vent roofs, a more permeable sheathing material than OSB is recommended.

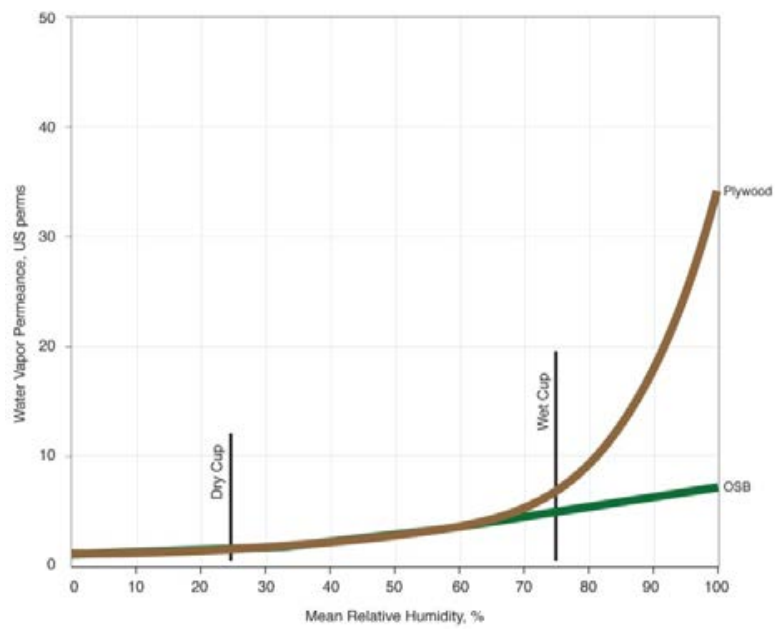

Figure 88. Vapor permeance of plywood and OSB sheathing as a function of RH

Another possible issue is that airflow through the ventilation space was likely restricted. Air had to flow through the $1 / 2$-in.-thick space created by the spacer mesh and through the openings cut into the house wrap cap at the ridge. A reduction in airflow would cause a commensurate reduction in available drying. 
Overall, this research demonstrated that a top vent system is not viable in CZ 5A with OSB sheathing and a relatively small airspace. If further research is considered on this topic, changing variables such as sheathing materials and airspace size should be considered.

\subsubsection{Air Leakage (Fiberglass Roofs)}

The monitored data and roof conditions during disassembly all indicate air leakage at the two fiberglass top vent roofs (4 and 5). The 30-day average temperature data indicated that the two fiberglass roofs were outliers and ran much warmer than the remaining roofs.

This leakage was due to insufficient air sealing at the dropped sheathing detail that was added to keep the asphalt shingles in a flat plane. Despite careful installation of the fiberglass batts, a blind installation from below resulted in air gaps between the batts and framing, which resulted in air leakage pathways. The worst leakage was seen in Roof 4 (top vent fiberglass, no GWB), based on the doghouse $\mathrm{MC}$ measurements. This issue was not found during air leakage $\Delta \mathrm{P}$ measurements given the lack of GWB on the interior. A pre- and post-GWB leakage test would have been ideal; however, it was not feasible in this experiment given that the vented assembly (Roof 1) has rafter bays that are directly connected to outdoors.

\subsubsection{Interior Vapor Control}

One potential criticism of this research is that insufficient interior vapor control was used: the GWB was finished with a single coat of latex paint, which is likely more permeable than a Class III (10 perm to 1 perm) vapor retarder. Additional air leakage and vapor control should nominally reduce wetting from the interior.

Although vapor retarders can reduce sheathing wetting, vapor control alone is by no means a recommended approach for unvented roof assemblies in cold climates. Unless the vapor barrier is detailed perfectly as an air barrier, incidental leakage of interior air will cause wetting of the assembly. An interior vapor barrier such as polyethylene (Class I, 0.06 perm) would completely eliminate drying to the interior. This combination results in an assembly that performs well in theory (and in one-dimensional simulations) but is not at all robust in real-world conditions.

This was demonstrated, for example, in a pool building investigated in CZ 3A (Wilmington, North Carolina; Figure 89). An interior polyethylene vapor barrier was installed, but connections were not made at the roof truss purlins. This roof failed because air leaked from the pool. This resulted in liquid water condensation at the ridge, which drained, ran out of the roof, and created visible interior staining.
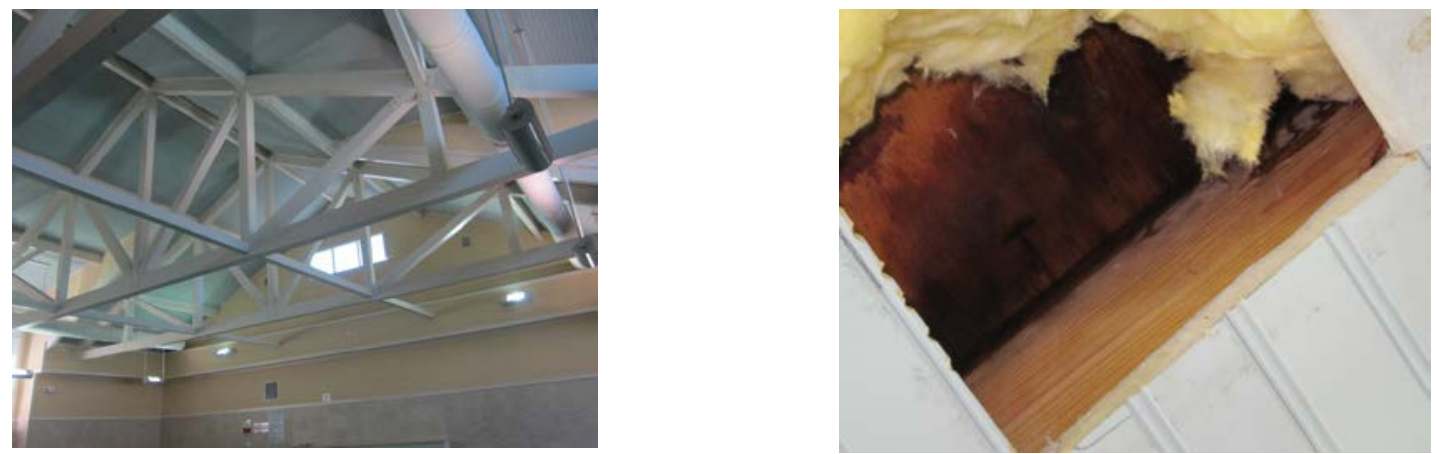

Figure 89. Ridge condensation issues; CZ 3A pool with interior polyethylene vapor barrier 


\section{Hot-Humid Climate (Houston) Experimental Setup}

\subsection{Overview}

The hot-humid test home is in Friendswood, Texas, roughly 30 miles southeast of Houston (CZ 2A). This two-story, $4,028 \mathrm{ft}^{2}$, slab-on-grade house was provided by David Weekley Homes. It is a model house that was unoccupied during the testing period; overview images are shown in Figure 90 and Figure 91. The front of the house faces north; the house is on a corner lot; streets border the north and east sides.
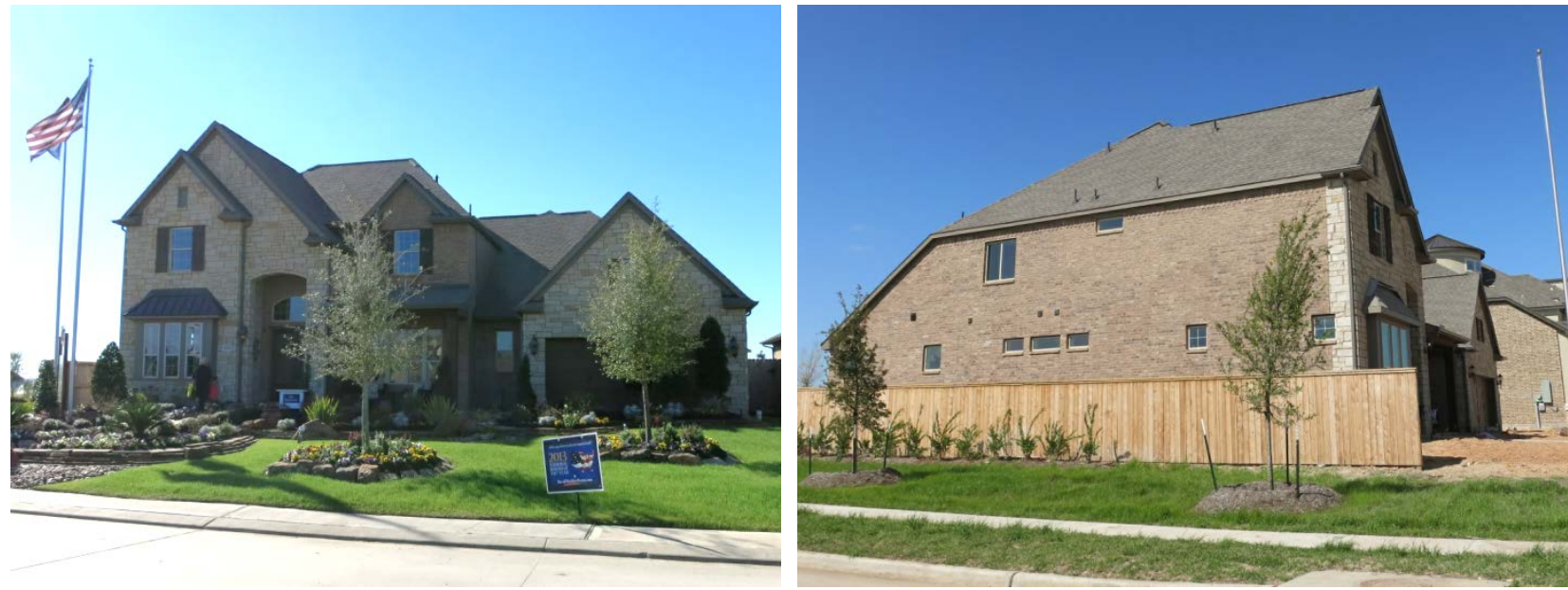

Figure 90. Front and side views of the Houston-area test house
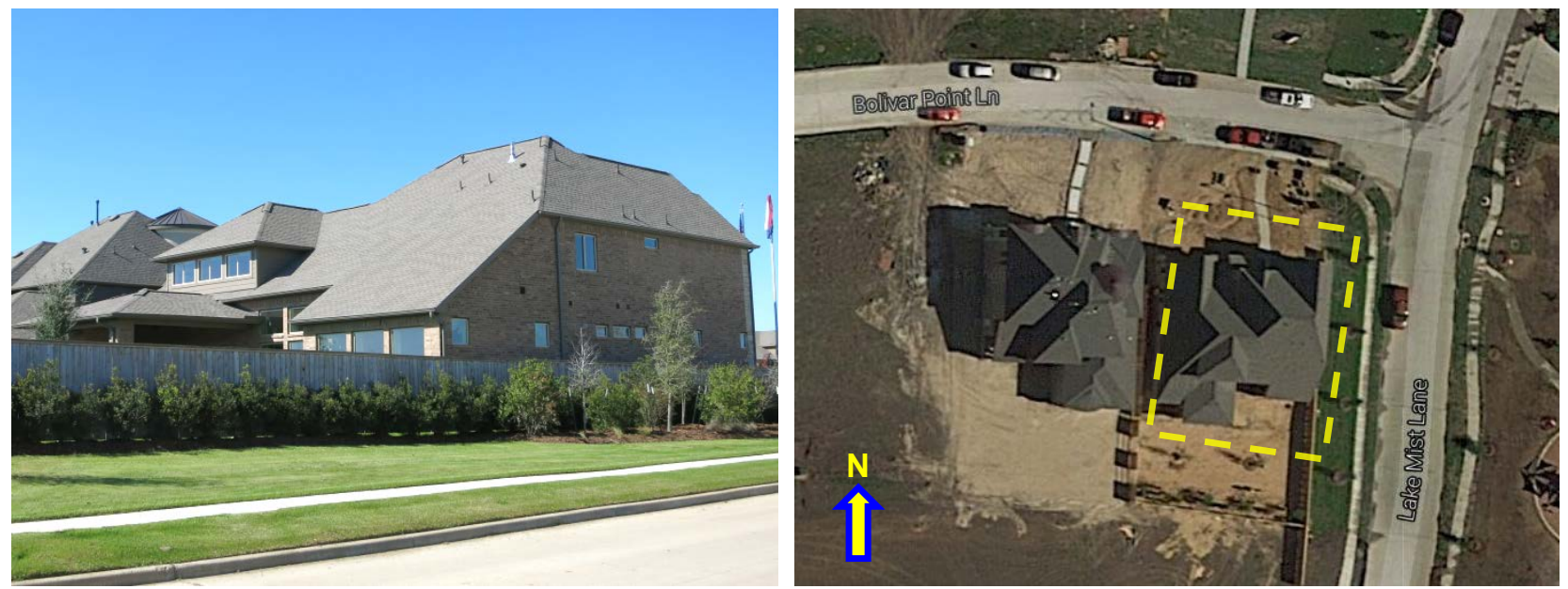

Figure 91. Rear quarter and overhead views of the Houston-area test house

\subsection{Unvented Roof Assembly and Geometry}

The test house was configured with an unvented/sealed attic that was insulated at the roofline. Unlike the cold-climate roof, the entire roof was insulated with a single material (sprayapplied/adhered fiberglass; Johns Manville Spider Spray-in Custom Fiber Glass Insulation System, $1.8 \mathrm{lb} / \mathrm{ft}^{3}$ density). The roof assembly section consists of asphalt shingles, underlayment (\#15 asphalt saturated felt), 7/16-in. OSB sheathing, and spray-applied fiberglass at R-38 (9 in. @ R-4.2/in.), encapsulating the $2 \times 8$ (typical) rafters (Figure 92). No interior finish or air barrier material was installed; the fiberglass was left exposed inside the attic. 


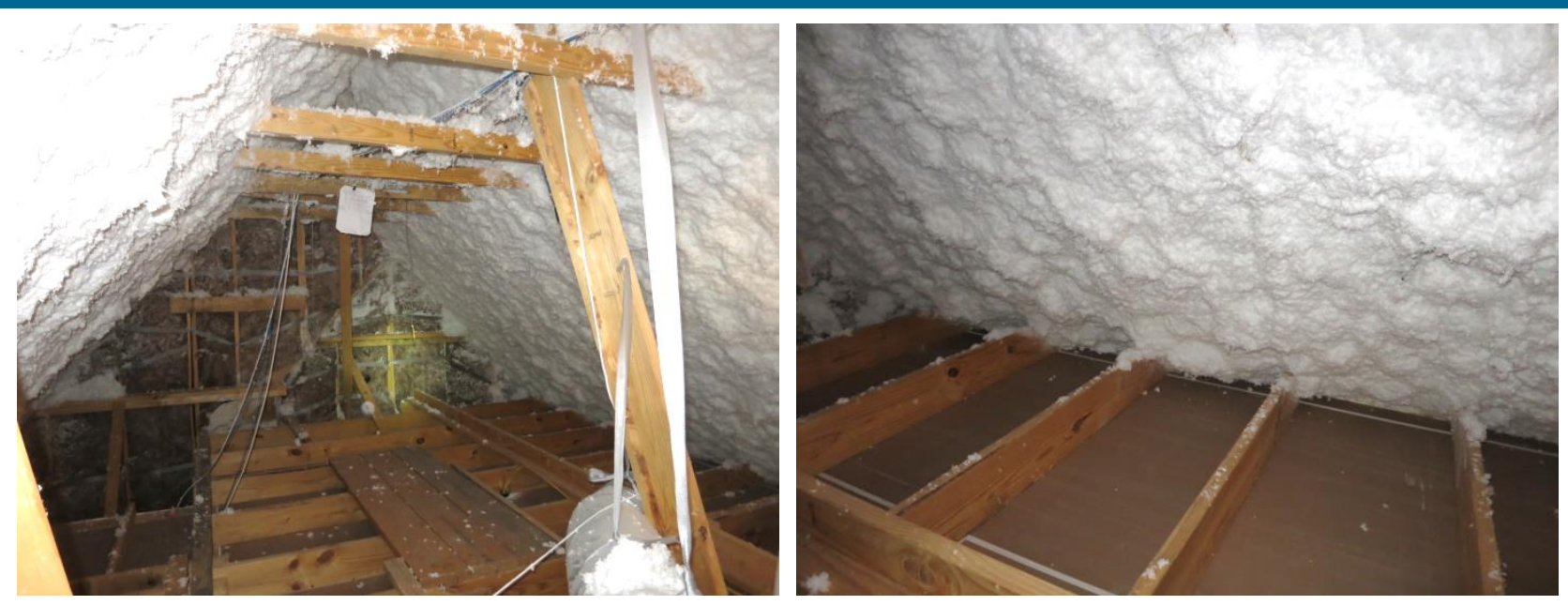

Figure 92. Interior of spray-applied fiberglass insulation in a conditioned attic

Closed-cell SPF was used at the roof-wall connections to transition the air barrier from the roof sheathing to the wall before the roof deck insulation was installed (Figure 93).
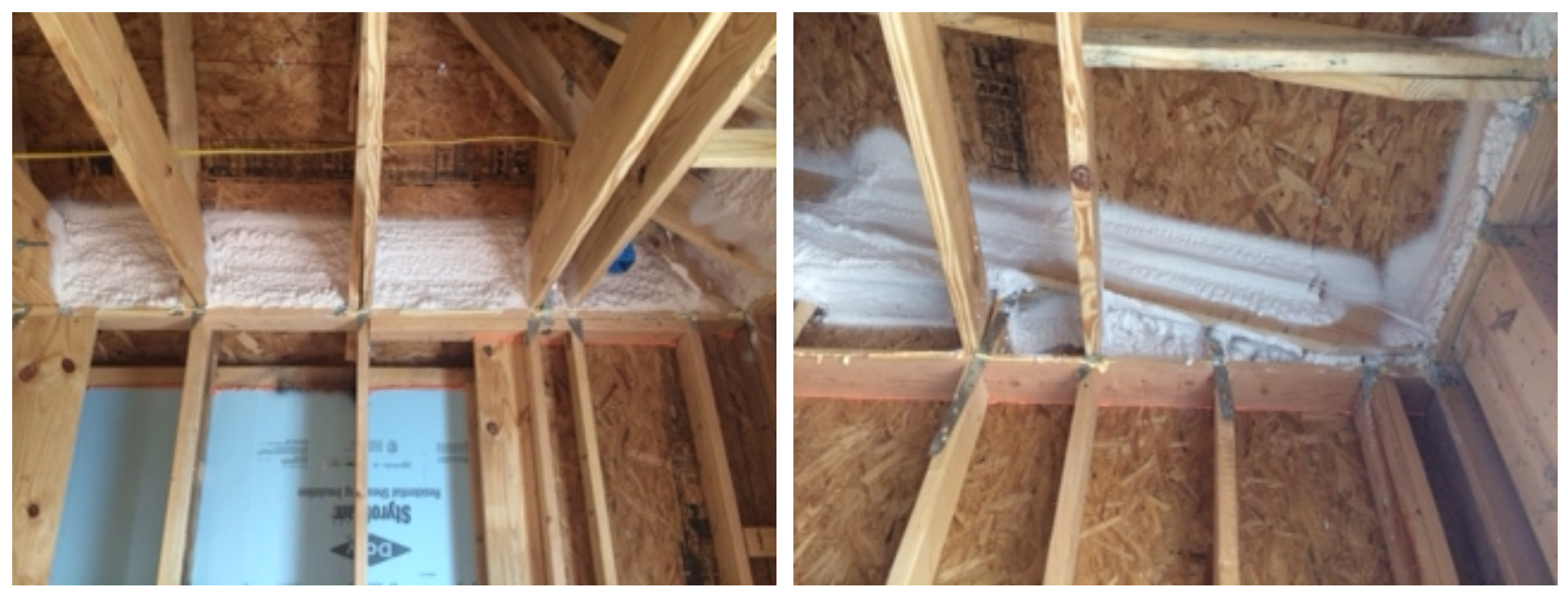

Figure 93. ccSPF used for the roof-wall air barrier connection

The roof extends over the garage, which is normally unconditioned but was conditioned as a sales office at the model. The garage roof was insulated at the roofline and the floor of the attic to bring the entire attic into the conditioned space rather than dividing the attic into sealed versus vented portions with more complicated detailing (Figure 94, left).

At the large porch overhang at the rear of the house, the porch roof was built as unconditioned space outside the sealed conditioned attic. Therefore, a short wall was built, insulated, and air sealed to separate the two areas (Figure 94, right). The attic over the porch was equipped with soffit vents to connect it to the exterior.

No intentional dehumidification or space conditioning was provided in the unvented attic space. The space floats at conditions between interior set point and exterior conditions, which is common for this type of roof assembly. Operating conditions were monitored and are a function 
of duct leakage, air leakage connection to the interior space, and air leakage from the attic to the exterior.

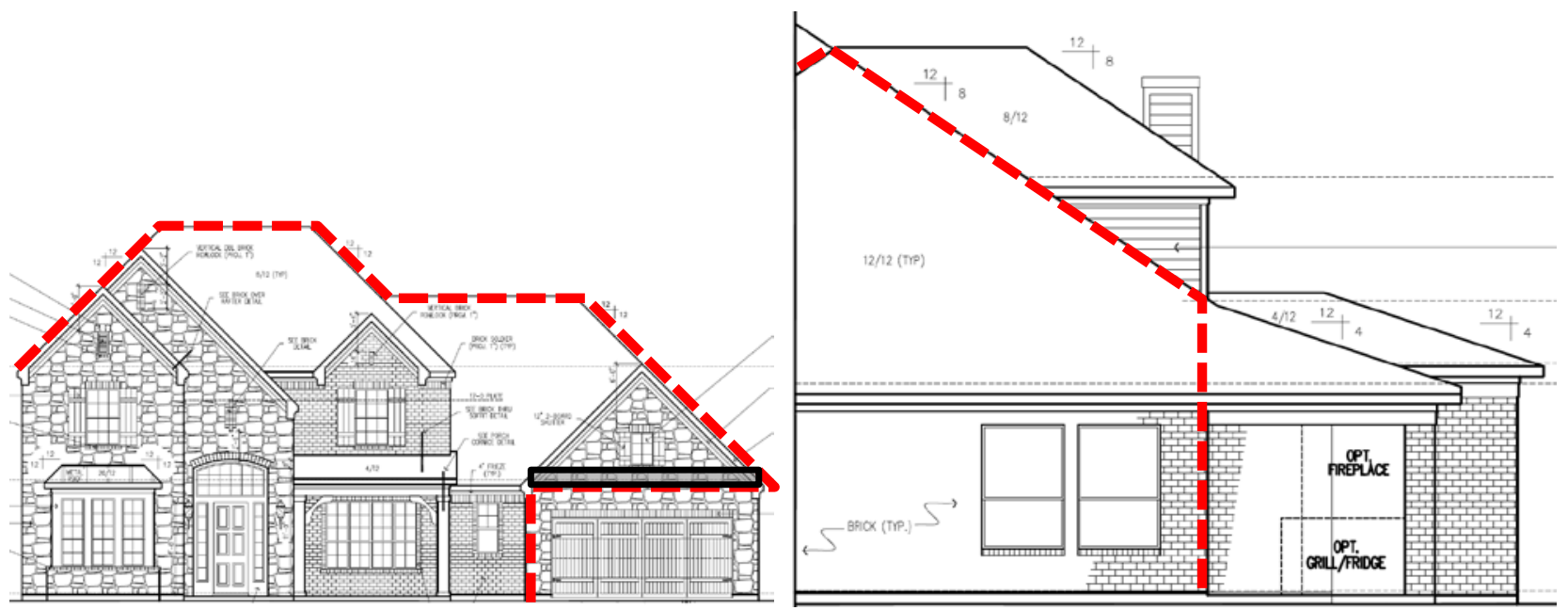

Figure 94. Air barrier and conditioned space line for an unvented attic, front (left); side (right)

\subsection{Diffusion Port Assembly}

The experimental roof assembly at this site is a diffusion vent detail. It allows for vapor diffusion drying at the ridge and tops of hips while still functioning as an air barrier. The detail is used at the peak of the roof rafter bay cavities (at the ridge and hip conditions), as shown in Figure 95; it was not used at the roof valleys.

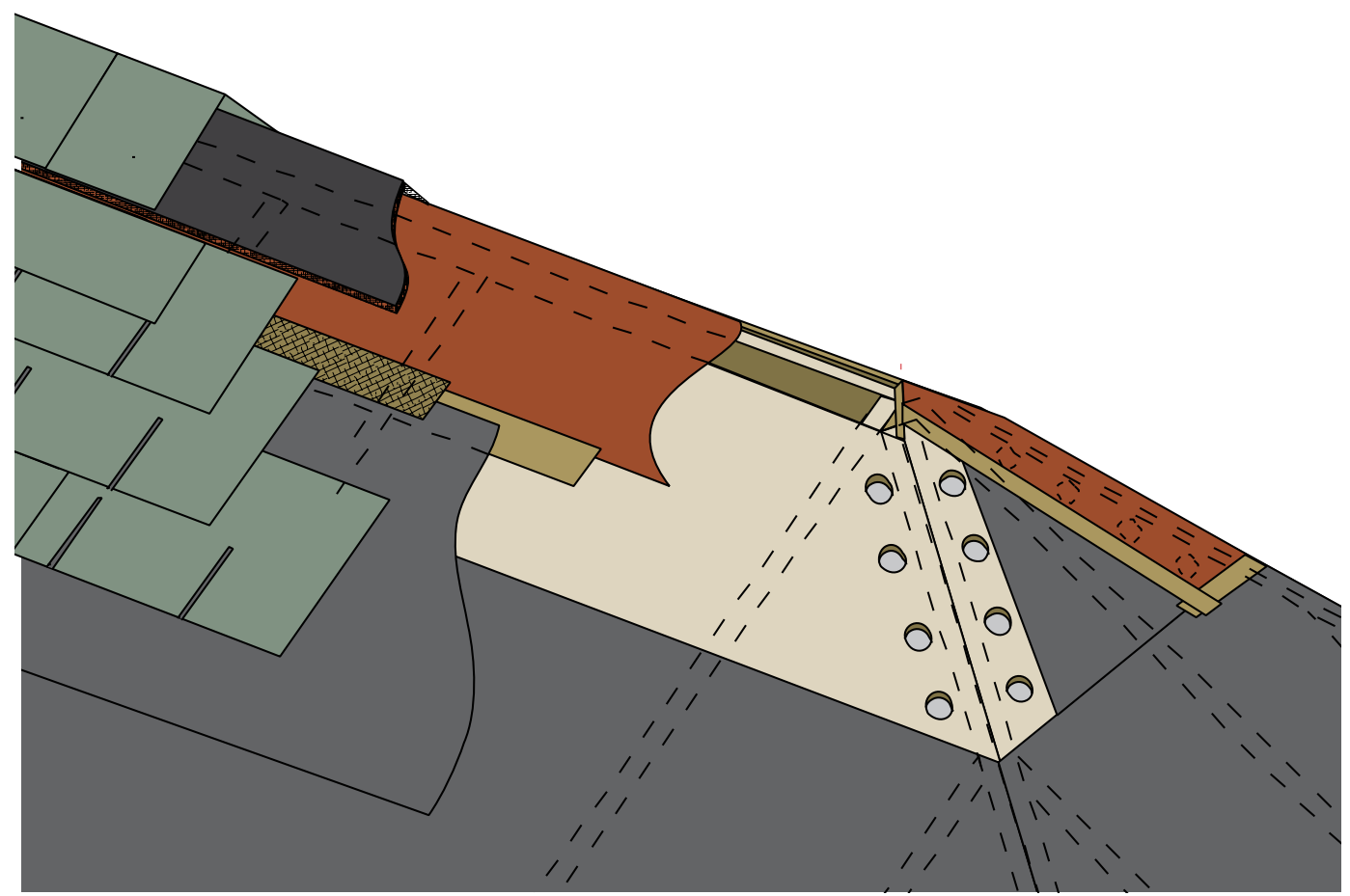

Figure 95. Diffusion vent design at the roof ridge and hip 
The components and details at the diffusion vent follow:

- Diffusion ports are created at the ridge and hip of the roof:

$\circ \quad$ At the ridge, $a \pm 3$-in. strip of roof sheathing is omitted on each side, similar to a typical detail for a ridge vent. This leaves an opening of \pm 2 in. on either side of the ridge beam (Figure 96, left).

- At the hips, a series of 2-in.-diameter holes were drilled in the roof sheathing at the top 2-3 ft. of the hip. The structural engineer did not accept the omitted sheathing detail at the hips, stating that a structural connection was required at the hip rafter. However, he accepted the drilled hole detail (Figure 97, left).

- The diffusion ports are covered with a strip of a highly vapor-permeable roof membrane (tear-resistant polyethylene terephthalate fabric with a diffusive waterproof dispersion coating; 214 perms dry cup, 550 perms wet cup). This material is Cosella-Dörken DeltaFoxx (Figure 96, right, and Figure 97, right).
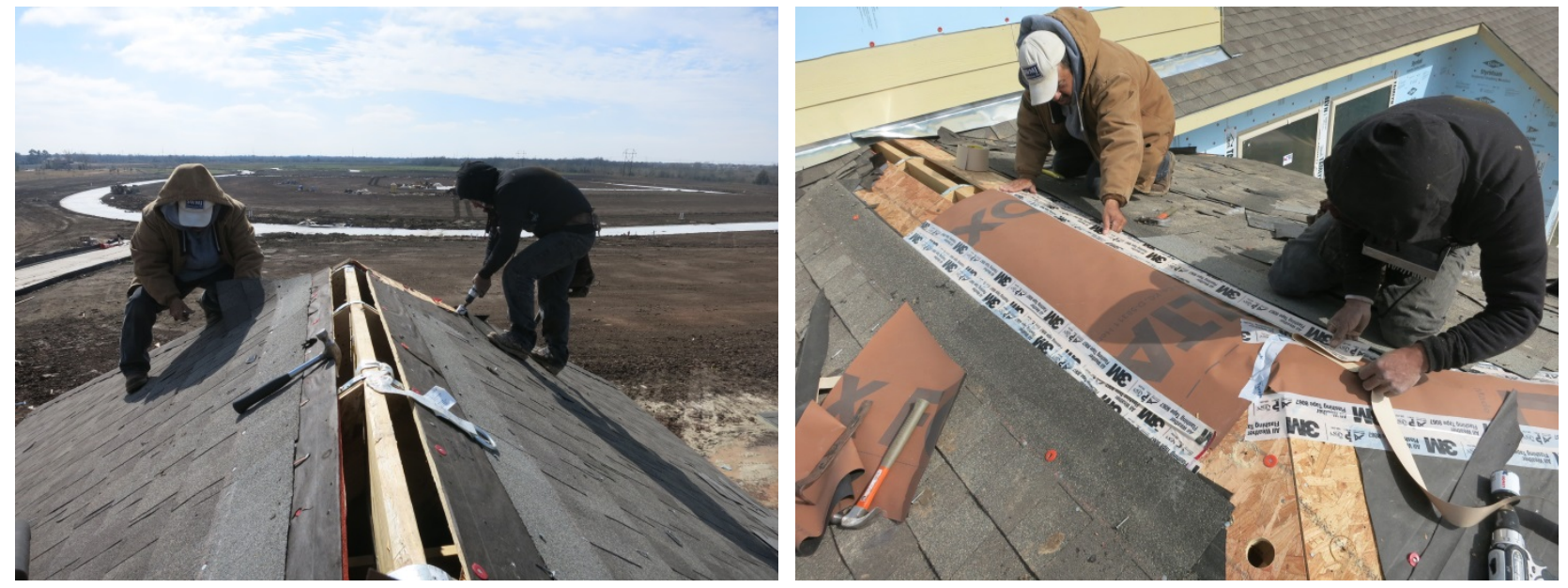

Figure 96. Open ridge (diffusion port) detail (left); permeable membrane applied over the ridge (right)
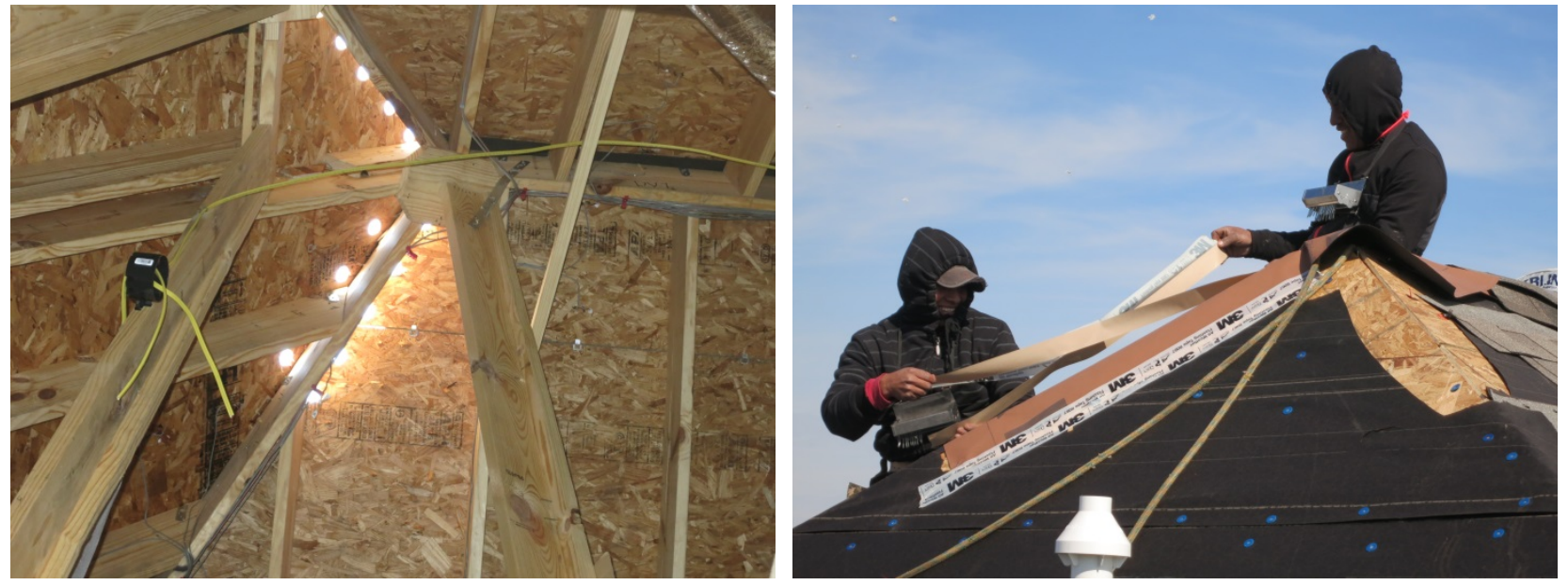

Figure 97. Hip diffusion port drilled hole detail (left); permeable membrane applied at the hips (right) 
- The edges of the permeable roof membrane were taped to the OSB roof sheathing to create an air barrier and allow vapor diffusion. Based on multisubstrate adhesion testing (Holladay 2013), a high-performance acrylic adhesive flashing tape (3M 8067 All Weather Flashing Tape) was used.

- The field of the roof was dried in using the builder's typical underlayment for asphalt shingles (\#15 asphalt saturated felt).

- The top edge of the roof underlayment created a reverse lap situation (for bulk water drainage) at the intersection with the permeable roof membrane. This is addressed by taping the connection with the same acrylic adhesive flashing tape (Figure 95).

- The asphalt shingles were installed on the roof as per typical practice.

- The ridge was covered with a typical attic ridge exhaust vent material, which was in turn covered by ridge cap shingles (Figure 98).
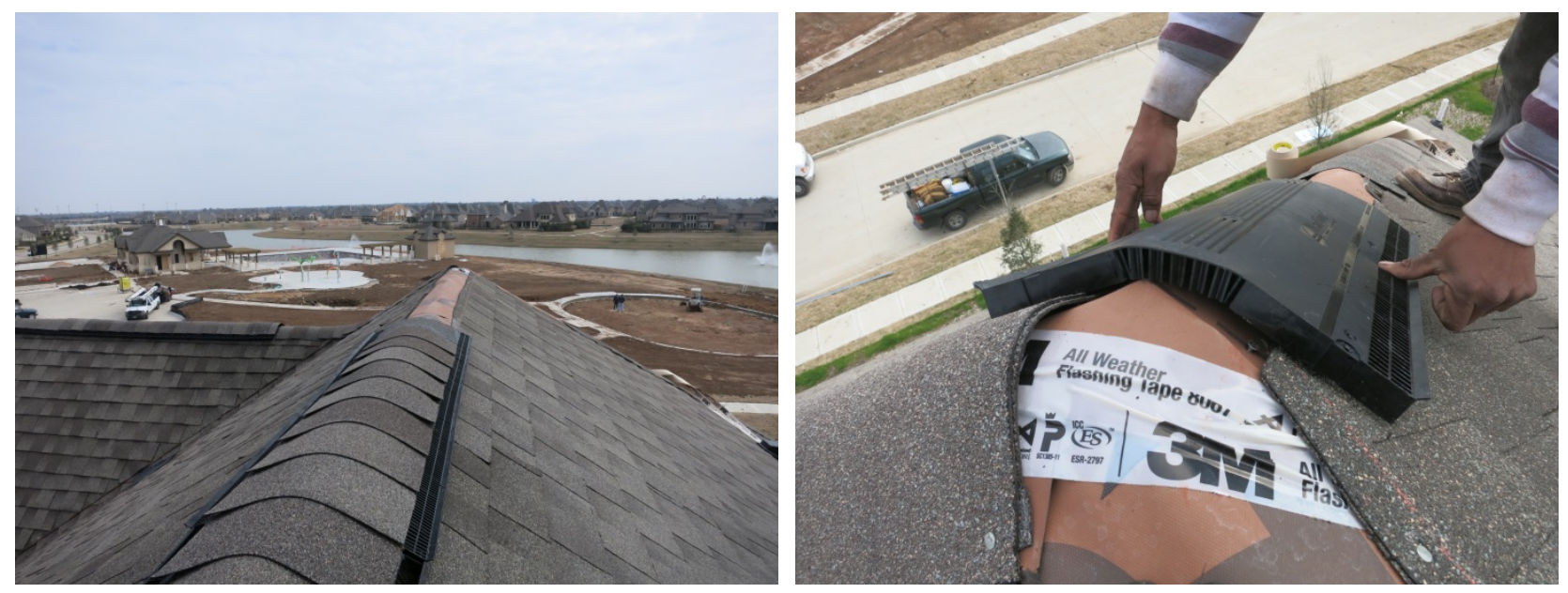

Figure 98. Venting detail at the ridge (left) and hip (right) showing the vent profile

As a control comparison, some sections of the roof were built as typical unvented roofs, which experienced failures in Houston in previous work (see Section 2.2). Vapor-impermeable membrane (self-adhered bituminous roofing membrane) was installed over the ridge at these sections rather than the diffusion port detail. These areas are shown on the roof plan in Figure 100. The goal was to demonstrate whether failure occurs at the control roof, and then whether the experimental (diffusion vent) roofs have sufficient drying to avoid failure.

\subsection{Roof Monitoring Setup}

The roof plan of the test house is shown in Figure 100 with the ridges, hips, and valleys marked, and roof slopes shown by blue arrows (pointing uphill). The areas that were constructed as typical unvented roofs (no diffusion port) are shaded.

The measurement locations are also shown in Figure 100: the instrumentation was set up to capture a sample of orientations and roof assembly types. This plan typically has a ridge package of several sensors (orange stars in Figure 99); this sensor package is concentrated at the ridge because moisture typically accumulates at the peaks. The notation in the figure calls out DV (diffusion vent) and UV (conventional unvented) monitoring packages. 
The ridge monitoring package is shown in Figure 99, Figure 101, and Figure 102. Sheathing MCs were measured as high as practical (on both orientations) near the top edge of the roof sheathing. In addition, at the ridge top, a T/RH sensor and MC "wafer" (small wood sample measured for MC, to act as a surrogate humidity sensor; see Ueno and Straube 2008) are installed. Finally, the sheathing MCs were measured on both orientations, roughly 16 in. downhill from the ridge, to capture the extent of the wetting.

At each bay with a ridge package, sheathing $\mathrm{T} / \mathrm{MC}$ are measured downslope (in the same rafter bay at the sheathing) in one or two locations (blue squares in Figure 99). This measures moisture accumulation in the rafter bays with the same condition, but lower on the roof. The number of lower roof sheathing MC sensors is based on roof geometry (length of unobstructed rafter bays).

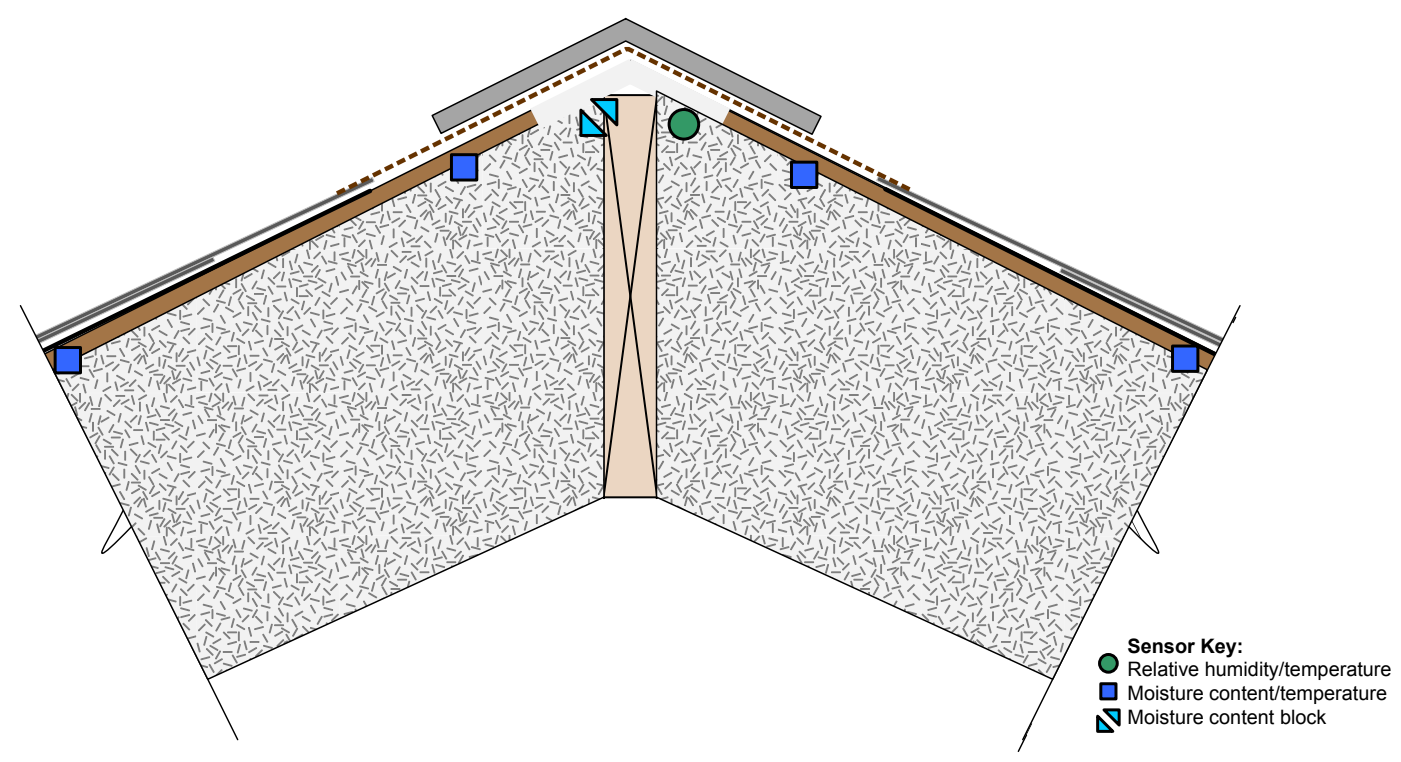

Figure 99. Ridge monitoring package (sensors at the ridge and hip peaks) 


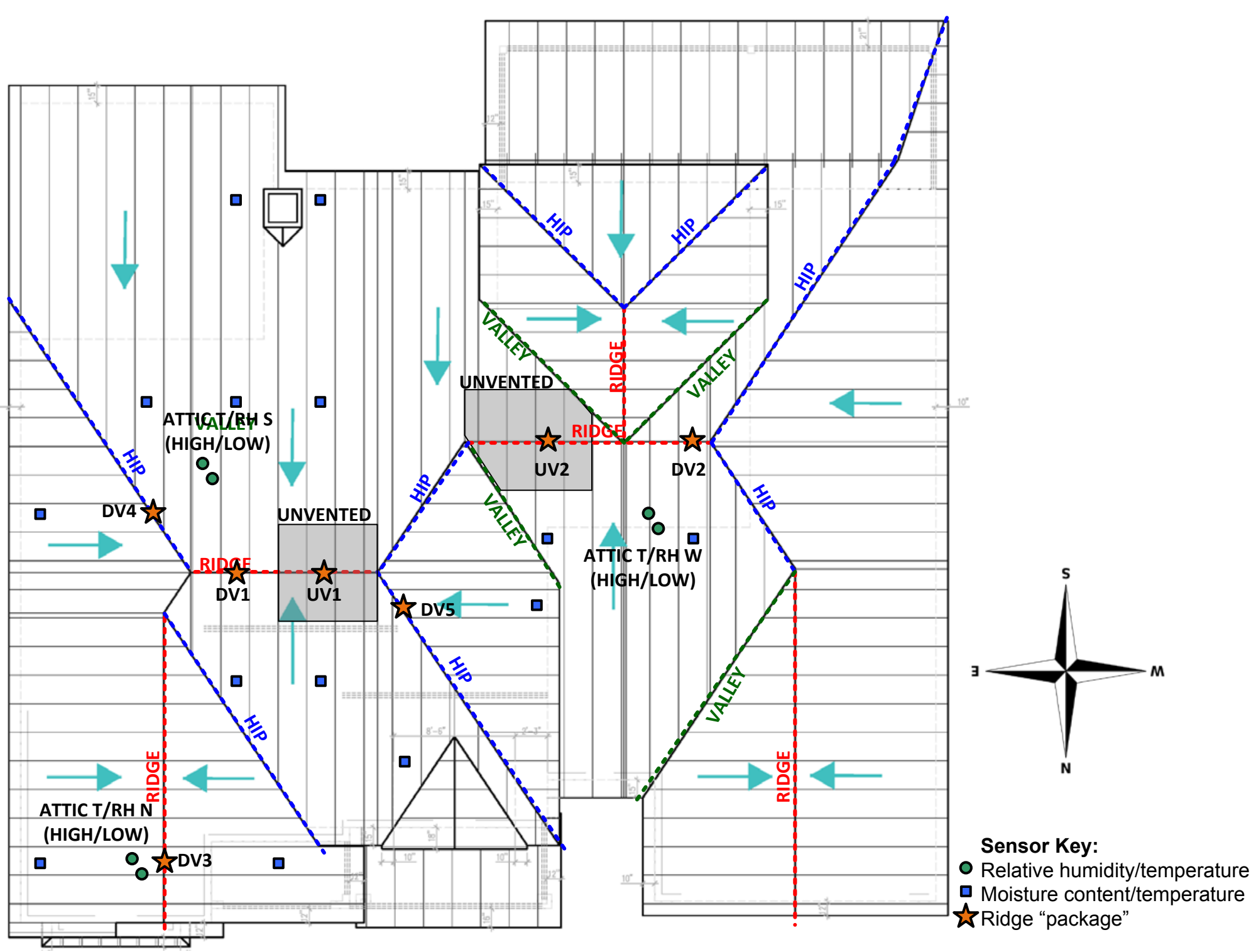

Figure 100. Houston roof plan showing ridges, hips, valleys, and measurement locations 


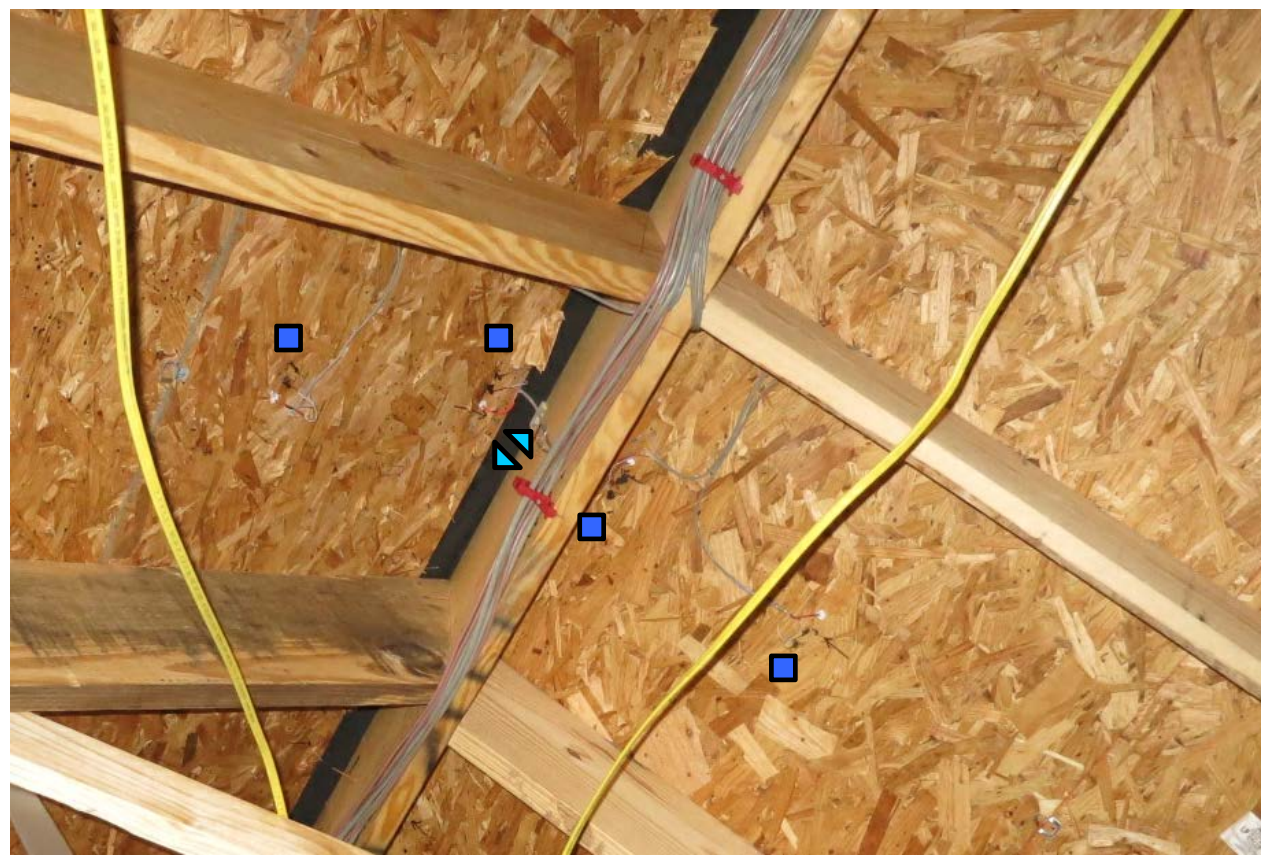

Figure 101. Typical ridge monitoring package with sensors highlighted
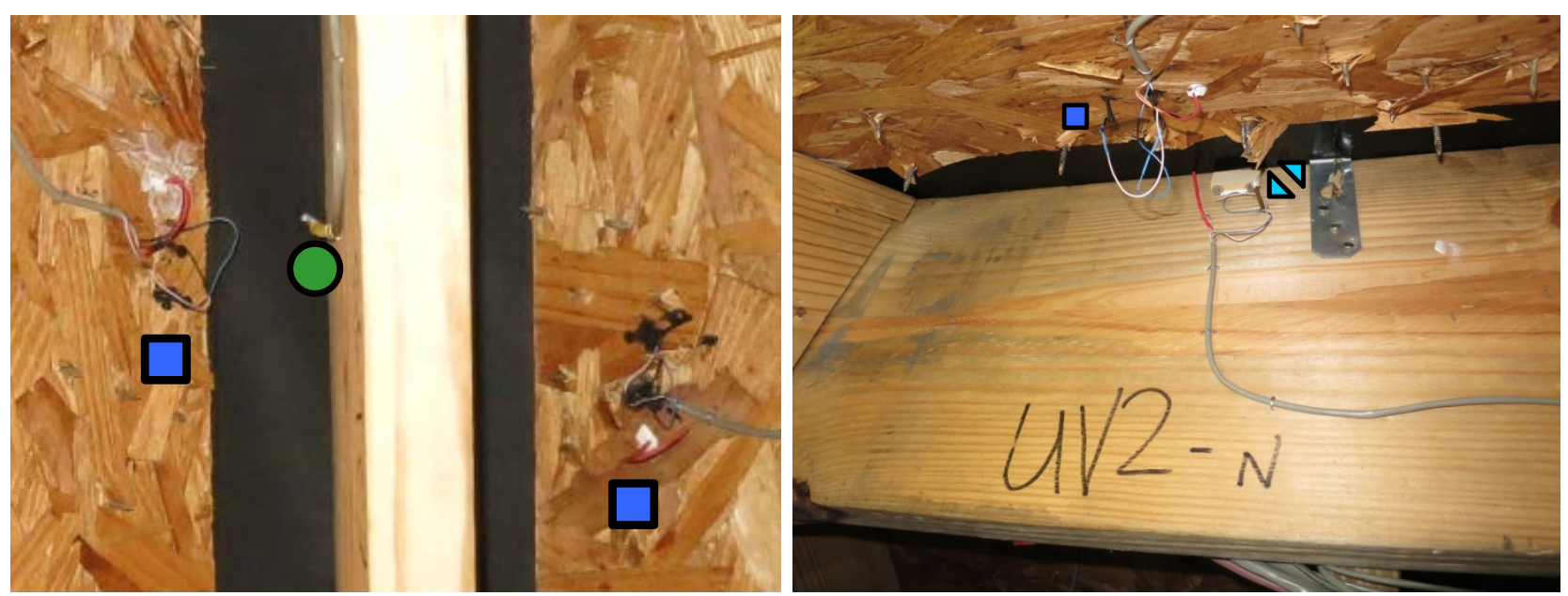

Figure 102. Ridge sheathing $\mathrm{MC} / \mathrm{T}$ sensor and $\mathrm{T} / \mathrm{RH}$ (left); ridge $\mathrm{MC} / \mathrm{T}$ and wafer sensor (right)

Attic (i.e., interior) T/RH are measured at three locations in the sealed attic (Figure 103, left and green circles in Figure 99). Measurements are paired high and low, to capture the effects of thermal and/or moisture stratification in the attic space. Interior main space T/RH are measured at a sensor in the return duct of the space-conditioning system near the interior grille. Exterior $\mathrm{T} / \mathrm{RH}$ are also measured onsite with a sensor mounted under the north soffit (Figure 103, right).

Measurements were taken at 5-minute intervals, and averages are recorded each hour. Data are periodically downloaded remotely via cellular modem to ensure data collection quality. 

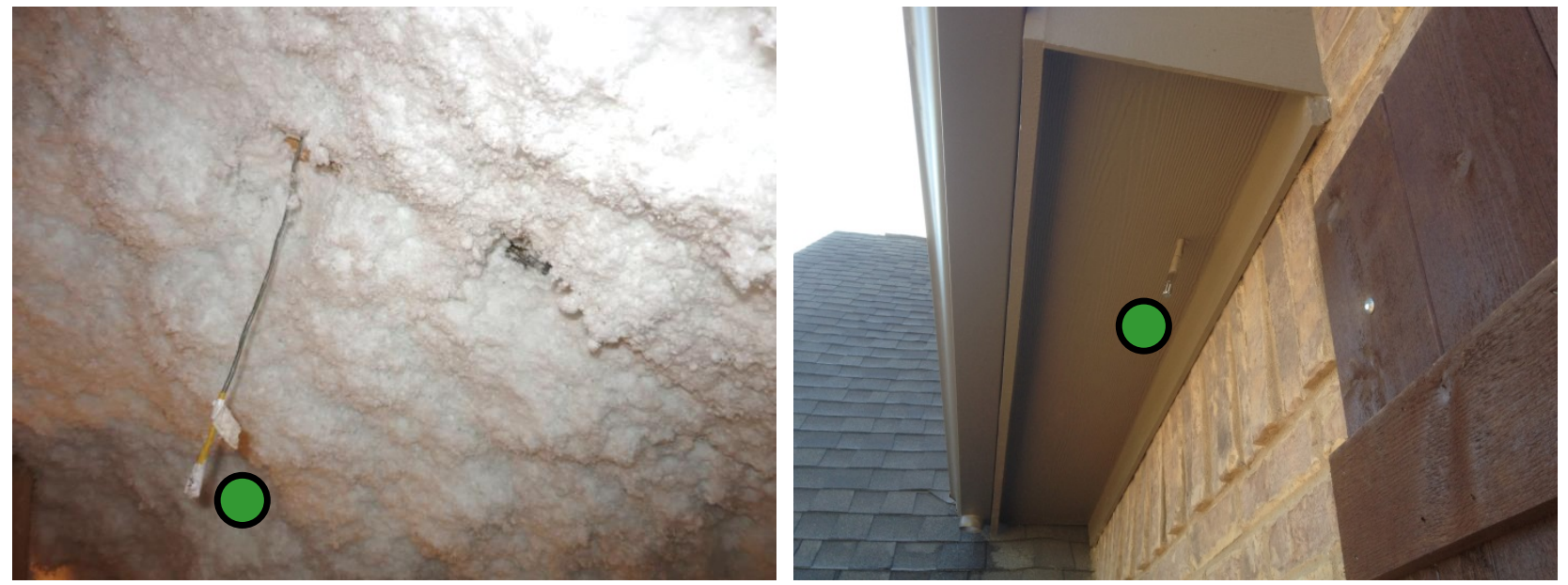

Figure 103. Interior attic T/RH sensor (left); exterior T/RH sensor under north soffit (right)

\subsection{Inward Vapor Drive Experiment}

Water accumulating in shingle laps (due to capillarity) and inward solar moisture vapor drives have been considered as contributors to attic humidity problems. This mechanism was discounted by hygrothermal modeling by Boudreaux et al. (2013) and by a field comparison of underlayments by Lstiburek (2014). However, given this opportunity, the issue was studied further with a small subexperiment described below.

A $2 \mathrm{ft} \times 2 \mathrm{ft}$ section of a south-facing roof rafter bay was isolated using 1-in. XPS foam blocking (Figure 104, left) covered with construction/house wrap tape (polypropylene film tape with an acrylic adhesive) to reduce its vapor permeance. The foam was then air sealed to the adjacent rafters with caulk and tape.

After insulation, the interior side was covered with a layer of 0.093-in. clear acrylic plastic (plexiglass) and sealed at the perimeter with flashing tape (Figure 104, right) to isolate the test area in an airtight manner. The acrylic plastic was added partway through the experiment; the date are indicated on subsequent graphs.
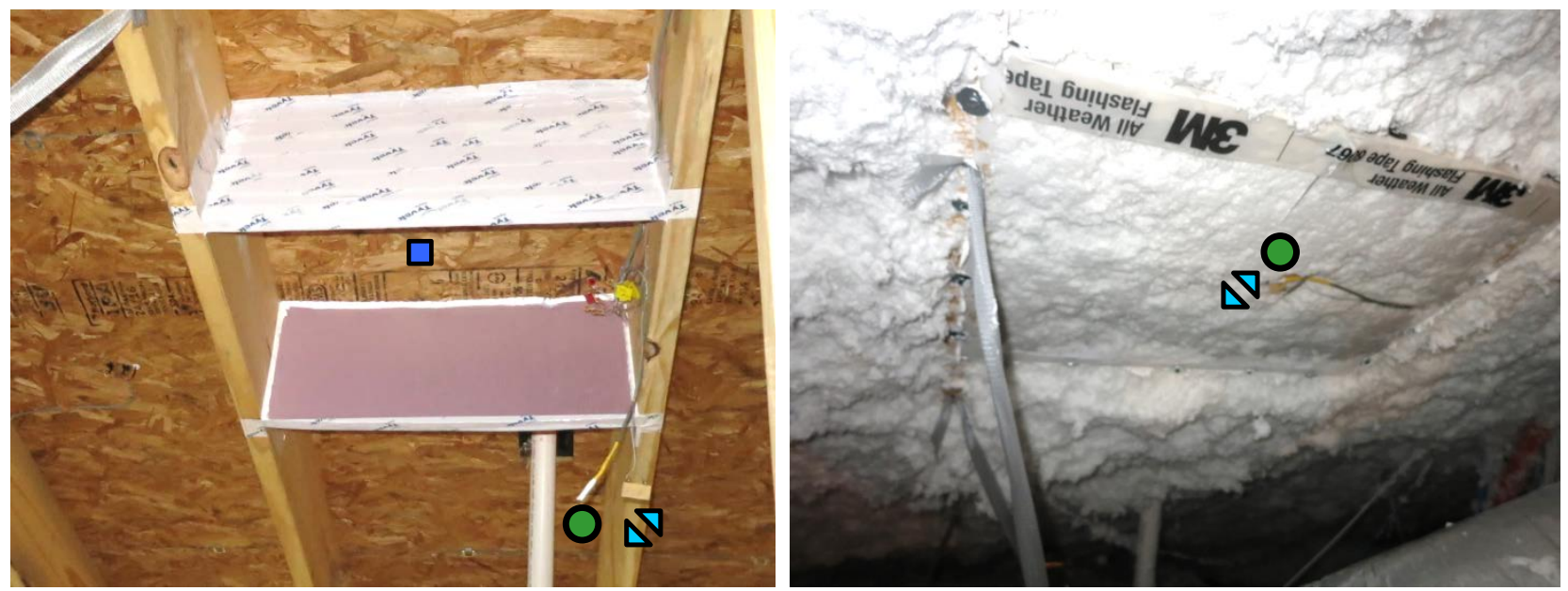

Figure 104. Inward drive box before insulation (left); after insulation and clear plastic cover (right) 


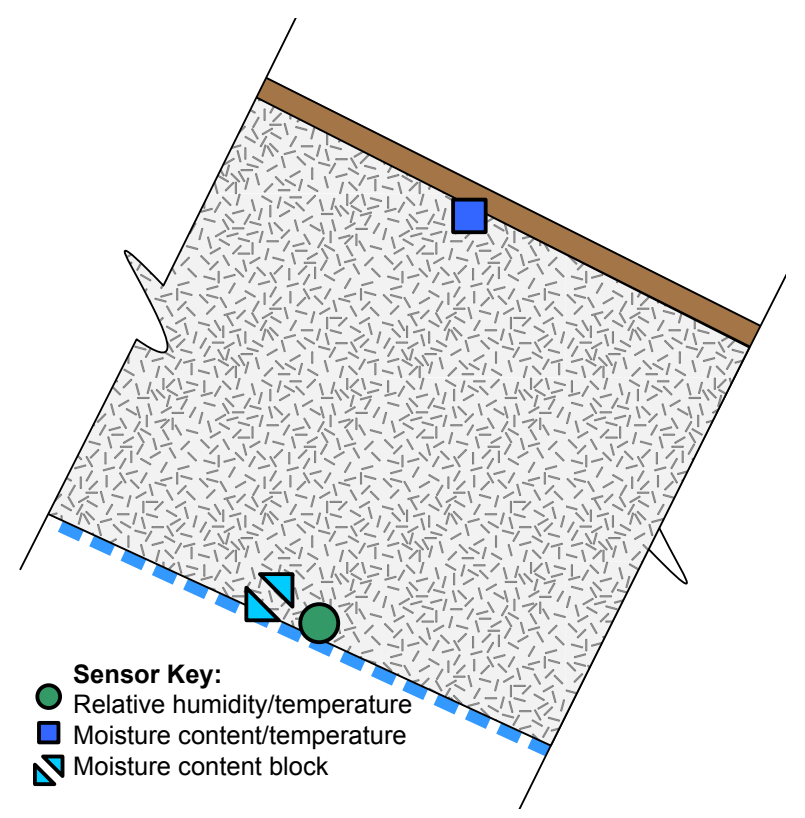

Figure 105. Inward drive sensor package
The sensors installed in the isolated area are shown in Figure 105:

- Roof sheathing MC/T sensor (exterior side of cavity)

- Insulation-to-acrylic plastic T/RH sensor (interior side of cavity)

- Insulation-to-plexiglass (acrylic plastic) wafer sensor (interior side of cavity)

The intent of this monitoring was to capture moisture that was driven through the exterior side of the assembly (shingles, underlayment, and sheathing) into the isolated area. Inward-driven moisture tends to accumulate at the insulation-to-acrylic plastic interface and would be measured by the T/RH and wafer sensors. Sheathing MC was measured to determine whether moisture within the system increased over time as moisture was driven from one side to the other seasonally.

This experiment was not intended to capture any diurnal or seasonal increase of MCs (i.e., ratcheting) caused by the increased storage of interior-sourced moisture in the sheathing. Instead, it was intended to capture inward-driven moisture only from the exterior source due to the closed system.

The initial sheathing MC was measured with a handheld meter (Tramex Moisture Encounter) at $8 \%-9 \% \mathrm{MC}$.

\subsection{Roof Air Leakage and Pressure Testing}

Air leakage (blower door) and duct leakage testing were initially conducted by a third-party rater as part of the builder's quality control process. The results are summarized in Table 8 .

This was followed by the research team's detailed air leakage measurements of the attic, main space, interconnections, and localization of air leakage.

Multipoint air leakage testing was conducted in the finished house (Figure 106, left) with the attic hatch either open or closed. The results of this testing are shown in Figure 106 (right) and Table 9. 
Table 8. Third-Party Air Leakage and Duct Leakage Test Results

\begin{tabular}{c|c|c}
\hline Measurement & Value & Normalization \\
\hline Enclosure Air Leakage & 1993 CFM @ 50 Pa & - \\
\hline $\begin{array}{c}\text { Volume-Normalized Leakage } \\
\text { Area-Normalized Leakage }\end{array}$ & $2.8 \mathrm{ACH} 50$ & $42,910 \mathrm{ft}^{3}$ volume \\
$\begin{array}{c}\text { System 1 Duct Leakage } \\
\text { (Total) }\end{array}$ & $\begin{array}{c}179 \mathrm{CFM} 25(4.5 \% \text { of floor } \\
\text { (Torea) }\end{array}$ & $\begin{array}{c}3,981 \mathrm{ft}^{2} \text { conditioned floor } \\
\text { area }\end{array}$ \\
$\begin{array}{c}\text { System } 1 \text { Duct Leakage (to } \\
\text { Exterior) }\end{array}$ & $\begin{array}{c}119 \mathrm{CFM} 25(3 \% \text { of floor } \\
\text { area) }\end{array}$ & $\begin{array}{c}3,981 \mathrm{ft}^{2} \text { conditioned floor } \\
\text { area }\end{array}$ \\
\hline
\end{tabular}
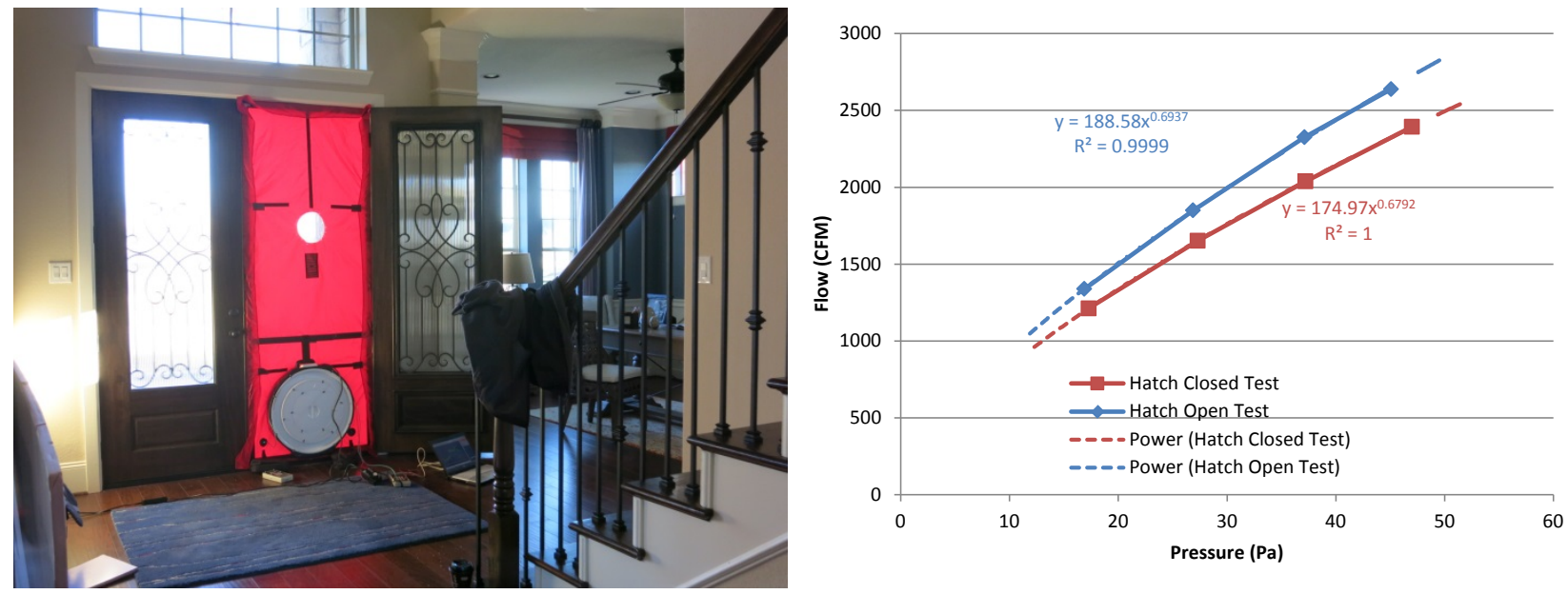

Figure 106. Air leakage (blower door) testing (left); multipoint hatch open/closed results (right)

The air leakage measurements are normalized based on an area/volume takeoff that includes the entire attic, assuming 11,594 $\mathrm{ft}^{2}$ surface area and $67,876 \mathrm{ft}^{3}$ volume. Results are shown normalized by volume (ACH50) and surface area (CFM50/ $\mathrm{ft}^{2}$ enclosure area) and are stated in terms of EqLA in square inches.

Table 9. Houston Test House Hatch Open and Closed Air Leakage Measurements

\begin{tabular}{c|c|c|c|c|c|c}
\hline Test & C & n & CFM 50 & ACH 50 & CFM50/ft & EqLA (in. ${ }^{2}$ ) \\
\hline Hatch Closed & 175.0 & 0.68 & 2494 & 2.2 & 0.22 & 257 \\
Hatch Open & 188.6 & 0.69 & 2846 & 2.5 & 0.25 & 293 \\
\hline
\end{tabular}

Opening the hatch caused the air leakage to increase by only 14\%. In either case, air leakage was less than $0.25 \mathrm{CFM} 50 / \mathrm{ft}^{2}$ and fewer than 2.5 air changes per hour at $50 \mathrm{~Pa}$ (half or less than the 5.0 ACH50 requirement in the 2012 IECC for CZs 1 and 2).

The pressures across closed hatches (to the three subattics) were measured with the main space at $-50 \mathrm{~Pa}$ to demonstrate the relative leakage connection to the interior versus the exterior (Table 10). The attic- exterior pressure drop was $76 \%-86 \%$ of the total, which is consistent with the hatch open/closed results, so this is a relatively tight attic. 
Table 10. Houston Test House Hatch Open and Closed Air Leakage Measurements

\begin{tabular}{|c|c|c|c|}
\hline Location & $\Delta \mathbf{P}(\mathbf{P a})$ & $\%$ Interior & \% Exterior \\
\hline Main Attic over $2^{\text {nd }}$ Floor & 11.8 & $76 \%$ & $24 \%$ \\
\hline Rear Attic over Master Bedroom & 7.1 & $86 \%$ & $14 \%$ \\
\hline Attic over Garage/Sales Office & 12.2 & $76 \%$ & $24 \%$ \\
\hline
\end{tabular}

The main attic hatch open/closed test and pressure measurements were used as inputs for zone pressure diagnostics or add-a-hole testing (Bohac 2002) shown in Table 11. However, results had very a high uncertainty (see minimum versus maximum in Table 11). The relative leakage areas from the attic to the exterior versus the interior are consistent, though. The team also attempted a guarded/nulled test, but the results were inconclusive and are not presented here.

Table 11. Houston Test House Zone Pressure Diagnostic (ZPD) Calculation Results

\begin{tabular}{c|c|c|c}
\hline Metric & Minimum & Maximum & Units \\
\hline House to Attic Leakage & 1,173 & 3,247 & in. $^{2}$ \\
Attic to Exterior Leakage & 415 & 821 & in. $^{2}$ \\
\hline Leak Ratio & $2.8: 1$ & $4.0: 1$ & - \\
\hline
\end{tabular}

The attic and main space were examined with an infrared camera during depressurization in an attempt to localize air leakage. Exterior conditions were cold $\left(4^{\circ}-7^{\circ} \mathrm{C}\left[40^{\circ}-45^{\circ} \mathrm{F}\right]\right)$ during this test, so exterior air leakage was evident as cold areas or plumes.

Overall, the roof plane was relatively airtight; few thermal anomalies were seen at the roof plane, except for uninsulated or unsealed gas appliance exhausts.
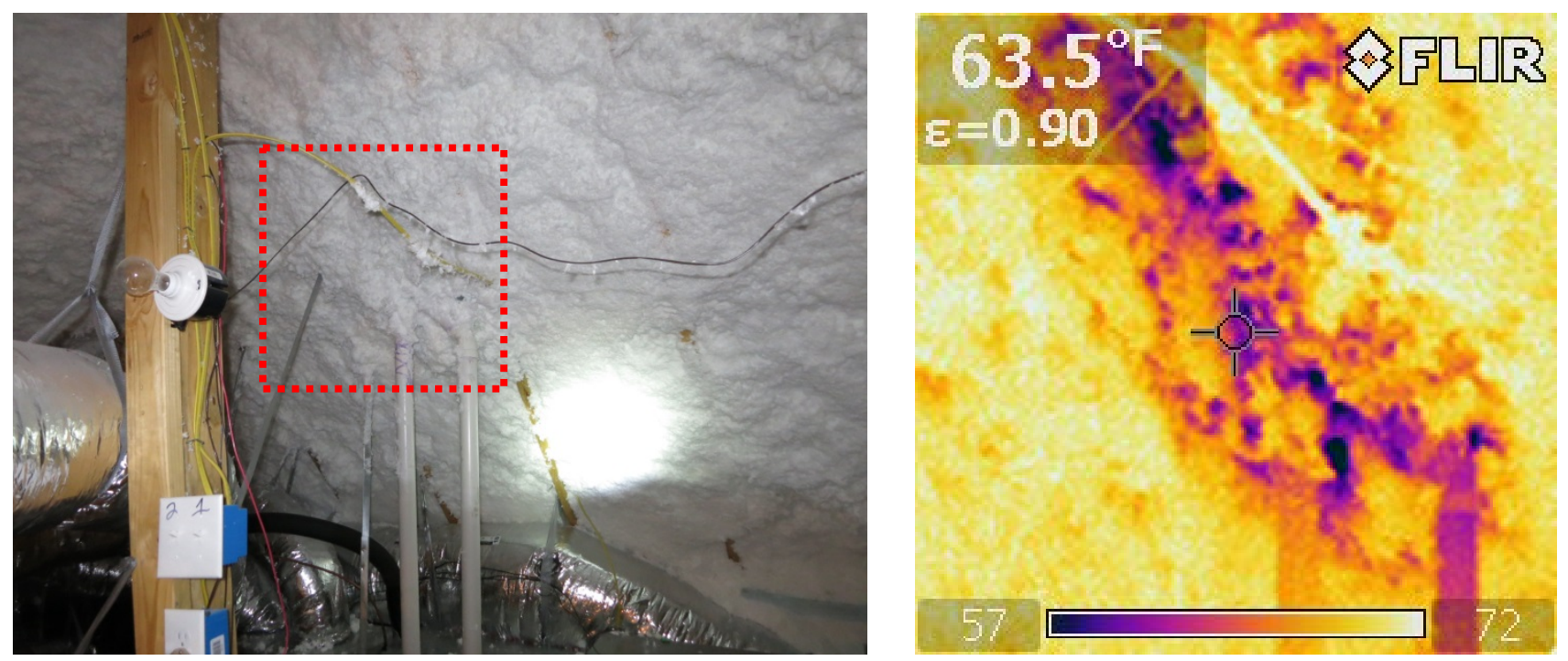

Figure 107. Unsealed gas appliance exhaust and intake with evidence of air leakage

The roof peaks were examined for any sign of air leakage at the diffusion vent details, but no evidence was found. However, leakage often occurred at transitions and connections between 
roofs and walls, especially at complicated details with multiple intersecting planes. For instance, leakage was evident at dormer and gable end intersecting planes at the front of the house (Figure 108 and Figure 109), and roof-wall connections at the rear of the house (Figure 111). These and the following leaks are keyed to Figure 110.
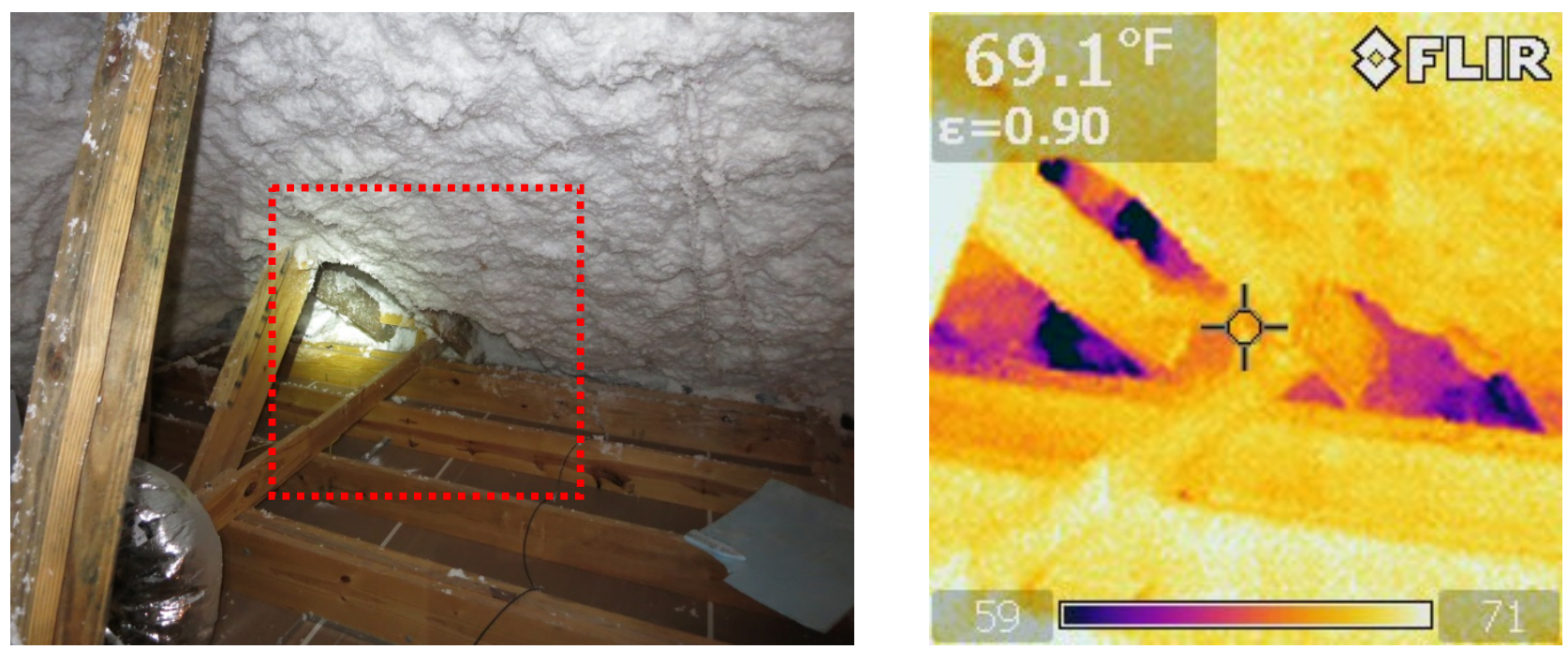

Figure 108. Air leakage at roof-to-wall details at dormer/intersecting roofs (location A)
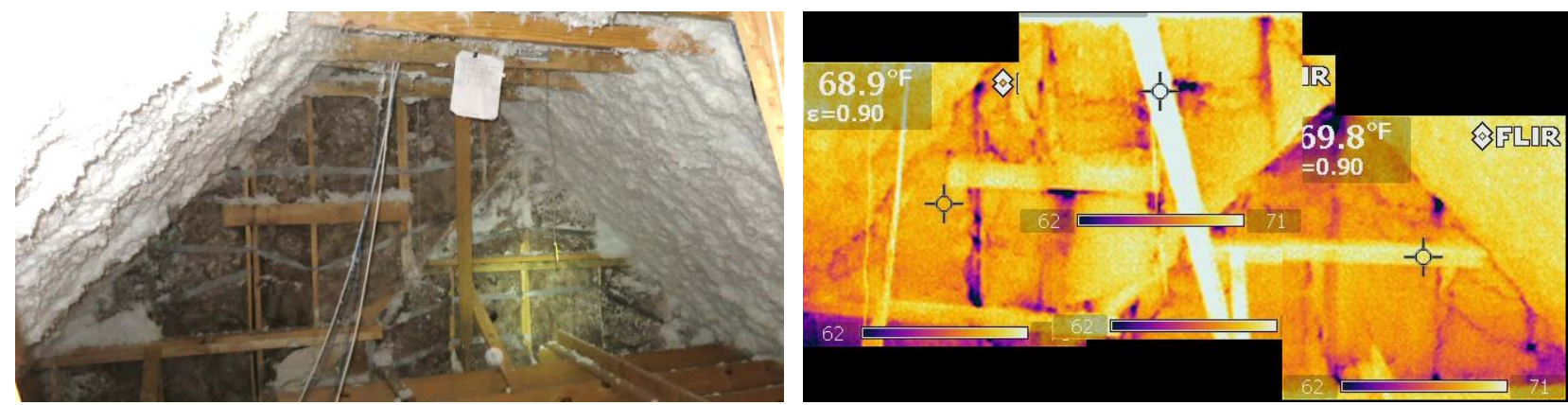

Figure 109. Air leakage at front attic gable end (location B)
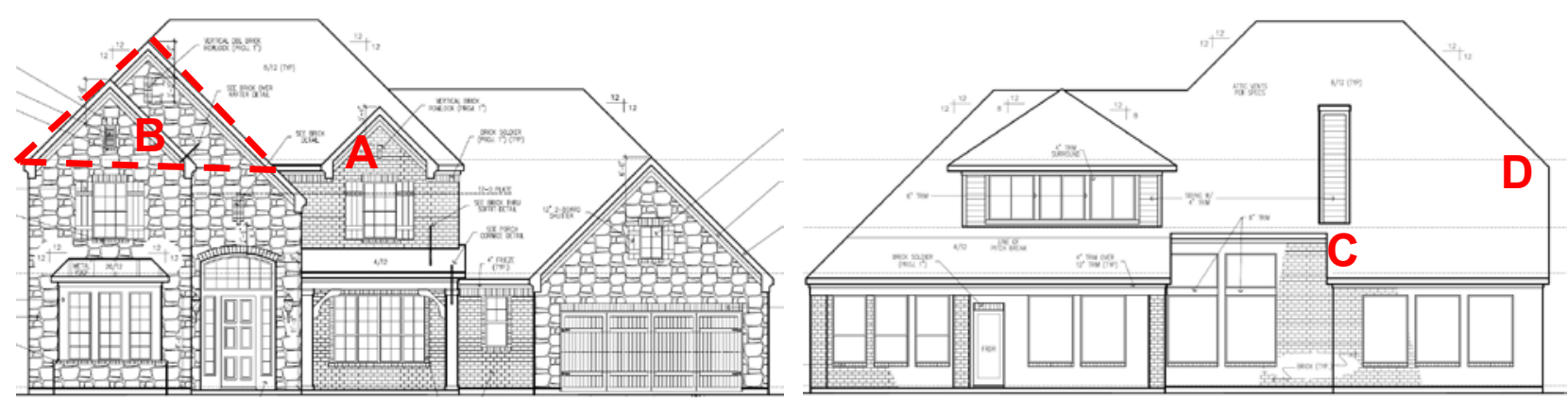

Figure 110. Front and rear elevations, showing air barrier failure locations 

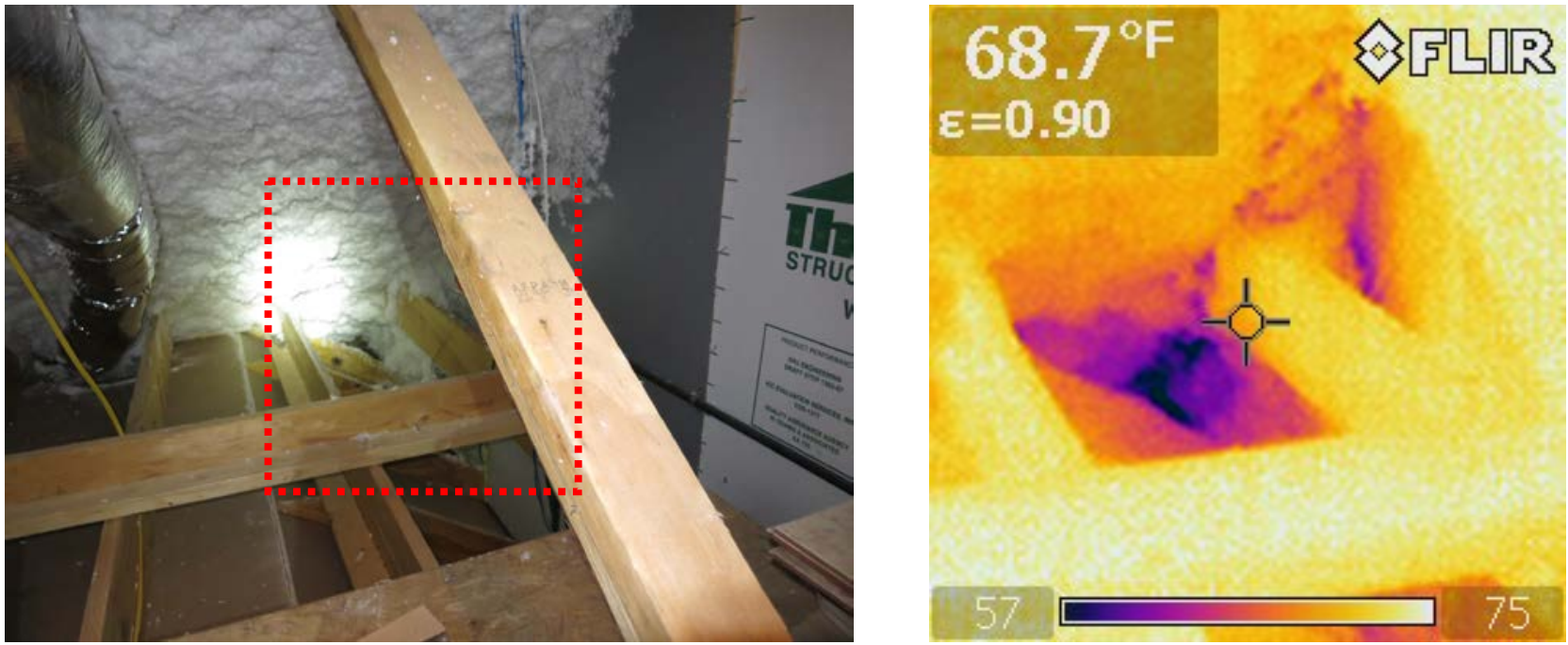

Figure 111. Air leakage at roof-to-wall details at roof-wall intersection (location C)

Noticeable leakage was found at the top of the roof-wall intersection at small rear attic over the master bedroom at an interior-attic wall (Figure 112). This occurred even though ccSPF was used to seal these connections; apparently some key areas were not sealed.
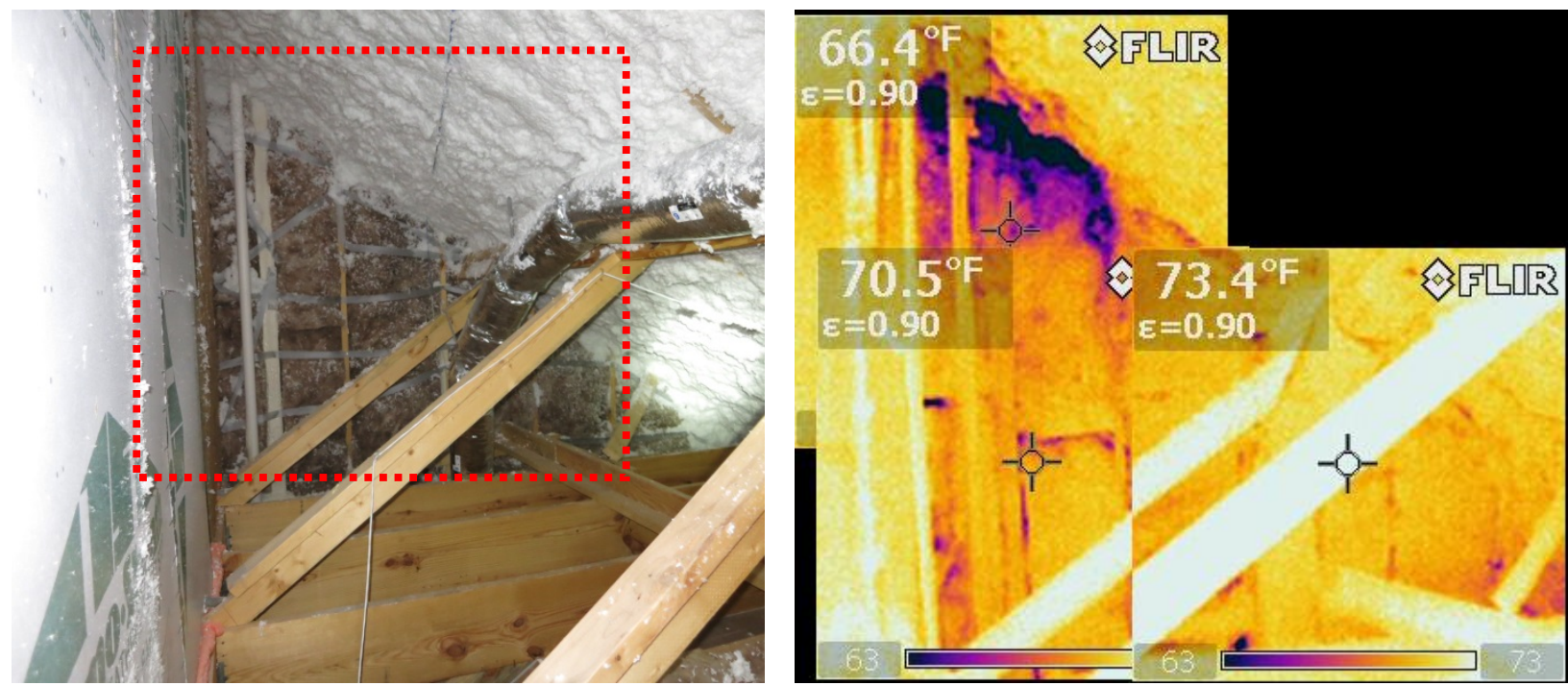

Figure 112. Air leakage at the rear attic over the master bedroom (location D)

Observations from below corroborated that air was leaking at roof framing connections and penetrations at the roof-to-wall connection (Figure 113 and Figure 114). 

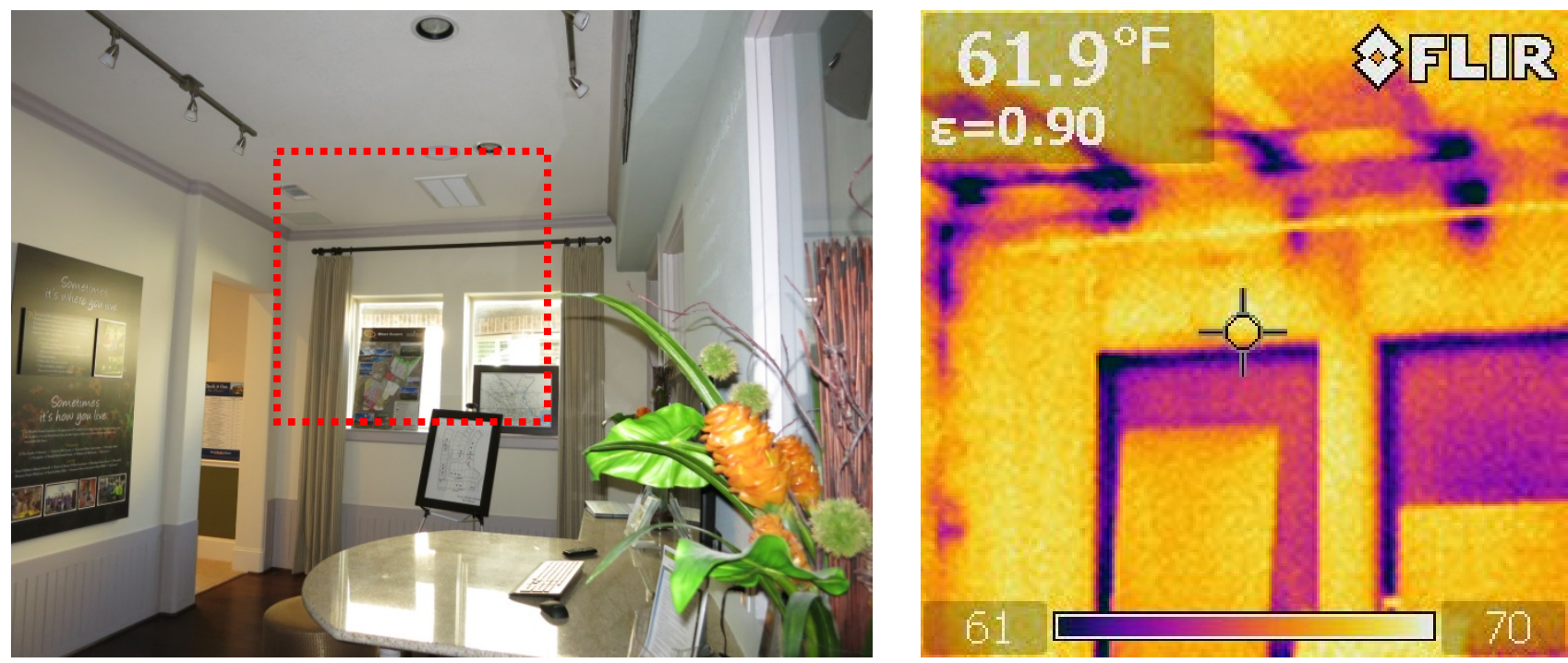

Figure 113. Air leakage at roof-wall connections from the interior space (first floor)
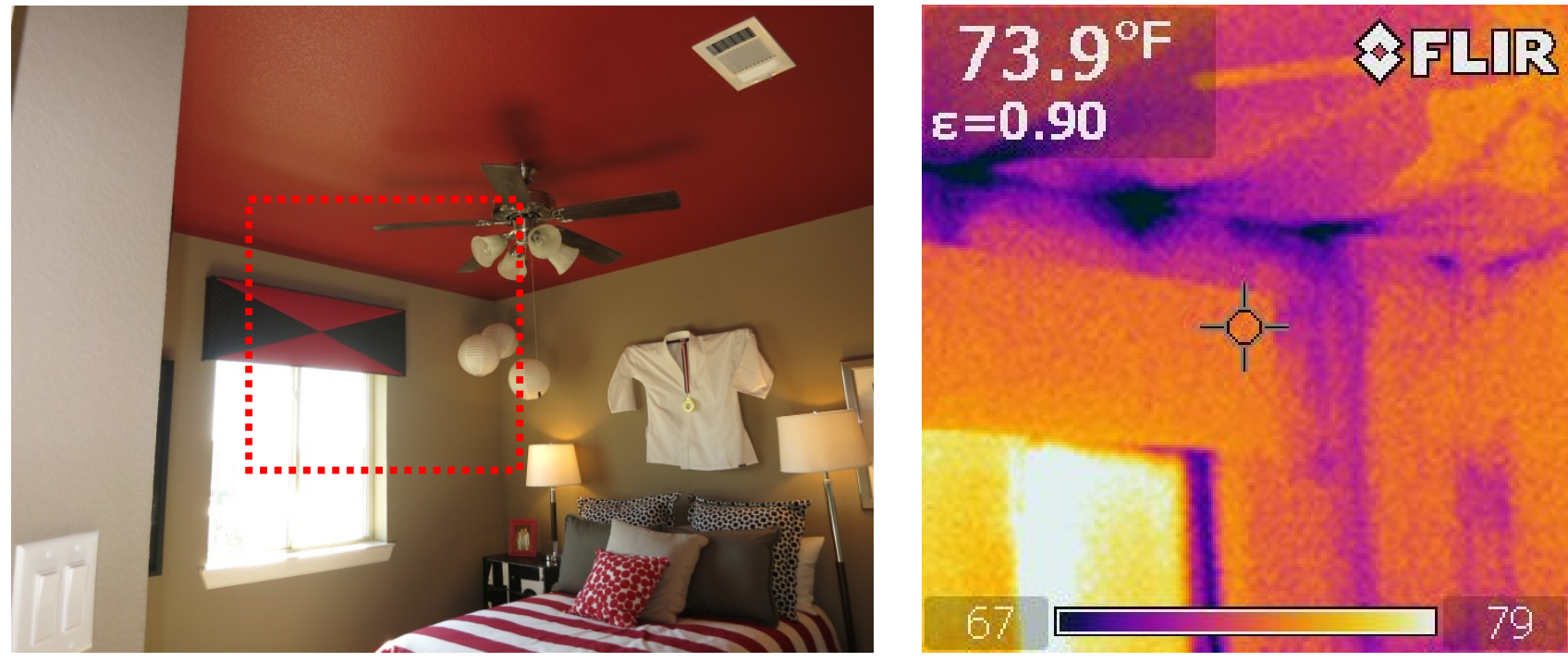

Figure 114. Air leakage at roof-wall connections from the interior space (second floor) 


\section{Hot-Humid Climate (Houston) Monitoring Results}

\subsection{Boundary Conditions}

Data were collected from February 2014 through June 2015 (16 months); data were not collected from mid-February 2014 through late March 2014 because site power was not available. Interior and exterior temperatures are plotted in Figure 115. Exterior temperatures include site-measured and airport (Houston Hobby/KHOU) data. Interior temperatures include six conditioned attic measurements at three pairs of vertical stacks and main space (HVAC return) conditions ("Interior T Downst.").

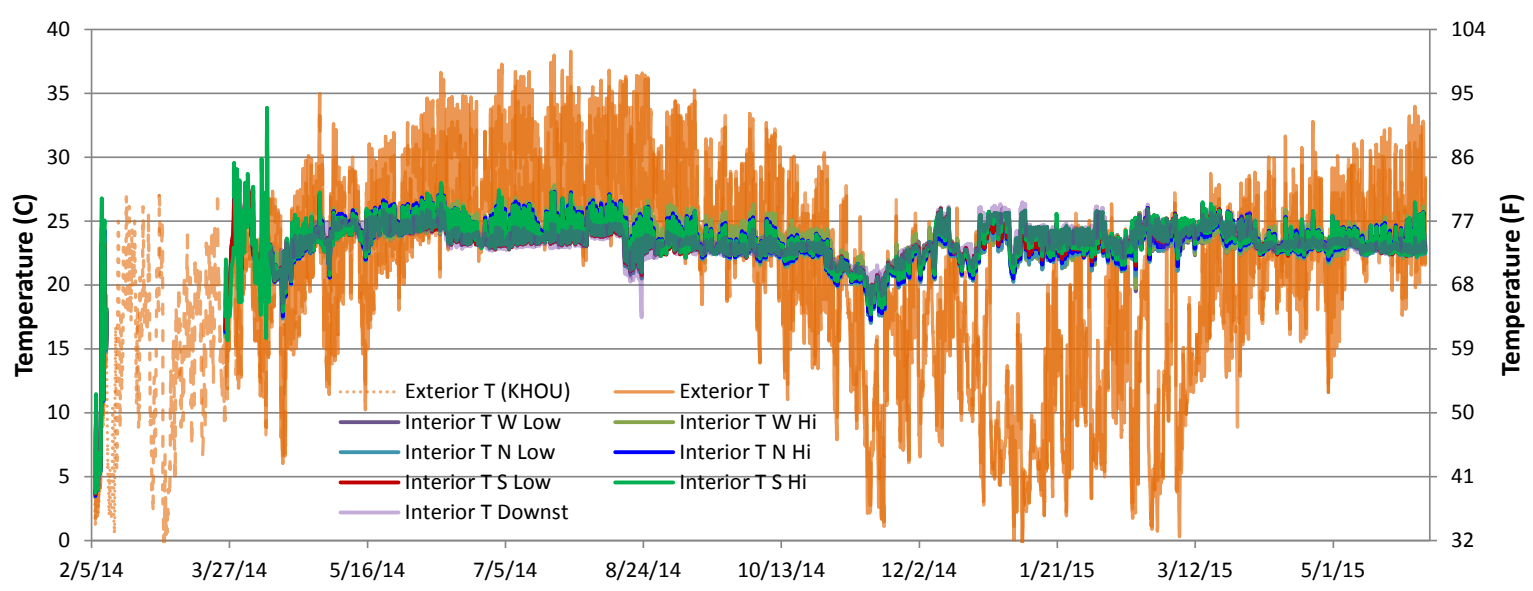

Figure 115. Houston exterior, attic, and main conditioned space temperatures

The temperature excursion in mid-November 2014 during cold exterior conditions appears to be an interior set point issue; later winter data at similar exterior temperatures show warmer interior conditions.

Monthly heating degree day and cooling degree day data for Houston are plotted in Figure 116; recent data are close to climate normals. The 2014 heating degree days were $2 \%$ higher than normal; the 2014 cooling degree days were 5\% higher than normal. The past 12 months were $96 \%$ of normal heating degree days and $110 \%$ of normal cooling degree days.
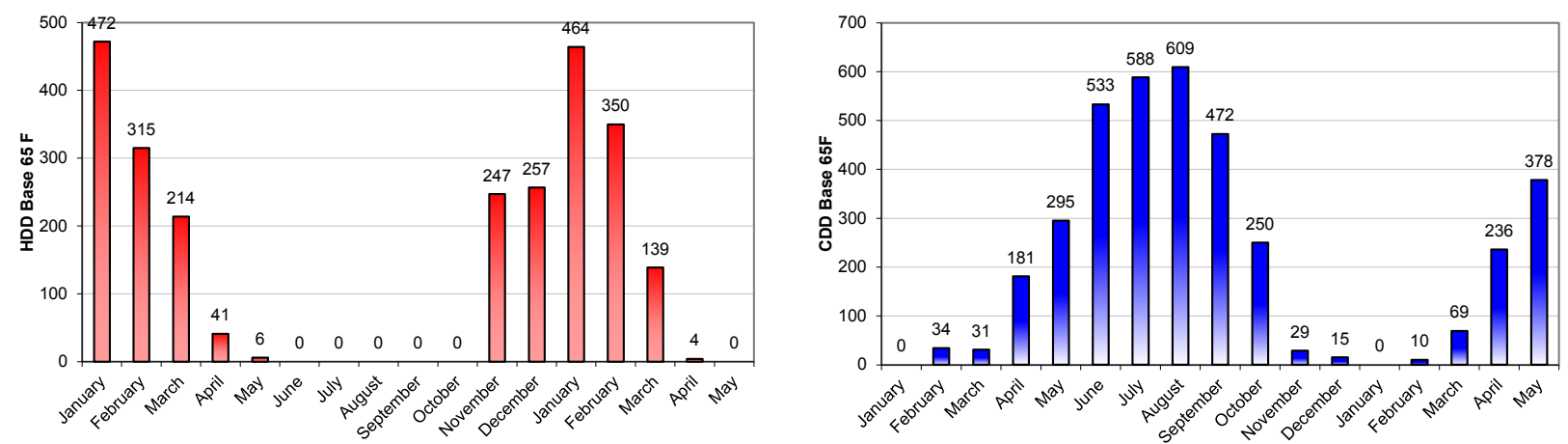

Figure 116. Heating degree days (left) and cooling degree days (right) for Houston (IAH airport) 
Attic/interior summertime temperatures for 2 weeks in July 2014 are shown in Figure 117; conditioned attic temperatures are warmer than interior/return conditions but are still closer to interior temperatures than outdoors. Daily cycles are typically $23^{\circ}-27^{\circ} \mathrm{C}\left[73^{\circ}-81^{\circ} \mathrm{F}\right]$; the interior is $\left.23^{\circ}-24^{\circ} \mathrm{C}\left[73^{\circ}-75^{\circ} \mathrm{F}\right]\right)$.

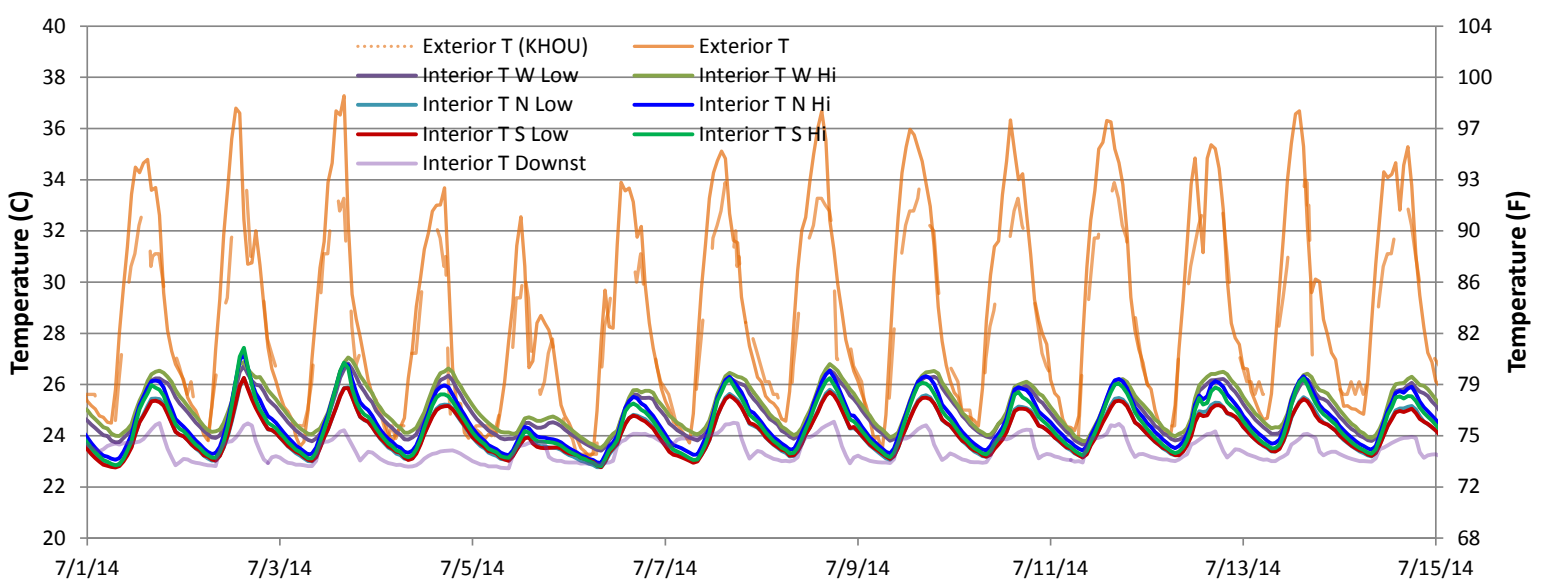

Figure 117. Houston temperatures in the summertime (July 2014) detail

Conditioned attic temperatures varied; the west side sensors (both high and low) were the warmest and were the slowest to cool in the afternoons and evenings. This could be explained by the placement near the west face of the attic space (which has afternoon solar gain; Figure 119). These temperatures might also show the relationship between duct leakage, thermal coupling to the interior space, and heat gain or loss from the exterior. The next two warmest are the north and south high sensors; this is consistent with temperature stratification.
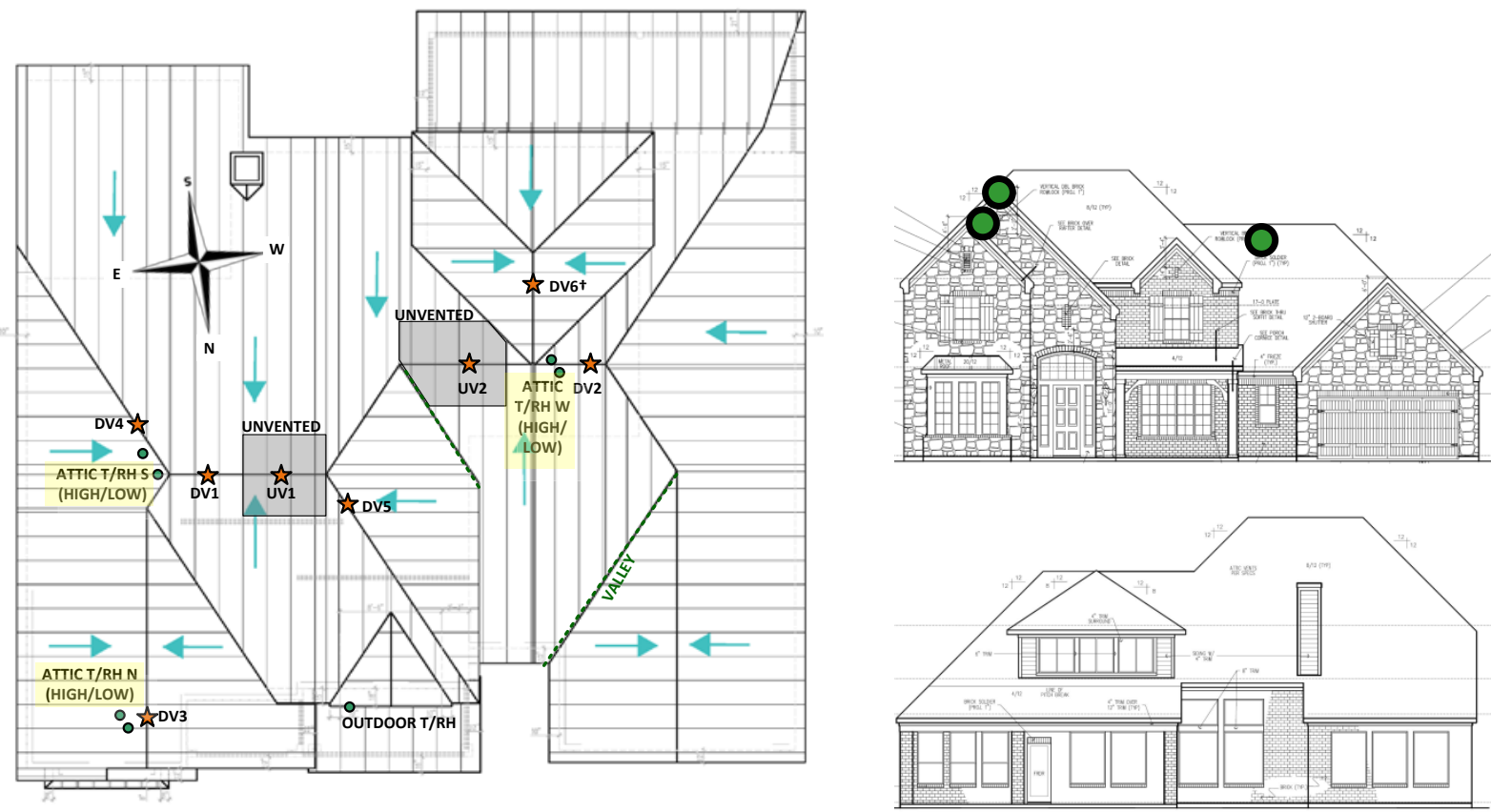

Figure 118. Attic T/RH sensor locations highlighted in plan (left) and front/rear elevations (right) 


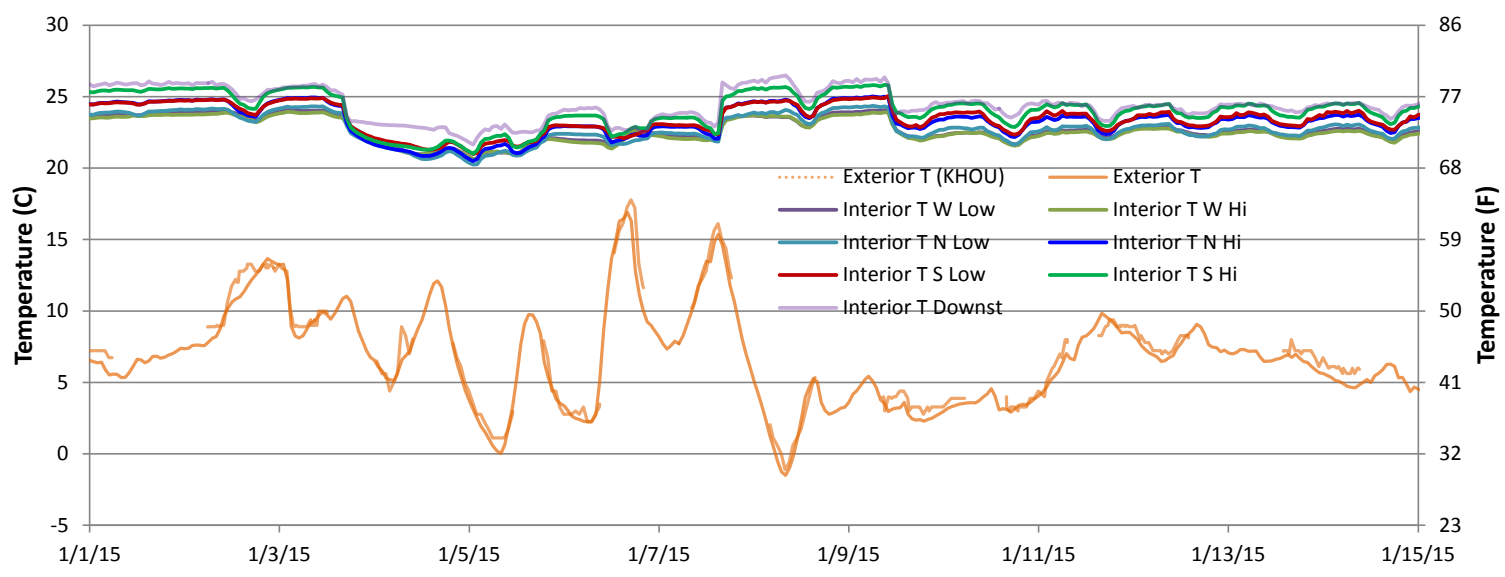

Figure 119. Houston temperatures in the wintertime (January 2015) detail

The warmest and coolest temperatures differed by about $1^{\circ} \mathrm{C}\left(2^{\circ} \mathrm{F}\right)$. The conditioned attic sensors were installed at roughly the $1 / 3$ and $2 / 3$ points of the attic height, so they did not capture the extremes of stratification.

A similar plot for wintertime conditions (2 weeks in January 2015) is shown in Figure 119. Interior temperatures clearly show a nighttime setback schedule. The main floor space conditions were typically warmer than the conditioned attic space, which was expected given minimal conditioning in the attic (duct leakage only; no intentional supply). The coldest temperatures were west high and low, followed by north low; the maximum difference was roughly $2^{\circ} \mathrm{C}\left(4^{\circ} \mathrm{F}\right)$. The west sensors were the outliers in the heating and cooling seasons, so temperature differences can likely be explained by the ratio of incidental space conditioning versus losses to and gains from the exterior.

Exterior and interior dew point (absolute air MC) conditions are shown in Figure 120; similar to temperatures, conditioned attic dew points operate between interior and exterior conditions in the summer. In the winter, interior dew points roughly track outdoor conditions (extremes are damped by house airtightness). No interior moisture is generated, because the house is an unoccupied model.

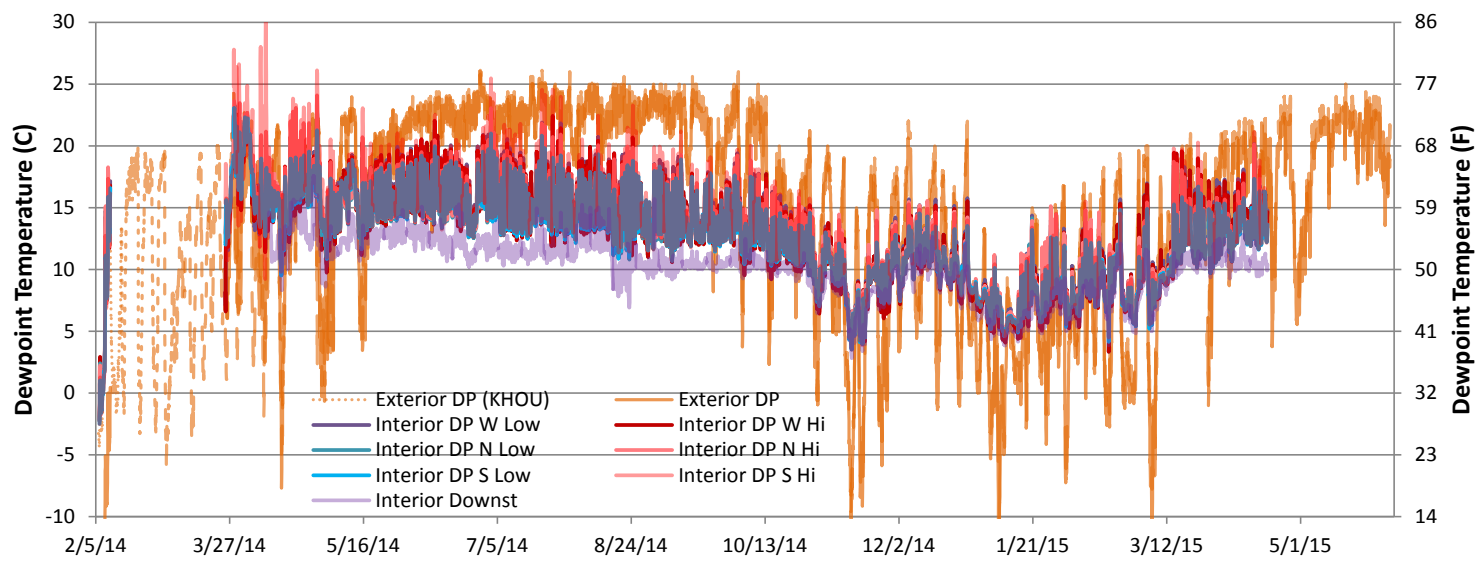

Figure 120. Houston exterior, attic, and main conditioned space dew point temperatures 
Attic and interior summertime dew point temperatures for 2 weeks in July 2014 are shown in Figure 121 ; interior main space dew points remained at a relatively stable level of $10^{\circ}-12^{\circ} \mathrm{C}$ $\left(50^{\circ}-54^{\circ} \mathrm{F}\right)$ dew point.

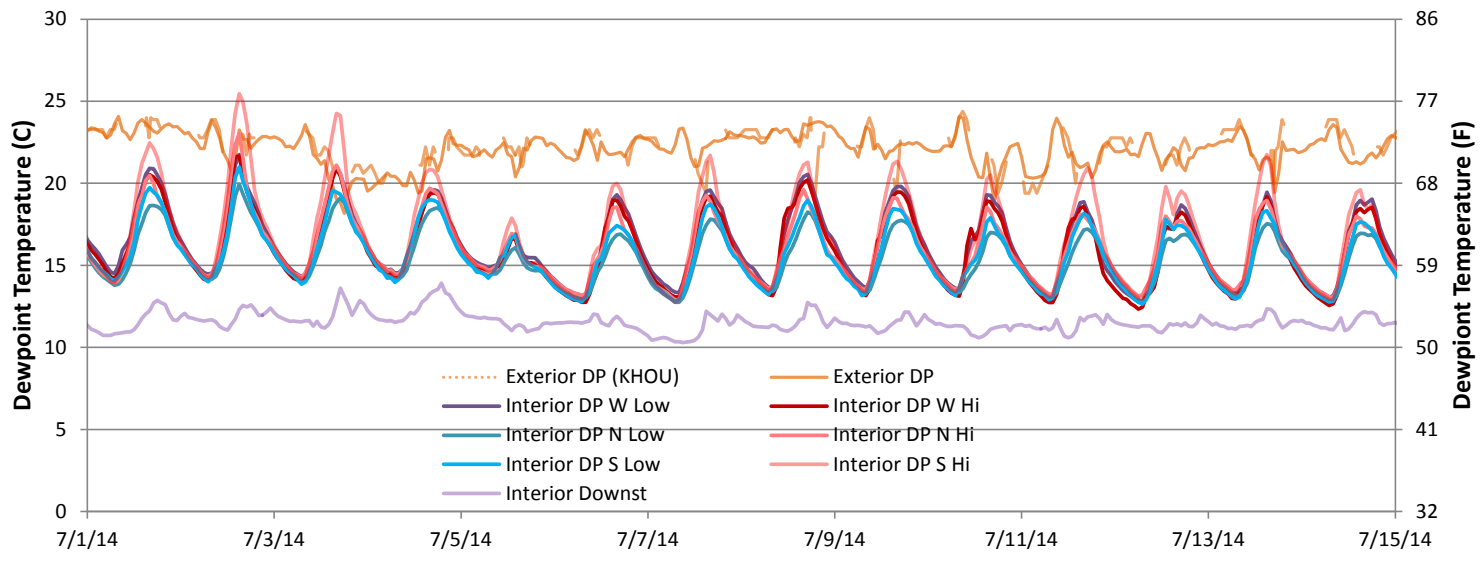

Figure 121. Houston dew point temperatures in the summertime (July 2014) detail

Attic conditions were wetter than the interior. Again the space was not directly conditioned or dehumidified) and had a strong diurnal cycle. The peaks occurred between 3 and 6 p.m., which is consistent with moisture adsorbed in sheathing being driven out by solar gain and dry bulb temperature difference. After sunset, the sheathing tended to adsorb moisture from the air and pull down the dew point.

The data show stratification. The south high sensor shows the highest peaks, which is consistent with its location at the highest spot in the attic (Figure 118). North low and south low sensors showed the lowest peaks, which is also consistent with moisture stratification.

Interior RH levels are shown in Figure 122; the initial data after the gap (semiconditioned construction period) has very high RHs $(60 \%-90 \%)$, which is consistent with the moisturegenerating construction activities (drywall mudding and interior painting) that occurred during that time.

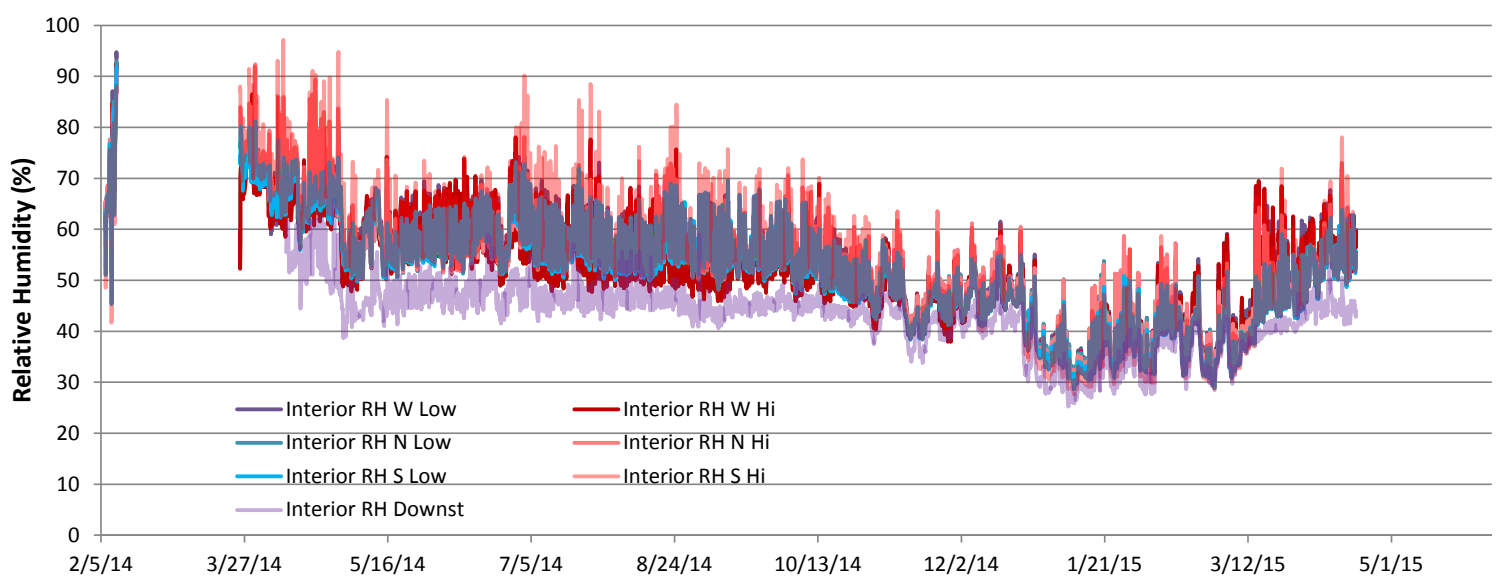

Figure 122. Houston attic and main conditioned space RH 
The high RH outliers in the early (March 2014) data are south high and north high attic sensors, which are consistent with previous dew point measurements and moisture stratification.

Space conditioning was run from May 2014 onward; the interior main floor space ran 45\%-55\% $\mathrm{RH}$ in summer, and the attic typically cycled at 50\%-70\%. Wintertime interior RHs were typically $30 \%-50 \%$ because the exterior dew point was lower and the house was unoccupied.

\subsection{Unvented Roof Measurements}

The following plots show roof sheathing and wafer sensor MCs on the left-hand axis); peak RH is on the right hand axis. Results for the unvented roofs UV1 and UV2 are plotted in Figure 123 and Figure 124.

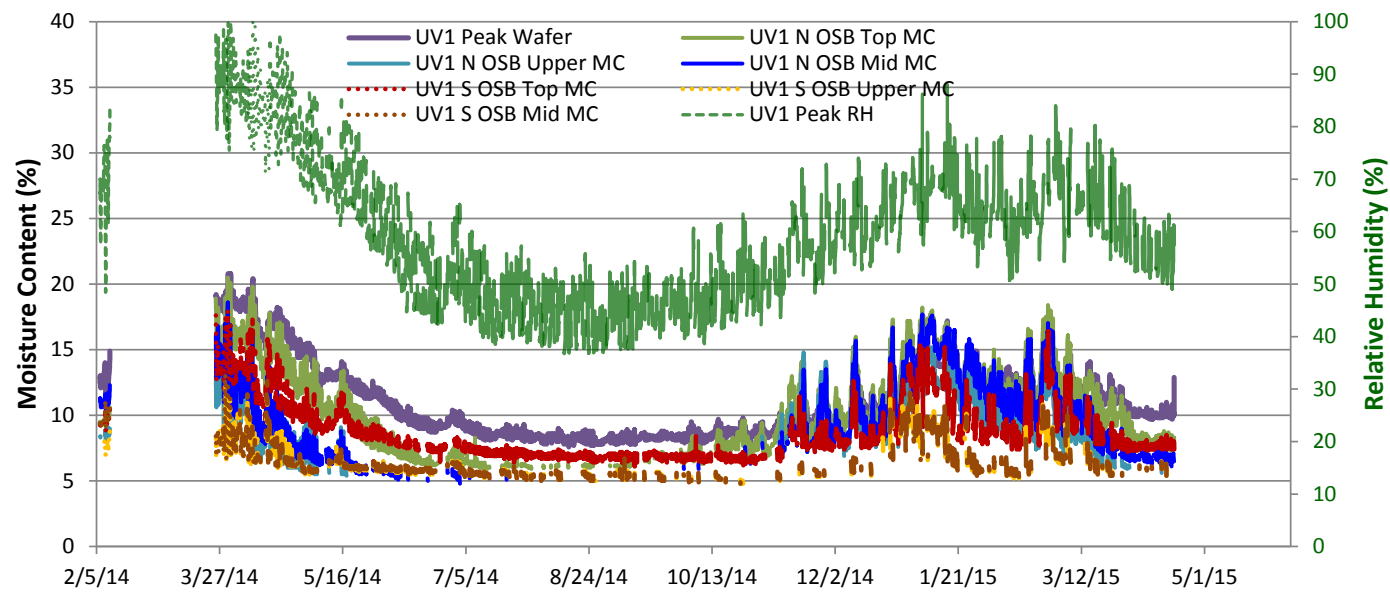

Figure 123. Unvented roof (UV1) roof MC and RH measurements

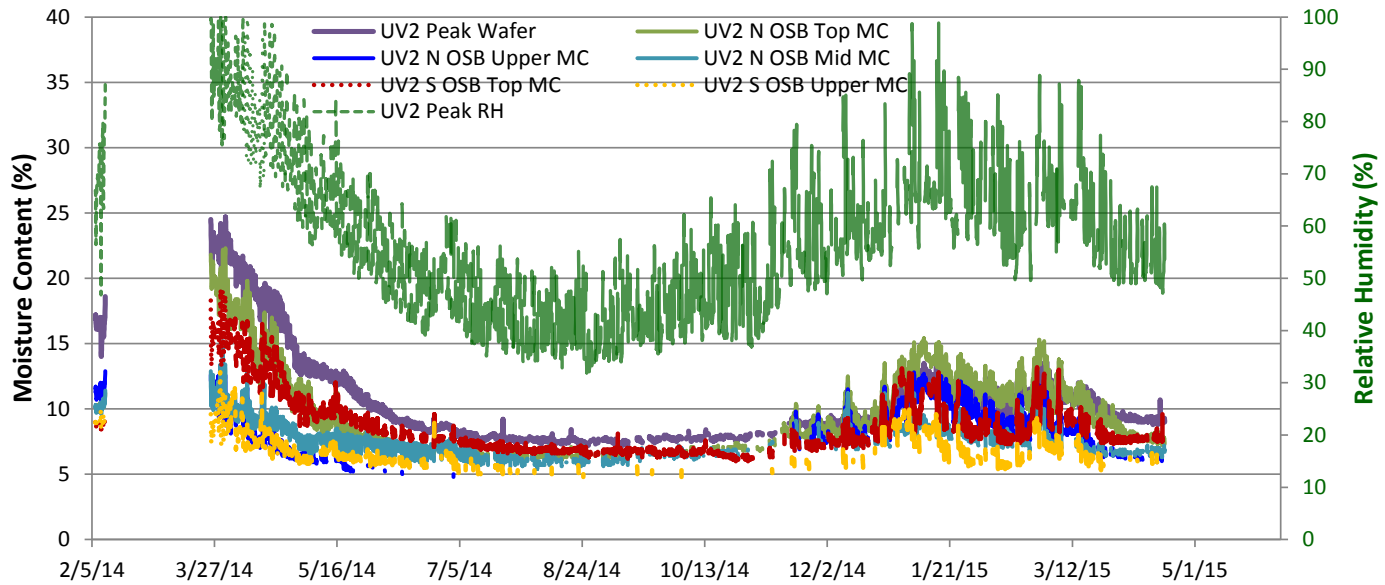

Figure 124. Unvented roof (UV2) roof MC and RH measurements

Unfortunately, the data logger failed in April 2014, so almost all the RH and MC channels were lost. The system will require a site visit for repair.

During the first winter (early 2014) the roof ridges/peaks clearly had high MCs and RHs; RHs were in the $80 \%-100 \%$ range, and some MCs were near or higher than $20 \%$. Only the falling 
side of the peak $\mathrm{MC} / \mathrm{RH}$ period was captured in data collection; the rising side occurred during the data gap during February and March). However, the trend in the gap is clear. The highest MC measurements were typically near the top of the roof assembly.

During the summer the outdoor temperatures rose and the thermal gradient shifted inward, so the RH and MCs both fell. Summertime peak RHs were 40\%-50\%. Wood MCs in the summer were consistently lower than $10 \%$, which is very dry and safe.

In winter 2014-2015 RH and MC measurements began to rise again, but stayed lower than the previous winter's measurements. RHs had occasional brief excursions higher than $80 \%$ in UV2. All MCs remained lower than 20\%, which does not reach the threshold for mold growth.

\subsection{Diffusion Vent Roof Measurements (Ridge)}

The diffusion vent roofs were plotted in a similar manner in Figure 125 (DV1), Figure 126 (DV2), Figure 127 (DV3), and Figure 128 (DV6). These roofs had a markedly different pattern than the unvented roofs: instead of a seasonal swing, the $\mathrm{RH}$ and $\mathrm{MC}$ measurements were relatively stable over the measurement period.

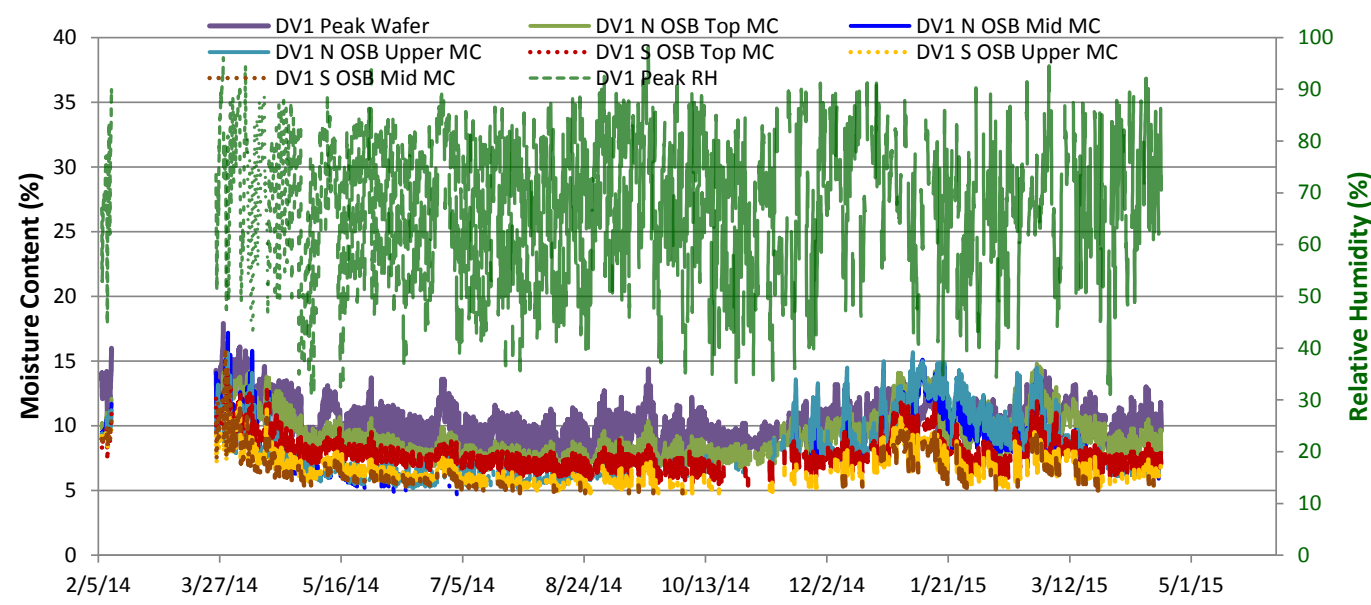

Figure 125. Diffusion vent (DV1) roof MC and RH measurements

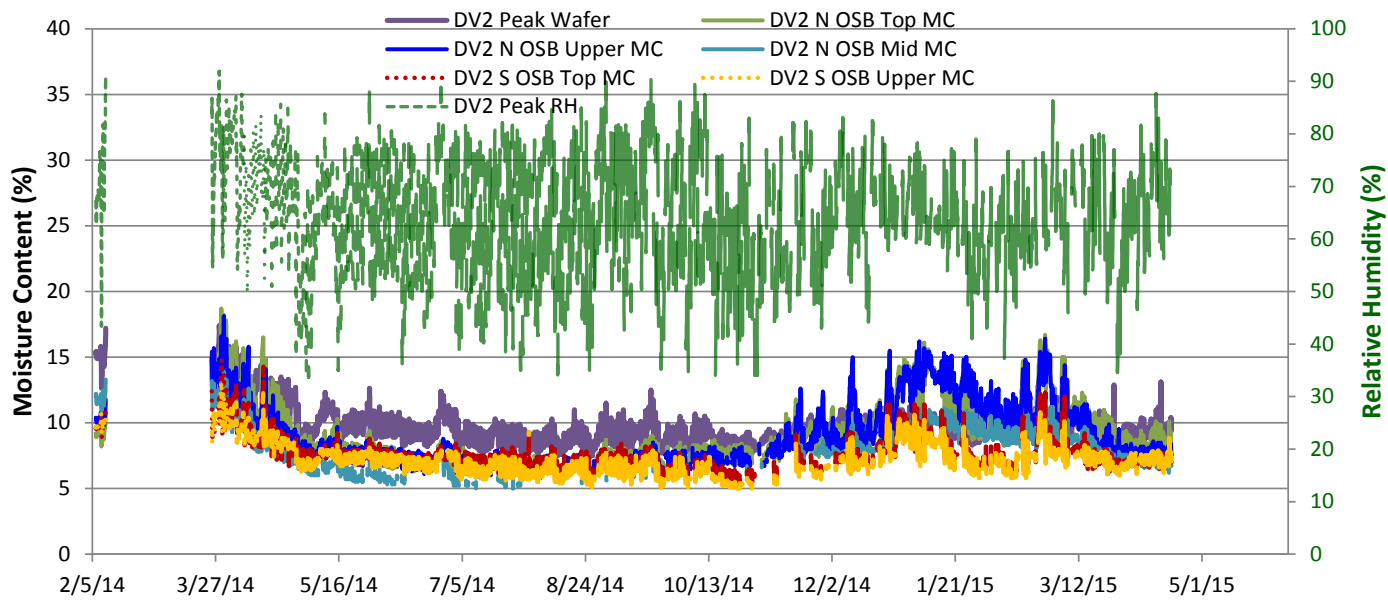

Figure 126. Diffusion vent (DV2) roof MC and RH measurements 


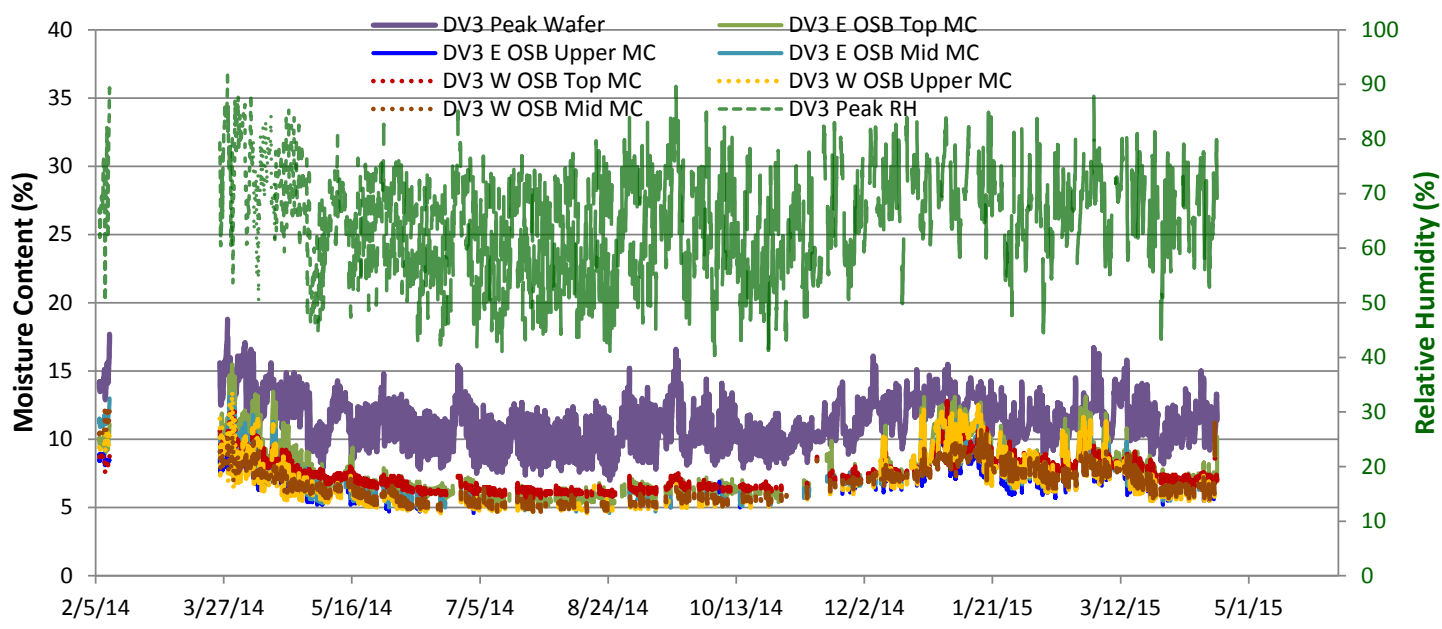

Figure 127. Diffusion vent (DV3) roof MC and RH measurements

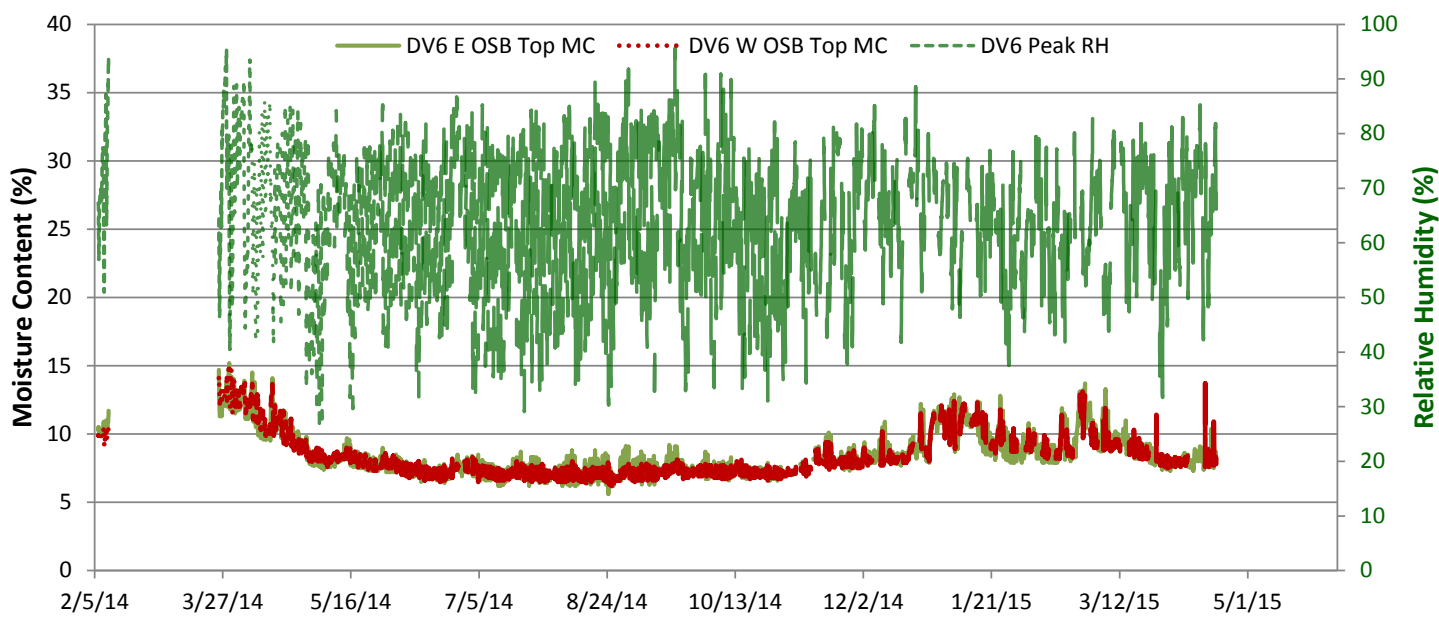

Figure 128. Diffusion vent (DV6) roof MC and RH measurements

In the diffusion vent roofs, initial winter MCs and RHs are much drier and safer than the unvented roofs. Peak MCs remain lower than 20\%. However, summertime MCs are higher than in the unvented roofs. In winter 2014-2015, wood MC rose but were again well within the safe range (typically lower than 15\%). The highest MCs were typically toward the peak of the roof. Roof peak RH measurements cycled on a diurnal basis; most readings are $50 \%-80 \%$. The diurnal RH cycling in the diffusion vent roofs shows a greater range than that in the unvented roofs.

The summertime diurnal pattern is shown in more detail in Figure 129, which plots 2 weeks from July 2014. The roof peak RH shows a consistent sawtooth pattern with a slow rise and a sharp daily fall. The drop in RH consistently occurs at 7 a.m., which is consistent with morning solar warming. In the late afternoons (typically 4-5 p.m.) the RH started to rise again and continued to overnight until the morning.

The MCs had a similar type of sawtooth behavior but over a much smaller range. 


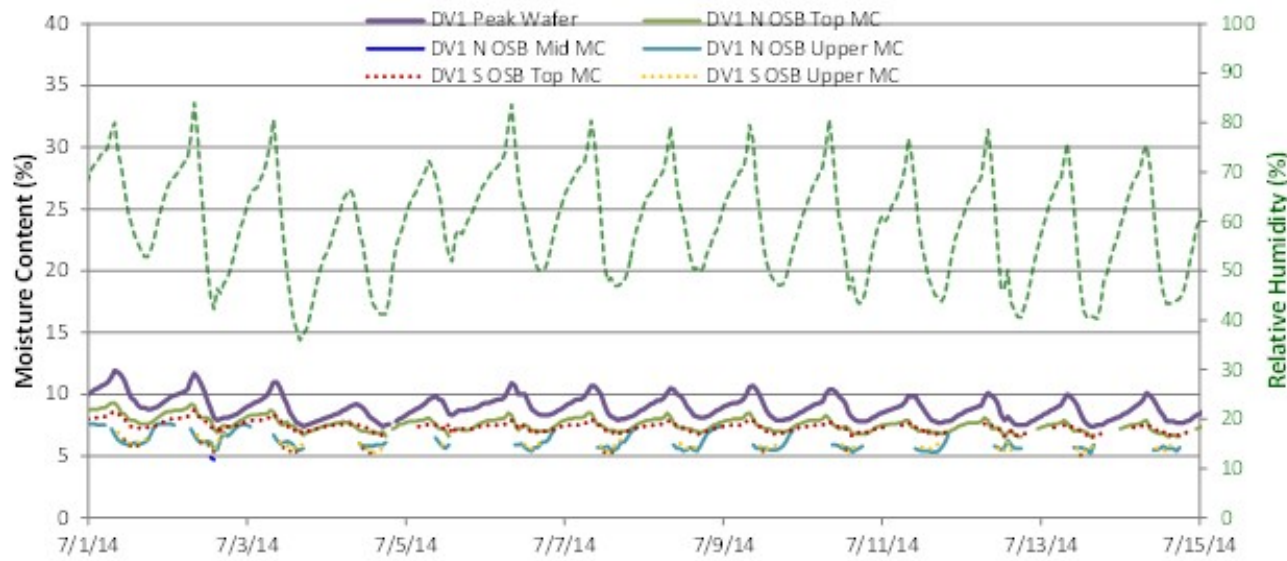

Figure 129. Diffusion vent (DV1) roof MC and RH measurements, summer (July 2014) detail

\subsection{Diffusion Vent Roof Measurements (Hip)}

Similar plots were generated for the diffusion vent roof detail at the hips (Figure 130 [DV4] and Figure 131 [DV5]). The hips are different from the ridge diffusion vents due to the limited amount of diffusion vent area (2-in.-diameter drilled holes near the peak).

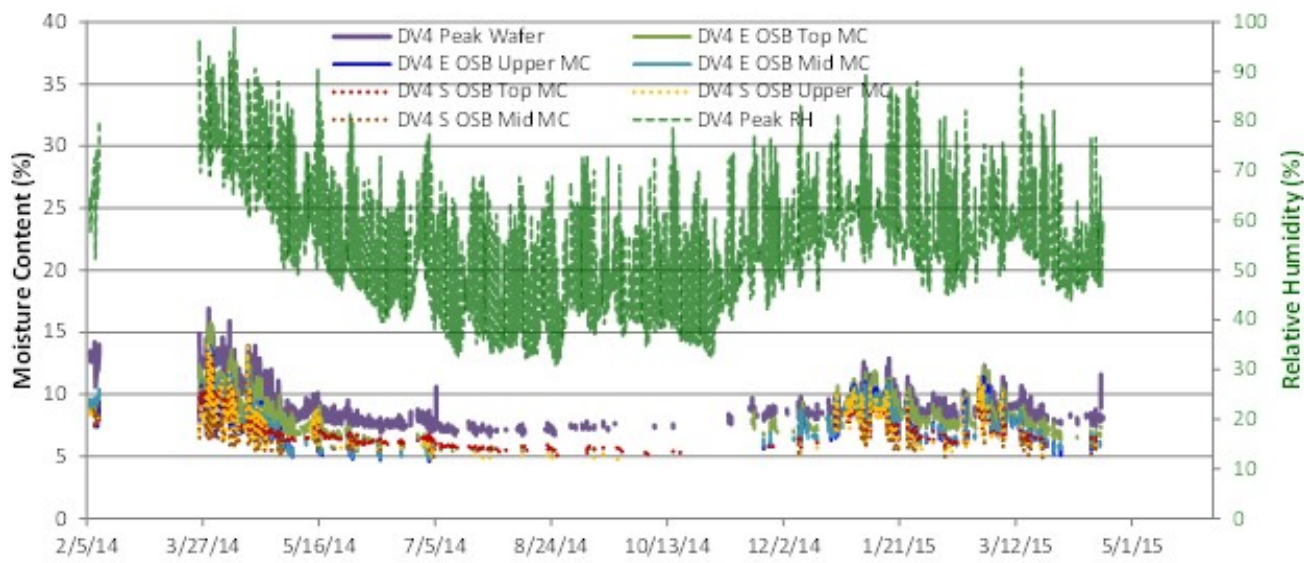

Figure 130. Diffusion vent at hip (DV4) roof MC and RH measurements

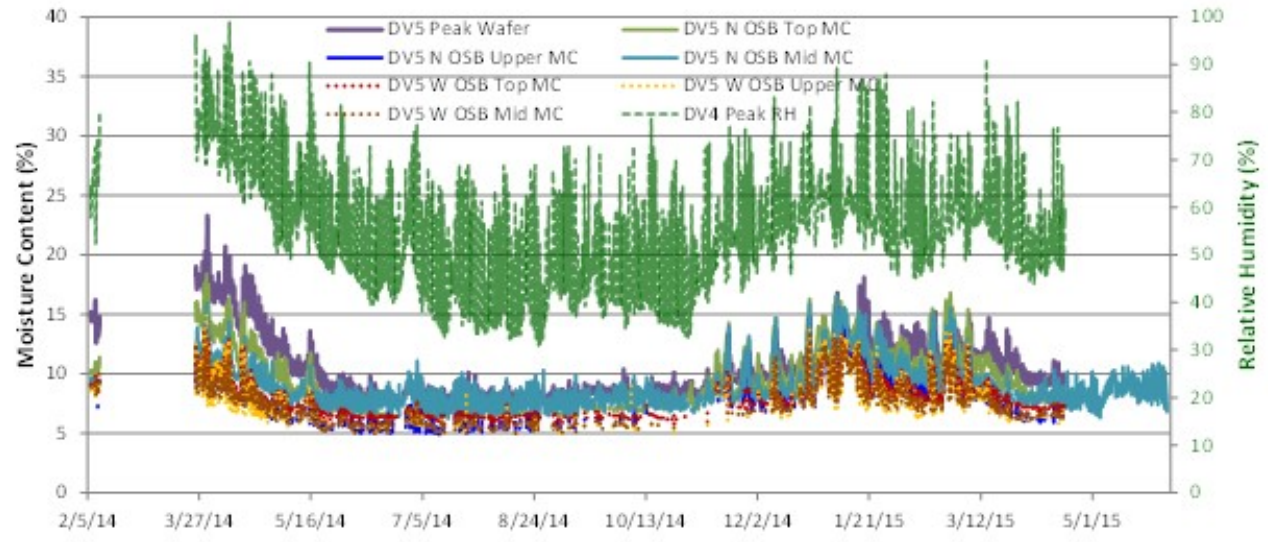

Figure 131. Diffusion vent at hip (DV5) roof MC and RH measurements 
These roofs exhibit behavior partway between the unvented and diffusion vent roofs. The RH and MC have noticeable seasonal swings; the peaks occur during the winters. Similar to the unvented roofs, winter 2014-2015 peak RHs and MCs were much drier than the first winter.

During the summer the RHs had a diurnal variation similar to the diffusion vent roofs with a slightly lower range $(40 \%-70 \% \mathrm{RH}$ versus $50 \%-80 \%)$.

Wood MCs remain mostly within the safe range; excursions higher than $20 \%$ occurred in only one roof during the initial winter.

\subsection{Inward Drive Experiment}

The interior-side RH and wafer MC for the inward drive experiment are shown in Figure 132; the exterior temperature is shown for reference. The experiment was put into operation in midApril 2014, when the clear acrylic plastic cover was installed and air sealed (red dotted line). This caused moisture to accumulate. The $\mathrm{RH}$ and wafer $\mathrm{MC}$ increased after the clear plastic cover was installed. Interior-side RHs had peaks higher than $90 \%$ during the summer, but decreased during the early winter when outdoor temperatures dropped.

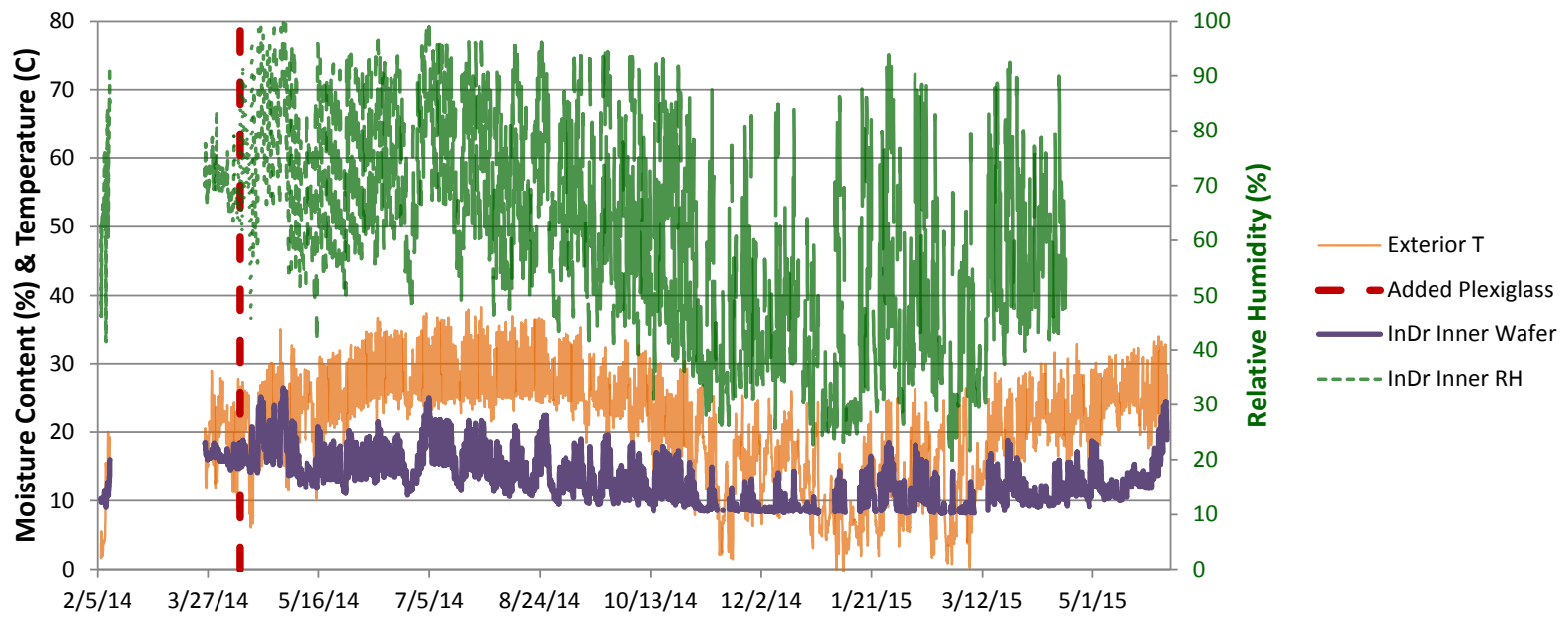

Figure 132. Inward drive interior-side RH and wafer sensor with outdoor temperature

The interior-side RH and wafer MC measurements moved in parallel, as expected. In a previous calibration (Ueno and Straube 2008), the wafer sensors came to equilibrium with $100 \% \mathrm{RH}$ conditions (air in a closed container over water) at 28\%-30\% MC; immersing the sensors in liquid water increased MCs to $40 \%-45 \%$. The wafer MCs remained lower than $28 \%-30 \%$, which indicates no condensation or $100 \% \mathrm{RH}$ conditions (consistent with RH results).

The inward drive roof sheathing MC is plotted with other lower sheathing MCs (same south orientation, both unvented and diffusion vent) in Figure 133. The wafer MC and outdoor temperature are also plotted for reference. The sheathing $\mathrm{MC}$ in the inward drive experiment is consistent with the other sheathing MCs, which points away from the accumulation of moisture within the sealed box. 


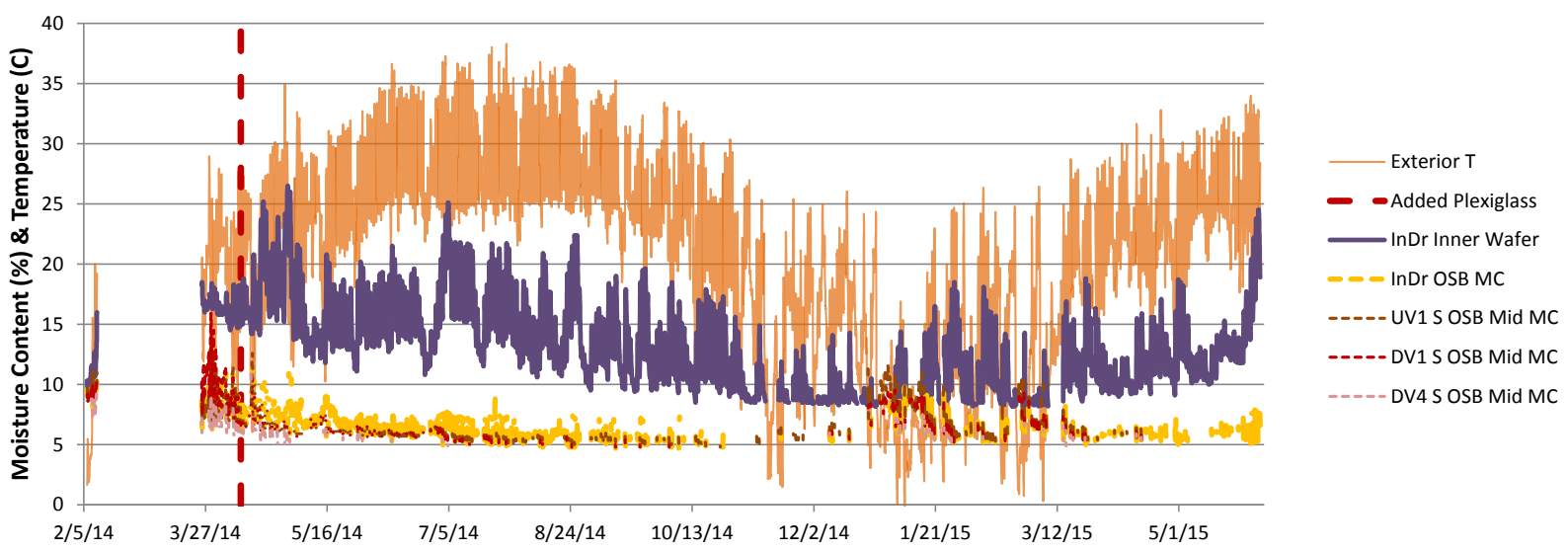

Figure 133. Inward drive wafer sensor MC and sheathing MCs with outdoor temperature

The wafer MC (and $\mathrm{RH}$ ) data were examined to see if correlations could be found with exterior weather events. Comparisons with interior and exterior dew point showed minimal relationships. Precipitation was also plotted for correlation (Figure 134), given that wetted shingles are a suspected moisture source for inward drive. Although some wafer MC spikes correlated with precipitation, many other events were uncorrelated.

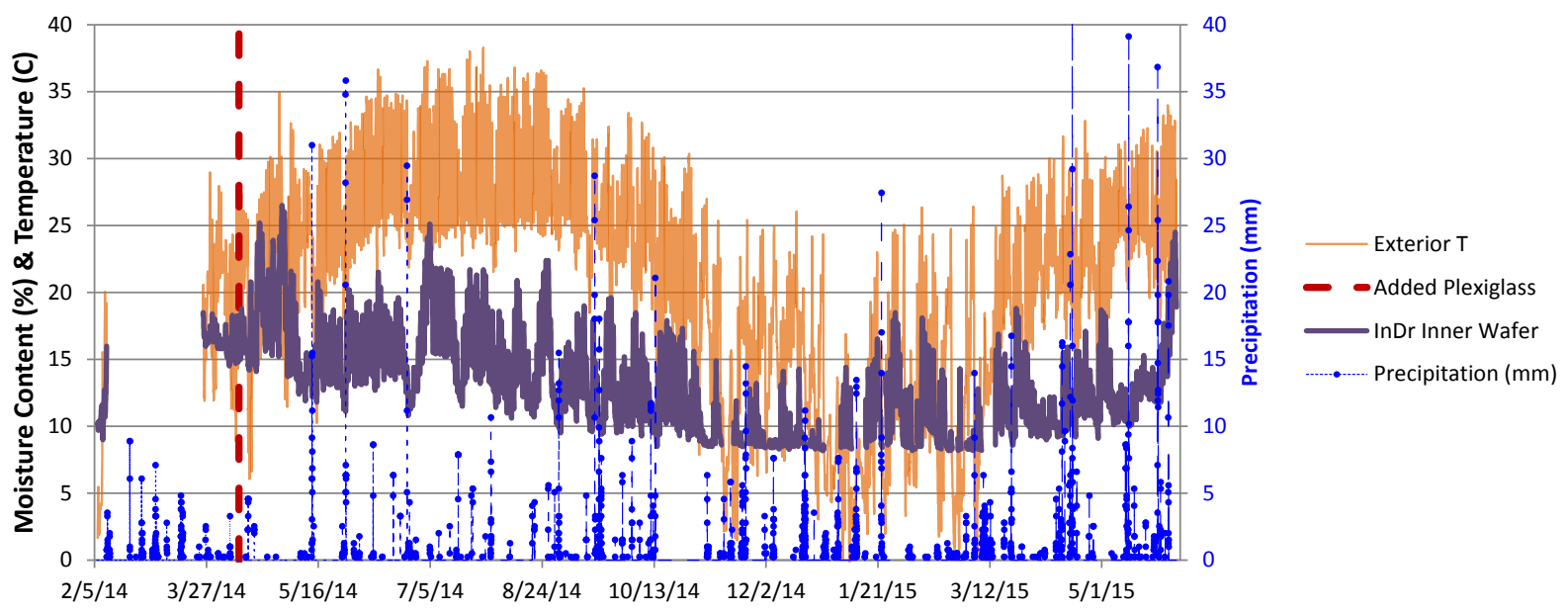

Figure 134. Inward drive wafer sensor MC and precipitation with outdoor temperature

The most direct correlation to the wafer data was found by plotting the exterior sheathing temperature as a 24-hour rolling average (Figure 135); this is consistent with adsorbed moisture being driven from warm/hot sheathing to the cool interior side of the assembly or ping-pong water within the closed system. The correlation was very clear from May through August 2014 (Figure 136). 

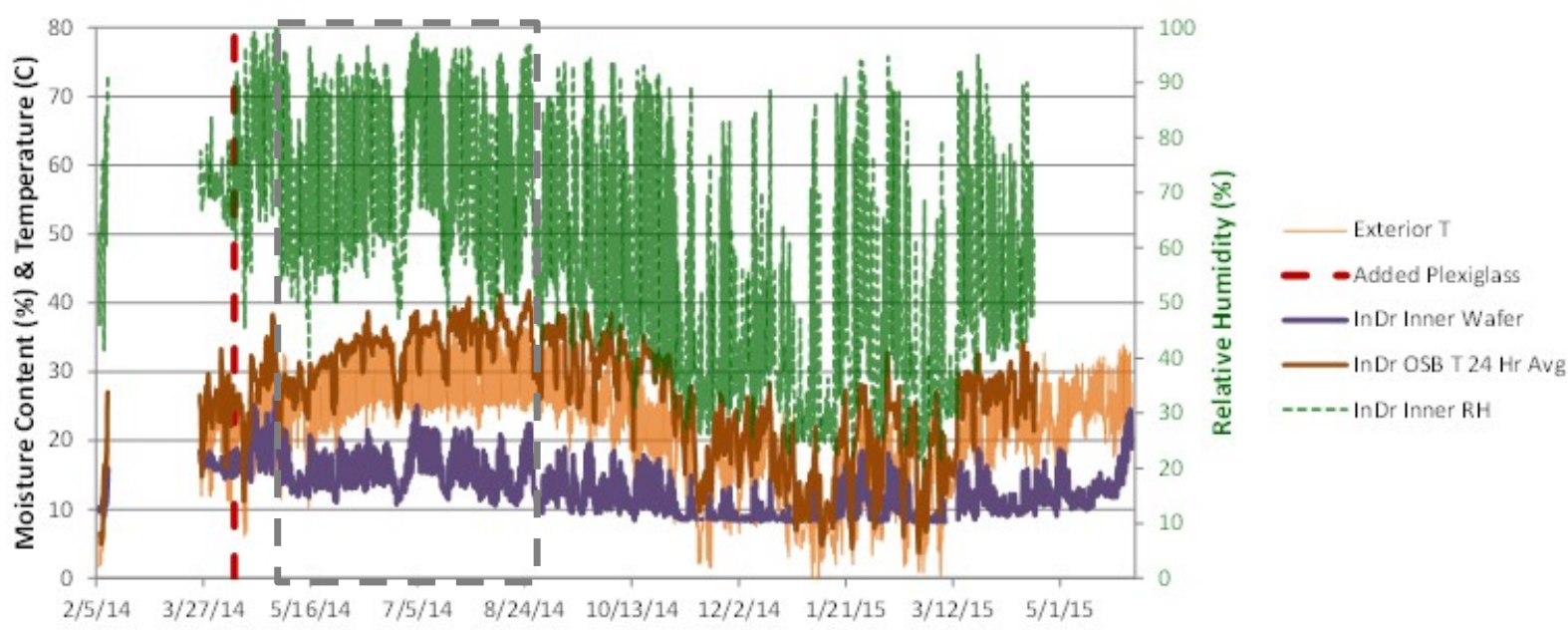

Figure 135. Inward drive interior-side $\mathrm{RH}$, wafer $\mathrm{MC}$, and sheathing temperature 24-hour average

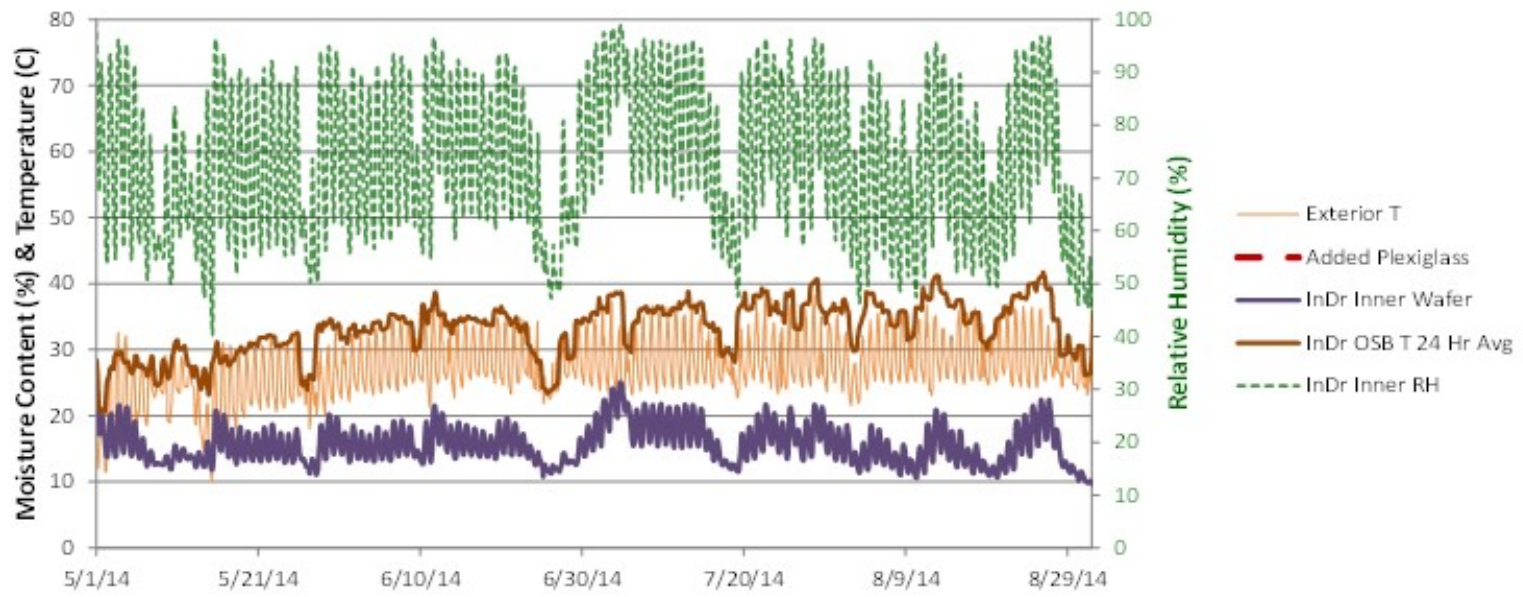

Figure 136. Inward drive interior-side $\mathrm{RH}$, wafer $\mathrm{MC}$, and sheathing temperature 24-hour average (summertime detail)

Overall MCs did not rise over time. This is an argument against moisture being driven through asphalt shingle layers (which would accumulate in the closed assembly) with a typical roof cladding and WRB (asphalt shingles with \#15 felt). 


\section{Hot-Humid Climate (Houston) Analysis}

\subsection{Diffusion Vent and Unvented Roof Comparisons}

A representative example of the relative behavior of the unvented and diffusion vent roof is shown in Figure 137, which plots roof ridge RH and wafer MC, for diffusion vent (DV1) and unvented (UV1) roofs.

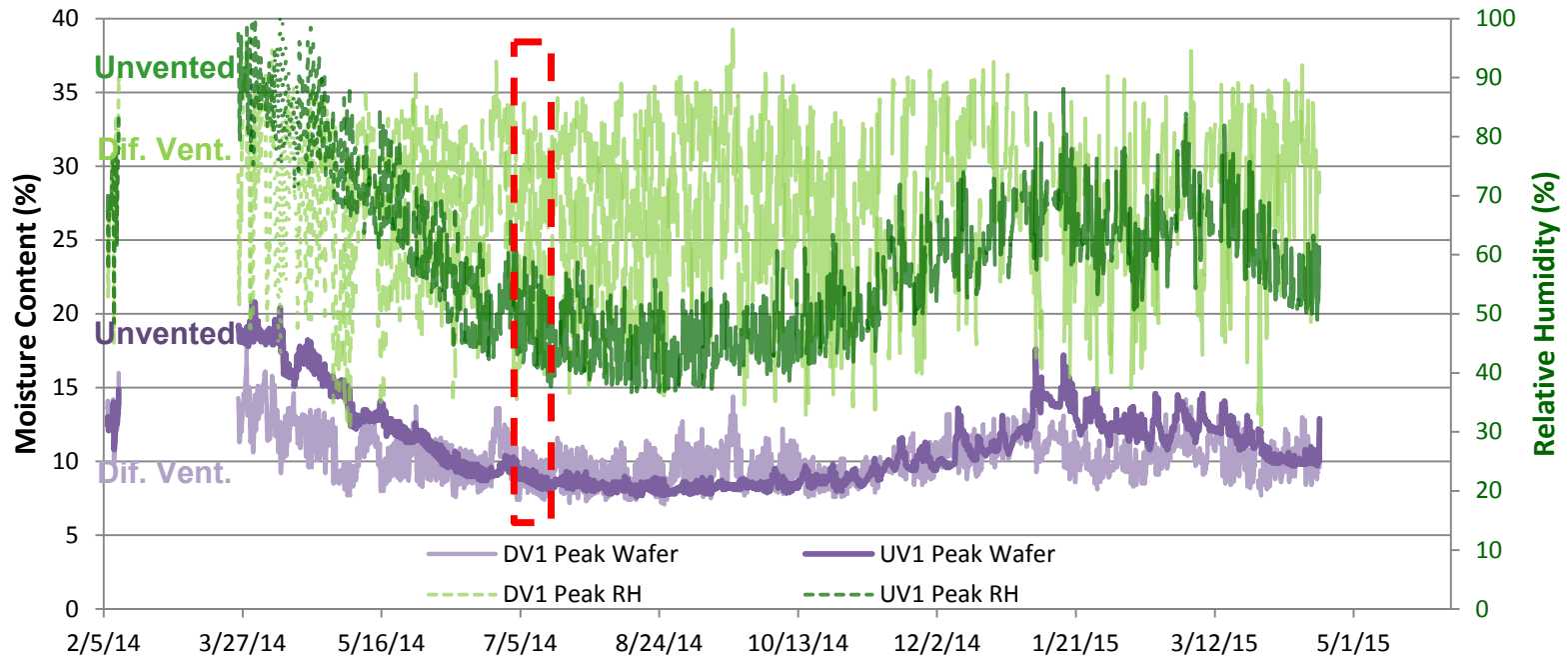

Figure 137. Diffusion vent (DV1) and unvented (UV1) comparison (ridge RH and wafer MC)

The unvented roof shows the seasonal rise and fall (wetter during the winter), and dry conditions during the summer. During the winter, interior moisture accumulates at the ridge under the vapor-impermeable membrane. During the summer, the thermal gradient drives moisture downward and out of the assembly; the vapor-impermeable membrane prevents exterior moisture from entering.

In comparison, the diffusion vent roof was drier during the winter, because the material is vapor permeable. During the summer RHs were higher than the unvented roof, possibly because it was connected to the exterior moisture conditions via the vapor-open ridge. This connection could also explain the diurnal cycling of RH levels.

The diurnal cycling of RH levels was examined more closely for July 2014 (Figure 138), which zooms in on the area highlighted by the red box in Figure 137. As mentioned earlier, the diffusion vent ridge $\mathrm{RH}$ has a sawtooth pattern; a sharp drop in RH occurred in the mornings between 6 a.m. and 8 a.m. In contrast, the unvented roof's diurnal cycles were offset by several hours; the peak and drop off occurred between $10 \mathrm{a} . \mathrm{m}$. and 12 noon. These two ridge locations were on the same roofline and should have seen identical solar exposure. 


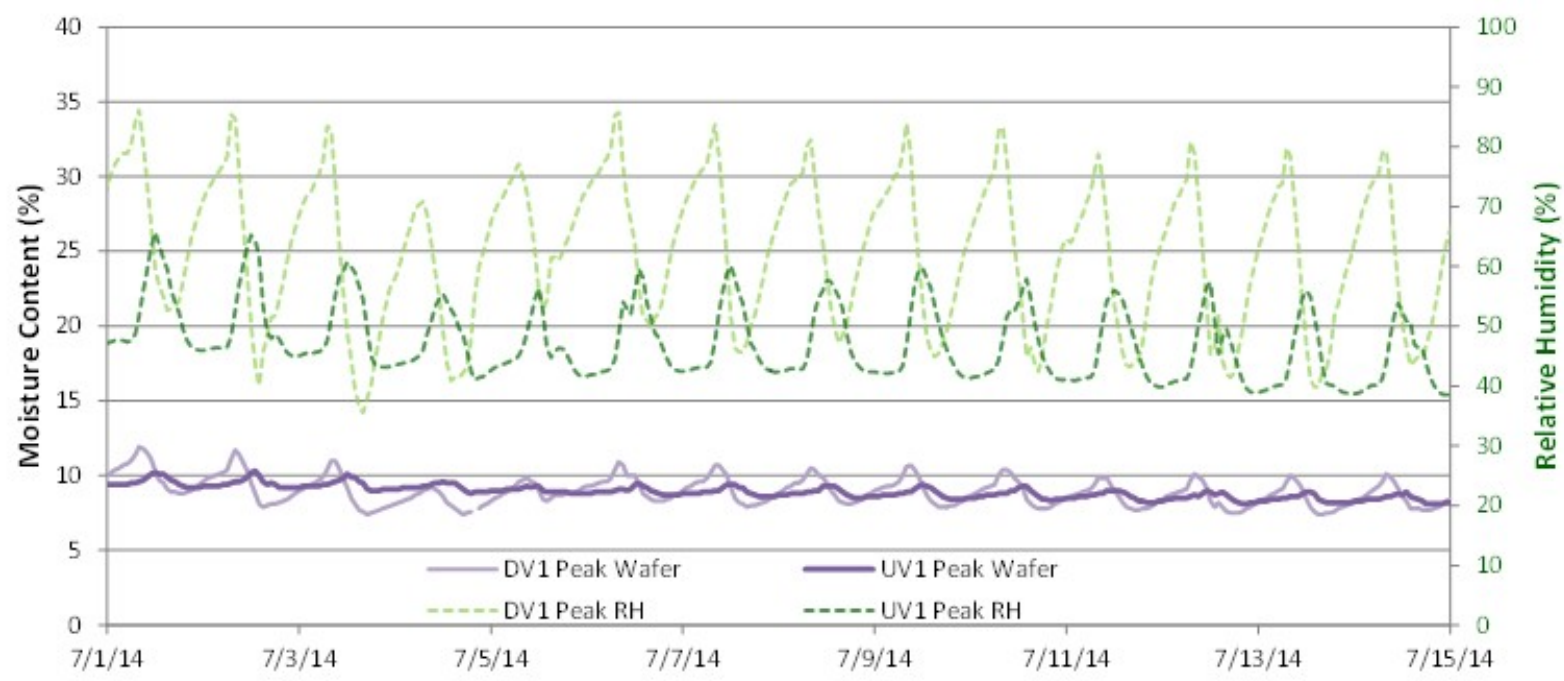

Figure 138. DV1 and UV1 comparison (ridge RH and wafer), summertime detail

Ridge RHs were plotted with ridge temperatures (Figure 139) to determine if temperature anomalies caused the offset behavior. Ridge temperatures tracked identically between the two roofs. Rising temperatures correlated with (1) a drop in DV1 RH and (2) a rise in UV1 RH (gray lines). The diffusion vent roof typically had $5.5^{\circ} \mathrm{F}\left(3^{\circ} \mathrm{C}\right)$ lower peak temperatures than the unvented roof. This difference may reflect evaporative cooling from the diffusion vent roof.

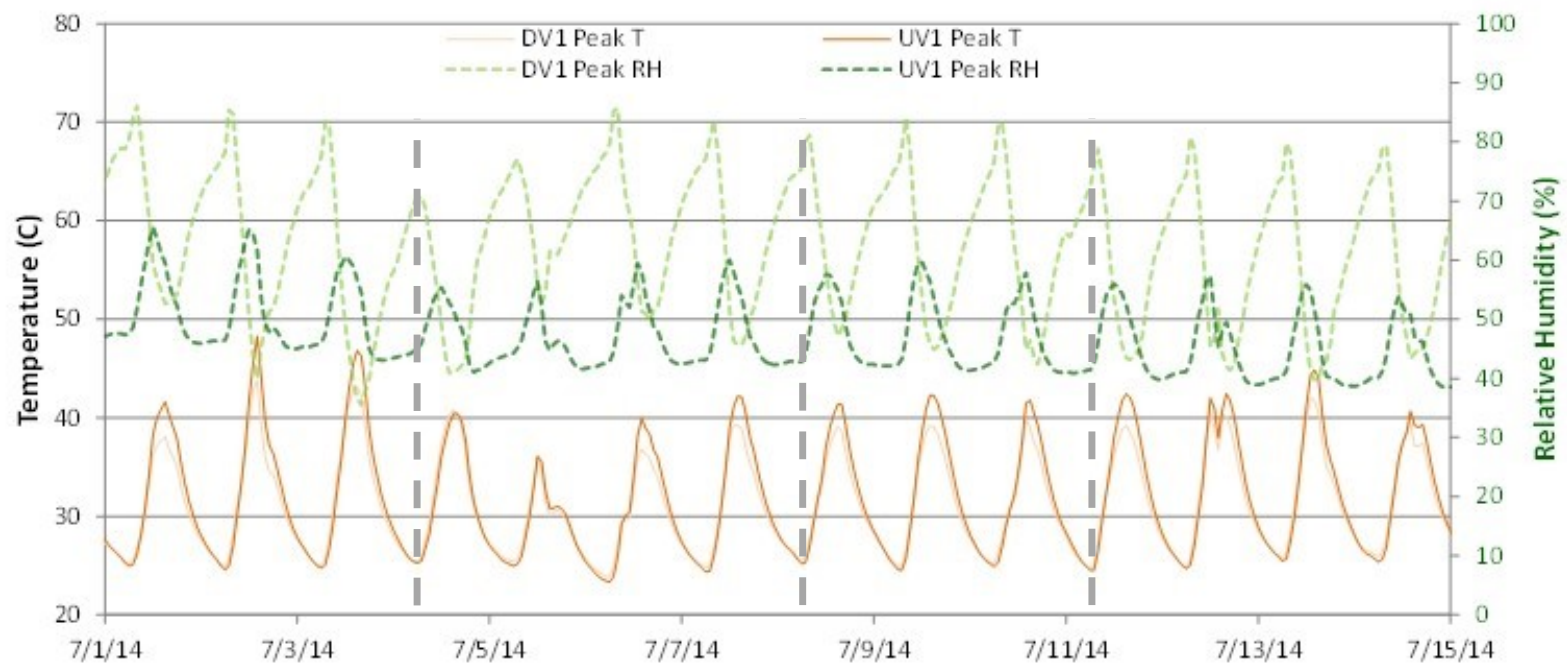

Figure 139. DV1 and UV1 comparison (ridge RH and wafer), summertime detail

As another reference, the roof $\mathrm{T} / \mathrm{RH}$ sensors are plotted in terms of dew point temperature (absolute air moisture content) with interior (attic) and exterior dew points (Figure 140). The dew point at the ridge rises higher than attic conditions (blue lines) and exterior conditions (orange). More importantly, in terms of absolute moisture content, the unvented roof has higher (wetter) peaks than the diffusion vent roof, so the order in Figure 138 is reversed. 


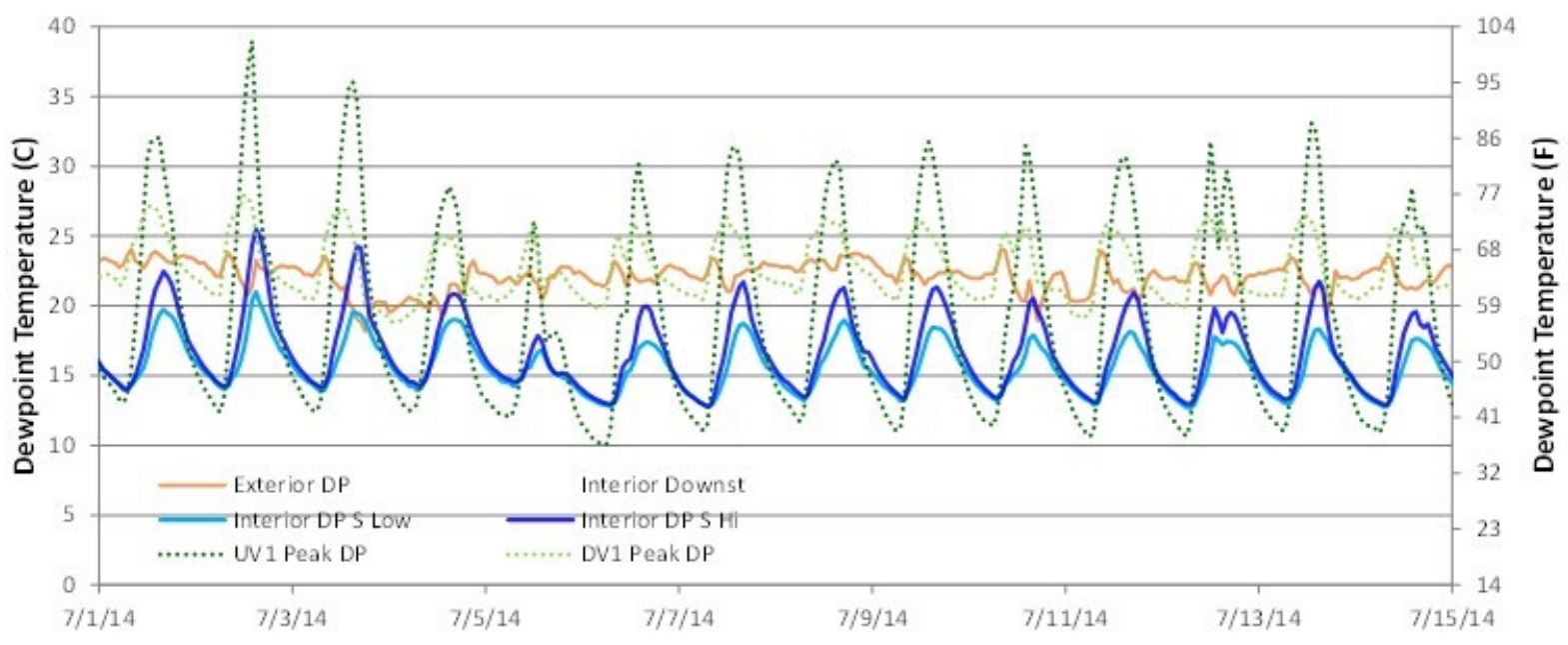

Figure 140. Summertime dew point comparison: interior, attic, exterior, and UV1/DV1

In general, dew point spikes at the ridge are likely caused by the heating of roof sheathing, which in turn releases (desorbs) adsorbed moisture. This could easily drive dew points higher than interior conditions in the main attic space given moisture stratification.

In the afternoons and evenings the ridge dew points dropped. The unvented roof dew point dropped much lower than ambient conditions, and the diffusion vent roof tracked closer to ambient. This reflects the vapor-open ridge material, which coupled exterior and interior moisture conditions.

Overall these monitoring results are consistent with the vapor-open diffusion vent ridge that allowed drying in winter and provided an entry point for ambient moisture in the summer.

\subsection{ASHRAE 160 Analysis}

ASHRAE Standard 160 (ASHRAE 2009b) provides guidance on moisture analysis for building envelope design, including the moisture performance evaluation criteria. The failure criteria (defined as the risk of mold growth) were redefined in addendum (a) (ASHRAE 2011), as follows:

6.1 Conditions Necessary to Minimize Mold Growth. In order to minimize problems associated with mold growth on the surfaces of components of building envelope assemblies, condition shall be met: a 30-day running average surface $\mathrm{RH}<80 \%$ when the 30-day running average surface temperature is between $5^{\circ} \mathrm{C}$ $\left(41^{\circ} \mathrm{F}\right)$ and $40^{\circ} \mathrm{C}\left(104^{\circ} \mathrm{F}\right)$.

Materials that are naturally resistant to mold or have been chemically treated to resist mold growth may be able to resist higher surface relative humidities and/or to resist for longer periods as specified by the manufacturer. The criteria used in Addendum a to Standard 160-2009 the evaluation shall be stated in the report.

The collected data were analyzed using ASHRAE 160 criteria; 30-day running averages of the ridge $\mathrm{RH}$ and temperature were calculated for each hour and the resulting pass/fail results 
tabulated. In a strict intepretation of Standard 160, a single failing hour would constitute an assembly failure. The number of failing hours for each assembly is shown in Table 12.

Table 12. Hours and Percent of Monitored Period Failing ASHRAE 160 Criteria

\begin{tabular}{c|c|c}
\hline Wall & \# Failure Hours & \% Time Failure \\
\hline Unvented 1 & 427 & $5 \%$ \\
Unvented 2 & 238 & $3 \%$ \\
\hline Diffusion Vent 1 & 0 & $0 \%$ \\
\hline Diffusion Vent 2 & 0 & $0 \%$ \\
\hline Diffusion Vent 3 & 0 & $0 \%$ \\
\hline Diffusion Vent 4 & 0 & $0 \%$ \\
\hline Diffusion Vent 5 & 0 & $0 \%$ \\
\hline Diffusion Vent 6 & 0 & $0 \%$ \\
\hline
\end{tabular}

The only roofs that have failing ASHRAE 160 hours are the unvented assemblies; these failures occurred during the first winter. These early data were missing 2 months due to power issues; the missing data would have added failing hours. No failing hours occurred in the unvented roofs during the second winter. However, there is no interior moisture generation in this house (unoccupied conditions/model home), which lowers wintertime condensation risks.

Although ASHRAE 160 is commonly considered to be an overly conservative standard, this analysis indicates that the diffusion vent roof has a greater margin of safety than conventional unvented designs. However, it does not answer the question whether the diffusion vent provides sufficient drying to avoid problems under typical occupancy conditions (with interior moisture generation). 


\section{Conclusions and Further Work}

\subsection{Cold Climate (Chicago) 10.1.1 Experimental Results and Conclusions}

Seven roof assemblies were monitored in a Chicago-area test bed, including six unvented assemblies and one control vented cathedral roof assembly. High interior moisture loading conditions were used $-22^{\circ} \mathrm{C}\left(72^{\circ} \mathrm{F}\right)$ and $50 \% \mathrm{RH}$; the roofs were monitored from October through June. The data captured winter 2013-2014 and the following spring and early summer.

Under these conditions, all roofs except the vented cathedral assembly experienced wood MC and RH levels high enough to constitute failure.

- The unvented dense-pack cellulose roof experienced sheathing MCs well in excess of $40 \%$ at the peak (risk of mold, rot, and decay). MCs lower in the roof were less severe (above 30\%) but were still high risk. In this roof and the remaining roofs, these sheathing MCs were corroborated by rafter MC and roof peak RH. The roof peak wafer MC indicated that liquid water condensation was occurring at the peak of all roofs except the vented cathedral assembly.

- The diffusion vent roof had similar behavior to the unvented cellulose roof; however, in the spring (as outdoor temperatures rose), moisture levels (both MCs and RHs) fell much more rapidly in the diffusion vent roof.

- The cellulose top vent roofs showed similar behavior to the unvented roof with very high MCs at the peak. The addition of the top vent detail showed no appreciable advantage over the unvented dense-pack cellulose assembly. The roof assembly with interior GWB has drier moisture levels at the lower portions of the roof than the assembly without GWB. This finding is consistent with that for painted GWB, which controls air leakage and vapor flow. These roofs had springtime drying rates similar to the diffusion vent roof, possibly due to upward drying into the air cavity.

- The fiberglass batt top vent roofs also had very high moisture levels; there was much more variation in MCs. A wintertime field visit showed significant condensation at the insulation-sheathing interface. When these roofs dried in the spring, the uppermost sections of the roof stayed wet the longest, and the lower sections dried out first.

Other general patterns from the roof monitoring were observed. They included consistent indications of moisture stratification (the highest MCs were in the upper sections of the roof), and drier conditions on the west side (due to solar gain) than on the east side.

The results were analyzed using ASHRAE Standard 160 to determine risk of mold growth. All the unvented roof assemblies failed for significant parts of the spring. These failures demonstrated that moisture levels remained high into the warmer weather and allowed mold growth.

The roof was disassembled at the end of the experiment to correlate measurements with actual assembly conditions. The unvented fiberglass batt roofs had wet sheathing and mold growth but no structural failure. The cellulose roofs had only slight issues, such as rusted fasteners, staining, 
and sheathing grain raise, despite the extreme moisture conditions measured. This difference was ascribed to cellulose's borate preservatives (borate salts added as a fire retardant and antifungal agent), its airflow-retarding properties, and its ability to safely store moisture. The worst moisture damage in the roof assemblies was seen closer to the ridge, consistent with the monitored data. The comparison between fiberglass batt and dense-pack cellulose puts the fiberglass at a disadvantage because the batt installation has voids and air gaps. A fairer comparison would have been dense-pack cellulose versus blown-in fiberglass.

Based on the high interior moisture loading $(50 \% \mathrm{RH})$ of this test, none of these unvented assemblies are recommended. These include unvented cellulose roofs; although minimal actual damage was observed, all monitoring results indicated very high-risk conditions for long-term durability.

\subsubsection{Further Work}

Although all the unvented roofs essentially failed under these experimental conditions, further research might be warranted for more robust assemblies in $\mathrm{CZ} 5 \mathrm{~A}$.

For instance, the use of a less-open vapor-control layer than latex paint on GWB (Class III vapor retarder) might be researched. Class II vapor retarders ( 0.1 to 1 perm) options should be considered, including vapor retarder paint on GWB or variable-permeability vapor retarder films. The experiment also should simulate air leakage (possibly in a second winter after a baseline is established) to show the effects of imperfections in the air barrier, which occur commonly in construction. A Class I vapor barrier (polyethylene) is not recommended.

Another option to consider is a diffusion vent roof with a higher perm rating, similar to the assembly installed in the Houston roof (200+ perm membrane versus 50+ perm exterior GWB). This configuration might be combined with the use of an interior vapor control layer.

If a top vent assembly is being considered as an experimental option, sheathing with a higher permeance than OSB (i.e., plywood) should be used (Schumacher and LePage 2012). A larger vent space should be considered.

Finally, a common geometry in retrofit insulation is a short section of sloped compact roofceiling assembly, which connects two smaller attics ( story-and-a-half geometry; Figure 141). Retrofit dense-packing of the short section of the rafter bay is a very cost-effective method to insulate and reduce air leakage, but it is nominally an unvented roof that does not meet code. On the other hand, the top of the assembly is typically vapor-open. It offers diffusion drying and limited air leakage drying at the terminations and transitions.

Experiments could be devised to test these types of assemblies to determine whether moisture risks are controlled in this assembly. This research may provide guidance about specifics such as acceptable materials, required densities, and maximum rafter bay lengths. 

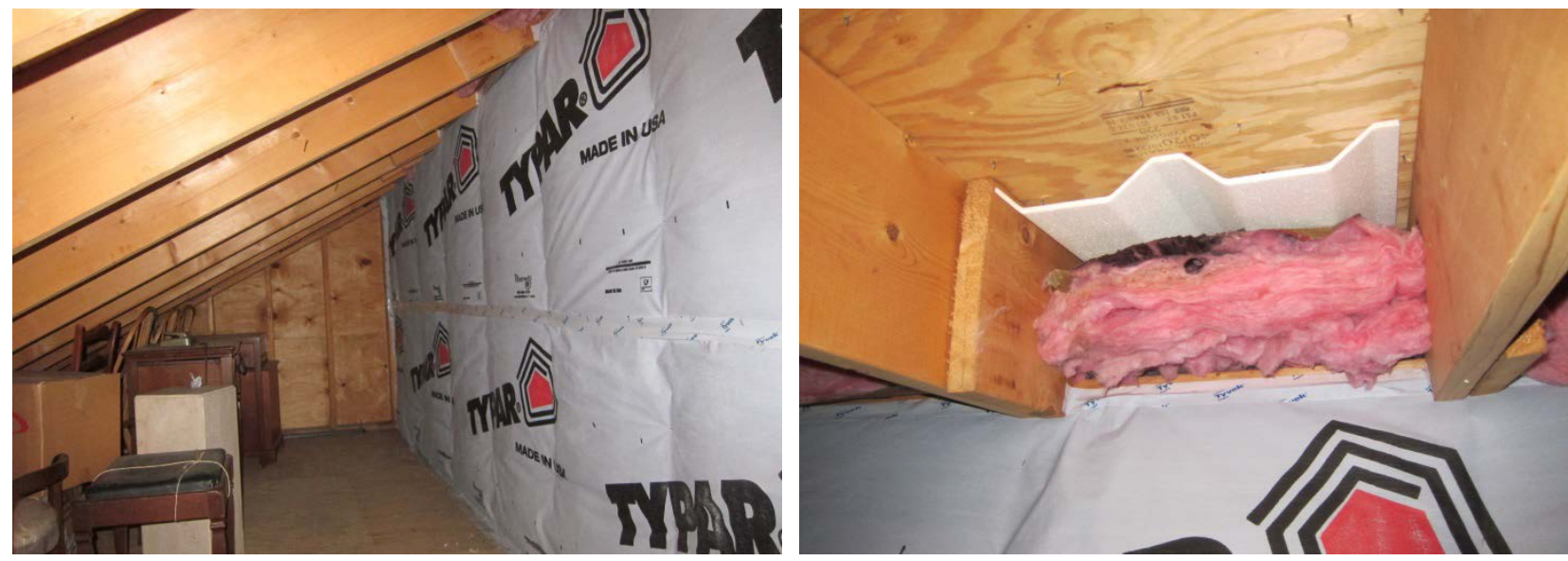

Figure 141. Story-and-a-half compact roof example (with insulation and ventilation chute)

\subsection{Hot-Humid Climate (Houston)}

\subsubsection{Experimental Results and Conclusions}

An unoccupied model house with a conditioned/unvented roof was built in the Houston area and monitored. The roof was insulated with fiberglass insulation blown/adhered directly onto the underside of the roof sheathing. Most of the roof has a diffusion vent detail at the ridge and hips (high-permeance membrane over openings) with some sections of conventional unvented roof (self-adhered bituminous membrane) used as a control comparison.

The roof was monitored February 2014 through June 2015 (16 months); attic conditions were not directly controlled, but were indirectly conditioned by duct leakage and air leakage from the interior. As expected, attic temperatures and dew point temperatures (absolute air MC) were between interior and exterior conditions but generally closer to interior conditions. The dew points showed a diurnal cycle that was consistent with moisture adsorption and desorption from the roof sheathing.

In the control unvented roofs, roof peak RHs reached $90 \%$ and higher during the first winter; as exterior conditions warmed, RHs quickly fell to $40 \%-50 \%$ in the summer because the inward thermal gradient pushed moisture out of the roof sheathing and inward. MC measurements were consistent with RH measurements. Initial winter conditions were higher than levels recommended for durability but fell to safe levels in the summer. In the second winter (2014-2015) peak RHs rose again (60\%-80\% was typical) but not to the same levels as during the first winter.

In contrast, the diffusion vent roofs had drier conditions at the roof peak in wintertime, but during the summer, RHs and MCs were higher than under the unvented roof. However, these moisture levels were well within the safe range. The diffusion vent roof also showed strong diurnal variations of RH levels. Both of these behaviors are consistent with the roof rafter bay having a hygric/moisture connection to outside air due to the vapor-open diffusion vent. The hip roofs treated with a diffusion vent showed behavior halfway between the unvented and diffusion vent roofs. This behavior was attributed to the limited diffusion vent area (2-in.-diameter drilled holes rather than a 3-in. strip) available in the hip geometry. 
The first and second winters had different interior conditions. The first winter had high RHs due to drying of construction moisture); the second winter had low RHs, because there were no occupants to generate moisture.

Overall, these results indicate that the diffusion vent roof experiences more drying and less wintertime moisture accumulation than the unvented roof. However, the unvented roof did not have MCs high enough to truly constitute failure.

An experiment was also devised to examine the effect of inward vapor drives in unvented roof assemblies; for instance, moisture in the shingle laps was driven inward. A section of rafter bay was isolated with vapor impermeable materials and an airtight acrylic plastic interior cover. The monitored data did not show a growing or ratcheting MC. These results are consistent with moisture adsorbing and desorbing from the sheathing (ping-pong moisture) rather than being driven through the shingles.

The air leakage measurements of the unvented attic showed leakage at roof-wall connections. This situation shows a potential challenge of substituting air-permeable insulation for airimpermeable spray foam; greater attention will be required to ensure good air barrier detailing at the connections.

\subsubsection{Further Work}

Results are still being collected and analyzed at the experimental roof in Houston. An instrumentation failure from April 2015 is slated to be repaired. As discussed earlier, the unvented roof assembly was not driven to failure; the failures seen in previous work in Houston and Jacksonville were not replicated.

One issue was the lack of interior moisture generation in the unoccupied model house, which results in lower wintertime RH levels. Higher interior RH levels would increase moisture conditions in the attic and increase condensation risks.

To understand the effect of operating the house in unoccupied conditions (no interior moisture generation), the interior conditions were compared to those collected circa 2001-2002 by Rudd and Henderson (2007). Their data covered new-construction Houston-area houses built under the Building America program with added energy-efficiency features (good airtightness, unvented attics, low solar gain windows). Some houses also had dehumidification systems installed (a standalone dehumidifier or two-stage cooling equipment). Data were recorded in both the main space and the unvented attic space. All of these houses were occupied.

Results are presented as whisker/box plots showing the range and distribution of measured MCs. The whisker/box plots show the data set's median (center of box), the lower and upper quartile (extent of box), and maximum/minimum (lines extending from box). Results are shown for interior temperature (Figure 142), RH (Figure 143), and dew point (Figure 144). Data were selected for the winter periods (December-February) in all houses.

Figure 142 shows that the diffusion vent roof test house was operated at a higher temperature than the circa 2001 Building America houses and with a smaller set point variation range. 
Figure 143 shows that wintertime RH levels were lower in the diffusion vent roof house. When results are plotted as dew point (Figure 144), interior conditions are closer to but still lower than the circa 2001 Building America houses.

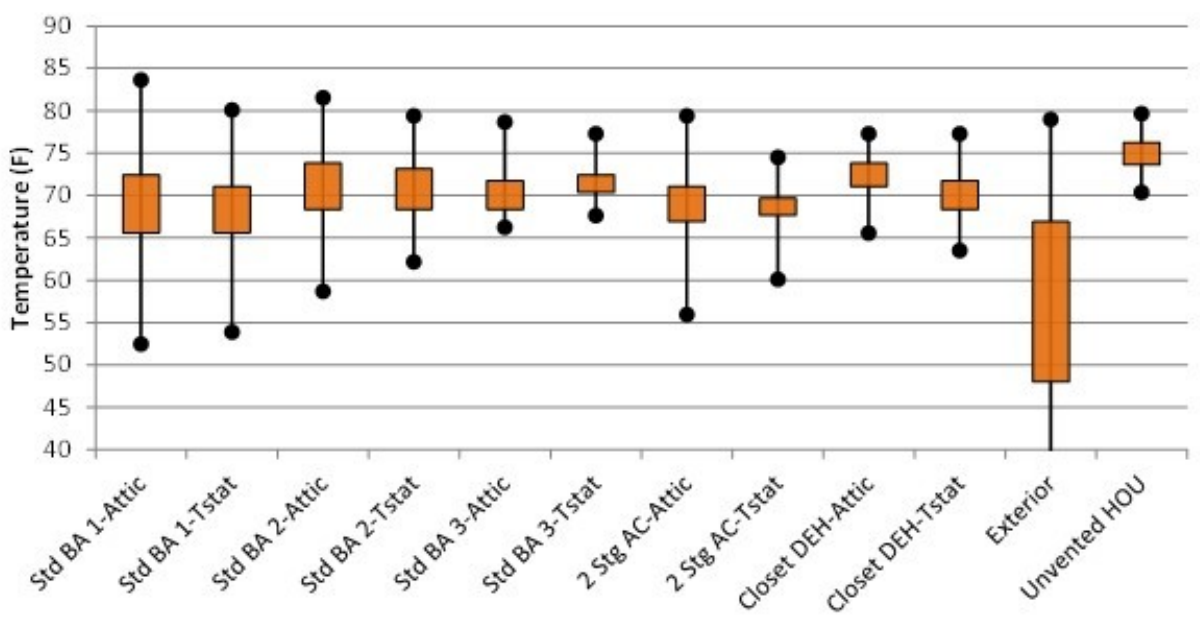

Figure 142. Interior temperature data and Houston unvented data

Source: Rudd and Henderson (2007)

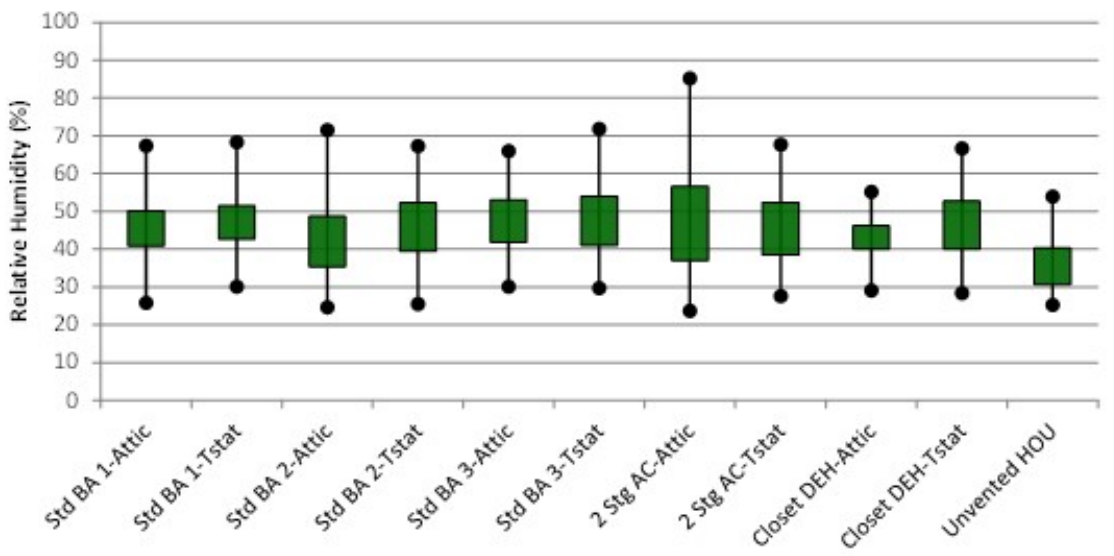

Figure 143. Interior RH data and Houston unvented data

Rudd and Henderson (2007) 


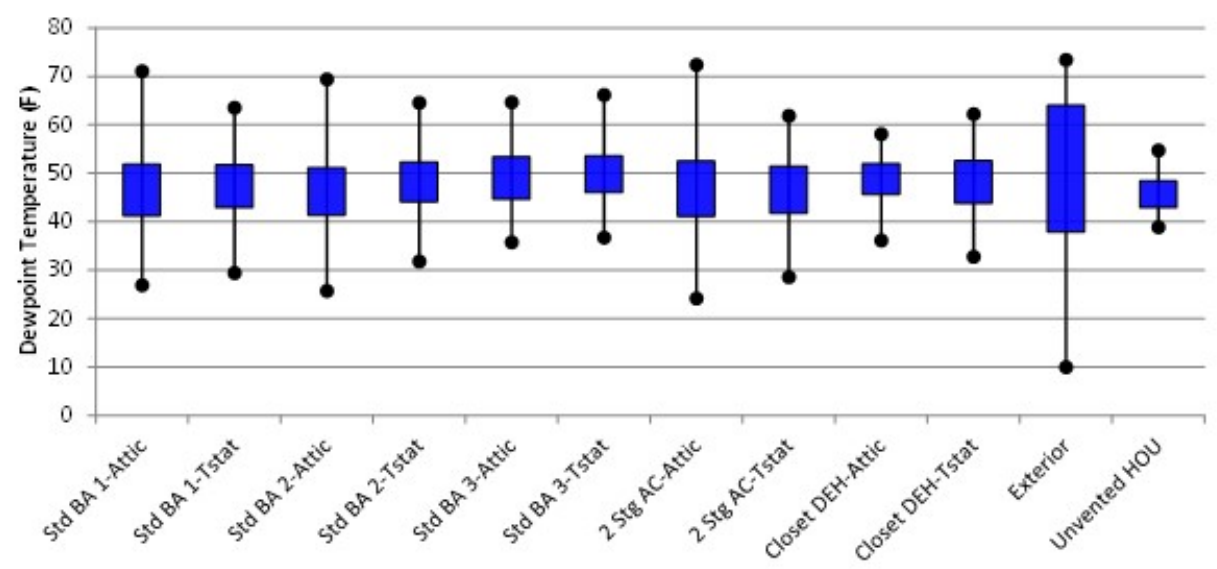

Figure 144. Interior dew point data and Houston unvented data

Source: Rudd and Henderson (2007)

Adding humidification during the fall and winter of 2015-2016 could demonstrate the difference in diffusion vent and unvented roof behavior under conditions simulating high occupancy. Interior RH conditions in the $40 \%-50 \%$ range will be used. 


\section{References}

Arena, L., Mantha, P., and Karagiozis, A. 2010. Monitoring of Internal Moisture Loads in Residential Buildings. Report for U.S. Department of Housing and Urban Development Washington, DC, December 2010.

Arena, L., Owens, D., and Mantha, P. (2013). "Measured Performance of an R-40 Double-Stud Wall in Climate Zone 5A." Buildings XII Conference Proceedings. Atlanta, GA: American Society of Heating, Refrigerating and Air-Conditioning Engineers, Inc.

Arena, L. 2014. “ASHRAE 160: Modeling and Measured Data.” Building America Expert Meeting 2014: Guidance on Modeling Enclosure Design in Above Grade Walls. http://www.buildingscience.com/documents/bareports/ba-1403-guidance-modeling-enclosuredesign-above-grade-walls-expert-meeting/view.

ASHRAE. 2009a. 2009 ASHRAE Handbook-Fundamentals. Atlanta, GA: American Society of Heating, Refrigerating and Air-Conditioning Engineers, Inc.

ASHRAE. 2009b. ANSI/ASHRAE Standard 160-2009: Criteria for Moisture-Control Design Analysis in Buildings. Atlanta, GA: American Society of Heating, Refrigerating and AirConditioning Engineers, Inc.

ASHRAE. 2011. ANSI/ASHRAE Standard 160-2009: Criteria for Moisture-Control Design Analysis in Buildings: Addendum a. Atlanta, GA: American Society of Heating, Refrigerating and Air-Conditioning Engineers, Inc.

Bohac, D. "Zone Pressure Diagnostics: A New Protocol Shows How To Make a Valuable Diagnostic Test Even More Useful,” Home Energy Magazine, May/June 2002.

Boudreaux, P., Pallin, S., and Jackson, R. (2013) Moisture Performance of Sealed Attics in the Mixed-Humid Climate. ORNL/TM-2013/525 Oak Ridge, TN: Oak Ridge National Laboratory.

Derome, D. "Moisture Accumulation in Cellulose Insulation Caused by Air Leakage in Flat Wood Frame Roofs," Journal of Building Physics 28:3 (2005), 269-87.

Fitzgerald, J. (2010). Personal communication.

FPL. 2010. Wood Handbook-Wood As an Engineering Material. General Technical Report FPL-GTR-190. Madison, WI: U.S. Department of Agriculture, Forest Service, Forest Products Laboratory.

Glass, S.V. 2013. Hygrothermal Analysis of Wood-Frame Wall Assemblies in a Mixed-Humid Climate. Research Paper FPL-RP-675. Madison, WI: U.S. Department of Agriculture, Forest Service, Forest Products Laboratory.

Holladay, M. 2013. "Musings of an Energy Nerd: Return to the Backyard Tape Test." Green Building Advisor. Accessed December 2013:

http://www.greenbuildingadvisor.com/blogs/dept/musings/return-backyard-tape-test. 
ICC. 2009. International Residential Code. Country Club Hills, IL: International Code Council.

James, W.L. 1963, rev. 1988. Electric Moisture Meters for Wood. General Technical Report FPL-GTR-6. Madison, WI: U.S. Department of Agriculture, Forest Service, Forest Products Laboratory.

Lstiburek, J. “Understanding Attic Ventilation,” ASHRAE Journal 48:4 (2006), 36-45. Atlanta, GA: American Society of Heating, Refrigerating and Air-Conditioning Engineers, Inc. Accessed June 26, 2015: http://www.buildingscience.com/documents/digests/bsd-102-understanding-atticventilation/.

Lstiburek, J. “Building Sciences: Mind the Gap, Eh?” ASHRAE Journal, January (2010a), 57-63. Atlanta, GA: American Society of Heating, Refrigerating and Air-Conditioning Engineers, Inc. Accessed June 26, 2015: http://www.buildingscience.com/documents/insights/bsi-038-mind-thegap-eh/.

Lstiburek, J. "Building Sciences: Don't Be Dense-Cellulose and Dense-Pack Insulation,” ASHRAE Journal, August (2010b), 54-57. Atlanta, GA: American Society of Heating, Refrigerating and Air-Conditioning Engineers, Inc. Accessed June 26, 2015: http://www.buildingscience.com/documents/insights/bsi-043-dont-be-dense/.

Lstiburek, J. "A Crash Course in Roof Venting.” Fine Homebuilding Magazine, August/September (2011), 68-72. Newtown, CT: Taunton Press. Accessed June 26, 2015: (http://www.buildingscience.com/documents/published-articles/pa-crash-course-in-roofventing/view).

Lstiburek, J. "Building Sciences: Cool Hand Luke Meets Attics," ASHRAE Journal, April (2014), 52-57, Atlanta, GA: American Society of Heating, Refrigerating and Air-Conditioning Engineers, Inc. Accessed June 26, 2015:

http://www.buildingscience.com/documents/insights/bsi-077-cool-hand-luke-meets-attics.

NREL. 2013a. FY 2014 Residential Energy System Research Needs. Golden, CO: National Renewable Energy Laboratory, 25 pp.

NREL. (2013b). Building America Technical Innovations Leading to 50\% Savings - A Critical Path. Golden, CO: National Renewable Energy Laboratory, 48 pp.

Rose, W., and McCaa, D. 1998. "Temperature and Moisture Performance of Wall Assemblies with Fiberglass and Cellulose Insulation." Proceedings: Thermal Performance of the Exterior Envelopes of Buildings VII, 133-44. (ISBN 1-883413-70-2). Atlanta, GA: American Society of Heating, Refrigerating and Air-Conditioning Engineers, Inc.

Rudd, A.F., Lstiburek, J.W., and Moyer, N.A. 1997. "Measurement of Attic Temperatures and Cooling Energy Use in Vented and Sealed Attics in Las Vegas, Nevada," EEBA Conference, Minneapolis, MN.

Rudd, A.F., and Lstiburek. J.W. 1998. "Vented and Sealed Attics in Hot Climates," ASHRAE Transactions, TO-98-20-3. 
Rudd, A.F., and Henderson, H. "Monitored Indoor Moisture and Temperature Conditions in Humid-Climate US Residences.” ASHRAE Transactions, 113, Part 1 (2007), DA-07-046.

Salonvaara, M., Karagiozis, A., and Desjarlais, A. 2013. "Moisture Performance of Sealed Attics in Climate Zones 1 to 4." Proceedings: Thermal Performance of the Exterior Envelopes of Buildings XII. Atlanta, GA: American Society of Heating, Refrigerating and Air-Conditioning Engineers, Inc.

Schumacher, C.J. 2011. High Impact Task: Support of Standards Development-Dense-Pack Airflow Resistance Final Research Report. Building America Report 1109. Accessed June 26, 2015: http://www.buildingscience.com/documents/bareports/ba-1109-high-impact-projectdensepack-airflow-resistance/.

Schumacher, C.J., and LePage, R. 2012. Moisture Control for Dense-Packed Roof Assemblies in Cold Climates: Final Measure Guideline. Building America Report 308. Accessed June 26, 2015: http://www.buildingscience.com/ documents/bareports/ba-1308-moisture-control-densepacked-roof-assemblies-cold-climates/view.

Smegal, J., and Straube, J. 2014. "Ventilation and Vapour Control for SPF-insulated Cathedral Ceilings." Presentation for the Canadian Urethane Foam Contractors Association Inc. Waterloo, ON: Building Science Consulting Inc.

Straube, J., Onysko, D., and Schumacher, C. "Methodology and Design of Field Experiments for Monitoring the Hygrothermal Performance of Wood Frame Enclosures." Journal of Thermal Envelope and Building Science, 26: 2 (2002).

Straube, J., and Burnett, E. 2005. Building Science for Building Enclosures, Building Science Press, Westford, MA.

Straube, J, Smith, R., and Finch, G. 2009. Spray Polyurethane Foam: The Need for Vapor Retarders in Above-Grade Residential Walls, Report for the Canadian Urethane Foam Contractors Association. Waterloo, ON: University of Waterloo. Building Science Press.

Ueno, K., and Straube J. 2008. "Laboratory Calibration and Field Results of Wood Resistance Humidity Sensors," Proceedings of BEST 1 Conference, Minneapolis, June 10-12, 2008.

Ueno, K., and Lstiburek. J.W. 2015. "Field Monitoring of Cold Climate Double Stud Walls with Cellulose and Low-Density Foam Insulation," Proceedings of BEST 4 Conference, Kansas City, April 2015.

Van Straaten, R. 2003. "Measurement of Ventilation and Drying of Vinyl Siding and Brick Clad Wall Assemblies." Master of Applied Science in Civil Engineering Thesis, University of Waterloo, Waterloo, ON.

Wilkinson, J.K., Ueno, K., De Rose, J.F. Straube, D. Fugler. 2007. "Understanding Vapour Permeance and Condensation in Wall Assemblies." 11th Canadian Conference on Building Science and Technology, Banff, Alberta. 


\section{Appendix A: Monitoring Equipment}

The testing and monitoring equipment required to perform the field monitoring of the two unvented roofs is as follows:

Table 13. Testing and Monitoring Equipment Specifications

\begin{tabular}{|c|c|}
\hline Measurement & Equipment Needed \\
\hline Temperature & Negative temperature coefficient thermistor, $\pm 0.2^{\circ} \mathrm{F}\left(0.1^{\circ} \mathrm{C}\right)$ \\
\hline RH & Thermoset polymer capacitive RH sensor, $\pm 3.5 \%$ RH \\
\hline Wood MC & Electric resistance-based MC pin sensors \\
\hline $\begin{array}{l}\text { Data Acquisition and } \\
\text { Collection }\end{array}$ & $\begin{array}{l}\text { Campbell Scientific CR1000 measurement and control system with } \\
\text { Campbell Scientific AM16/32B multiplexers }\end{array}$ \\
\hline $\begin{array}{c}\text { Outdoor Temperature/ } \\
\text { RH }\end{array}$ & $\begin{array}{c}\text { Campbell Scientific HMP60- } \mathrm{L}-40^{\circ} \mathrm{C} \text { to }+60^{\circ} \mathrm{C}\left(-40^{\circ} \mathrm{F} \text { to } 140^{\circ} \mathrm{F}\right) \\
\text { range; } \pm 1.1^{\circ} \mathrm{F}\left(0.6^{\circ} \mathrm{C}\right) \text { accuracy; } \\
\mathrm{RH} \text { accuracy at } 0^{\circ} \text { to }+40^{\circ} \mathrm{C} \text { : } \\
\pm 3 \% \mathrm{RH}(0 \%-90 \% \mathrm{RH}) ; \pm 5 \% \mathrm{RH}(90 \%-100 \% \mathrm{RH}) \\
\mathrm{RH} \text { Accuracy at }-40^{\circ} \text { to } 0^{\circ} \mathrm{C} \text { and }+40^{\circ} \text { to }+60^{\circ} \mathrm{C}: \\
\pm 5 \% \mathrm{RH}(0 \%-90 \% \mathrm{RH}) ; \pm 7 \% \mathrm{RH}(90 \%-100 \% \mathrm{RH})\end{array}$ \\
\hline Telecommunications & Raven XTG GPRS/EDGE Sierra wireless cellular modem \\
\hline
\end{tabular}




\section{Appendix B: Chicago Attic Roof Ventilation Dew Points}

$\mathrm{T} / \mathrm{RH}$ sensors were installed in the airstream of the ventilated roof assemblies (1 through 5) to provide some indication of whether moisture was being removed. To measure absolute air moisture content, dew points were calculated for the T/RH data and compared with interior (test attic) and exterior dew point data.

\section{Roof 1 (Vented)}

The intake (soffit/eave), exhaust (ridge), interior, and exterior dew point for the vented roof (1) are plotted in Figure 145. The general trend is that the ventilation space dew points mostly match exterior conditions. However, there is one period (highlighted in the gray rectangle) when the exhaust dew point is noticeably higher; these data are expanded in Figure 146.

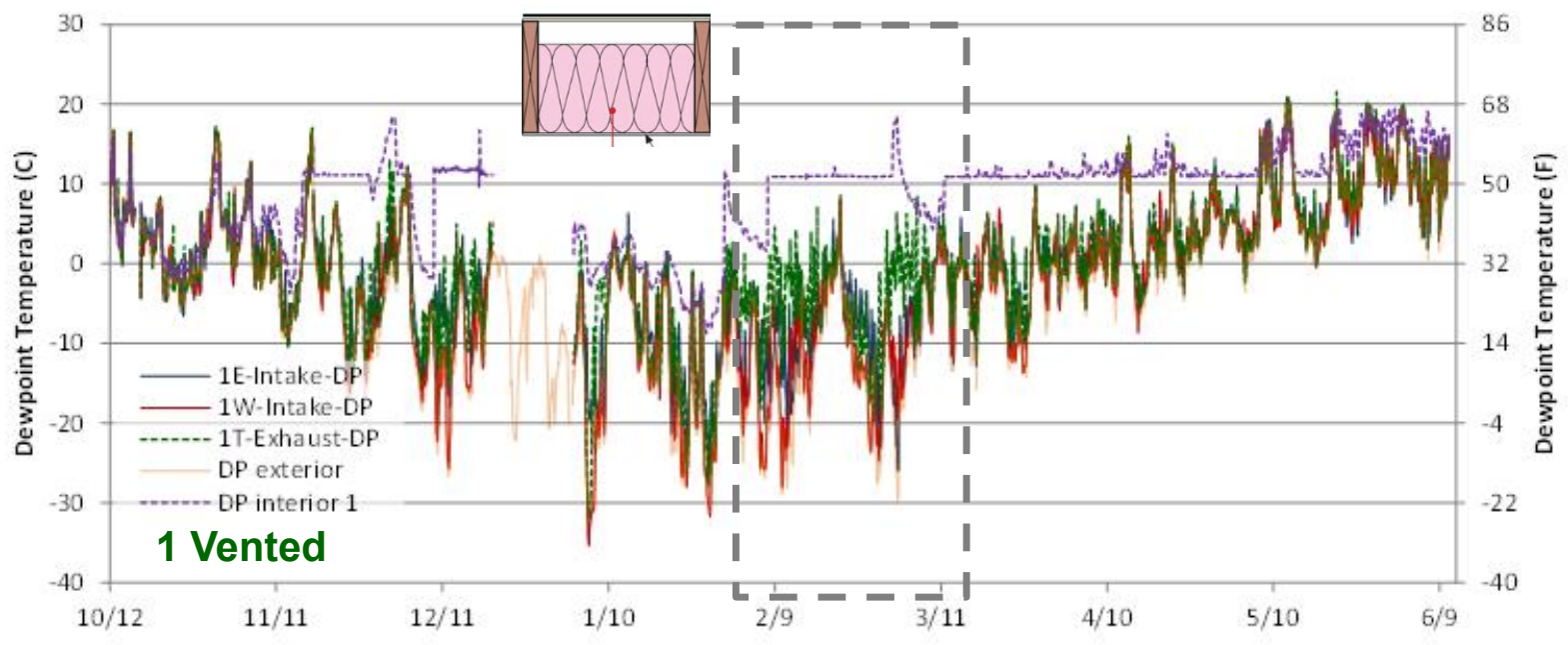

Figure 145. Intake and exhaust dew points, interior and exterior (Roof 1-vented)

This expanded period appears to match when the humidification system was running during colder weather. This might indicate some level of moisture removal at low exterior dew points.

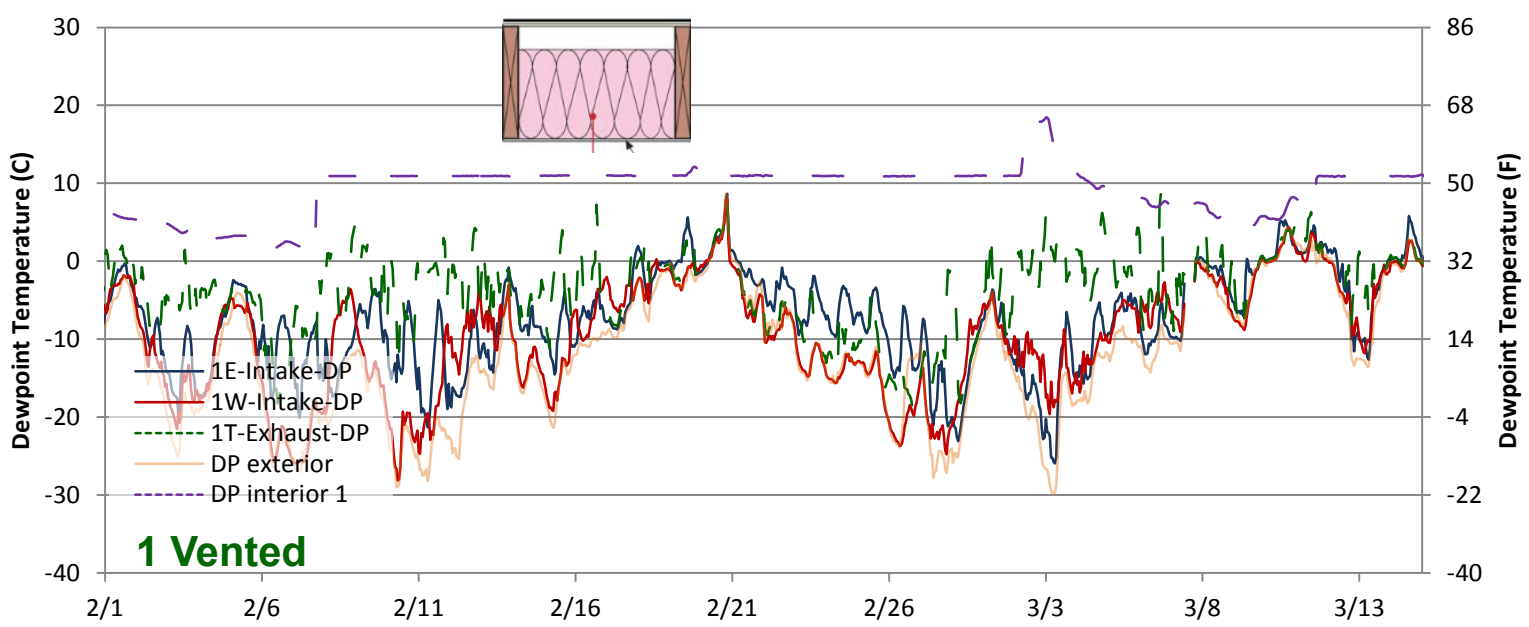

Figure 146. Intake and exhaust dew points, interior and exterior (Roof 1-vented) detail 


\section{Roofs 2 and 3 (Top Vent Cellulose)}

The T/RH sensors for the top vent (mesh space under shingle) roofs are shown in Figure 147; the intake is behind the mesh at the soffit, and the exhaust is inserted into the house wrap ridge covering (shown before cutting the ventilation holes).
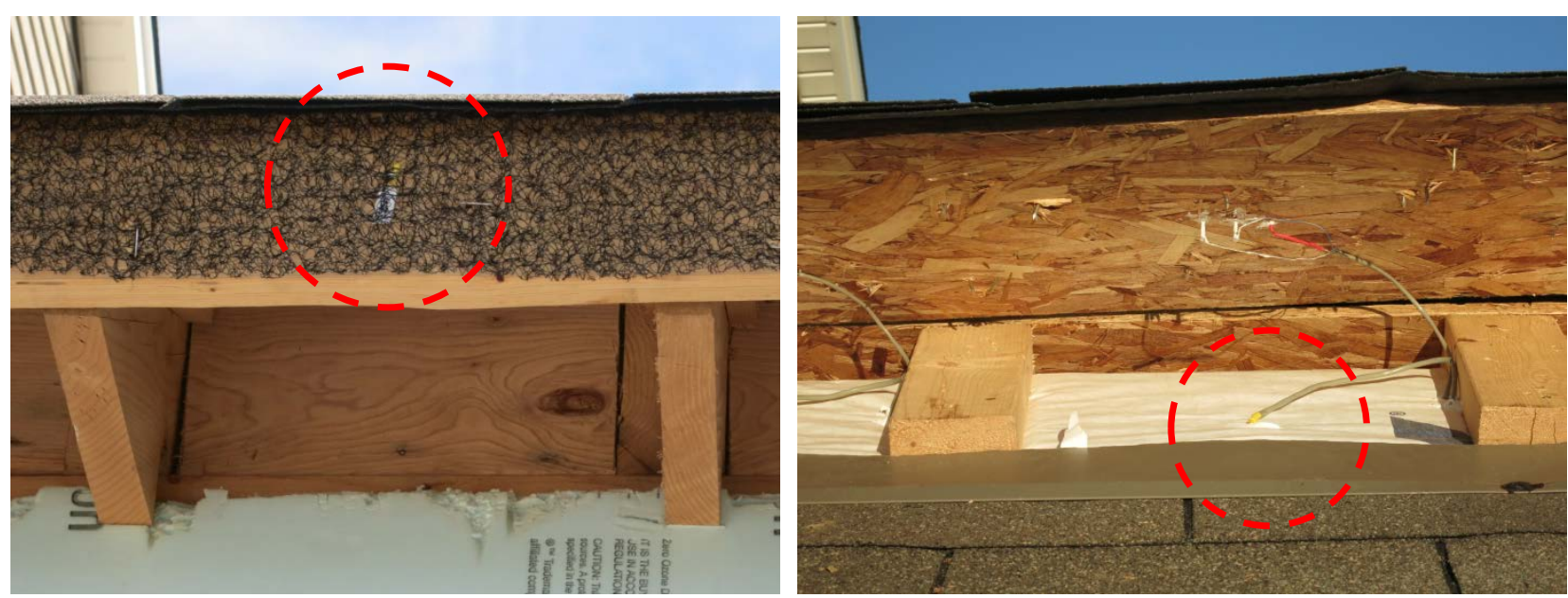

Figure 147. Intake (left) and exhaust (right) T/RH sensors for top vent roofs

The data for the top vent cellulose roof with GWB (2) are shown in Figure 148; the highlighted period from Roof 1 is shown here, but in this roof, the dew points are all close to exterior conditions. A close-up of that period (Figure 149) seems to indicate that the exhaust dew point is slightly higher during this period, but not by the same degree as the vented assembly. This would indicate that more moisture is removed from the vented roof than from the top vent roof.

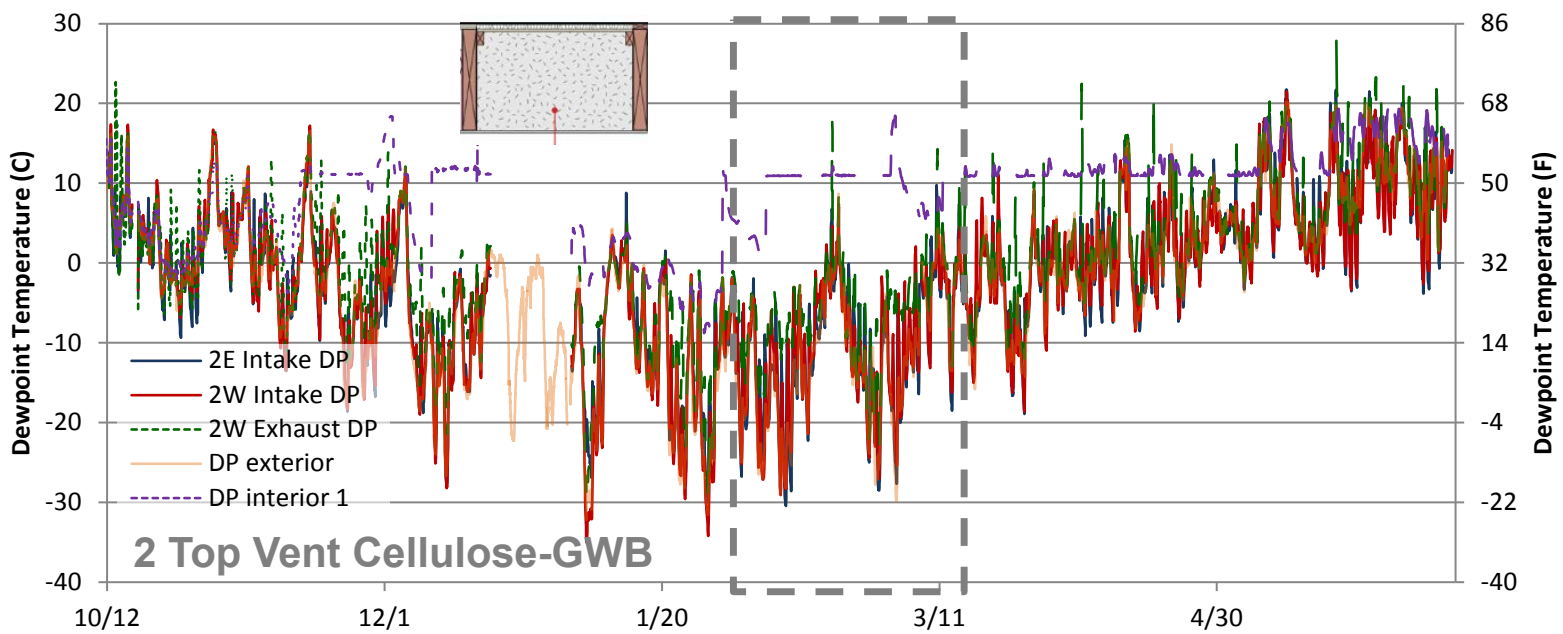

Figure 148. Intake and exhaust dew points, interior and exterior (Roof 2-top vent cellulose with GWB) 


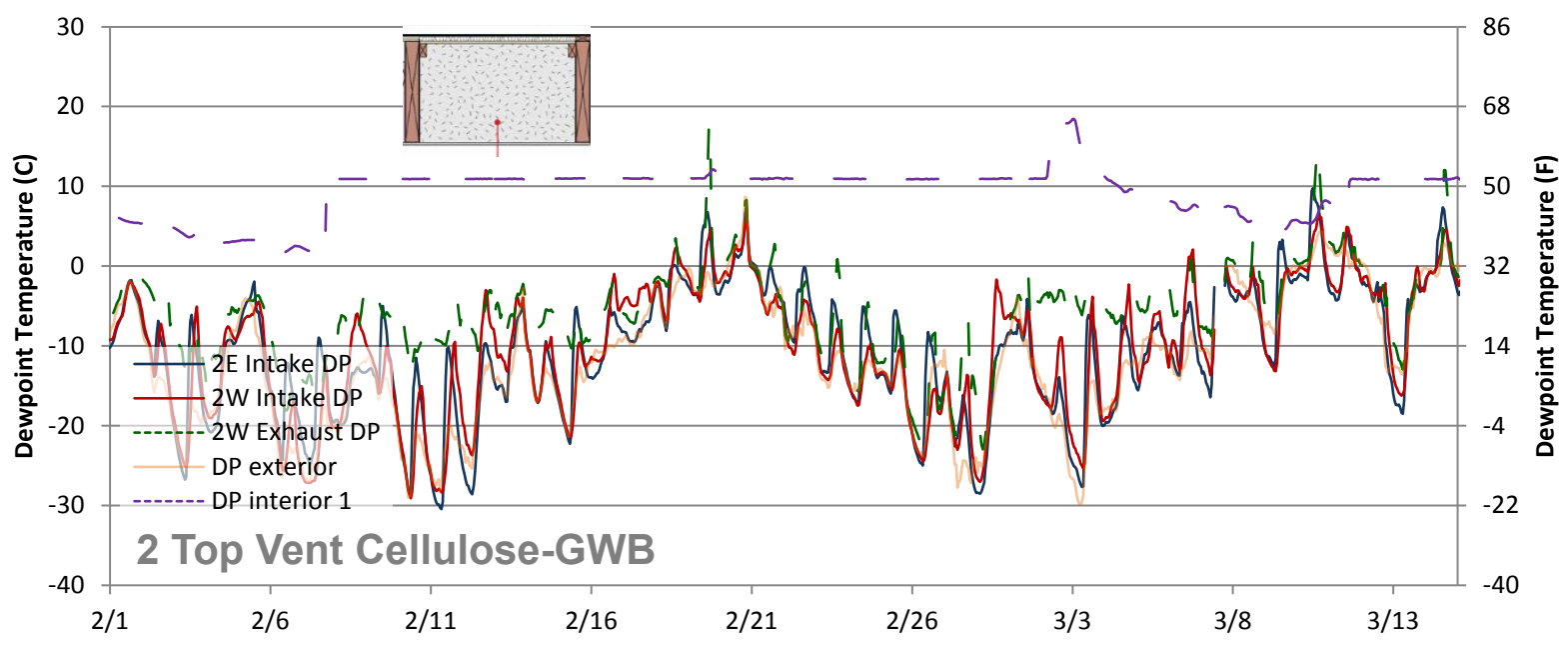

Figure 149. Intake and exhaust dew points, interior and exterior (Roof 2-top vent cellulose with GWB), detail

Similar plots are shown for the top vent cellulose roof - no GWB (3), - in Figure 150 and Figure 151 with mostly similar patterns.

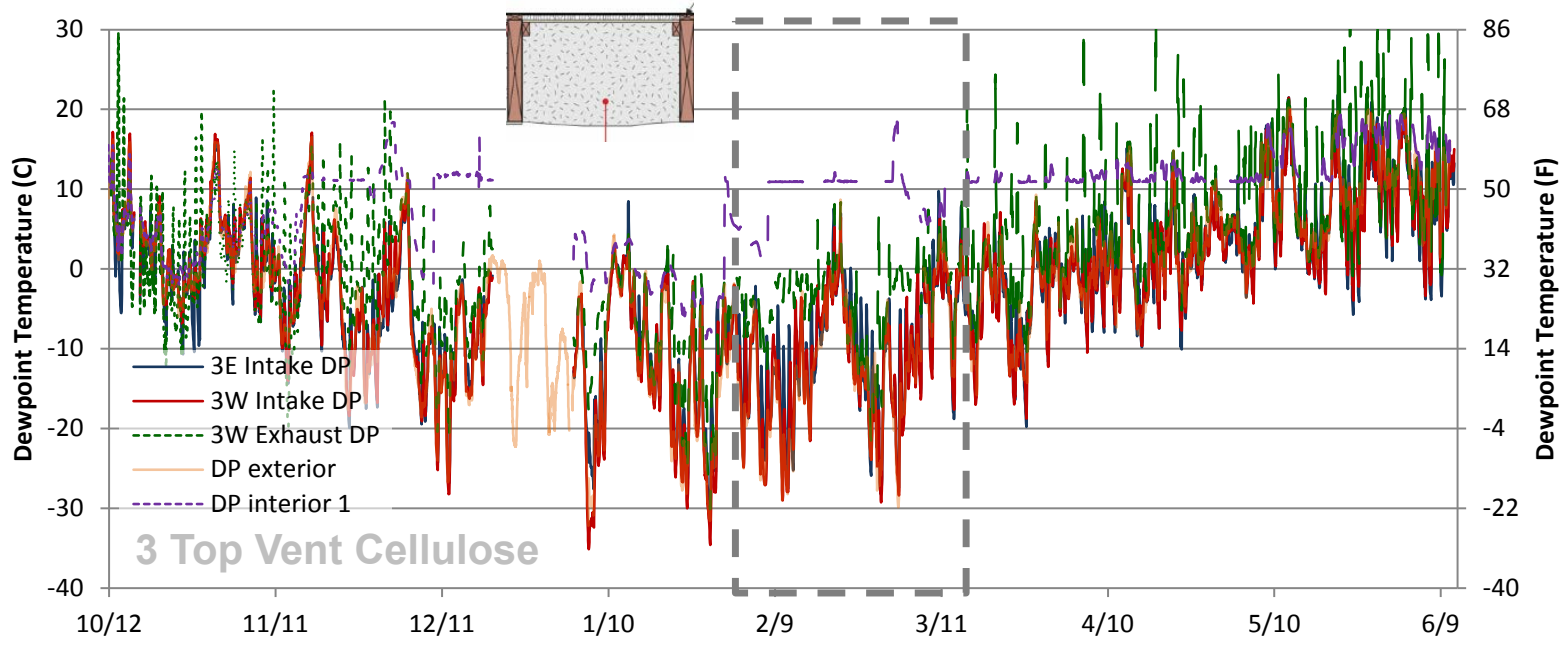

Figure 150. Intake and exhaust dew points, interior and exterior (Roof 3-top vent cellulose) 


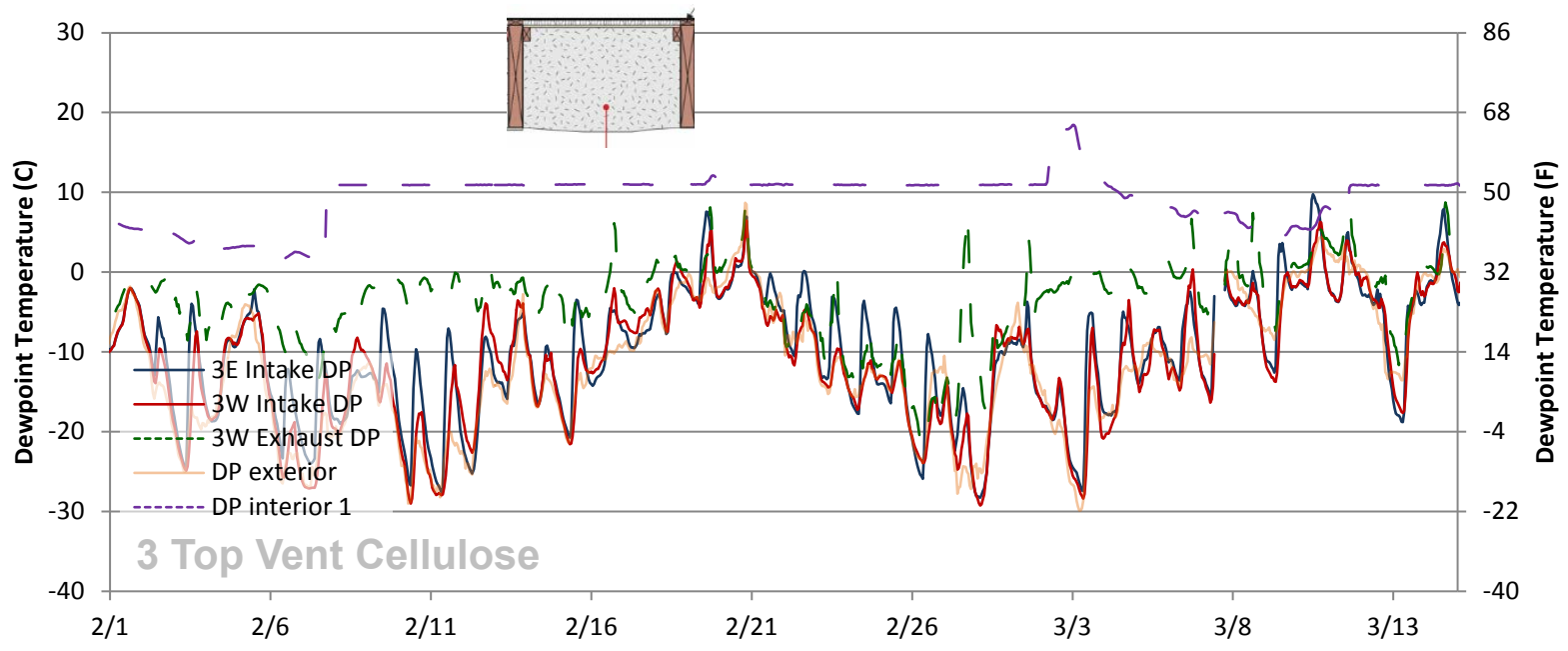

Figure 151. Intake and exhaust dew points, interior and exterior (Roof 3-top vent cellulose), detail

\section{Roofs 4 and 5 (Top Vent Fiberglass)}

Dew points are plotted for the top vent fiberglass roofs with GWB (5) and without GWB (4) in Figure 152 and Figure 153, respectively. Roof 5 shows elevated exhaust dew points (compared to exterior/intake). Roof 4 shows smaller differences but greater variations.

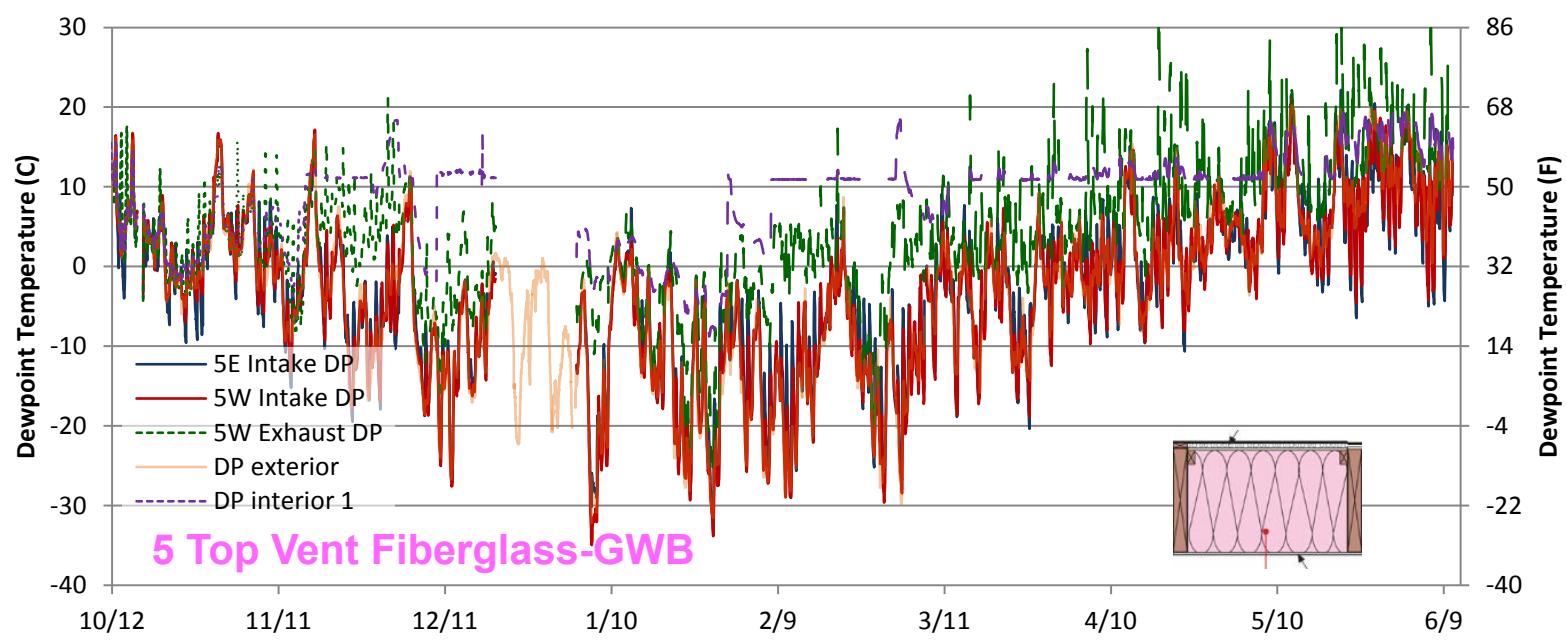

Figure 152. Intake and exhaust dew points, interior and exterior (Roof 5-top vent fiberglass with GWB) 


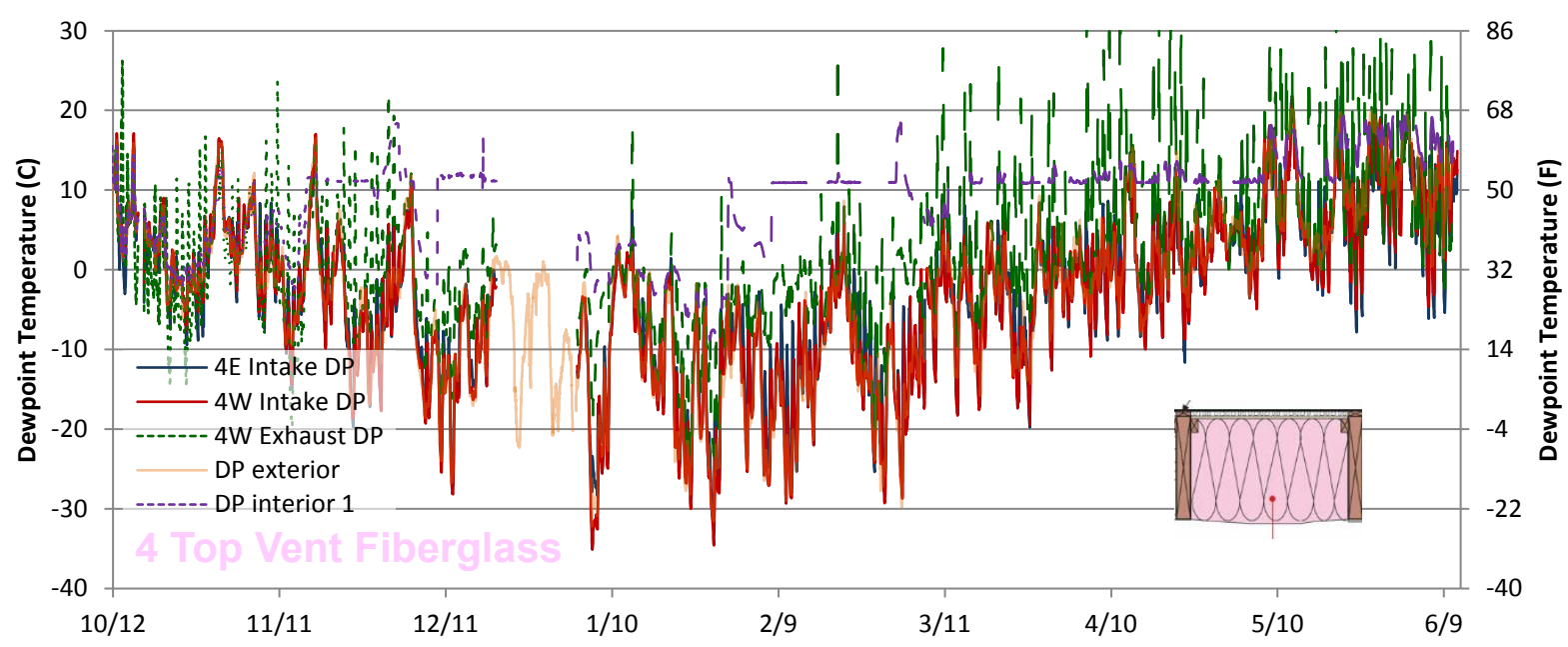

Figure 153. Intake and exhaust dew points, interior and exterior (Roof 4-top vent fiberglass)

\section{Ventilation Space Conclusions}

Unfortunately, few conclusions can be drawn from the ventilation space measurements. Although higher dew points at the exhaust may indicate moisture removal, they might also simply indicate static accumulation (and stratification) of moisture, if there is minimal airflow. To truly measure moisture removal, both intake/exhaust air moisture content and airflow would need to be measured. Given the limited ( $\sim 1 / 2$ in.) mesh airspace under the shingles, it seems plausible that the airflow might be relatively low. However, the low-velocity airflows that occurred in in the ventilation cavities are difficult and instrumentation-intensive to measure and monitor in-situ (Van Straaten 2003). 


\section{Appendix C: Chicago Sheathing Temperature and Ventilation Space}

Examination of dew point temperatures of the ventilation spaces (in the top vent roofs) gave inconclusive results: the difference in dew point might reflect moisture removal or simply moisture accumulation (see Section 4.4). Another way of gauging whether effective ventilation is occurring through the top vent mesh is to examine the sheathing temperatures. Ventilation air movement up the roof might carry some heat with it, possibly cooling the lower roof surfaces (or the entire roof surface) relative to the analogous unvented roof.

Sheathing temperatures were plotted for top vent cellulose (2) and unvented (7) roofs; they are basically identical except for the presence or absence of the mesh spacer under the asphalt shingles.

Temperatures plots from 2 weeks in winter are shown in Figure 154 and Figure 155. As a general behavior, both roofs show temperature peaks for the east side several hours before the west side, which is consistent with the sun path and geometry.

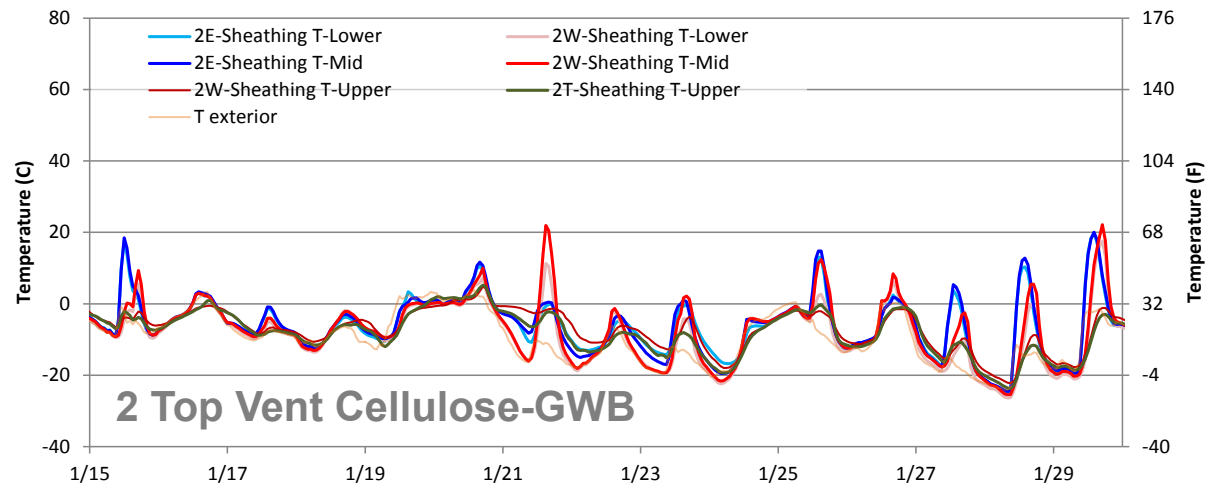

Figure 154. Wintertime sheathing temperatures for Roof 2 (top vent cellulose with GWB)

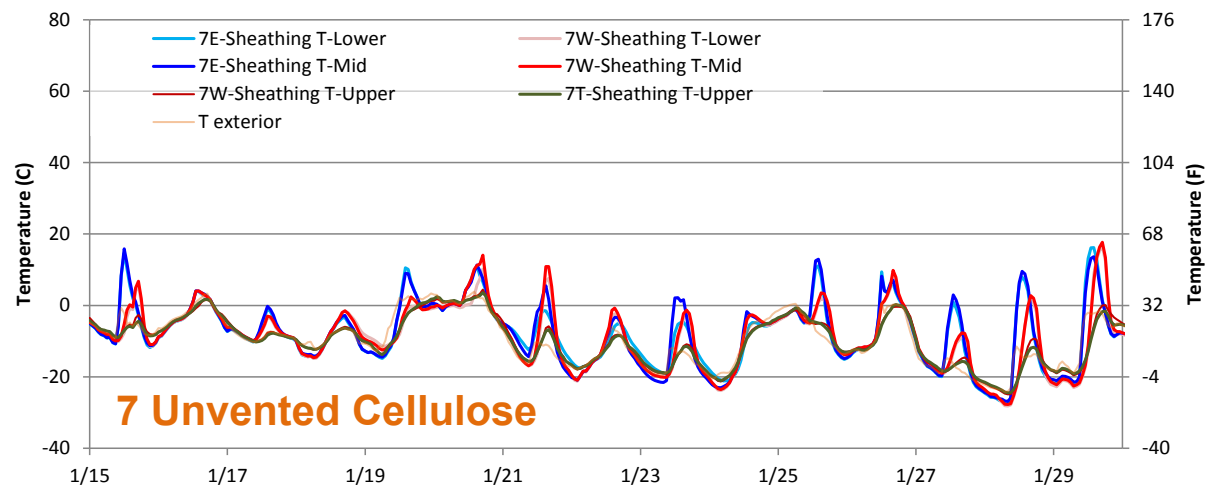

Figure 155. Wintertime sheathing temperatures for Roof 7 (unvented cellulose)

One significant difference was seen on January 21; the top vent (2) cellulose west-facing sensors spike higher than the unvented cellulose (7) roofs. However, the presence or absence of snow on 
the roof (Figure 156) is likely causing this difference rather than ventilation effects. The snow melt pattern might be influenced by heat loss through the roof assemblies, but it is probably mostly caused by wind-blown snow deposition and other geometry effects.
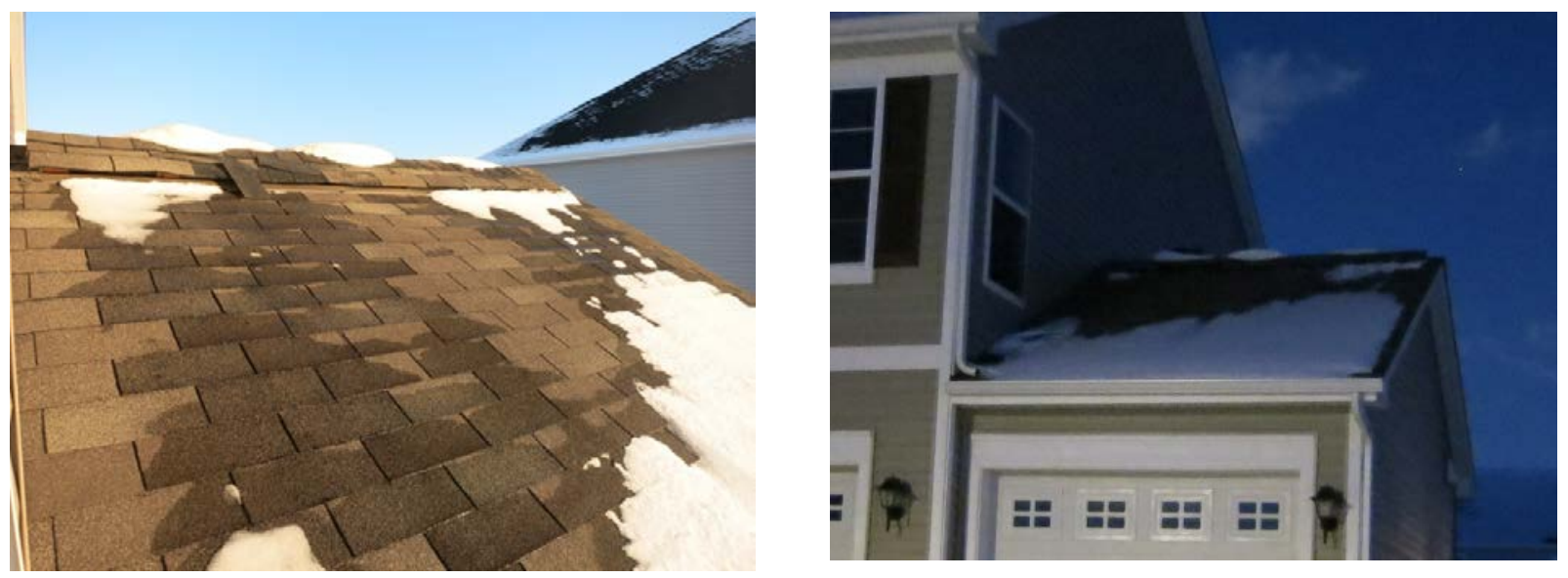

Figure 156. Snow deposits and melting at front (west) orientation of test roof

Similar plots for summertime (May) conditions are shown in Figure 157 and Figure 158. The roof sheathing temperatures are close enough to be basically indistinguishable between the two roofs. The east-west peaking patterns are similar to wintertime behavior.

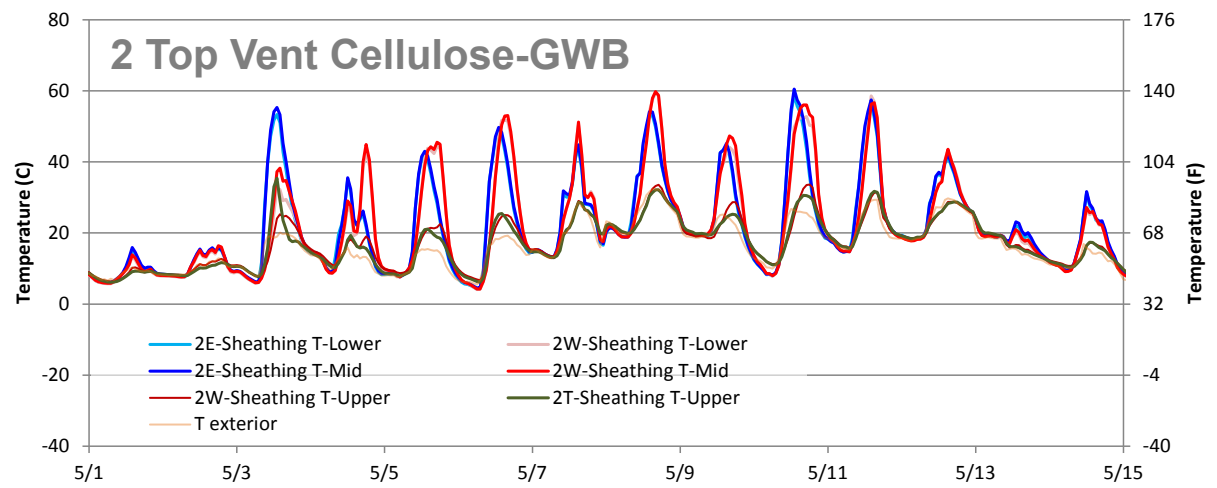

Figure 157. Summertime sheathing temperatures for Roof 2 (top vent cellulose with GWB)

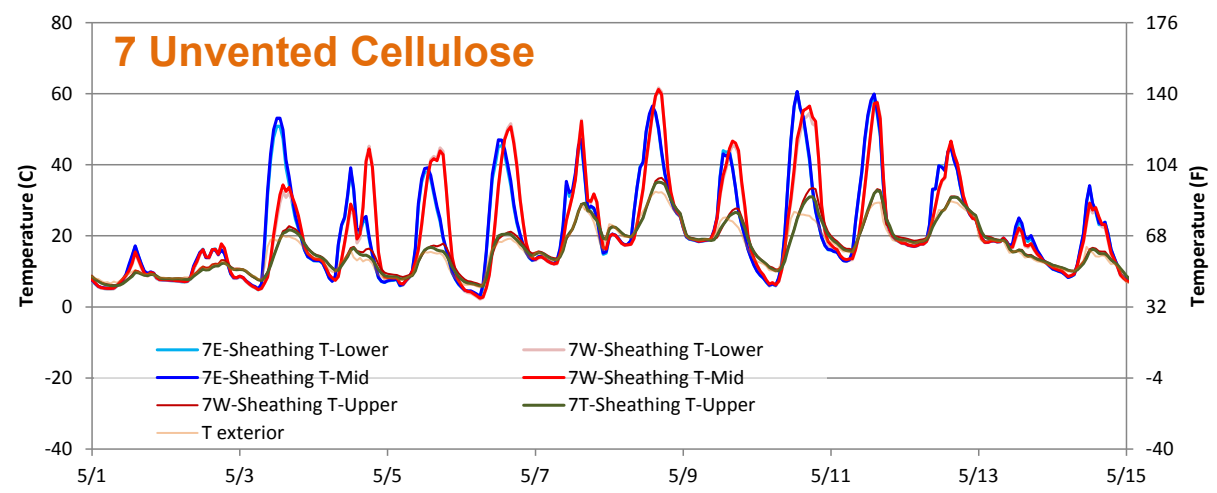

Figure 158. Summertime sheathing temperatures for Roof 7 (unvented cellulose) 
The one striking pattern is the lower Ts seen at the upper sheathing areas, which are seen on both orientations in both roofs. The reason is likely the shading effect of the doghouse detail; the upper/top sheathing Ts are shaded or shielded from direct solar gain by this ventilated roof area (Figure 159). Overall, the temperature measurements show little indication that the top vent detail affect sheathing temperatures.

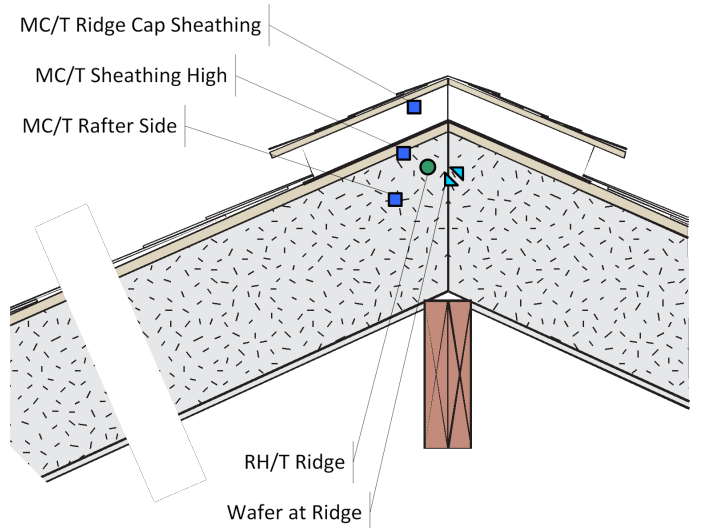

Figure 159. Ridge and doghouse monitoring detail, unvented cellulose roof

As another comparison, sheathing Ts for the vented fiberglass roof (1) are plotted in Figure 160, given that it is known to have good ventilation with its open geometry ( $\sim 4$-in. air space between the sheathing and the fiberglass batt). The summertime roof sheathing $T$ s in the vented fiberglass (1) roof are noticeably lower than in the top vent (2) cellulose and unvented cellulose (7) roofs.

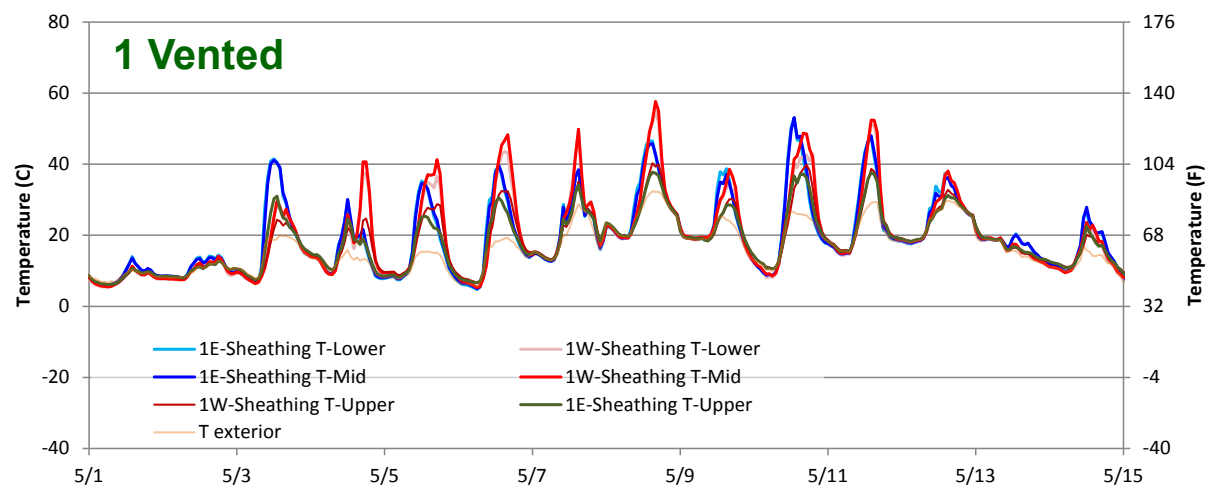

Figure 160. Summertime sheathing temperatures for Roof 1 (vented fiberglass)

As a general point, small airflows can have a substantial effect on effective vapor permeance of claddings (e.g., asphalt shingles). However, given the limited heat capacity of air, these small airflows would have almost insignificant effects on temperature and energy flows (Straube and Burnett 2005). 
buildingamerica.gov

U.S. DEPARTMENT OF Energy Efficiency \& Nㅡㄹㅡ Renewable Energy 